\title{
SUPPORTING INFORMATION Heptaketides from an Endolichenic Fungus Biatriospora sp. and Their Antifungal Activity
}

Yan-Hui Zhou, ${ }^{\dagger}$ Ming Zhang, ${ }^{\dagger}$ Rong-Xiu Zhu, ${ }^{\star}$ Jiao-Zhen Zhang,${ }^{\dagger}$ Fei-Xie, ${ }^{\dagger}$ Xiao-Bin

Li,${ }^{\dagger}$ Wen-Qiang Chang, ${ }^{\dagger}$ Xiao-Ning Wang, ${ }^{\dagger}$ Zun-Tian Zhao, ${ }^{*}{ }^{\S}$ and Hong-Xiang Lou ${ }^{*}{ }^{\dagger}$

${ }^{\dagger}$ Department of Natural Product Chemistry, Key Lab of Chemical Biology of Ministry of Education, School of Pharmaceutical Sciences, Shandong University, 44 Wenhua

West Road, Jinan 250012, People's Republic of China

${ }^{ \pm}$School of Chemistry and Chemical Engineering, Shandong University, 27 Shanda

Nanlu, Jinan 250100, People's Republic of China

${ }^{\S}$ College of Life Sciences, Shandong Normal University, 88 Wenhua East Road, Jinan

250014, People's Republic of China

* To whom correspondences should be addressed.

Tel: +86-531-8838-2012. Fax: +86-531-8838-2019. E-mail:

louhongxiang@sdu.edu.cn. 


\section{Table of Content}

Part 1. Experimental Section

\section{Part 2. Figures}

Figure S1. Experimental and calculated ECD spectra of compounds 5 (a), 6 (a), 12 (b).

Figure S2. ${ }^{1} \mathrm{H}$ NMR spectrum of $\mathbf{1}$ in DMSO-d 6

Figure S3. ${ }^{13} \mathrm{C}$ NMR spectrum of $\mathbf{1}$ in DMSO- $\mathrm{d}_{6}$

Figure S4. ${ }^{1} \mathrm{H}-{ }^{1} \mathrm{H}$ COSY spectrum of $\mathbf{1}$ in DMSO-d $\mathrm{d}_{6}$

Figure S5. HSQC spectrum of $\mathbf{1}$ in DMSO- $\mathrm{d}_{6}$

Figure S6. HMBC spectrum of 1 in DMSO-d 6

Figure S7. NOESY spectrum of $\mathbf{1}$ in DMSO-d 6

Figure S8. HRESIMS spectrum of $\mathbf{1}$

Figure S9. IR ( $\mathrm{KBr}$ disc) spectrum of $\mathbf{1}$

Figure S10. UV spectrum of 1

Figure S11. ECD spectrum of 1

Figure S12. ${ }^{1} \mathrm{H}$ NMR spectrum of $\mathbf{2}$ in DMSO- $\mathrm{d}_{6}$

Figure S13. ${ }^{13} \mathrm{C}$ NMR spectrum of 2 in DMSO-d 6

Figure S14. ${ }^{1} \mathrm{H}-{ }^{1} \mathrm{H}$ COSY spectrum of $\mathbf{2}$ in DMSO- $\mathrm{d}_{6}$

Figure S15. HSQC spectrum of 2 in DMSO- $\mathrm{d}_{6}$

Figure S16. HMBC spectrum of $\mathbf{2}$ in DMSO- $\mathrm{d}_{6}$

Figure S17. NOESY spectrum of 2 in DMSO-d 6

Figure S18.HRESIMS spectrum of 2

Figure S19. IR ( $\mathrm{KBr}$ disc) spectrum of $\mathbf{2}$

Figure S20. UV spectrum of 2

Figure S21. ECD spectrum of 2

Figure S22. ${ }^{1} \mathrm{H}$ NMR spectrum of 3 in DMSO- $\mathrm{d}_{6}$

Figure S23. ${ }^{13} \mathrm{C}$ NMR spectrum of 3 in DMSO- $\mathrm{d}_{6}$

Figure S24. ${ }^{13} \mathrm{C}$ NMR spectrum of $\mathbf{3}$ in $\mathrm{CDCl}_{3}$

Figure S25. ${ }^{1} \mathrm{H}-{ }^{1} \mathrm{H}$ COSY spectrum of $\mathbf{3}$ in $\mathrm{CDCl}_{3}$

Figure S26. HSQC spectrum of $\mathbf{3}$ in $\mathrm{CDCl}_{3}$

Figure S27. $\mathrm{HMBC}$ spectrum of $\mathbf{3}$ in $\mathrm{CDCl}_{3}$

Figure S28. NOESY spectrum of $\mathbf{3}$ in $\mathrm{CDCl}_{3}$

Figure S29. HRESIMS spectrum of $\mathbf{3}$

Figure S30. IR ( $\mathrm{KBr}$ disc) spectrum of $\mathbf{3}$

Figure S31. UV spectrum of $\mathbf{3}$

Figure S32. ECD spectrum of $\mathbf{3}$

Figure S33. ${ }^{1} \mathrm{H}$ NMR spectrum of 4 in $\mathrm{CDCl}_{3}$ 
Figure S34. ${ }^{13} \mathrm{C}$ NMR spectrum of $\mathbf{4}$ in $\mathrm{CDCl}_{3}$

Figure S35. HSQC spectrum of 4 in $\mathrm{CDCl}_{3}$

Figure S36. $\mathrm{HMBC}$ spectrum of 4 in $\mathrm{CDCl}_{3}$

Figure S37. HRESIMS spectrum of 4

Figure S38. IR ( $\mathrm{KBr}$ disc) spectrum of $\mathbf{4}$

Figure S39. UV spectrum of 4

Figure S40. ${ }^{1} \mathrm{H}$ NMR spectrum of 5 in Acetone- $d_{6}$

Figure S41. ${ }^{13} \mathrm{C}$ NMR spectrum of 5 in Acetone- $d_{6}$

Figure S42. ${ }^{13} \mathrm{C}$ NMR spectrum of 5 in $\mathrm{CD}_{3} \mathrm{OD}$

Figure S43. HSQC spectrum of 5 in Acetone- $d_{6}$

Figure S44. HMBC spectrum of 5 in Acetone- $d_{6}$

Figure S45. HRESIMS spectrum of 5

Figure S46. IR ( $\mathrm{KBr}$ disc) spectrum of 5

Figure S47. UV spectrum of 5

Figure S48. ECD spectrum of 5

Figure S49. ${ }^{1} \mathrm{H}$ NMR spectrum of 6 in DMSO-d 6

Figure S50. ${ }^{13} \mathrm{C}$ NMR spectrum of 6 in DMSO-d 6

Figure S51. HSQC spectrum of 6 in DMSO- $\mathrm{d}_{6}$

Figure S52. HMBC spectrum of 6 in DMSO- $\mathrm{d}_{6}$

Figure S53. HRESIMS spectrum of 6

Figure S54. IR ( $\mathrm{KBr}$ disc) spectrum of 6

Figure S55. UV spectrum of 6

Figure S56. ECD spectrum of 6

Figure S57. ${ }^{1} \mathrm{H}$ NMR spectrum of 7 in DMSO- $\mathrm{d}_{6}$

Figure S58. ${ }^{13} \mathrm{C}$ NMR spectrum of 7 in DMSO- $\mathrm{d}_{6}$

Figure S59. ${ }^{1} \mathrm{H}-{ }^{1} \mathrm{H}$ COSY spectrum of 7 in DMSO- $\mathrm{d}_{6}$

Figure S60. HSQC spectrum of 7 in DMSO- $\mathrm{d}_{6}$

Figure S61. HMBC spectrum of 7 in DMSO- $\mathrm{d}_{6}$

Figure S62. NOESY spectrum of 7 in $\mathrm{CD}_{3} \mathrm{OD}$

Figure S63. HRESIMS spectrum of 7

Figure S64. IR ( $\mathrm{KBr}$ disc) spectrum of 7

Figure S65. UV spectrum of 7

Figure S66. ECD spectrum of 7

Figure S67. ${ }^{1} \mathrm{H}$ NMR spectrum of 8 in $\mathrm{CD}_{3} \mathrm{OD}$

Figure S68. ${ }^{13} \mathrm{C}$ NMR spectrum of $\mathbf{8}$ in $\mathrm{CD}_{3} \mathrm{OD}$

Figure S69. ${ }^{1} \mathrm{H}-{ }^{1} \mathrm{H}$ COSY spectrum of 8 in $\mathrm{CD}_{3} \mathrm{OD}$

Figure S70. HSQC spectrum of 8 in $\mathrm{CD}_{3} \mathrm{OD}$

Figure S71. $\mathrm{HMBC}$ spectrum of 8 in $\mathrm{CD}_{3} \mathrm{OD}$

Figure S72. NOESY spectrum of 8 in $\mathrm{CD}_{3} \mathrm{OD}$

Figure S73. HRESIMS spectrum of 8 
Figure S74. IR ( $\mathrm{KBr}$ disc) spectrum of 8

Figure S75. UV spectrum of 8

Figure S76. ECD spectrum of 8

Figure S77. ${ }^{1} \mathrm{H}$ NMR spectrum of 9 in DMSO- $\mathrm{d}_{6}$

Figure S78. ${ }^{13} \mathrm{C}$ NMR spectrum of 9 in DMSO-d $\mathrm{d}_{6}$

Figure S79. ${ }^{1} \mathrm{H}-{ }^{1} \mathrm{H}$ COSY spectrum of 9 in DMSO- $\mathrm{d}_{6}$

Figure S80. HSQC spectrum of 9 in DMSO-d 6

Figure S81. HMBC spectrum of 9 in DMSO- $\mathrm{d}_{6}$

Figure S82. NOESY spectrum of 9 in DMSO- $\mathrm{d}_{6}$

Figure S83. HRESIMS spectrum of 9

Figure S84. IR ( $\mathrm{KBr}$ disc) spectrum of 9

Figure S85. UV spectrum of 9

Figure S86. ECD spectrum of 9

Figure S87. ${ }^{1} \mathrm{H}$ NMR spectrum of $\mathbf{1 0}$ in DMSO-d 6

Figure S88. ${ }^{13} \mathrm{C}$ NMR spectrum of $\mathbf{1 0}$ in DMSO- $\mathrm{d}_{6}$

Figure S89. ${ }^{1} \mathrm{H}-{ }^{1} \mathrm{H}$ COSY spectrum of $\mathbf{1 0}$ in DMSO-d 6

Figure S90. HSQC spectrum of $\mathbf{1 0}$ in DMSO-d $\mathrm{d}_{6}$

Figure S91. HMBC spectrum of $\mathbf{1 0}$ in DMSO- $\mathrm{d}_{6}$

Figure S92. NOESY spectrum of $\mathbf{1 0}$ in DMSO- $\mathrm{d}_{6}$

Figure S93. HRESIMS spectrum of $\mathbf{1 0}$

Figure S94. IR ( $\mathrm{KBr}$ disc) spectrum of $\mathbf{1 0}$

Figure S95. UV spectrum of $\mathbf{1 0}$

Figure S96. ECD spectrum of 10

Figure S97. ${ }^{1} \mathrm{H}$ NMR spectrum of 10a in DMSO- $\mathrm{d}_{6}$

Figure S98. ${ }^{1} \mathrm{H}$ NMR spectrum of $\mathbf{1 0 b}$ in DMSO-d $\mathrm{d}_{6}$

Figure S99. ${ }^{1} \mathrm{H}$ NMR spectrum of $\mathbf{1 1}$ in $\mathrm{CDCl}_{3}$

Figure S100. ${ }^{13} \mathrm{C}$ NMR spectrum of 11 in $\mathrm{CDCl}_{3}$

Figure S101. ${ }^{1} \mathrm{H}-{ }^{1} \mathrm{H}$ COSY spectrum of 11 in $\mathrm{CDCl}_{3}$

Figure S102. HSQC spectrum of $\mathbf{1 1}$ in $\mathrm{CDCl}_{3}$

Figure S103.HMBC spectrum of 11 in $\mathrm{CDCl}_{3}$

Figure S104. NOESY spectrum of $\mathbf{1 1}$ in $\mathrm{CDCl}_{3}$

Figure S105. HRESIMS spectrum of $\mathbf{1 1}$

Figure S106. IR ( $\mathrm{KBr}$ disc) spectrum of $\mathbf{1 1}$

Figure S107. UV spectrum of $\mathbf{1 1}$

Figure S108. ECD spectrum of $\mathbf{1 1}$

Figure S109. ${ }^{1} \mathrm{H}$ NMR spectrum of 12 in $\mathrm{CDCl}_{3}$

Figure S110. ${ }^{13} \mathrm{C}$ NMR spectrum of 12 in $\mathrm{CDCl}_{3}$

Figure S111. ${ }^{1} \mathrm{H}-{ }^{1} \mathrm{H}$ COSY spectrum of 12 in $\mathrm{CDCl}_{3}$

Figure S112. HSQC spectrum of 12 in $\mathrm{CDCl}_{3}$ 
Figure S113. $\mathrm{HMBC}$ spectrum of $\mathbf{1 2}$ in $\mathrm{CDCl}_{3}$

Figure S114. NOESY spectrum of $\mathbf{1 2}$ in $\mathrm{CDCl}_{3}$

Figure S115. HRESIMS spectrum of $\mathbf{1 2}$

Figure S116. IR ( $\mathrm{KBr}$ disc) spectrum of $\mathbf{1 2}$

Figure S117. UV spectrum of 12

Figure S118. ECD spectrum of $\mathbf{1 2}$

Figure S119. ${ }^{1} \mathrm{H}$ NMR spectrum of $\mathbf{1 3}$ in DMSO-d $\mathrm{d}_{6}$

Figure S120. ${ }^{13} \mathrm{C}$ NMR spectrum of $\mathbf{1 3}$ in DMSO- $\mathrm{d}_{6}$

Figure S121. ${ }^{1} \mathrm{H}-{ }^{1} \mathrm{H}$ COSY spectrum of $\mathbf{1 3}$ in DMSO-d 6

Figure S122. HSQC spectrum of $\mathbf{1 3}$ in DMSO-d $\mathrm{d}_{6}$

Figure S123. HMBC spectrum of $\mathbf{1 3}$ in DMSO-d 6

Figure S124. NOESY spectrum of $\mathbf{1 3}$ in DMSO- $\mathrm{d}_{6}$

Figure S125. HRESIMS spectrum of $\mathbf{1 3}$

Figure S126. IR ( $\mathrm{KBr}$ disc) spectrum of $\mathbf{1 3}$

Figure S127. UV spectrum of $\mathbf{1 3}$

Figure S128. ECD spectrum of $\mathbf{1 3}$

Figure S129. ${ }^{1} \mathrm{H}$ NMR spectrum of $\mathbf{1 4}$ in DMSO-d 6

Figure S130. ESIMS spectrum of $\mathbf{1 4}$

Figure S131. ${ }^{1} \mathrm{H}$ NMR spectrum of 15 in DMSO- $\mathrm{d}_{6}$

Figure S132. ESIMS spectrum of $\mathbf{1 5}$

Figure S133. ${ }^{1} \mathrm{H}$ NMR spectrum of $\mathbf{1 6}$ in DMSO-d $\mathrm{d}_{6}$

Figure S134. ESIMS spectrum of $\mathbf{1 6}$

Figure S135. ${ }^{1} \mathrm{H}$ NMR spectrum of $\mathbf{1 7}$ in $\mathrm{CDCl}_{3}$

Figure S136. ESIMS spectrum of 17

Figure S137. ${ }^{1} \mathrm{H}$ NMR spectrum of 18 in $\mathrm{CDCl}_{3}$

Figure S138. ${ }^{13} \mathrm{C}$ NMR spectrum of 18 in $\mathrm{CDCl}_{3}$

Figure S139. ${ }^{1} \mathrm{H}$ NMR spectrum of 19 in $\mathrm{CD}_{3} \mathrm{OD}$

Figure S140. ESIMS spectrum of 19

Figure S141. ${ }^{1} \mathrm{H}$ NMR spectrum of 20 in $\mathrm{CDCl}_{3}$

Figure S142. ESIMS spectrum of 20

Figure S143. ${ }^{1} \mathrm{H}$ NMR spectrum of 21 in Acetone- $d_{6}$

Figure S144. ESIMS spectrum of 21

Figure S145. ${ }^{1} \mathrm{H}$ NMR spectrum of 22 in $\mathrm{CDCl}_{3}$

Figure S146. ${ }^{13} \mathrm{C}$ NMR spectrum of 22 in $\mathrm{CDCl}_{3}$ 
Figure S147. ${ }^{1} \mathrm{H}$ NMR spectrum of 23 in $\mathrm{CDCl}_{3}$

Figure S148. ESIMS spectrum of 23

Figure S149. ${ }^{1} \mathrm{H}$ NMR spectrum of 24 in $\mathrm{CD}_{3} \mathrm{OD}$

Figure S150. ESIMS spectrum of $\mathbf{2 4}$

Figure S151. ${ }^{1} \mathrm{H}$ NMR spectrum of 25 in $\mathrm{CD}_{3} \mathrm{OD}$

Figure S152. ESIMS spectrum of $\mathbf{2 5}$

Figure S153. ${ }^{1} \mathrm{H}$ NMR spectrum of 26 in DMSO- $\mathrm{d}_{6}$

Figure S154. ESIMS spectrum of 26

Figure S155. ${ }^{1} \mathrm{H}$ NMR spectrum of 27 in $\mathrm{CDCl}_{3}$

Figure S156. ESIMS spectrum of 27

Figure S157. ${ }^{1} \mathrm{H}$ NMR spectrum of 28 in $\mathrm{CDCl}_{3}$

Figure S158. ESIMS spectrum of $\mathbf{2 8}$

Figure S159. ${ }^{1} \mathrm{H}$ NMR spectrum of 29 in DMSO-d

Figure S160. ESIMS spectrum of 29

Figure S161. ${ }^{1} \mathrm{H}$ NMR spectrum of $\mathbf{3 0}$ in DMSO-d $\mathrm{d}_{6}$

Figure S162. ESIMS spectrum of $\mathbf{3 0}$

Figure S163. ${ }^{1} \mathrm{H}$ NMR spectrum of $\mathbf{3 1}$ in DMSO-d

Figure S164. ESIMS spectrum of $\mathbf{3 1}$

Figure S165. ${ }^{1} \mathrm{H}$ NMR spectrum of $\mathbf{3 2}$ in DMSO-d $\mathrm{d}_{6}$

Figure S166. ESIMS spectrum of $\mathbf{3 2}$ 


\section{Part 1. Experimental Section}

\section{X-ray Crystallographic Analysis of Compound 1, 2, 7, 9 and 32. Upon}

crystallization from $\mathrm{MeOH}$ using the vapor diffusion method, colorless crystals were obtained for 1, 2, 7, 9 and 32. The data were collected on an Oxford Diffraction Xcalibur Eos Gemini diffractometer with graphite monochromator at $291.15 \mathrm{~K}, \mathrm{Cu}$ $\mathrm{K} \alpha$ radiation. Crystal data for $\mathbf{1}: \mathrm{C}_{15} \mathrm{H}_{20} \mathrm{O}_{5}, M=280.31$, space group orthorhombic; unit cell dimensions $a=5.0164(3) \AA, b=14.1582(7) \AA, c=19.7723(11) \AA, \alpha=90^{\circ}$, $\beta=90^{\circ}, \gamma=90^{\circ}, V=1404.29(13) \AA^{3}, Z=4, D_{\text {calcd }}=1.326 \mathrm{mg} / \mathrm{mm}^{3}, F(000)=600, \mu$ $(\mathrm{Cu} \mathrm{K} \alpha)=0.821 \mathrm{~mm}^{-1}, 6586$ reflections measured $(3.84 \leq 2 \theta \leq 61.27), 6586$ unique reflections which were used in all calculations. The final $R_{1}$ was 0.0436 (I $\left.>2 \sigma(\mathrm{I})\right)$ and $w R_{2}$ was 0.1067 (all data). The Flack parameter is $0.11(10)$. Crystal data for 2: $\mathrm{C}_{14} \mathrm{H}_{18} \mathrm{O}_{5}, M=266.28$, space group orthorhombic; unit cell dimensions $a=$ 4.7381(3) $\AA$, $b=10.7346(5) \AA, c=25.8999(15) \AA, \alpha=90^{\circ}, \beta=90^{\circ}, \gamma=90^{\circ}, V=$ $1317.31(13) \AA^{3}, Z=4, D_{\text {calcd }}=1.343 \mathrm{mg} / \mathrm{mm}^{3}, F(000)=568, \mu(\mathrm{Cu} \mathrm{K} \alpha)=0.847$ $\mathrm{mm}^{-1}, 8344$ reflections measured $(3.41 \leq 2 \theta \leq 68.25), 6586$ unique reflections which were used in all calculations. The final $R_{1}$ was $0.0389(\mathrm{I}>2 \sigma(\mathrm{I}))$ and $w R_{2}$ was 0.0826 (all data). The Flack parameter is -0.02 (13). Crystal data for 7: $\mathrm{C}_{16} \mathrm{H}_{20} \mathrm{O}_{6}, M=308.30$, space group monoclinic; unit cell dimensions $a=9.6147(5) \AA$, $b=7.1513(4) \AA$, $c=$ 10.9518(6) $\AA, \alpha=90^{\circ}, \beta=97.5040(10)^{\circ}, \gamma=90^{\circ}, V=746.57(7) \AA^{3}, Z=2, D_{\text {calcd }}=$ $1.363 \mathrm{mg} / \mathrm{mm}^{3}, F(000)=324, \mu(\mathrm{Cu} \mathrm{K} \alpha)=0.877 \mathrm{~mm}^{-1}, 10248$ reflections measured $(4.64 \leq 2 \theta \leq 65.14), 10248$ unique reflections which were used in all calculations. The final $R_{1}$ was 0.0371 (I $\left.>2 \sigma(\mathrm{I})\right)$ and $w R_{2}$ was 0.0929 (all data). The Flack parameter is 
0.04 (6). Crystal data for 9: $\mathrm{C}_{15} \mathrm{H}_{18} \mathrm{O}_{5}, M=278.12$, space group orthorhombic; unit cell dimensions $a=7.7573(6) \AA, b=12.8283(11) \AA, c=13.9400(12) \AA, \alpha=90^{\circ}, \beta=$ $90^{\circ}, \gamma=90^{\circ}, V=1387.2(2) \AA^{3}, Z=41, D_{\text {calcd }}=1.323 \mathrm{mg} / \mathrm{mm}^{3}, F(000)=584, \mu(\mathrm{Cu}$ $\mathrm{K} \alpha)=0.830 \mathrm{~mm}^{-1}, 8256$ reflections measured $(4.68 \leq 2 \theta \leq 68.30), 8256$ unique reflections which were used in all calculations. The final $R_{1}$ was 0.1035 (I $\left.>2 \sigma(\mathrm{I})\right)$ and $w R_{2}$ was 0.2649 (all data). The Flack parameter is 0.04 (6). Crystal data for 32: $\mathrm{C}_{10} \mathrm{H}_{14} \mathrm{O}_{4}, M=198.21$, space group orthorhombic; unit cell dimensions $a=4.7759(2)$ $\AA, \quad b=14.0008(5) \AA, c=14.3800(5) \AA, \alpha=90^{\circ}, \beta=90^{\circ}, \gamma=90^{\circ}, V=961.54(6) \AA^{3}$, $Z=4, D_{\text {calcd }}=1.369 \mathrm{mg} / \mathrm{mm}^{3}, F(000)=424, \mu(\mathrm{Cu} \mathrm{K} \alpha)=0.884 \mathrm{~mm}^{-1}, 5652$ reflections measured $(4.41 \leq 2 \theta \leq 68.24), 5652$ unique reflections which were used in all calculations. The final $R_{1}$ was 0.041 (I $\left.>2 \sigma(\mathrm{I})\right)$ and $w R_{2}$ was 0.1024 (all data). The Flack parameter is $0.01(6)$.

Using Olex $2,{ }^{1}$ the structures of compounds 1, 2, 7, 9 and 32 were solved with the olex2.solve structure solution program using Charge Flipping and refined with the SHELXL $^{2}$ refinement package using Least Squares minimisation. Details of crystallographic data (excluding structure factors) of compounds 1, 2, 7, 9 and 32 have been deposited with the Cambridge Crystallographic Data Center as supplementary publication number CCDC 1433640, 1472537, 1433641, 1433639 and 1472535 respectively. The data can be obtained free of charge via www.ccdc.cam.ac.uk/products/csd/request.

Theory and Calculation Details. The calculations were performed with the Gaussian 09 program package. ${ }^{3}$ Conformational searches were performed by MD simulations based on the COMPASS force field ${ }^{4}$ and by scanning the potential energy 
surface (PES) on the main chain dihedral angles using the semiempirical AM1. All ground-state geometries were optimized at the B3LYP/6-31G* level at $298 \mathrm{~K}$, followed by calculations of their harmonic frequency analysis to confirm these minima and then calculations of room-temperature free energies. Electronic excitation energies and rotational strengths in gas phase and in $\mathrm{MeOH}$ were calculated using TDDFT $^{5}$ at the same level in velocity formalism for the first 50 states. The solvent effect of $\mathrm{MeOH}$ has been modeled by a conductor-like screening model for real solvents (COSMO). ${ }^{6-7}$ The rotatory strengths were summed and energetically weighted following the Boltzmann statistics, and the ECD curves were simulated by using the Gaussian function: ${ }^{8}$

$$
\Delta \varepsilon(E)=\frac{1}{2.296 \times 10^{-39}} \frac{1}{\sigma \sqrt{\pi}} \times \sum_{i} \Delta E_{i} R_{i} e^{-\left[\left(E-\Delta E E_{i}\right) / \sigma\right]^{2}}
$$

where $\sigma$ is half the band width at $1 / e$ height and $\Delta E_{i}$ and $R_{i}$ are the excitation energies and rotatory strengths for transition $i$, respectively. Here a value of $\sigma=0.4 \mathrm{eV}$.

Strains and Culture. Seven $C$. albicans strains including one wild-type strain (SC5314) and six clinical-derived FLC-resistant isolates (24D, 28I, 142, 144, 145, 147) were used in this study. The clinical isolates 24D and 28I were kindly donated by Dr Qi Qingguo from School of Stomatology in Shandong University, and 142, 144, 145, and 147 were kindly donated by Qianfoshan Hospital. These strains were stored in physiological saline supplemented with $20 \%$ glycerol at $-80{ }^{\circ} \mathrm{C}$. Before each experiment, the $C$. albicans strains were grown on YPD (1\% yeast extract, $2 \%$ tryptone, $2 \%$ glucose) agar plates at $30{ }^{\circ} \mathrm{C}$ and subcultured in YPD broth (1\% yeast extract, $2 \%$ tryptone, $2 \%$ glucose) overnight at $30{ }^{\circ} \mathrm{C}, 200 \mathrm{rpm}$. In each bioexperiment, the maximal final concentration of DMSO was less than $1 \%$, with $1 \%$ final concentration of DMSO as vehicle control. 
Minimal Inhibition Concentrations (MICs) Test. The MICs of all tested compounds against $C$. albicans were determined by the broth microdilution method according to the Clinical and Laboratory Standards Institute (CLSI) guidelines (M27-A3). ${ }^{9}$

Microdilution Checkerboard Assay. The interactions of compound 4 and FLC against $C$. albicans were tested by broth microdilution checkerboard assays with a final inoculum of $0.5-2.5 \times 10^{3}$ cells $/ \mathrm{mL}$ in RPMI 1640 medium buffered with MOPS. ${ }^{10}$ 2-fold serial dilutions of FLC and $\mathbf{4}$ were prepared by diluting the drug in fungal suspensions at a concentraton 2-fold higher than the final desired concentration. A $50 \mu \mathrm{L}$ aliquot of each FLC suspensions was added to columns $1-10$, and $50 \mu \mathrm{L}$ aliquot of $\mathbf{4}$ was added to rows $\mathrm{A}-\mathrm{H}$. The final concentrations of $\mathbf{4}$ ranged from 0 to 8 $\mu \mathrm{g} / \mathrm{mL}$, and FLC from 0 to $128 \mu \mathrm{g} / \mathrm{mL}$. The 96 -well plate was incubated at $35^{\circ} \mathrm{C}$ for $24 \mathrm{~h}$. The XTT reduction assays were performed to determine the percent of viable cells compering with vehicle control. ${ }^{11}$ The fraction inhibited concentration index (FICI) was determined as previously described. ${ }^{12}$

Rhodamine 123 (Rh123) Efflux Assay. The FLC-resistant isolate 24D was selected to perform the experiment of Rh123 efflux. ${ }^{13}$ Overnight cultured cells were collected, washed and resuspended in RPMI 1640 medium. After incubated at $30{ }^{\circ} \mathrm{C}$ for $4 \mathrm{~h}$, the cells were pelleted, washed and incubated with $5 \mu \mathrm{M}$ Rh123 (Sigma, St Louis, MO, USA) in PBS (pH 7.2, without glucose). Then, a $200 \mu \mathrm{L}$ sample was withdrawn, washed and detected by flow cytometry (FACS Calibur; BD Biosciences, San Jose, CA, USA). The rest cells were washed and resuspended in PBS containing 
$2 \mu \mathrm{g} / \mathrm{mL}$ FLC or $1 \mu \mathrm{g} / \mathrm{mL}$ compound 4 and $1 \%$ glucose to initiate the ATP-driven efflux. After $30 \mathrm{~min}$ incubation at $30{ }^{\circ} \mathrm{C}$, all samples were collected and washed three times. The florescence intensity of intracellular remaining Rh123 was determined by flow cytometry and observed using confocal microscopy. The experiment was performed in triplicate.

Quantification Analysis by qPCR. The FLC-resistant strain 24D was grown overnight and diluted to a cell density of $1 \times 10^{6}$ cells/mL in RPMI 1640 medium. Yeasts were incubated for $12 \mathrm{~h}$ with $2 \mu \mathrm{g} / \mathrm{mL}$ FLC or $1 \mu \mathrm{g} / \mathrm{mL} 4$. The total RNAs were respectively isolated using the hot phenol method as previous described ${ }^{13}$ and converted to cDNA using the RT kit (Totobo CO., Osaka, Japan). Then transcript levels of $C D R 1$ and $C D R 2$ were analyzed by the quantitative real-time PCR technique. Primer sequences, reaction systems and conditions were set as our lab described previously. ${ }^{14}$ The housekeeping gene $18 \mathrm{~s}$ was taken as the internal reference gene. The transcript level of detected genes was calculated using the formula $2^{-\triangle \Delta \mathrm{CT}}$. This experiment was repeated three times in three different days. 


\section{REFERENCES}

(1) Dolomanov, O. V.; Bourhis, L. J.; Gildea, R. J.; Howard, J. A. K.; Puschmann, H. J. Appl. Cryst. 2009, 42, 339-341.

(2) Sheldrick, G. M. Acta Cryst. 2008, 64, 112-122.

(3) Frisch, M. J.; Trucks, G. W.; Schlegel, H. B.; Scuseria, G. E.; Robb, M. A.; Cheeseman, J. R.;

Scalmani, G.; Barone, V.; Mennucci, B.; Petersson, G. A.; Nakatsuji, H.; Caricato, M.; Li, X.; Hratchian, H. P.; Izmaylov, A. F.; Bloino, J.; Zheng, G.; Sonnenberg, J. L.; Hada, M.; Ehara, M.; Toyota, K.;

Fukuda, R.; Hasegawa, J.; Ishida, M.; Nakajima, T.; Honda, Y.; Kitao, O.; Nakai, H.; Vreven, T.;

Montgomery Jr., J. A.; Peralta, J. E.; Ogliaro, F.; Bearpark, M.; Heyd, J. J.; Brothers, E.; Kudin, K. N.;

Staroverov, V. N.; Kobayashi, R.; Normand, J.; Raghavachari, K.; Rendell, A.; Burant, J. C.; Iyengar, S.

S.; Tomasi, J.; Cossi, M.; Rega, N.; Millam, J. M.; Klene, M.; Knox, J. E.; Cross, J. B.; Bakken, V.;

Adamo, C.; Jaramillo, J.; Gomperts, R.; Stratmann, R. E.; Yazyev, O.; Austin, A. J.; Cammi, R.;

Pomelli, C.; Ochterski, J. W.; Martin, R. L.; Morokuma, K.; Zakrzewski, V. G.; Voth, G. A.; Salvador, P.;

Dannenberg, J. J.; Dapprich, S.; Daniels, A. D.; Farkas, Ö.; Foresman, J. B.; Ortiz, J. V.; Cioslowski, J.;

Fox, D. J. Gaussian 09 (Revision B.01), Gaussian, Inc., Wallingford, CT, 2010.

(4) Sun, H. J. Phys. Chem. B 1998, 102, 7338-7364.

(5) Diedrich, C.; Grimme, S. J. Phys. Chem. A 2003, 107, 2524-2539.

(6) Klamt, A.; Jonas, V. J. Chem. Phys. 1996, 105, 9972-9981.

(7) Klamt, A. J. Phys. Chem. 1995, 99, 2224-2235.

(8) Stephens, P. J.; Harada, N. Chirality 2010, 22, 229-233.

(9) Clinical and Laboratory Standards Institute (CLSI). M27-A3, Reference Method for Broth Dilution Antifungal Susceptibility Testing of Yeasts: Approved Standard, $3^{\text {rd }}$ edn. Wayne, PA: Clinical and 
Laboratory Standards Institute. 2008.

(10) Zhou, y.; Wang, G.; Li, y.; Song, Y.; Zheng, W.; Zhang, N.; Hu, X.; Yan, S.; Jia, J. Antimicrob Agents Chemother. 2012, 56, 3250-3260.

(11) Sun, L.M.; Liao, K; Liang, S; Yu, P.H.; Wang, D.Y. J. Appl. Microbiol. 2014, 118, 826-838.

(12) Odds, F.C. J. Antimicrob Chemother. 2003, 52, 1.

(13) Li, Y.;Chang, W.Q.; Zhang, M.; Li, X.B.; Jiao, Y.; Lou, H.X. FEMS Yeast Res. $2015,15$.

(14) Sun, L.M.; Cheng, A.X.; Wu, X.Z.; Zhang, H.J; Lou, H.X. J. Appl Microbiol. 2009, 108, 341-348. 


\section{Part 2. Figures}
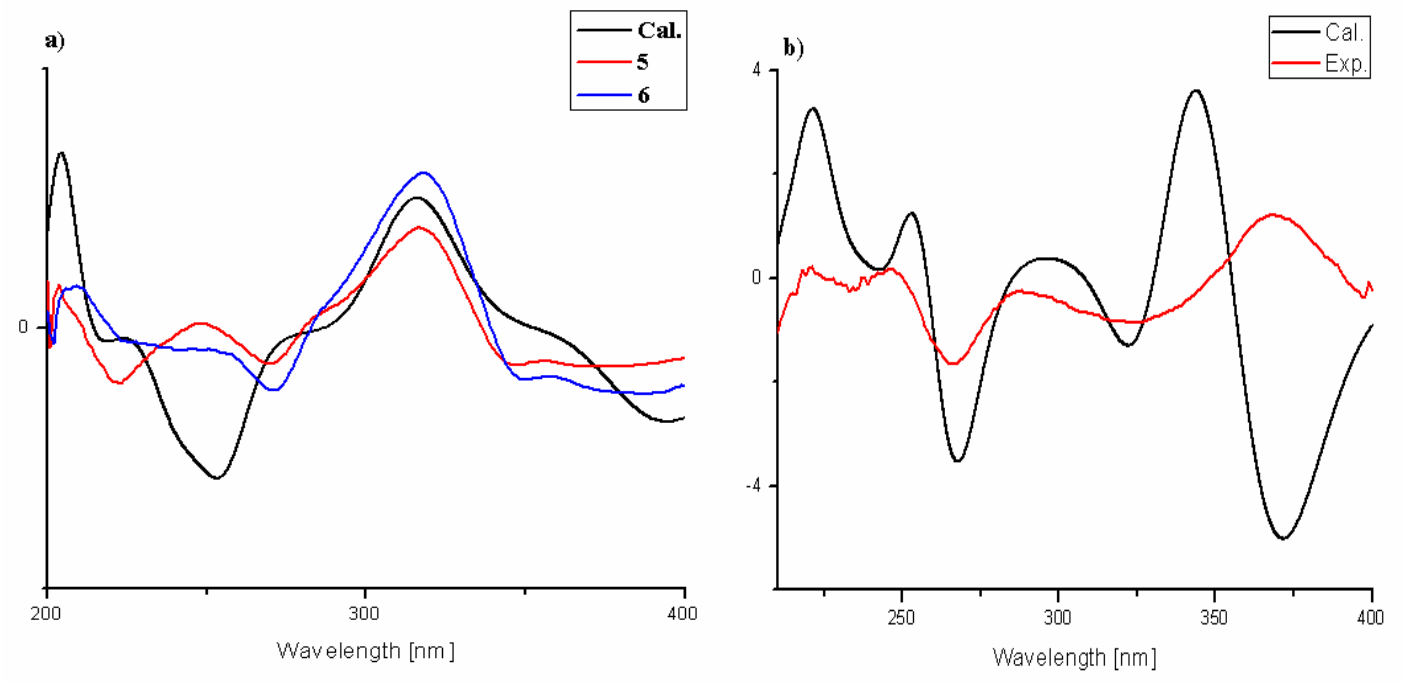

Figure S1. Experimental and calculated ECD spectra of compounds 5 (a), 6 (a), 12 (b). 


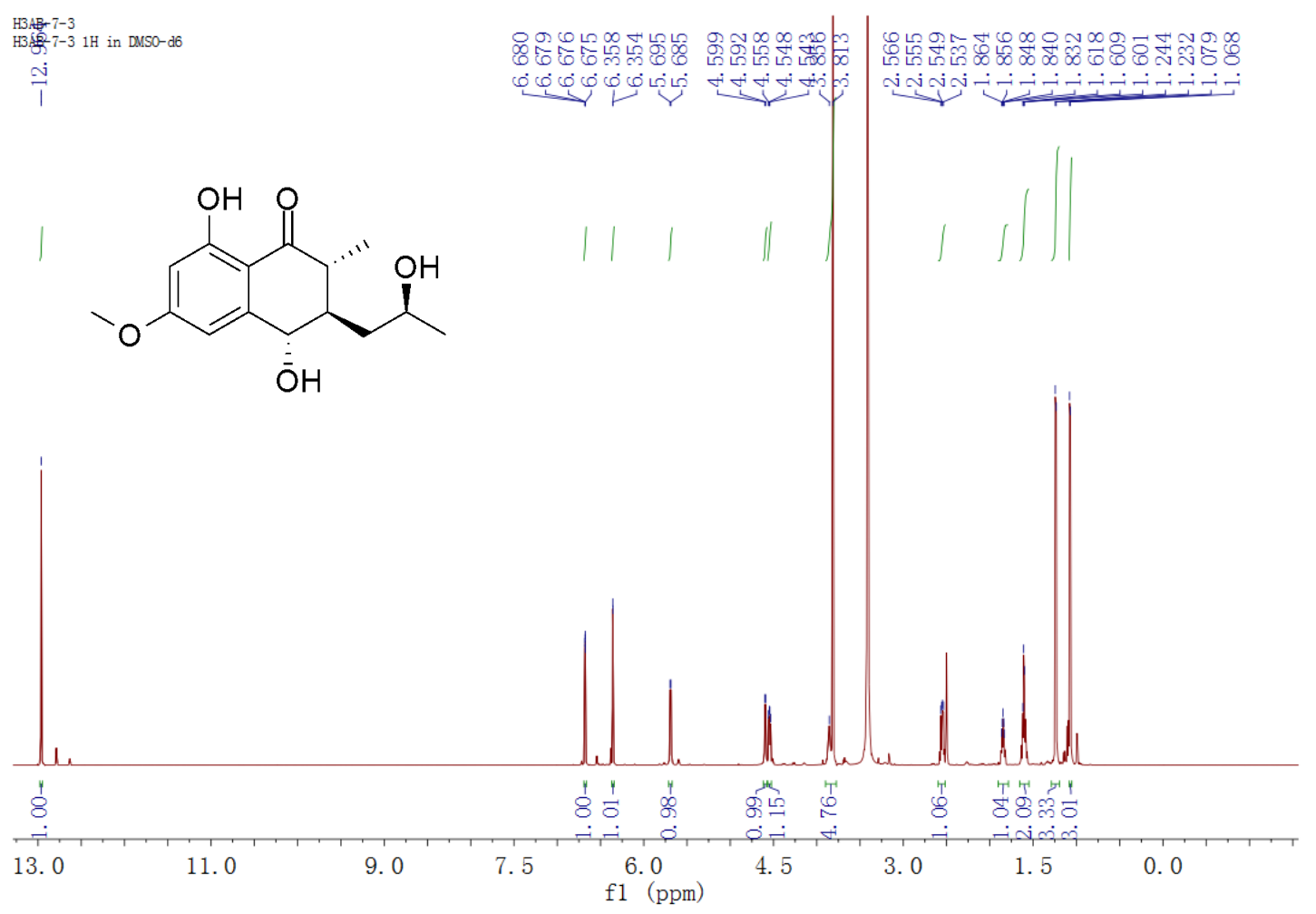

Figure S2. ${ }^{1} \mathrm{H}$ NMR spectrum of $\mathbf{1}$ in DMSO-d 6
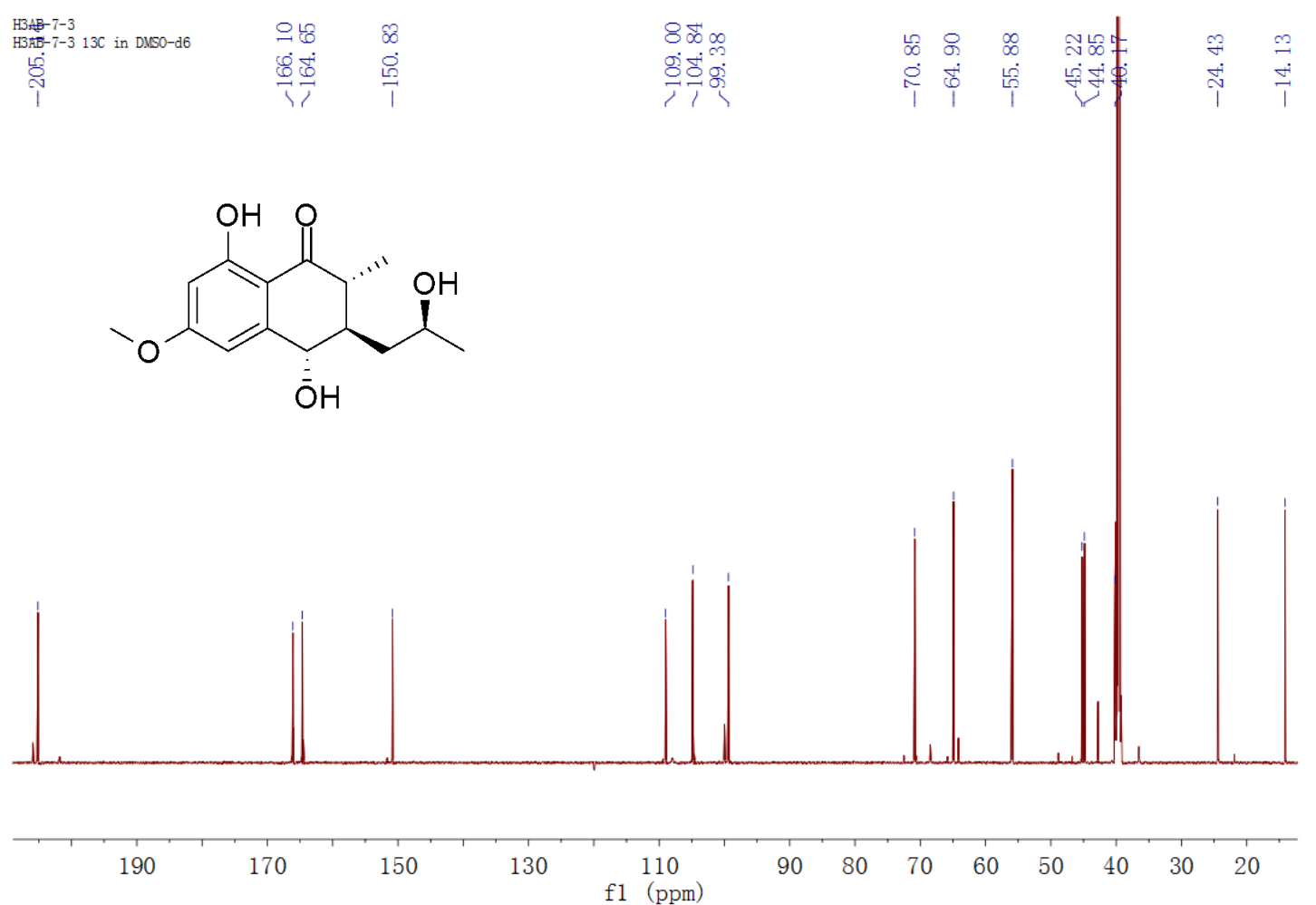

Figure S3. ${ }^{13} \mathrm{C}$ NMR spectrum of $\mathbf{1}$ in DMSO- $\mathrm{d}_{6}$ 


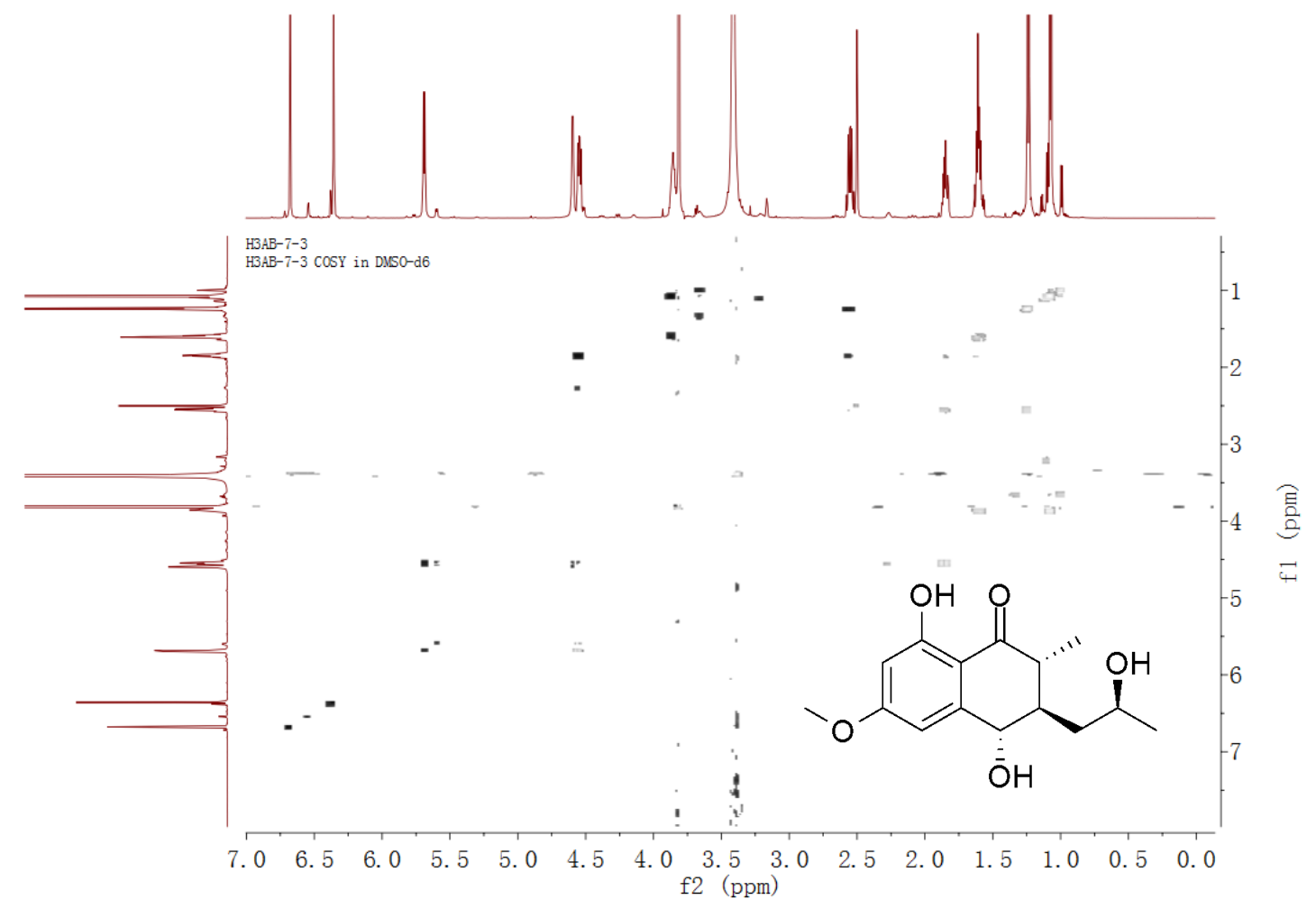

Figure S4. ${ }^{1} \mathrm{H}-{ }^{1} \mathrm{H}$ COSY spectrum of $\mathbf{1}$ in DMSO-d 6

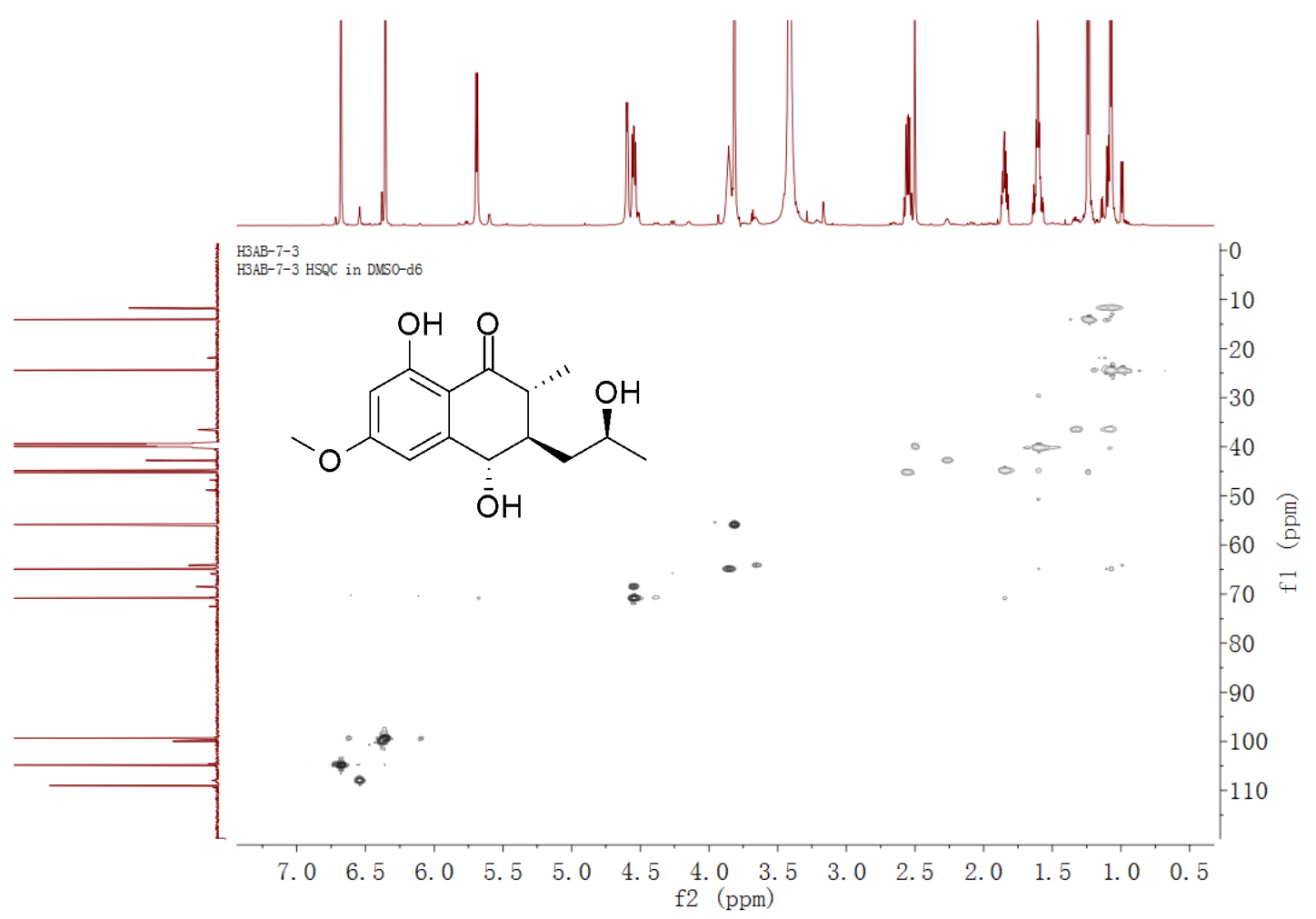

Figure S5. HSQC spectrum of $\mathbf{1}$ in DMSO-d 6 


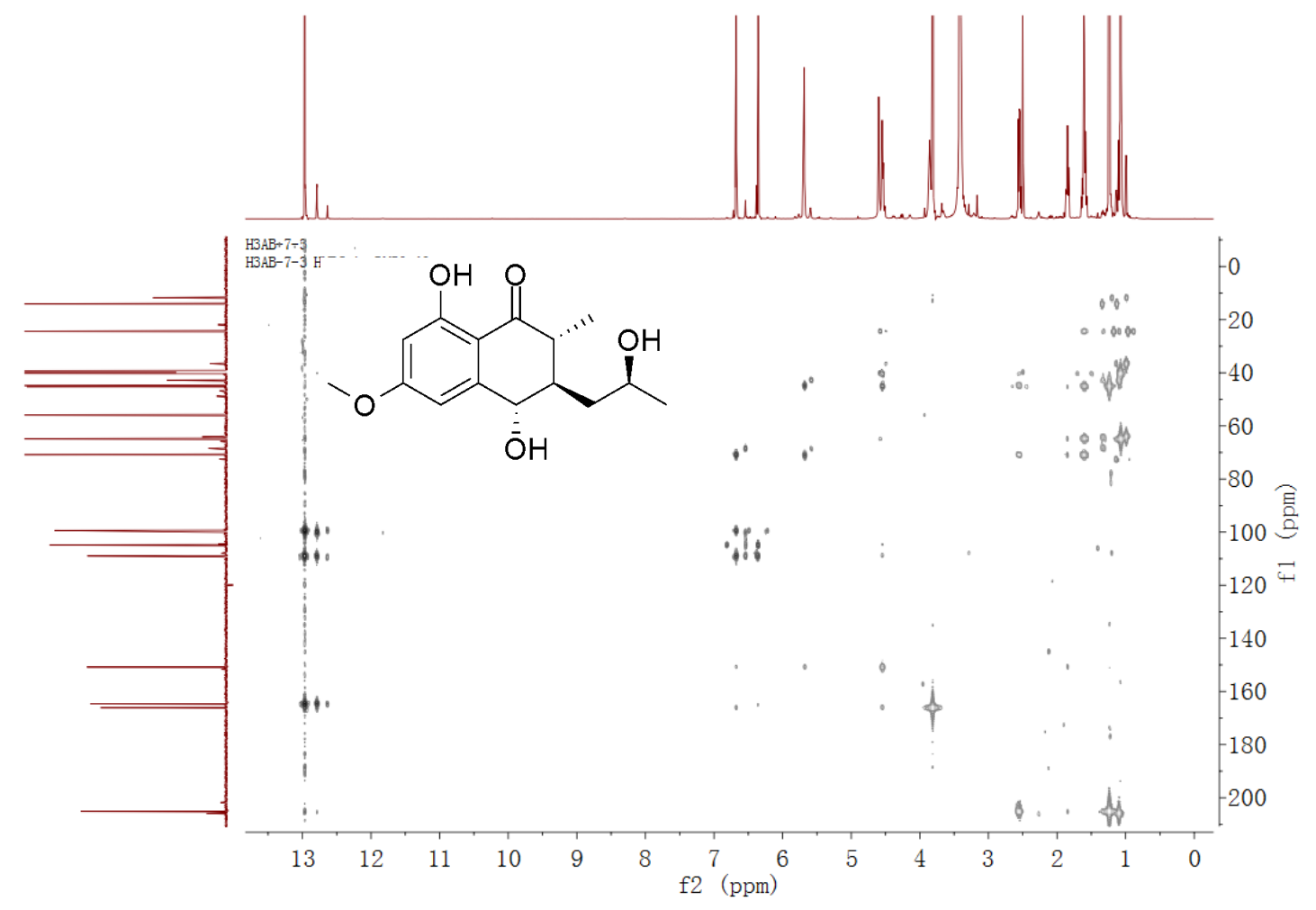

Figure S6. HMBC spectrum of 1 in DMSO-d

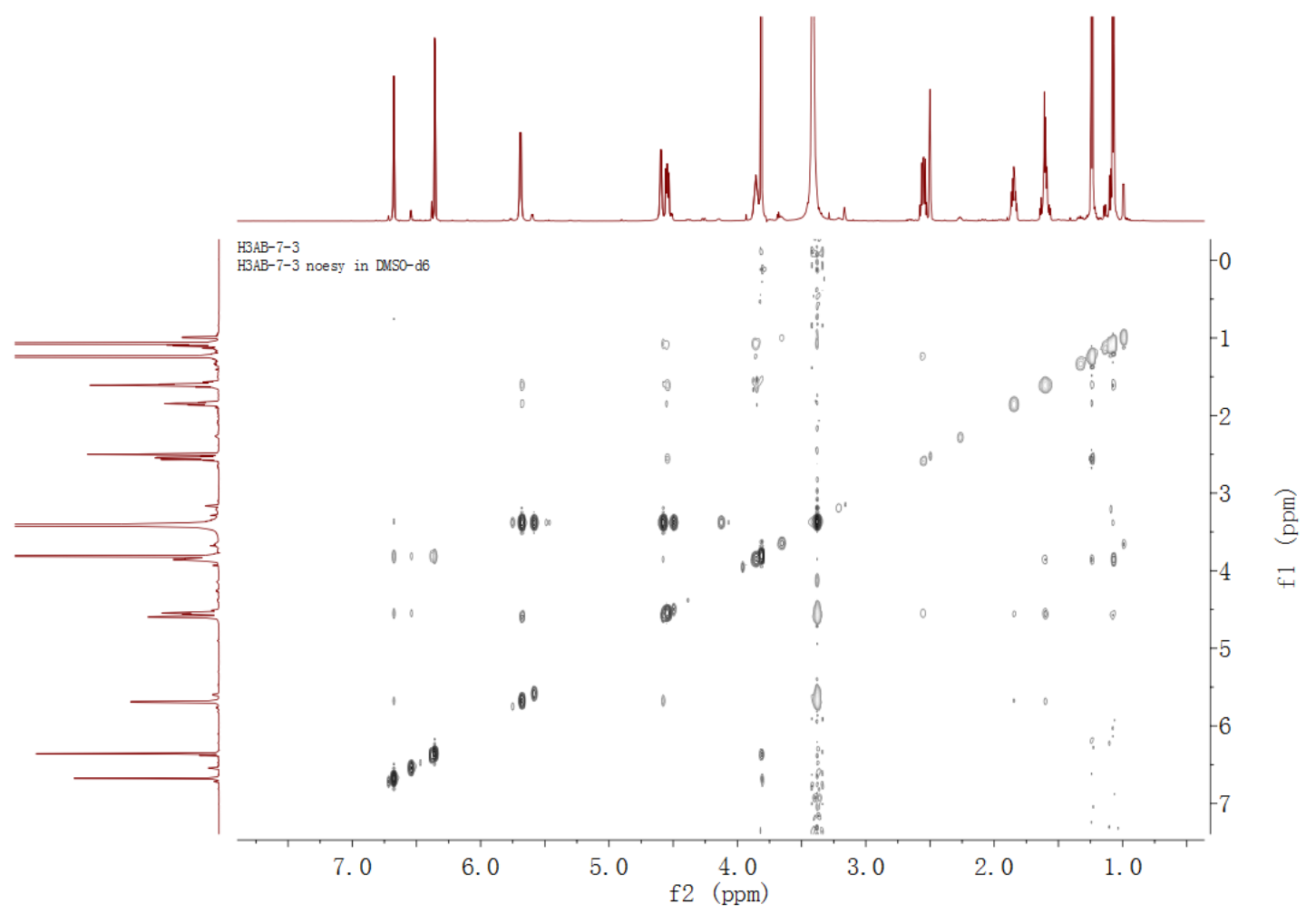

Figure S7. NOESY spectrum of $\mathbf{1}$ in DMSO-d 6 


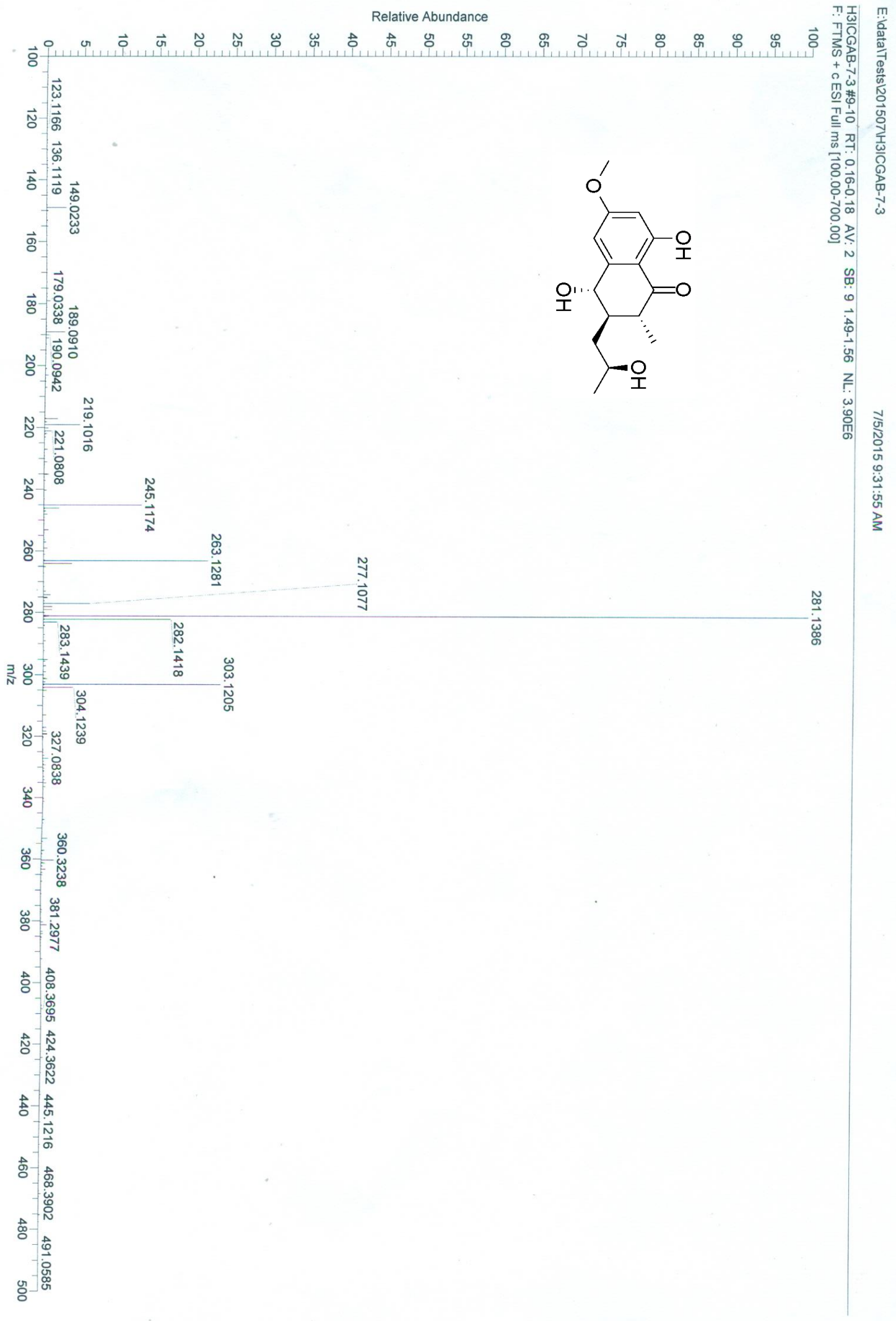

Figure S8. HRESIMS spectrum of $\mathbf{1}$ 


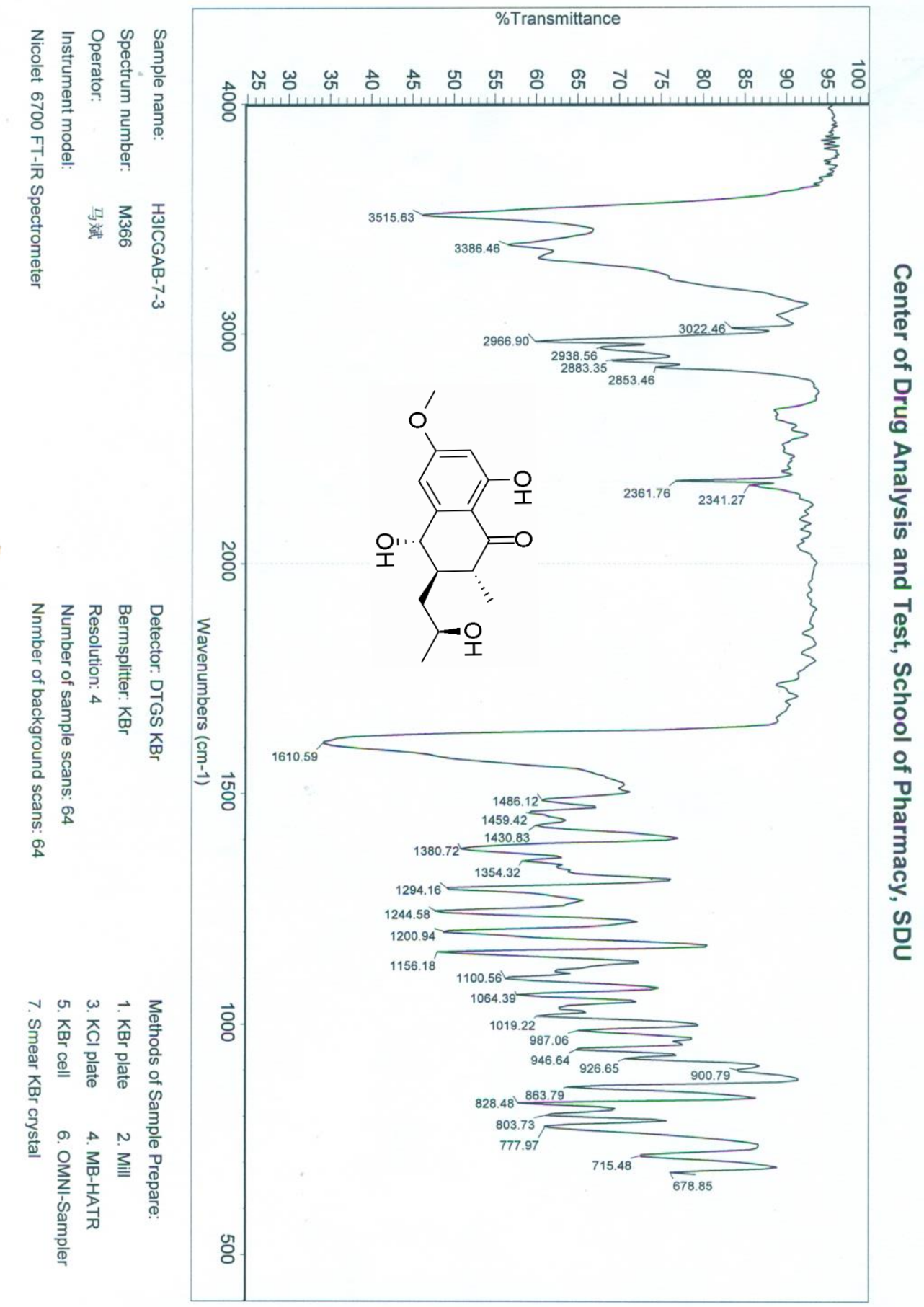

Figure S9. IR ( $\mathrm{KBr}$ disc) spectrum of $\mathbf{1}$ 


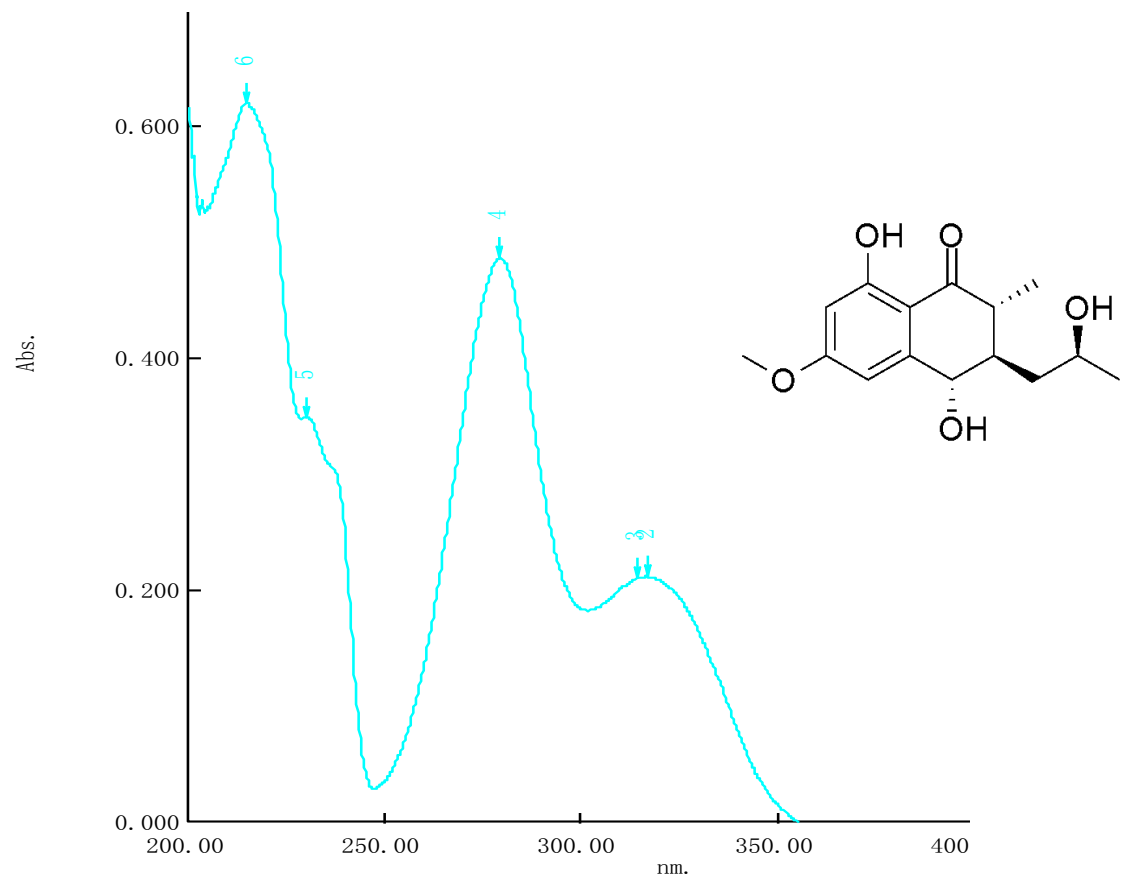

Figure S10. UV spectrum of $\mathbf{1}$

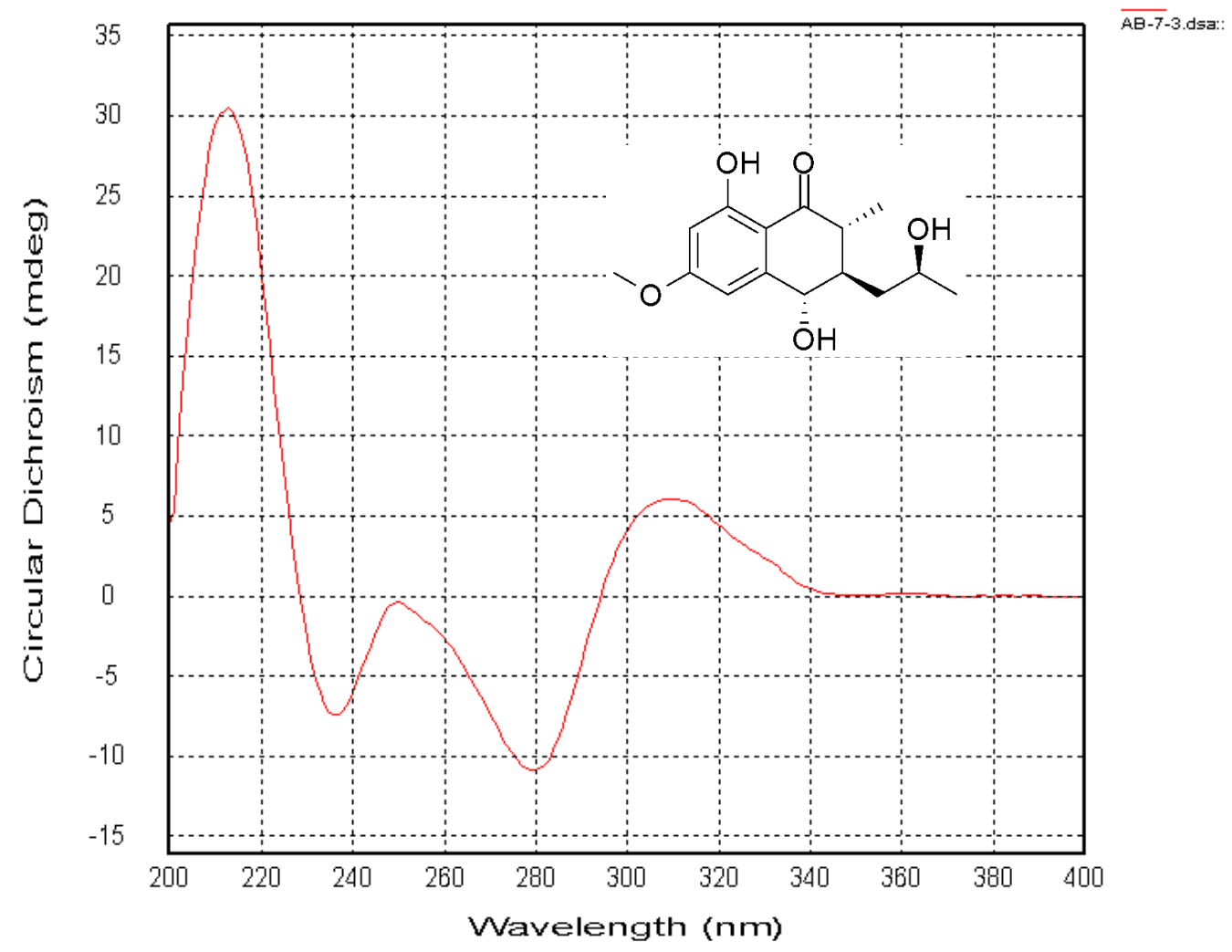

Figure S11. ECD spectrum of 1 


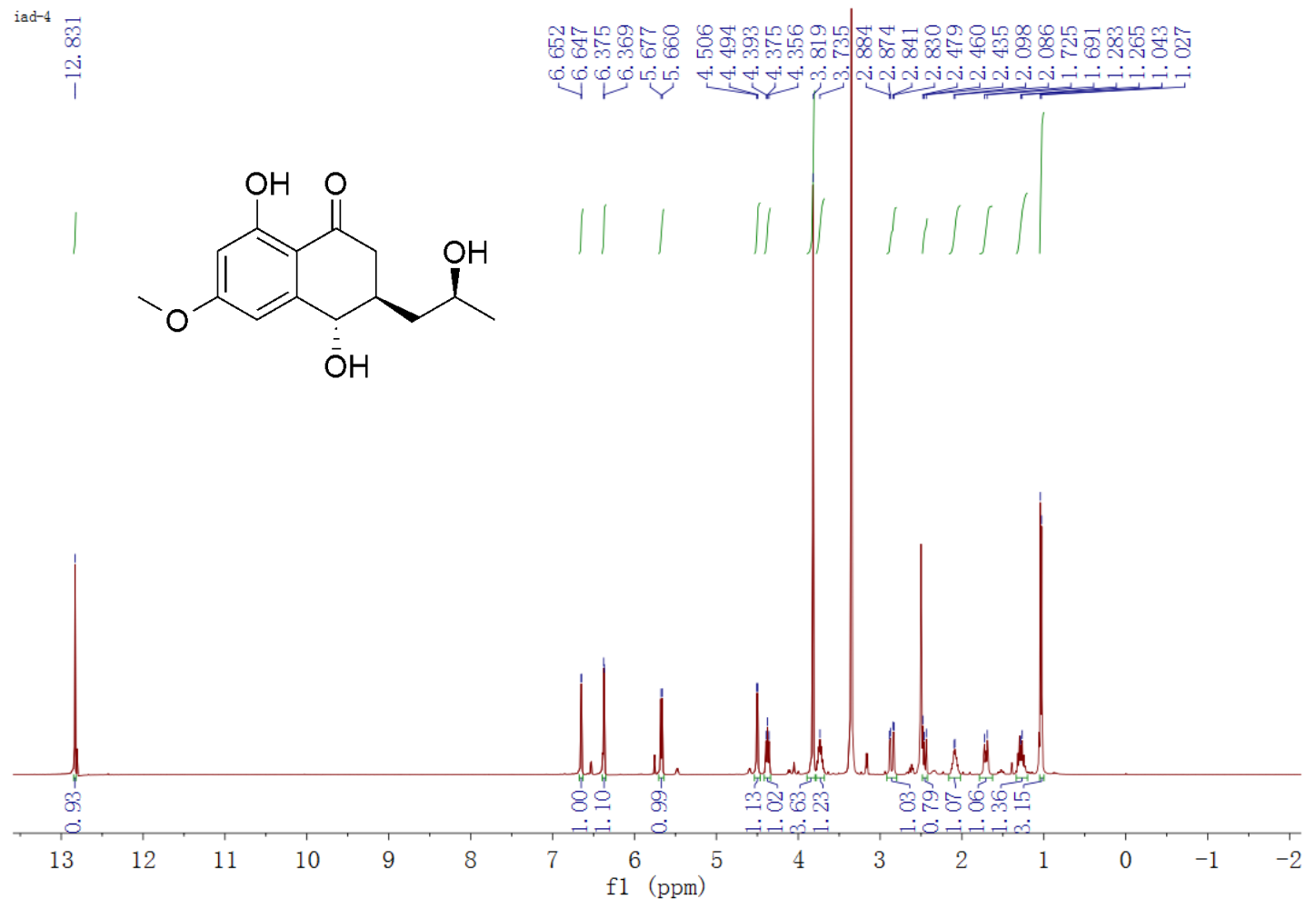

Figure S12. ${ }^{1} \mathrm{H}$ NMR spectrum of 2 in DMSO-d 6

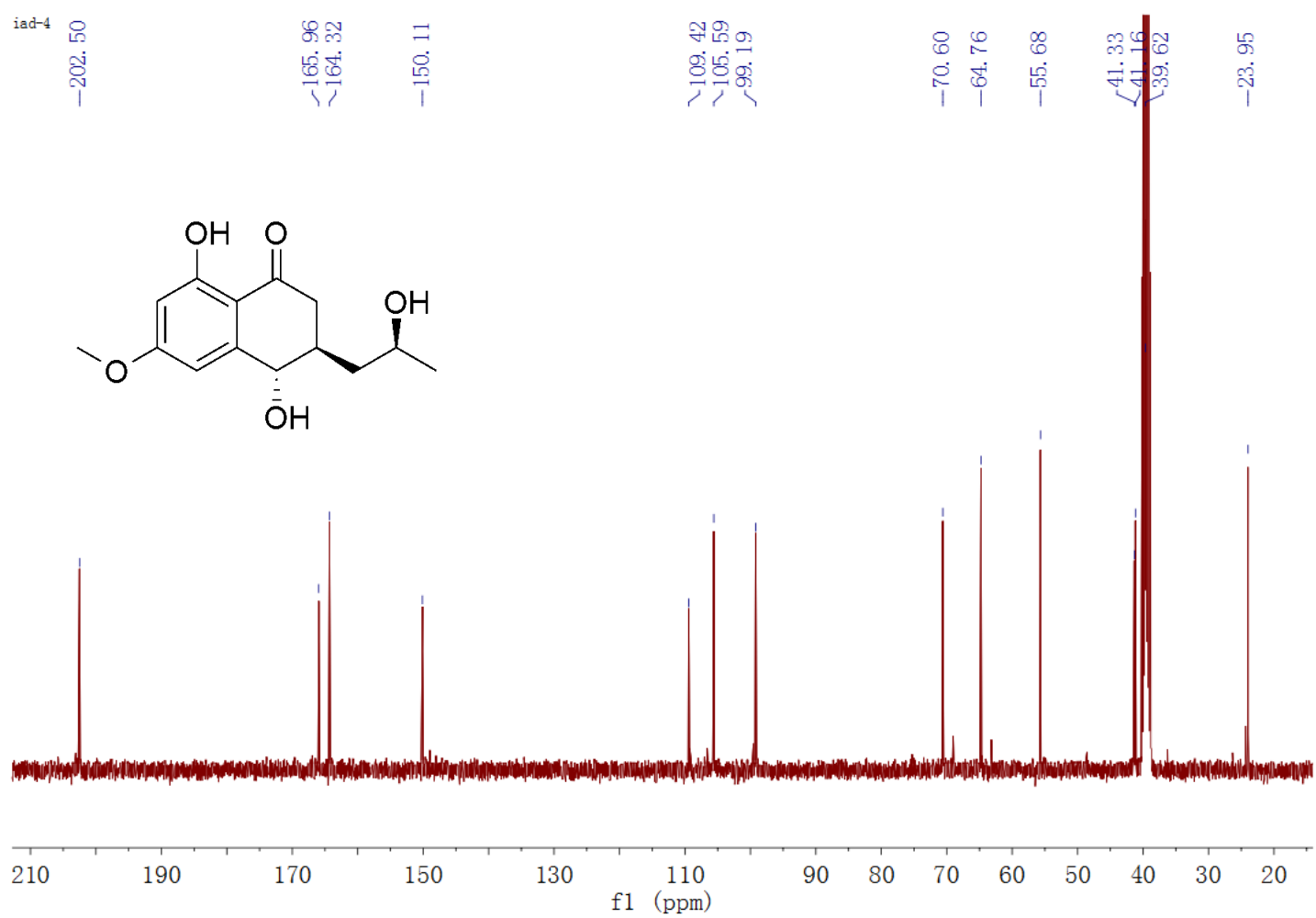

Figure S13. ${ }^{13} \mathrm{C}$ NMR spectrum of 2 in DMSO-d 6 


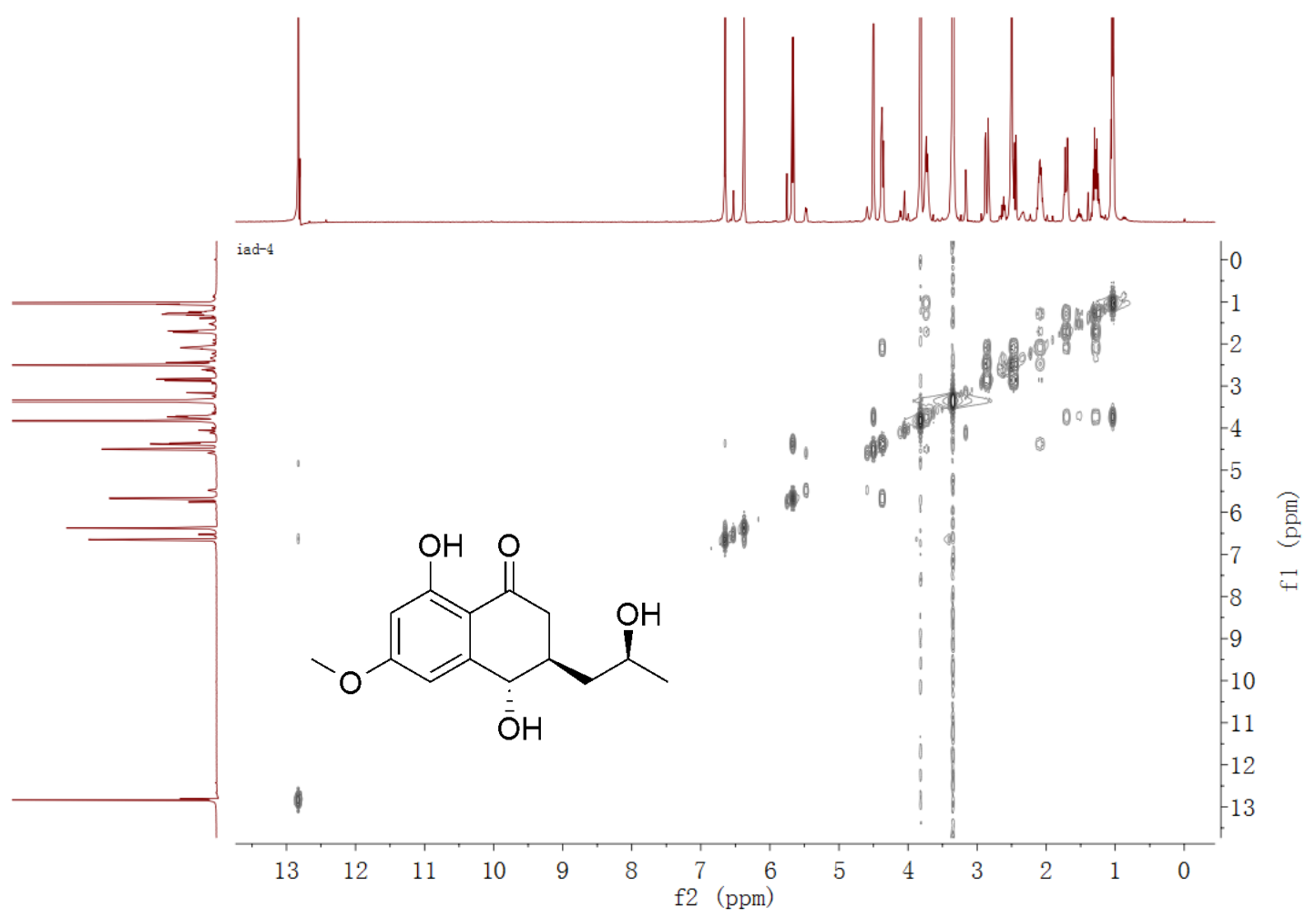

Figure S14. ${ }^{1} \mathrm{H}-{ }^{1} \mathrm{H}$ COSY spectrum of 2 in DMSO-d 6

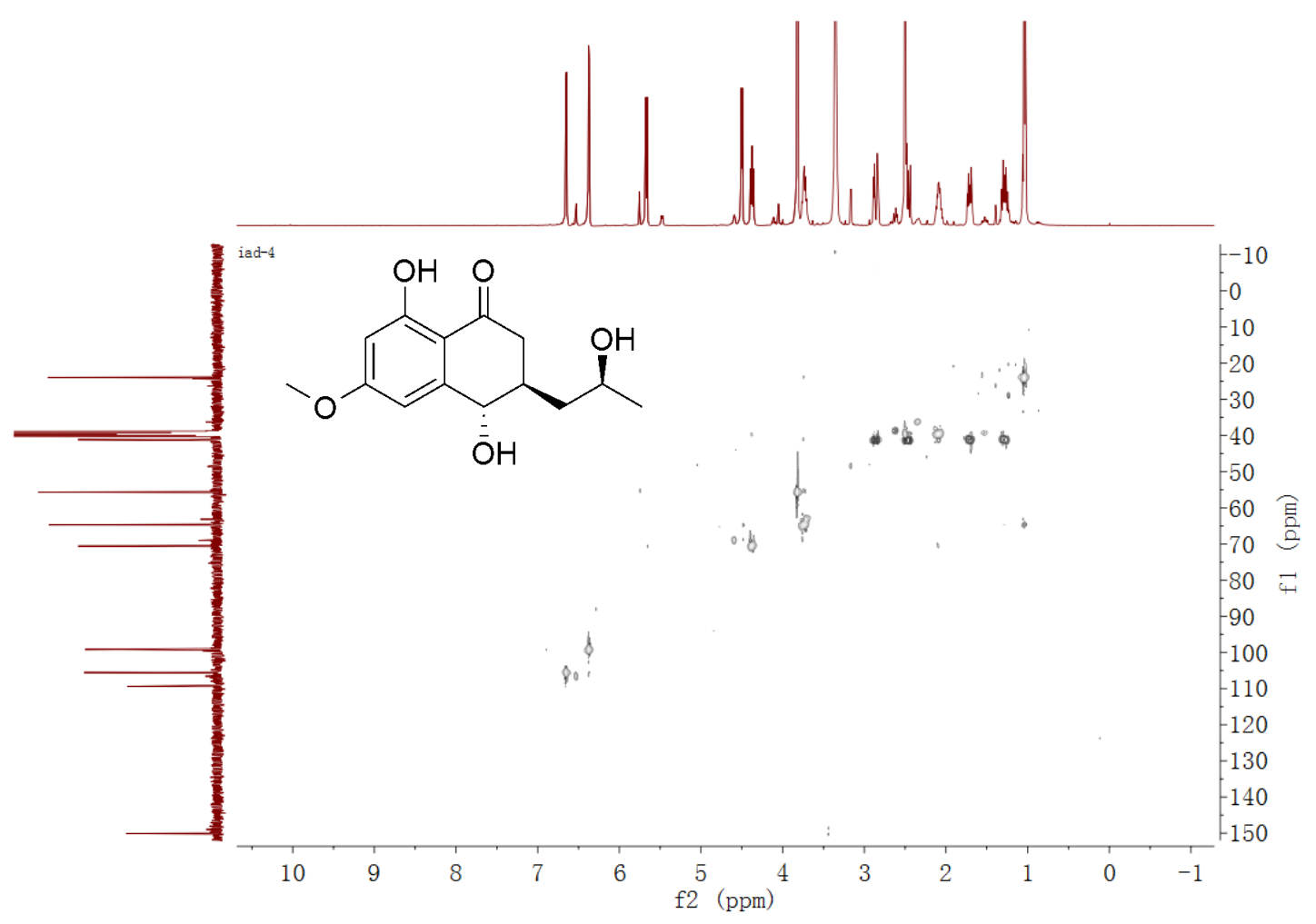

Figure S15. HSQC spectrum of 2 in DMSO-d 6 


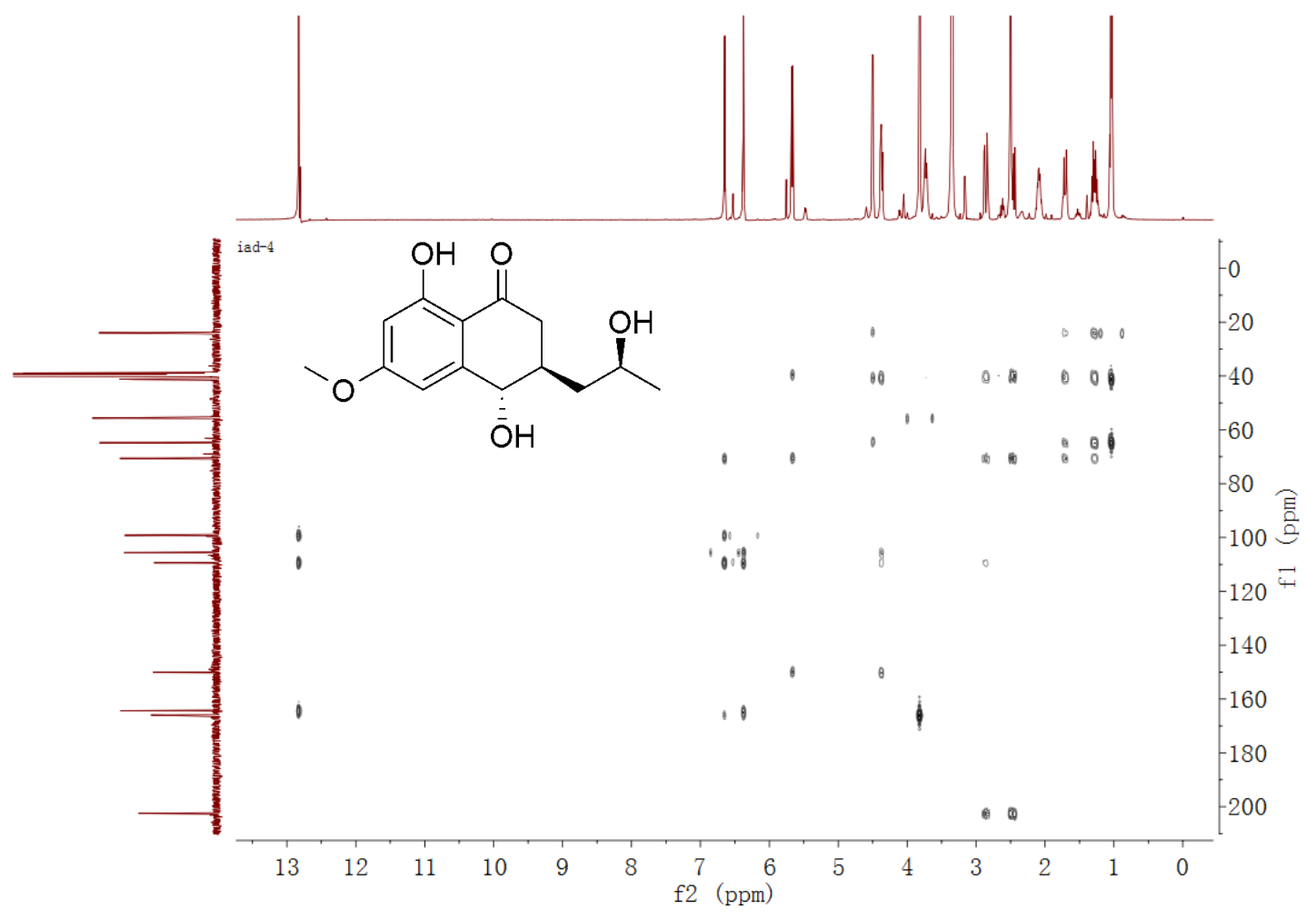

Figure S16. HMBC spectrum of 2 in DMSO- $\mathrm{d}_{6}$ 

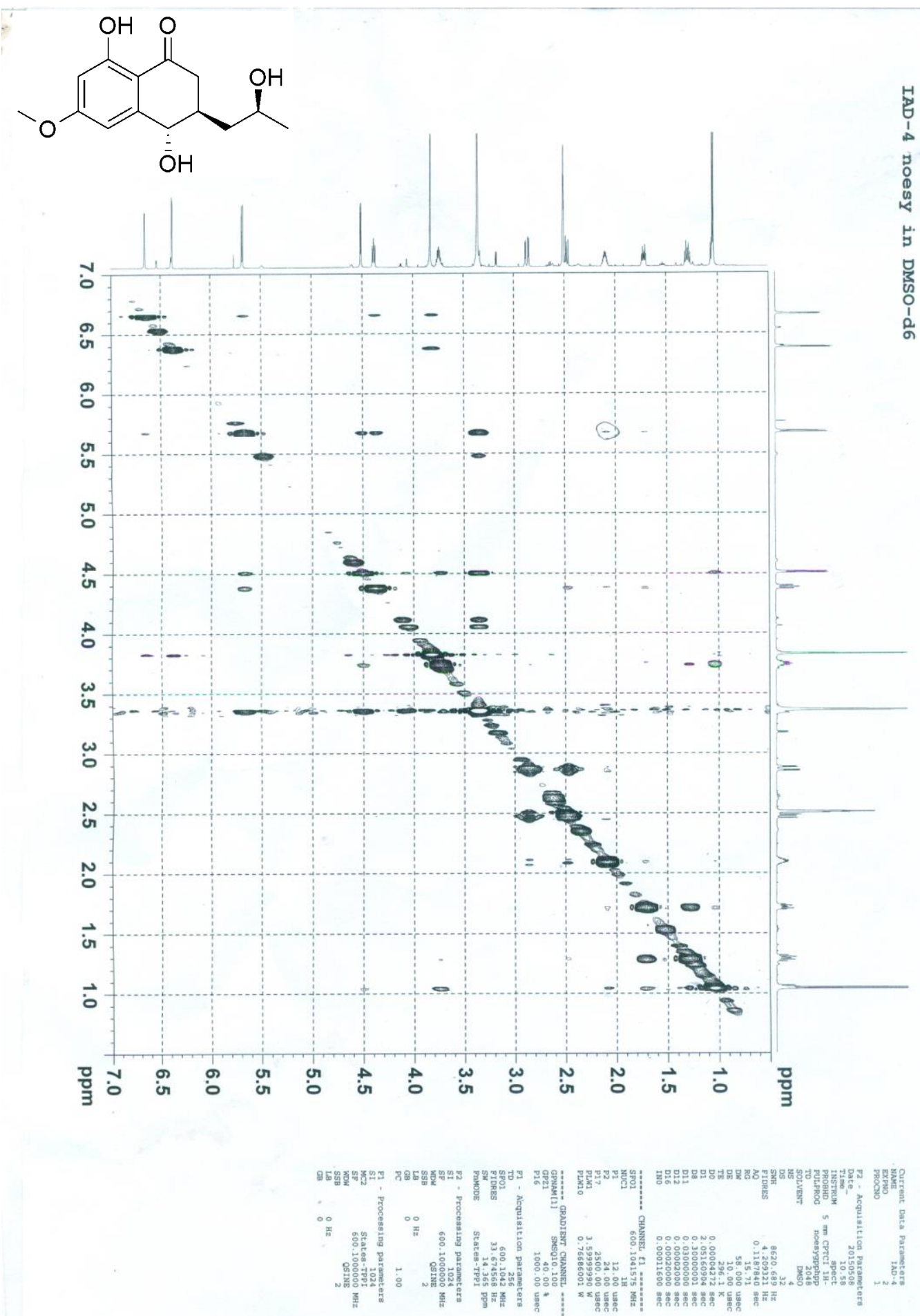

Figure S17. NOESY spectrum of 2 in DMSO-d 6 


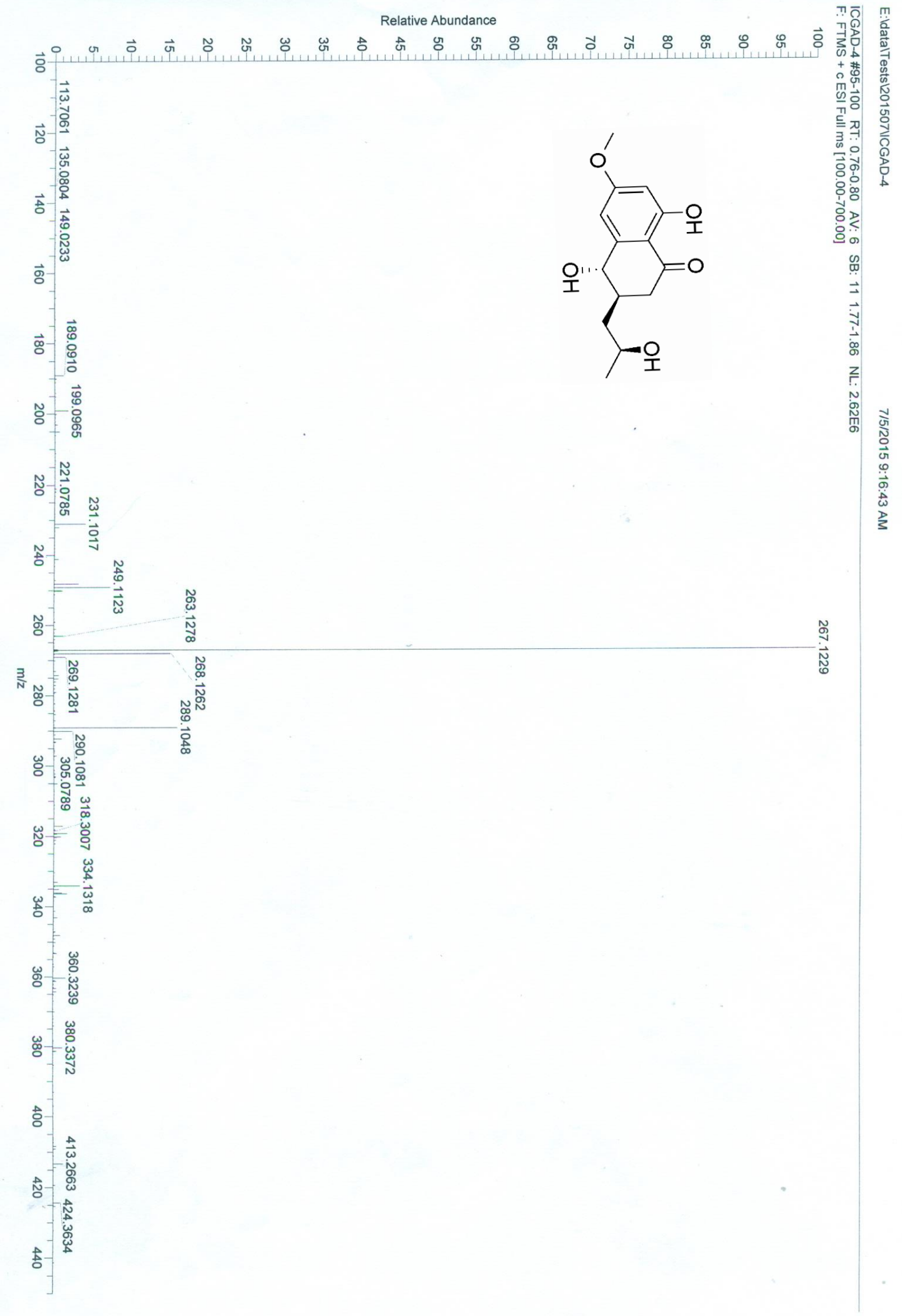

Figure S18.HRESIMS spectrum of 2 


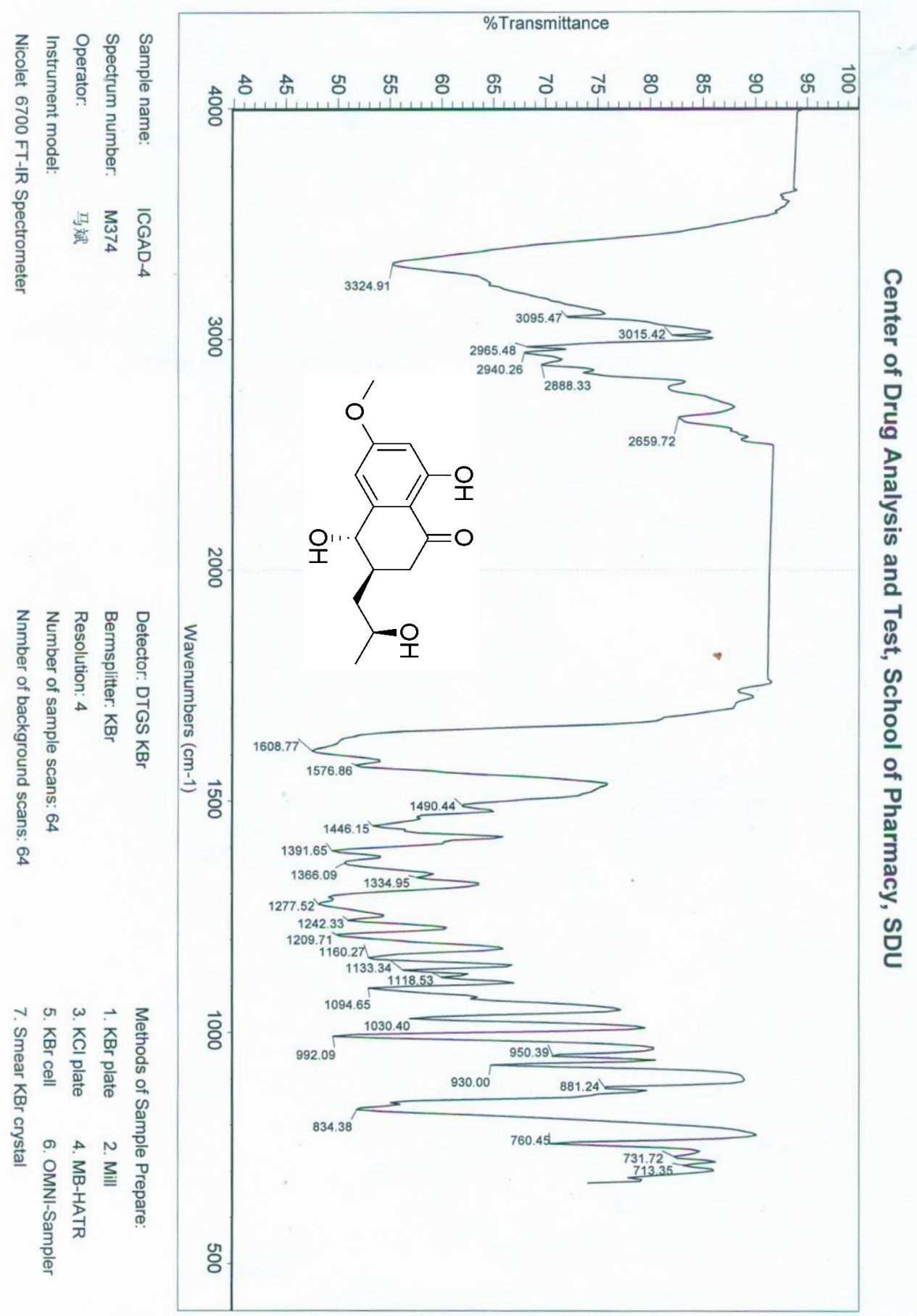

Figure S19. IR ( $\mathrm{KBr}$ disc) spectrum of 2 


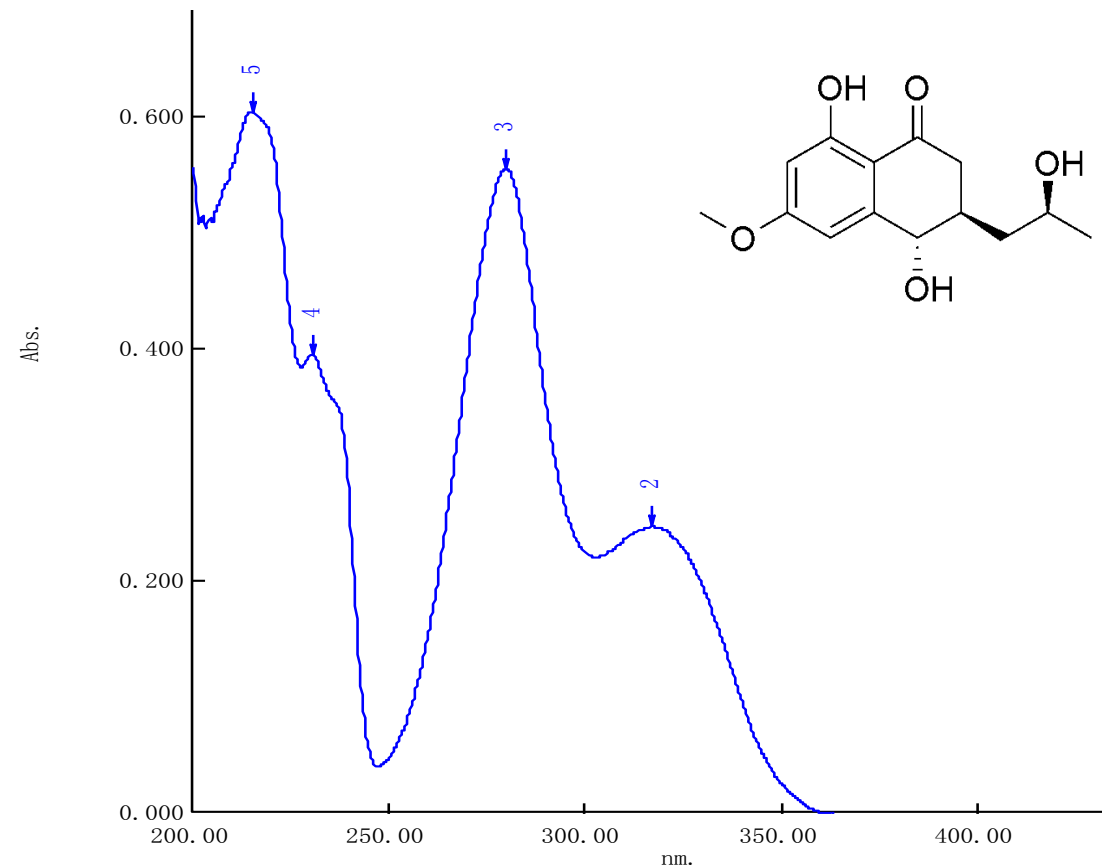

Figure S20. UV spectrum of 2

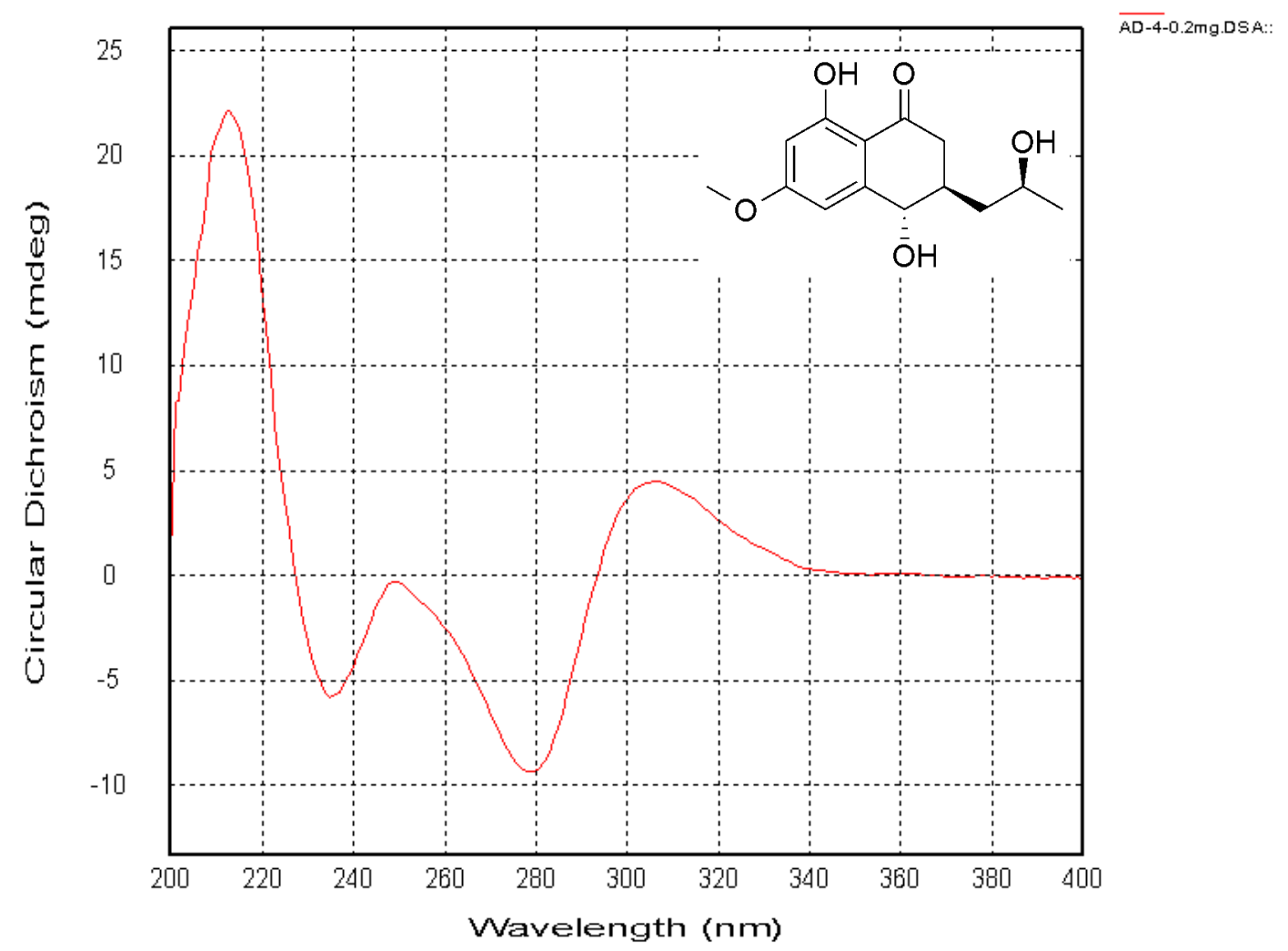

Figure S21. ECD spectrum of 2 


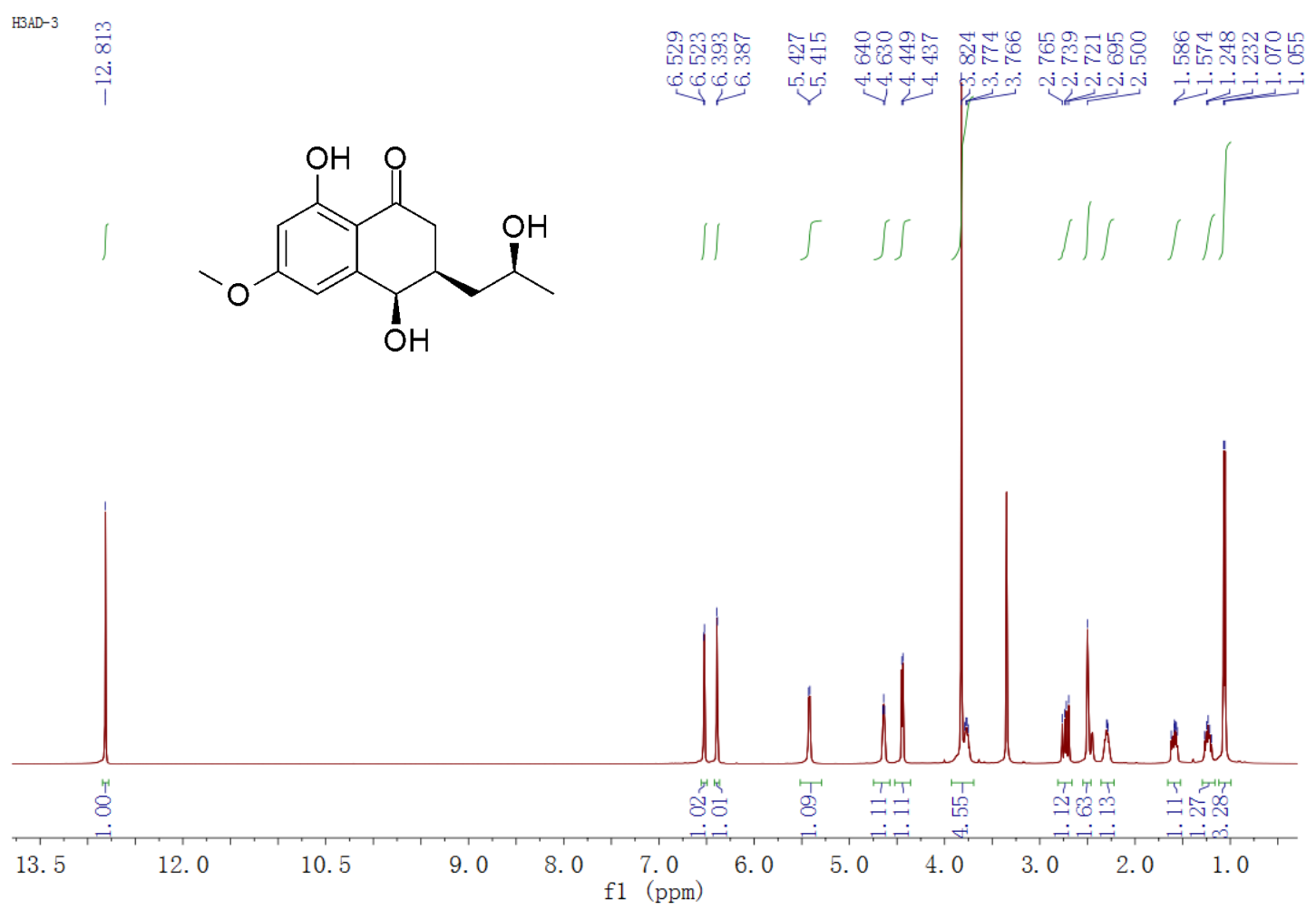

Figure S22. ${ }^{1} \mathrm{H}$ NMR spectrum of 3 in DMSO-d 6

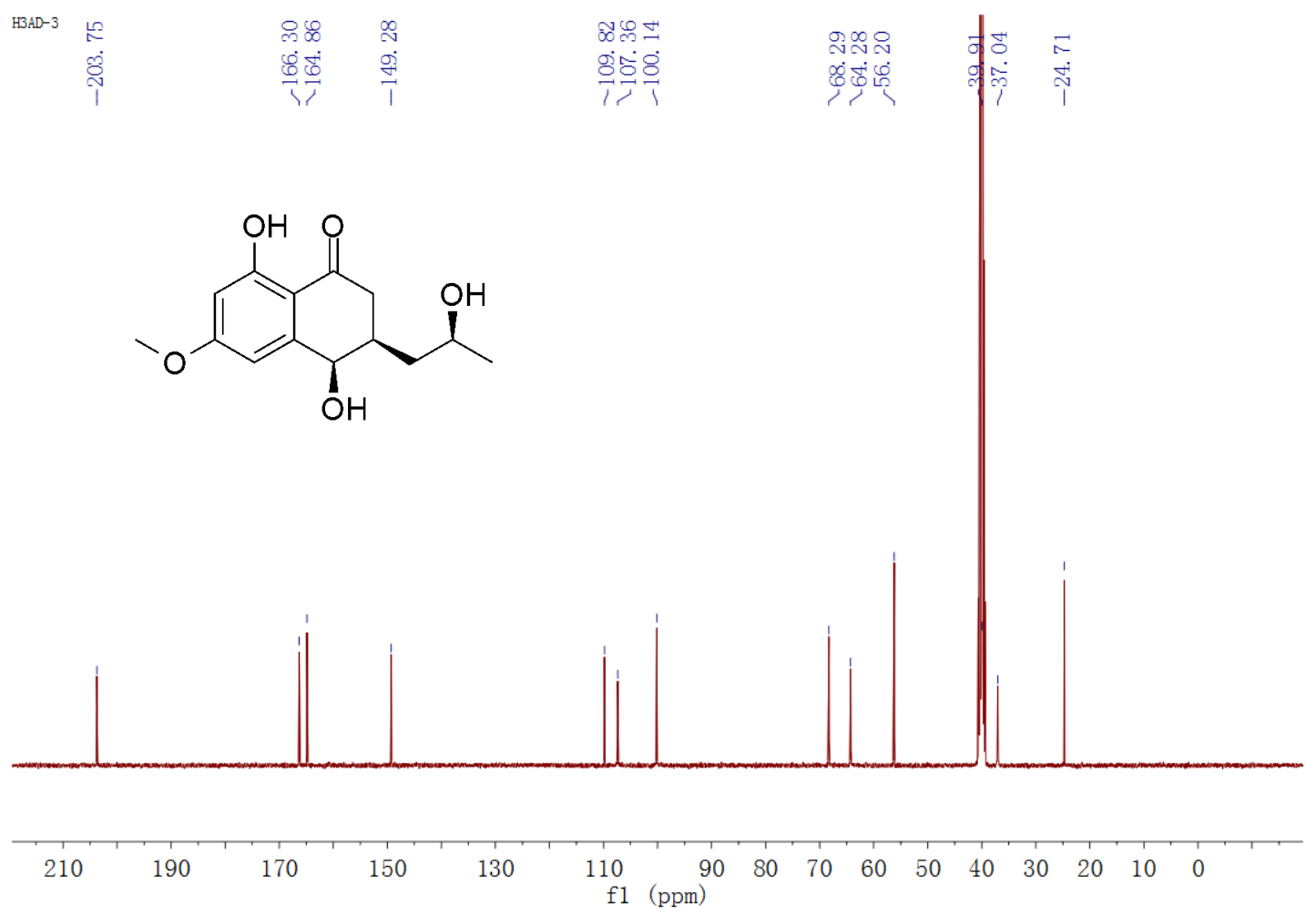

Figure S23. ${ }^{13} \mathrm{C}$ NMR spectrum of 3 in DMSO-d 6 


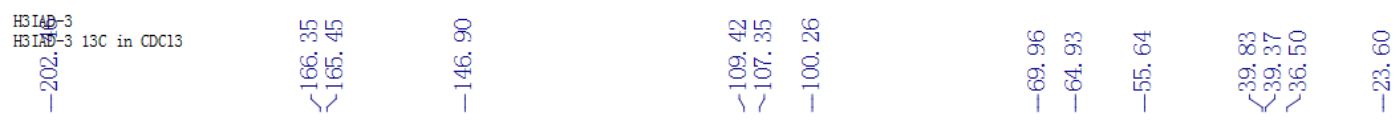<smiles>COc1cc(O)c2c(c1)[C@H](O)[C@H](C[C@H](C)O)CC2=O</smiles>

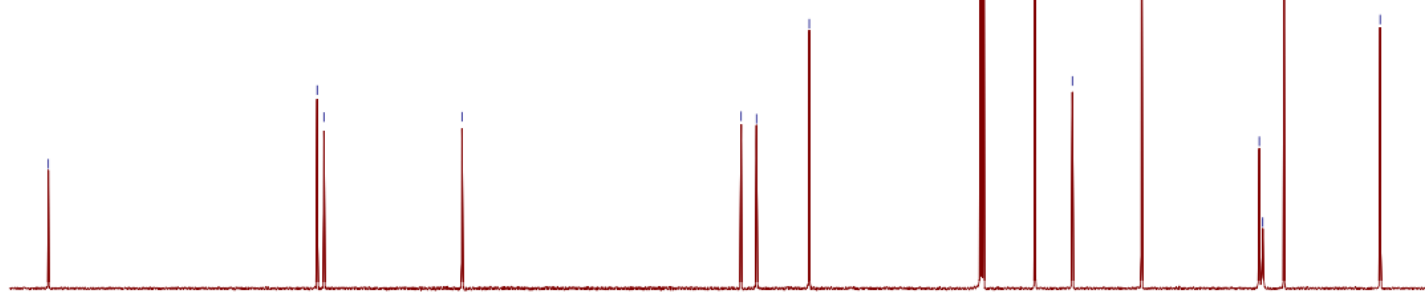

$\begin{array}{lllllllllllllllllll}200 & 190 & 180 & 170 & 160 & 150 & 140 & 130 & 120 & 110 & 100 & 90 & 80 & 70 & 60 & 50 & 40 & 30 & 20\end{array}$

Figure S24. ${ }^{13} \mathrm{C}$ NMR spectrum of $\mathbf{3}$ in $\mathrm{CDCl}_{3}$

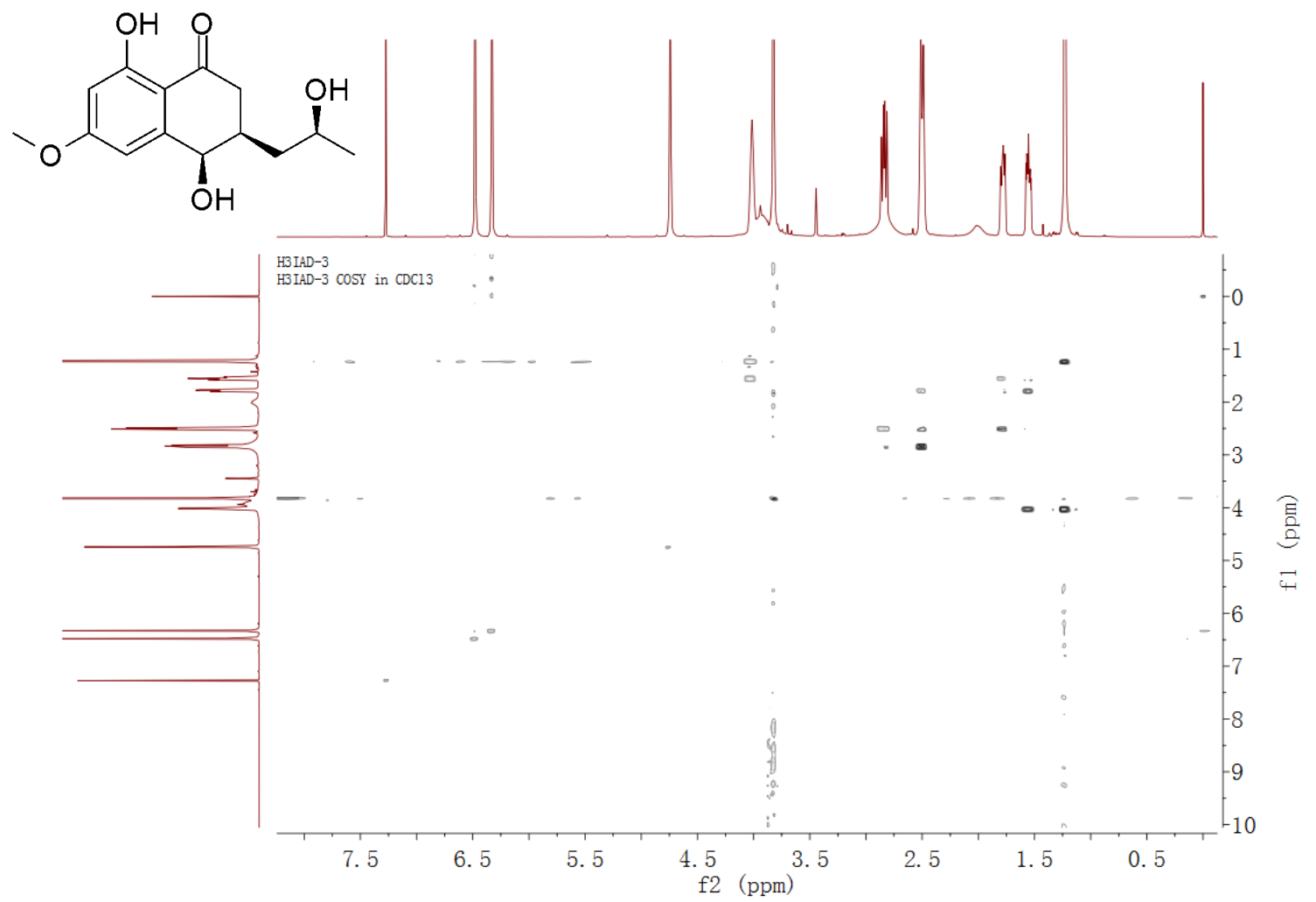

Figure S25. ${ }^{1} \mathrm{H}-{ }^{1} \mathrm{H}$ COSY spectrum of 3 in $\mathrm{CDCl}_{3}$ 


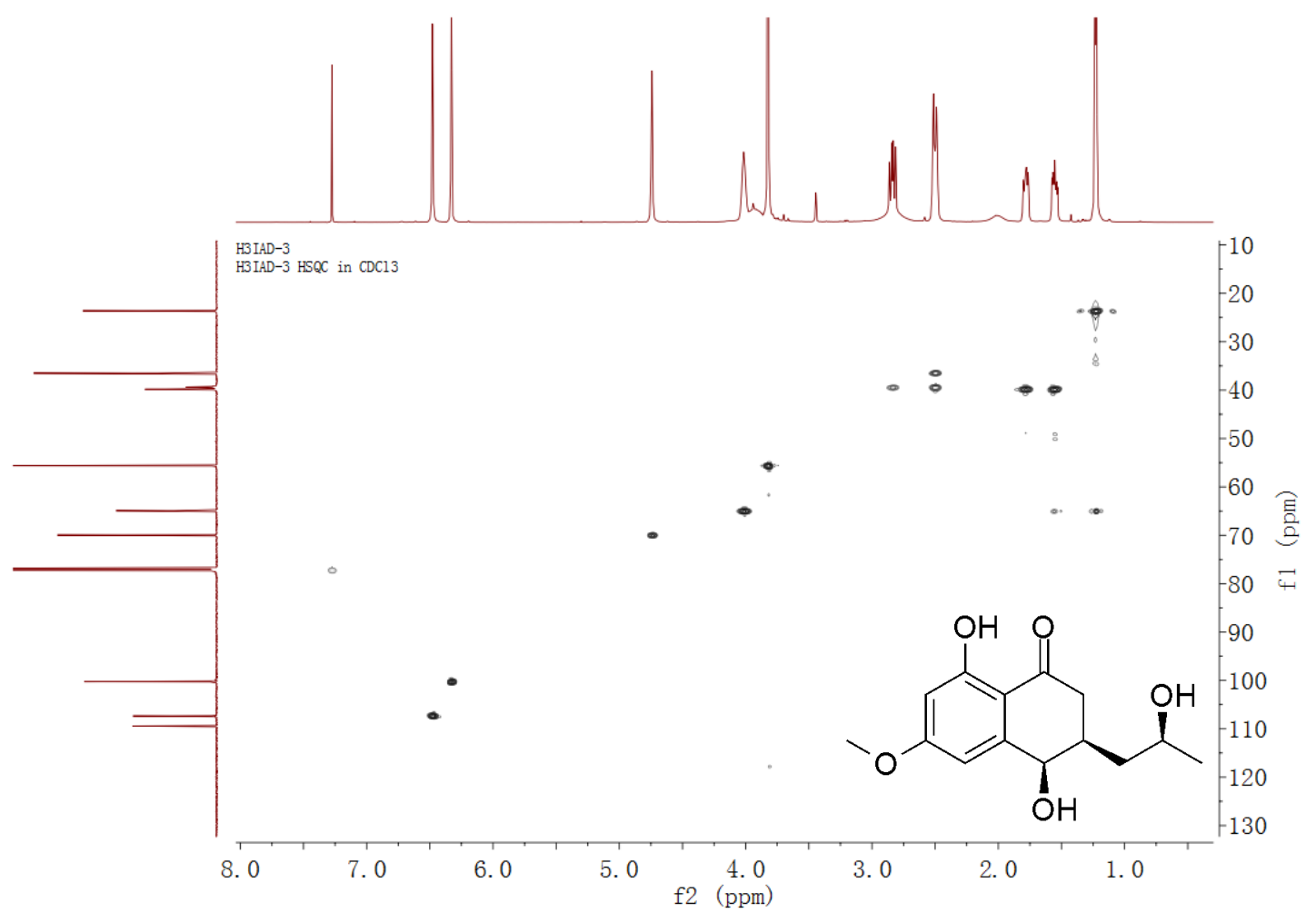

Figure S26. $\mathrm{HSQC}$ spectrum of $\mathbf{3}$ in $\mathrm{CDCl}_{3}$

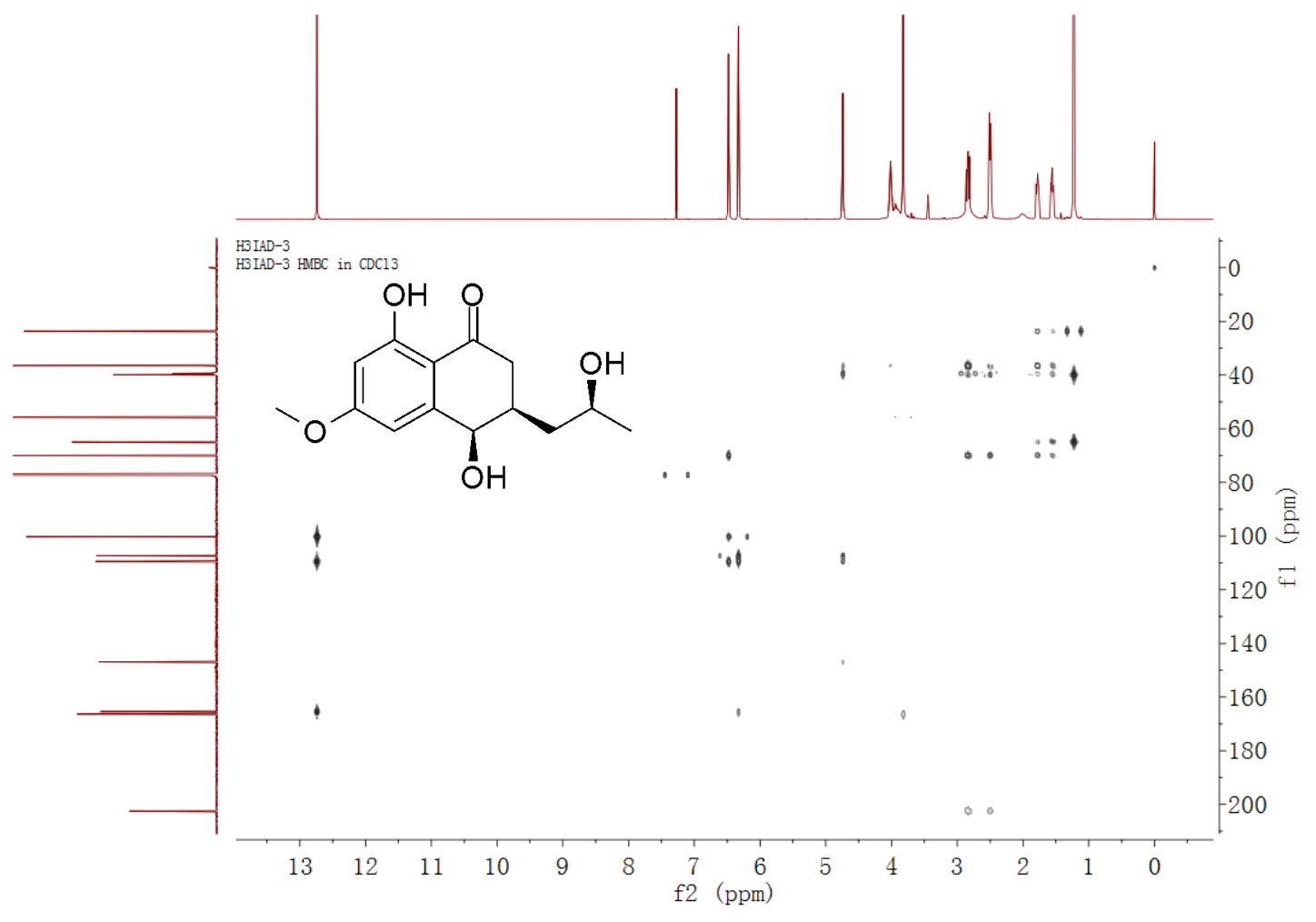

Figure S27. $\mathrm{HMBC}$ spectrum of $\mathbf{3}$ in $\mathrm{CDCl}_{3}$ 


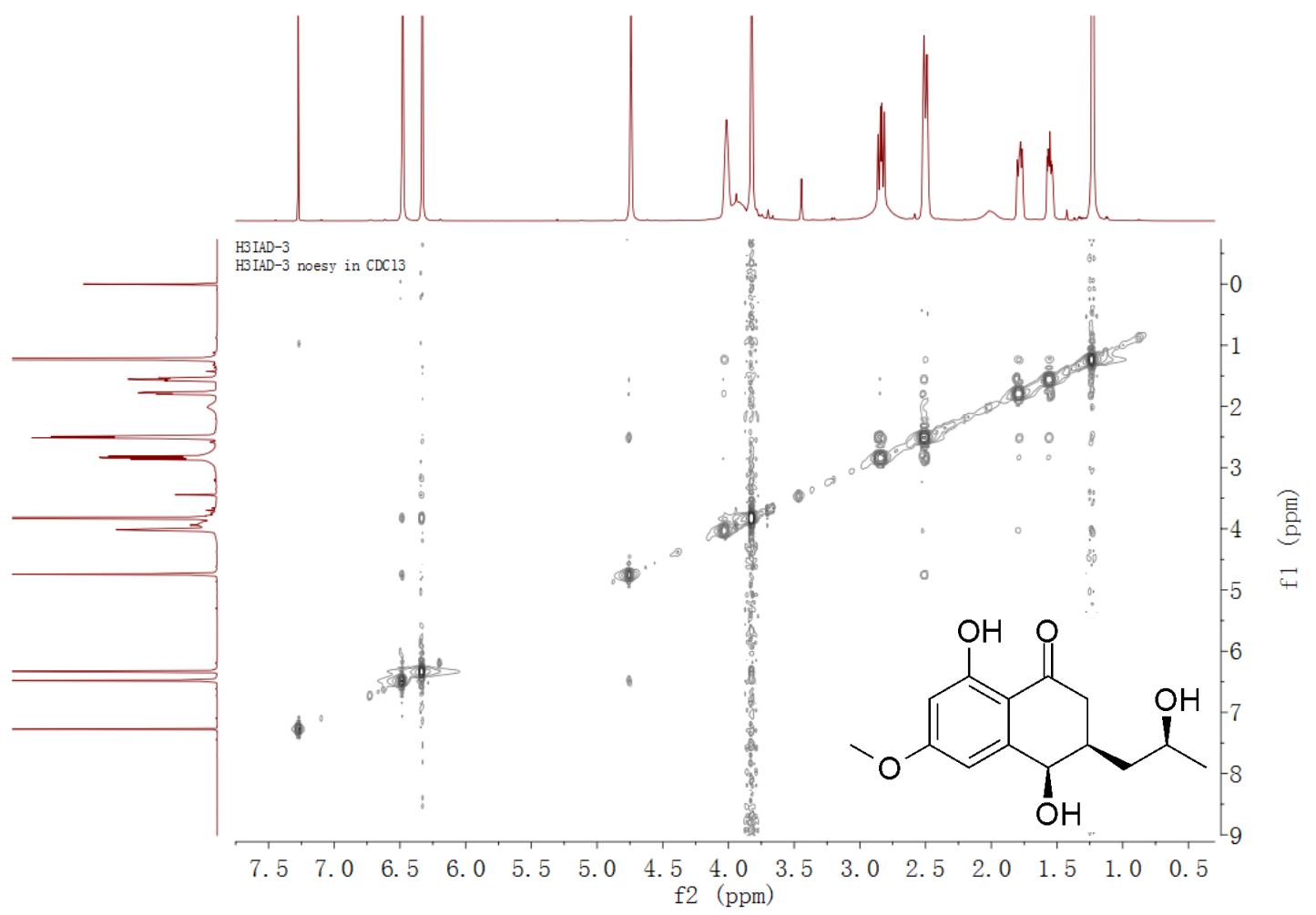

Figure S28. NOESY spectrum of $\mathbf{3}$ in $\mathrm{CDCl}_{3}$ 


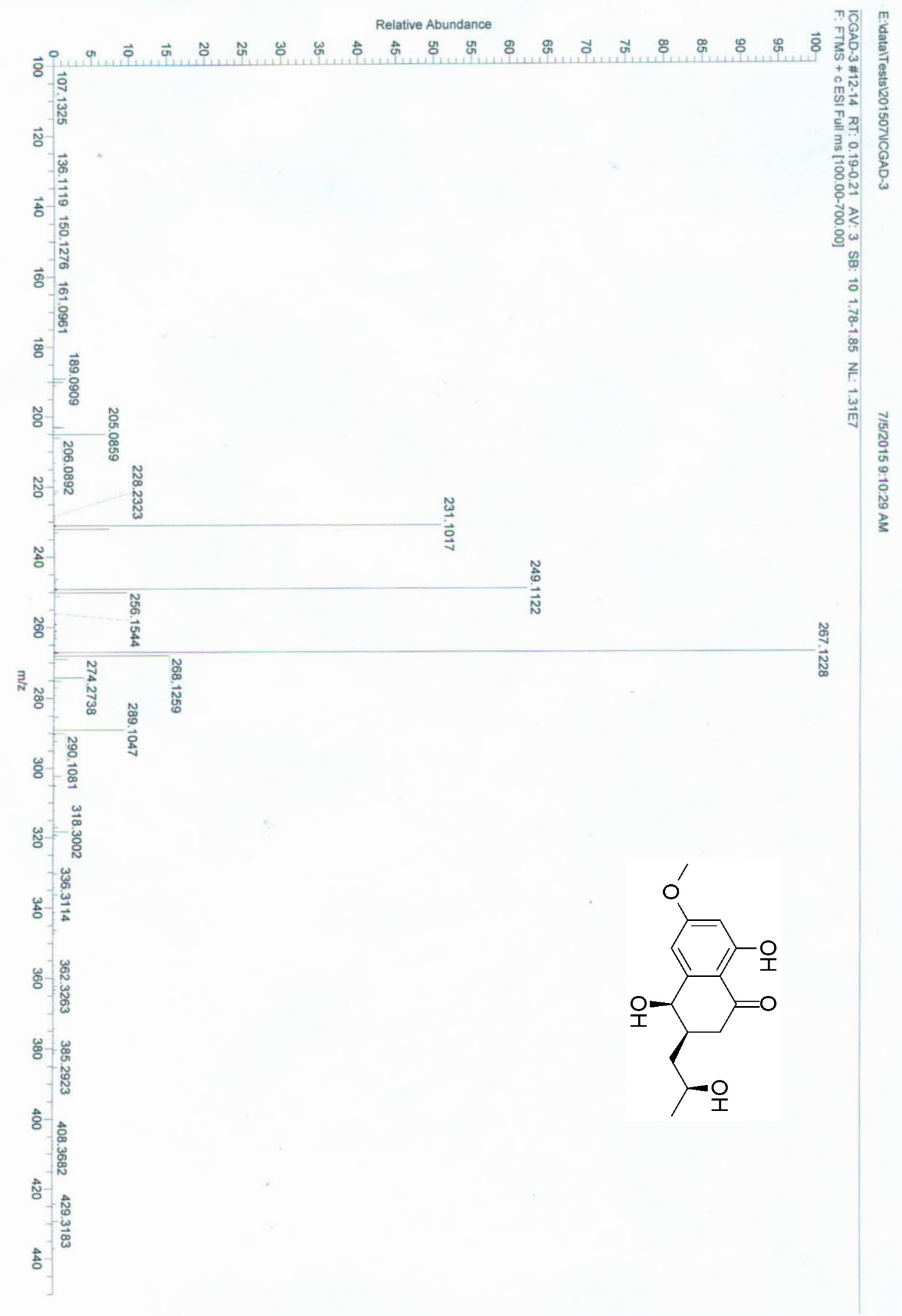

Figure S29. HRESIMS spectrum of $\mathbf{3}$ 


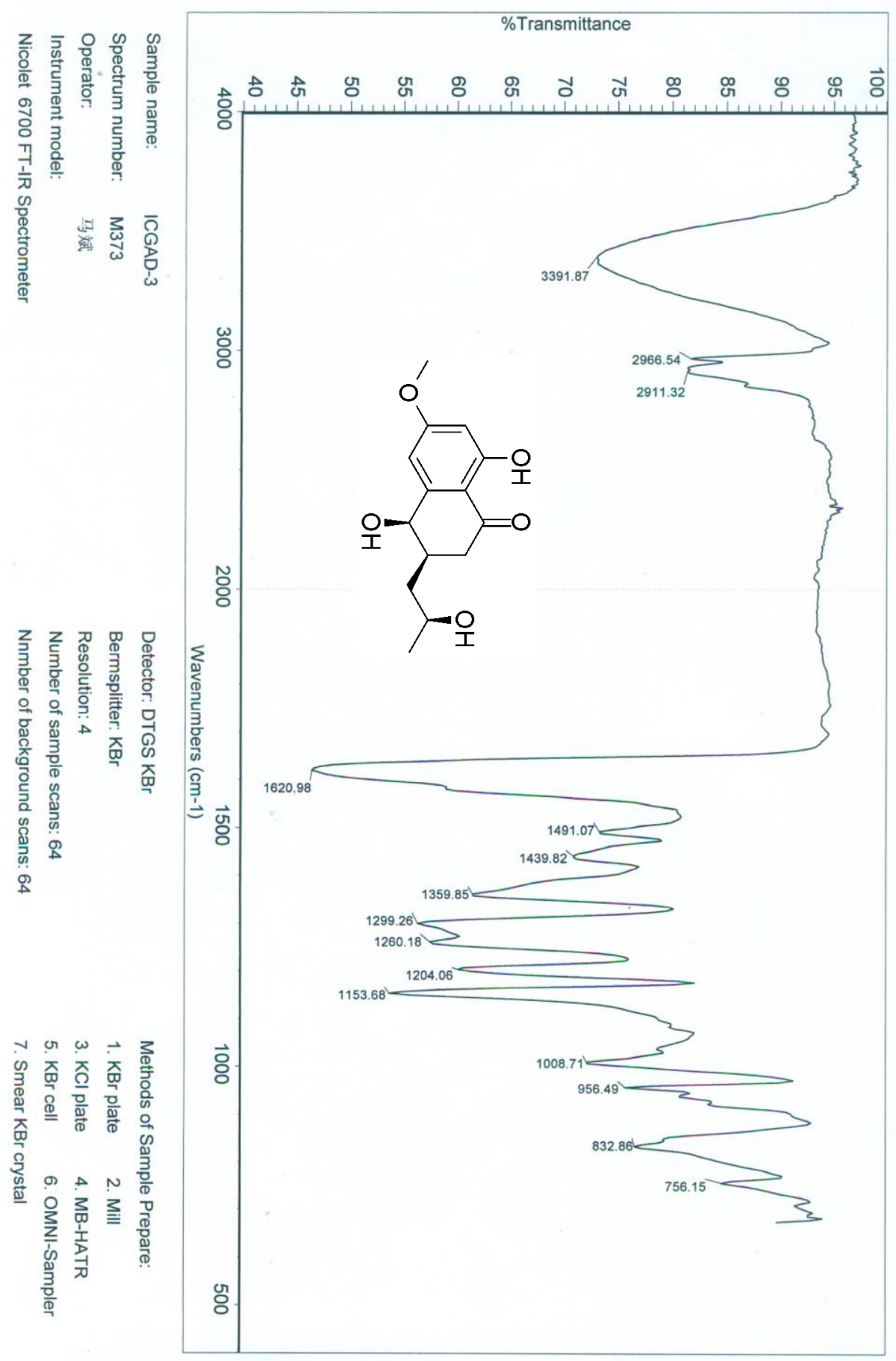

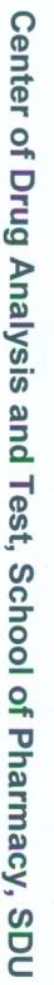

Figure S30. IR ( $\mathrm{KBr}$ disc) spectrum of $\mathbf{3}$ 


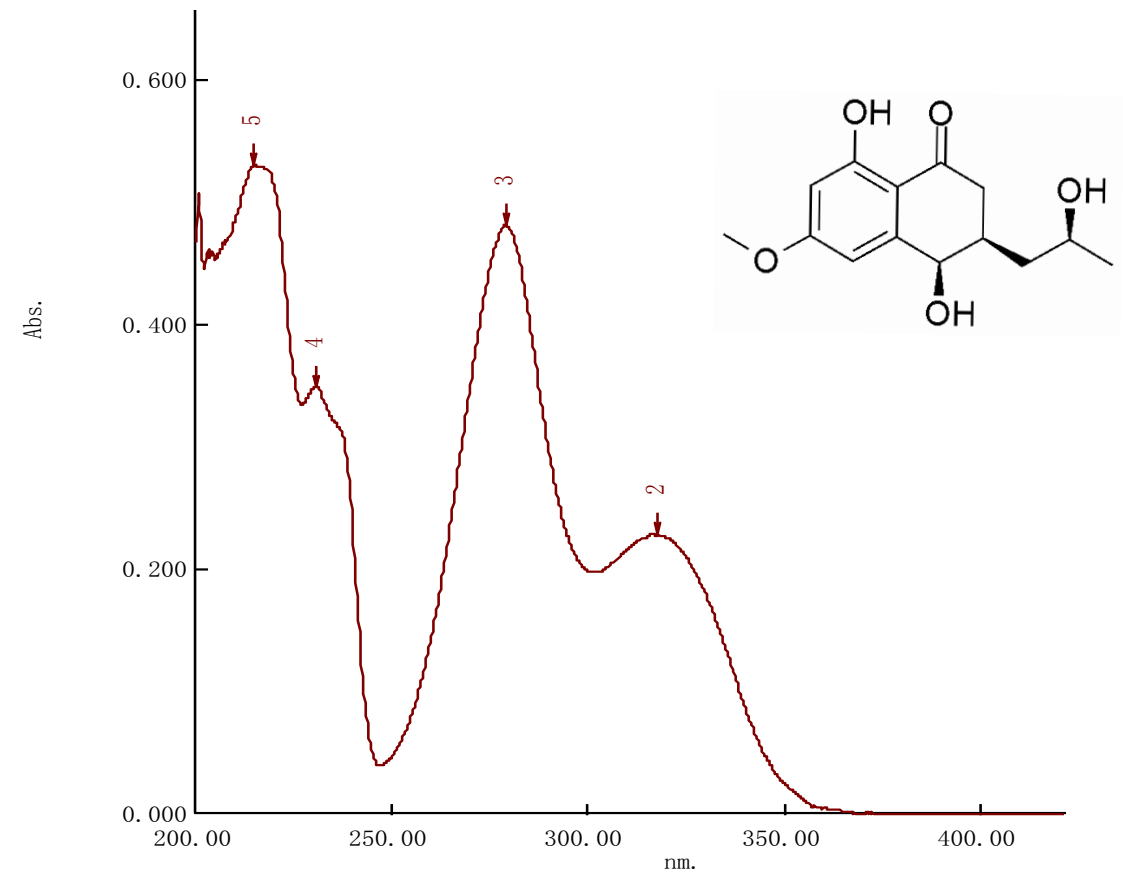

Figure S31. UV spectrum of $\mathbf{3}$

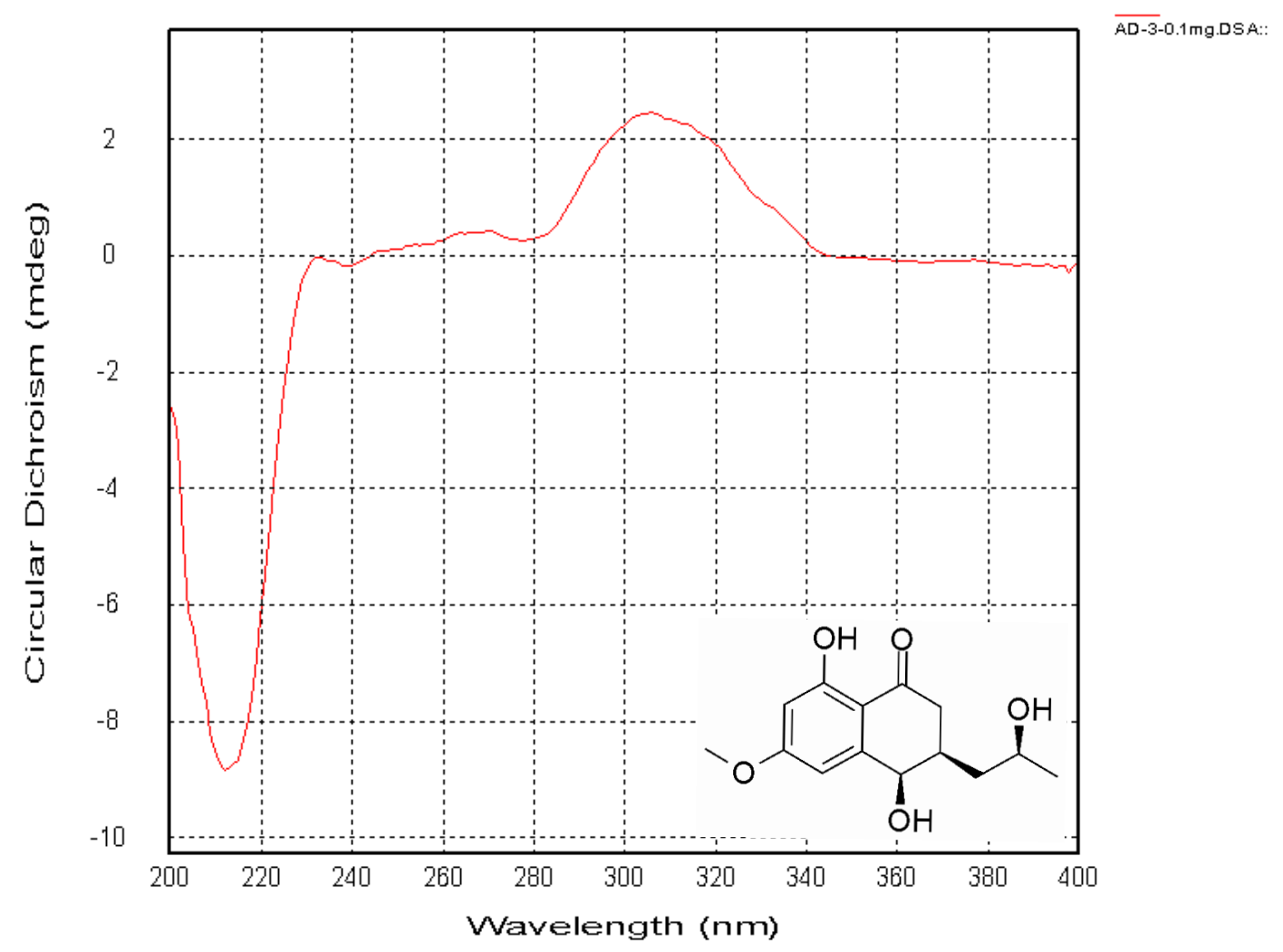

Figure S32. ECD spectrum of $\mathbf{3}$ 


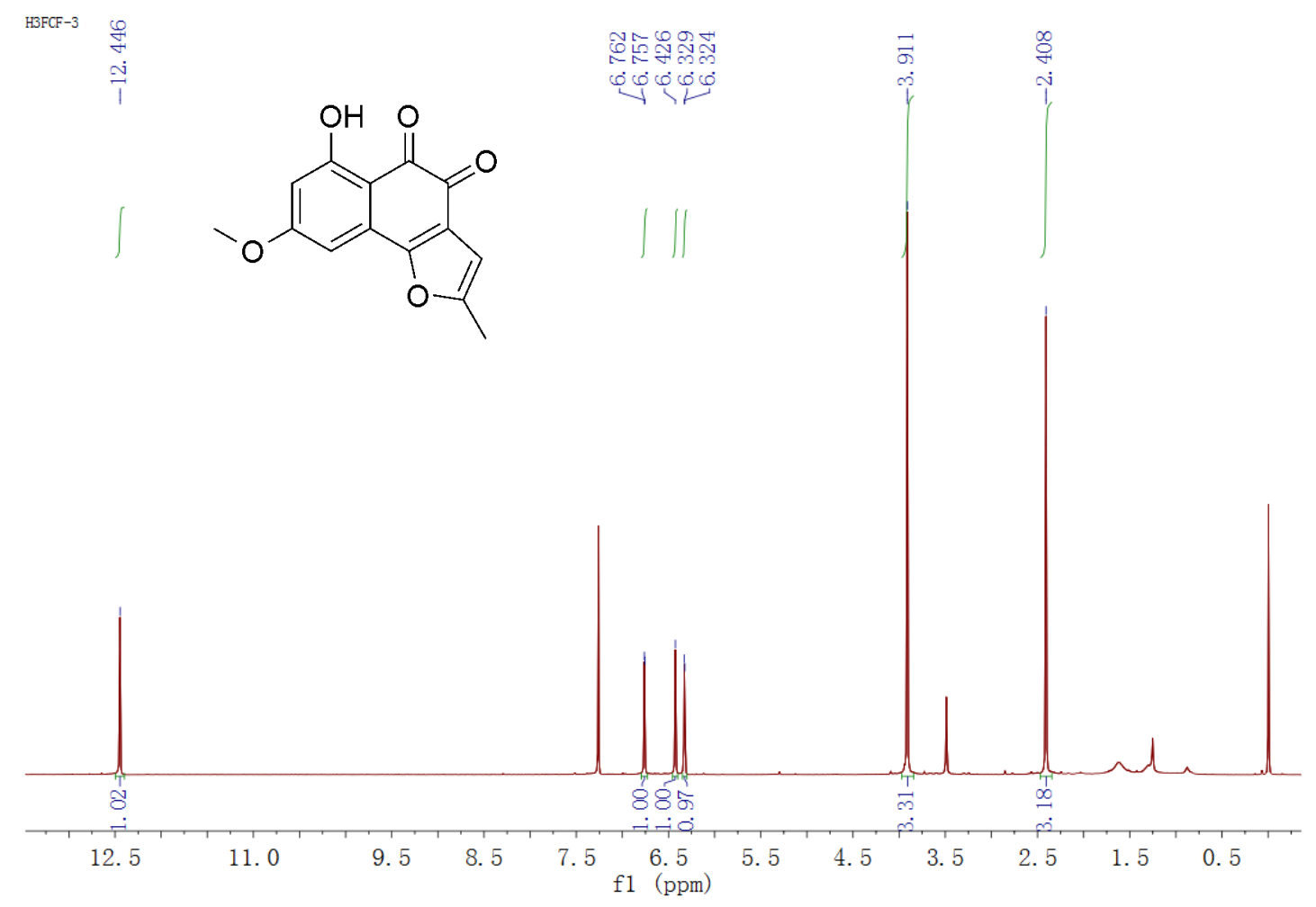

Figure S33. ${ }^{1} \mathrm{H}$ NMR spectrum of $\mathbf{4}$ in $\mathrm{CDCl}_{3}$
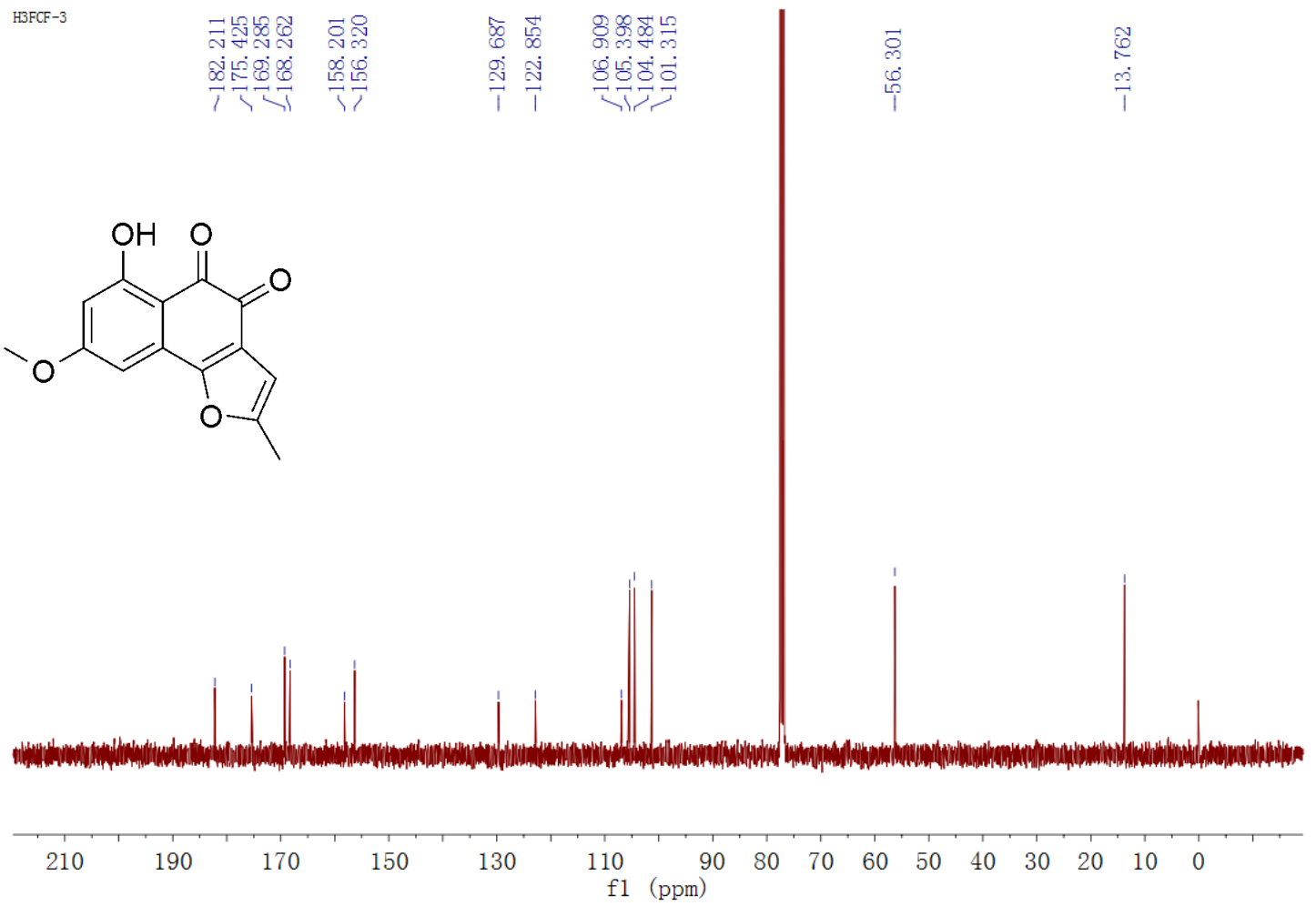

Figure S34. ${ }^{13} \mathrm{C}$ NMR spectrum of $\mathbf{4}$ in $\mathrm{CDCl}_{3}$ 


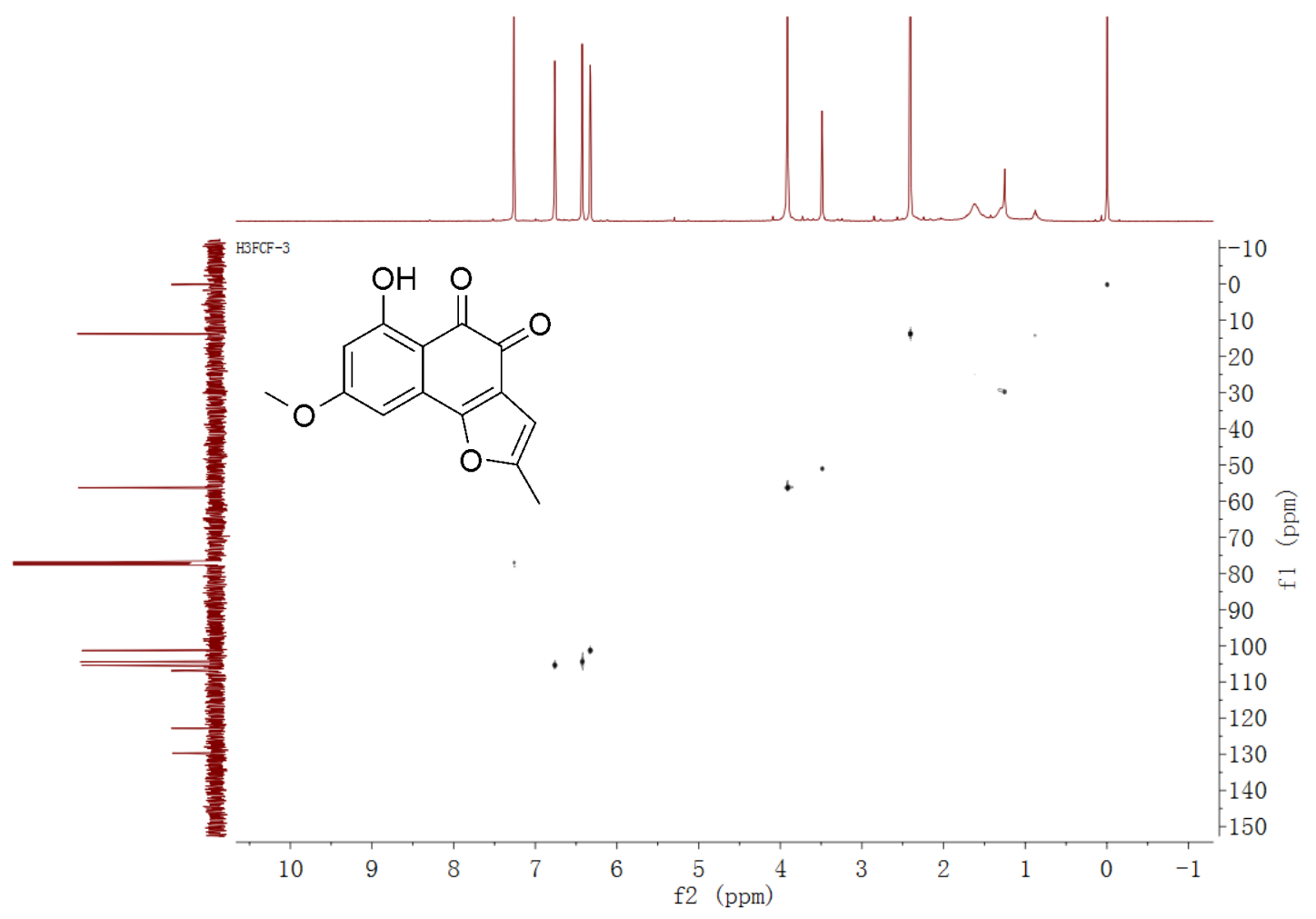

Figure S35. HSQC spectrum of 4 in $\mathrm{CDCl}_{3}$

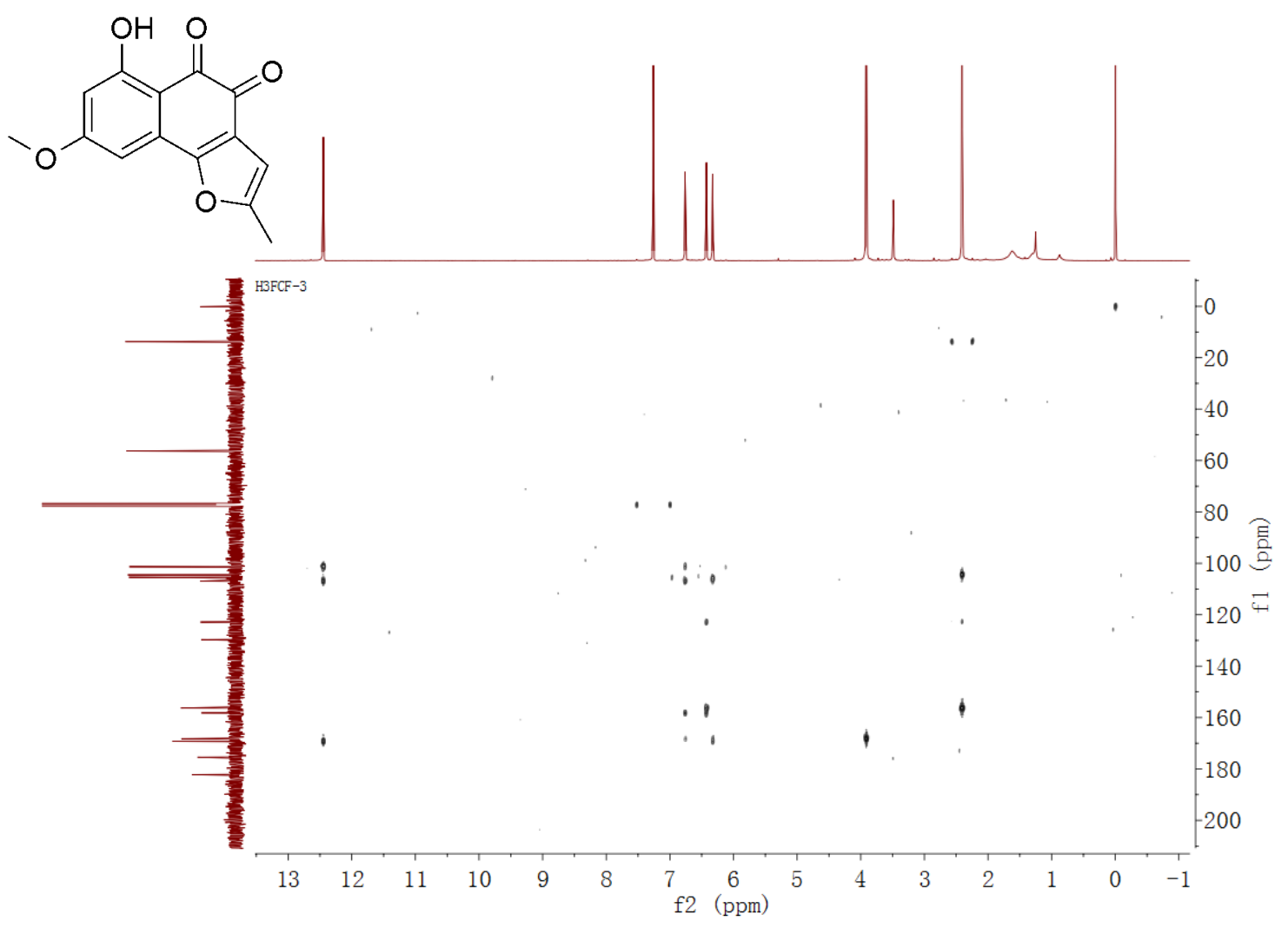

Figure S36. $\mathrm{HMBC}$ spectrum of $\mathbf{4}$ in $\mathrm{CDCl}_{3}$ 


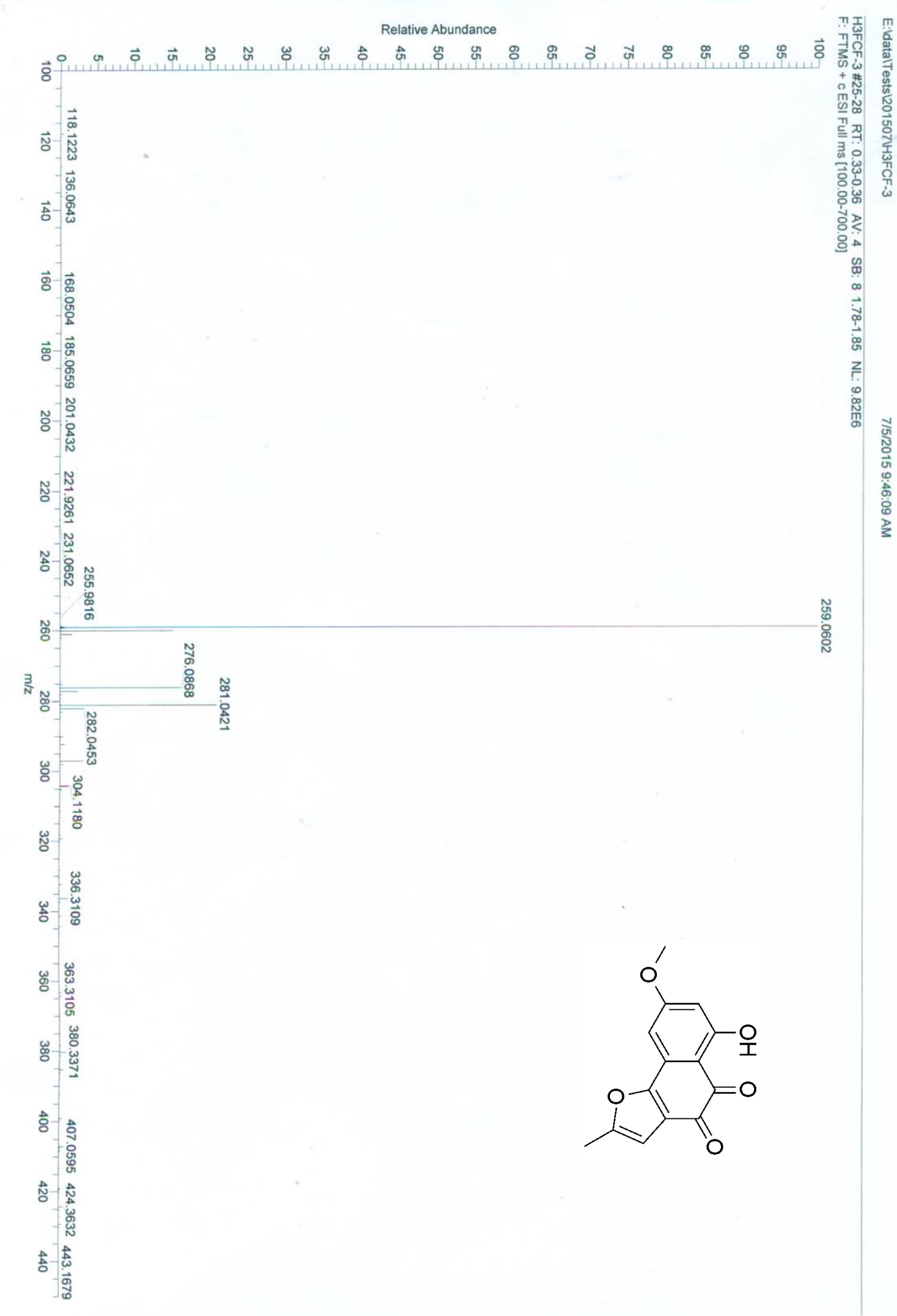

Figure S37. HRESIMS spectrum of $\mathbf{4}$ 


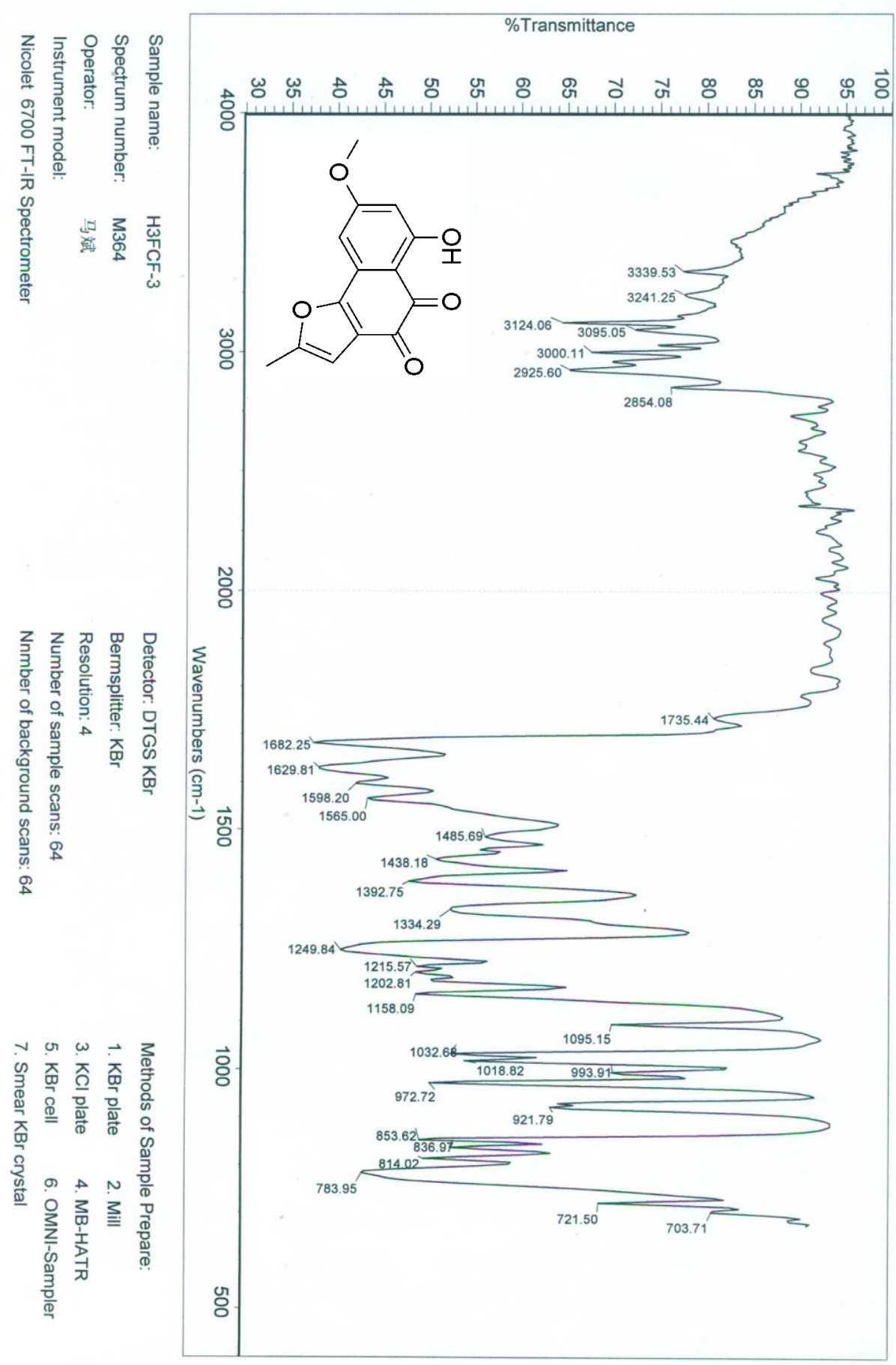

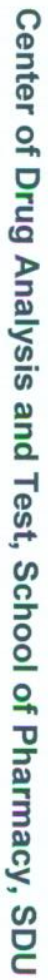

Figure S38. IR ( $\mathrm{KBr}$ disc) spectrum of 4 


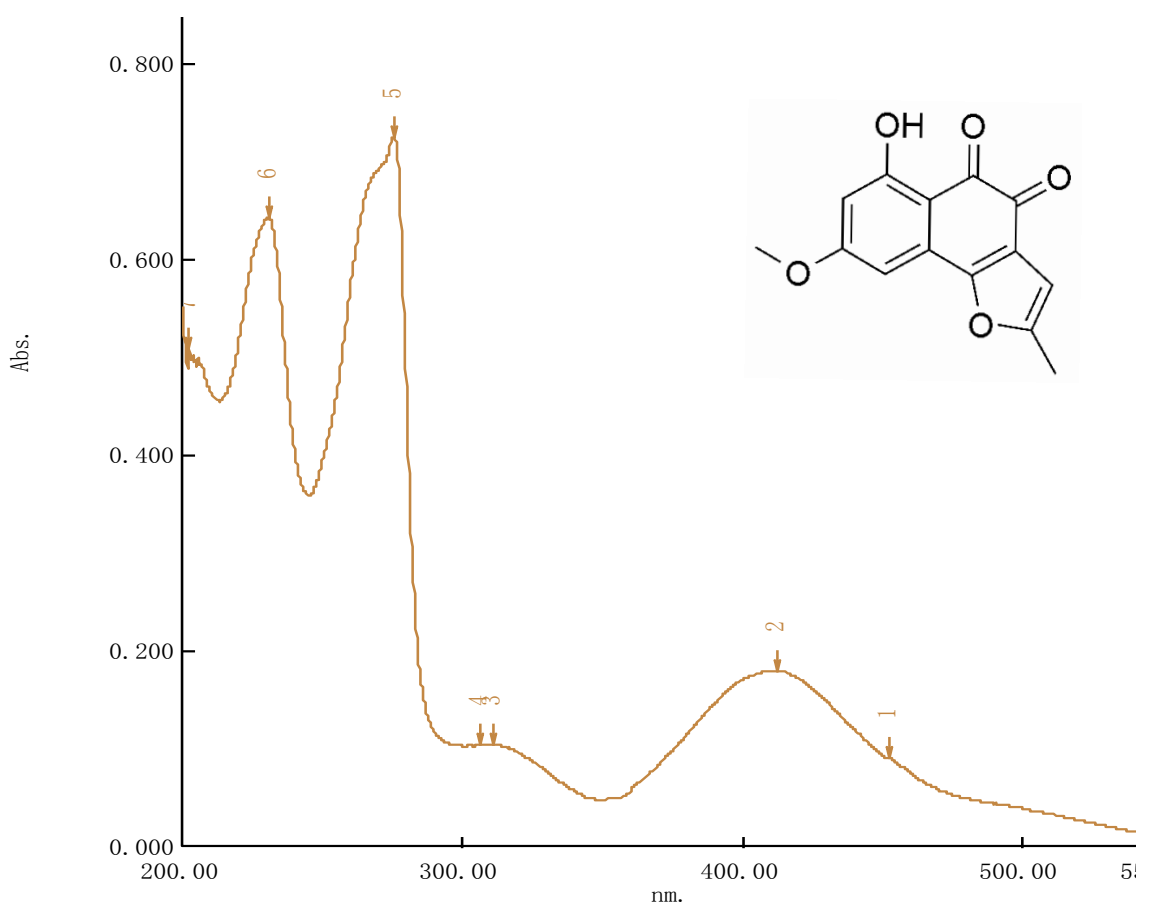

Figure S39. UV spectrum of 4

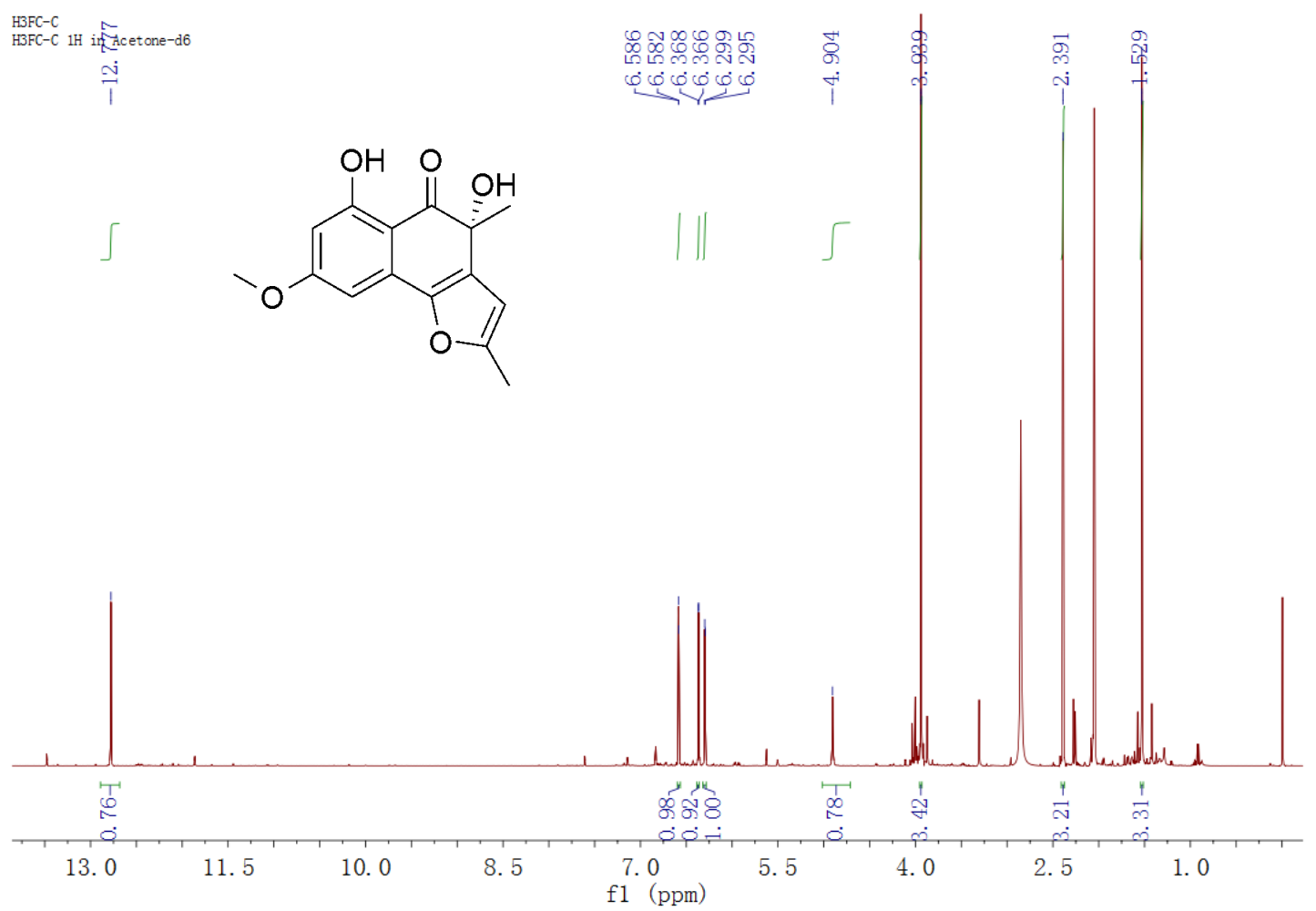

Figure S40. ${ }^{1} \mathrm{H}$ NMR spectrum of 5 in Acetone- $d_{6}$ 


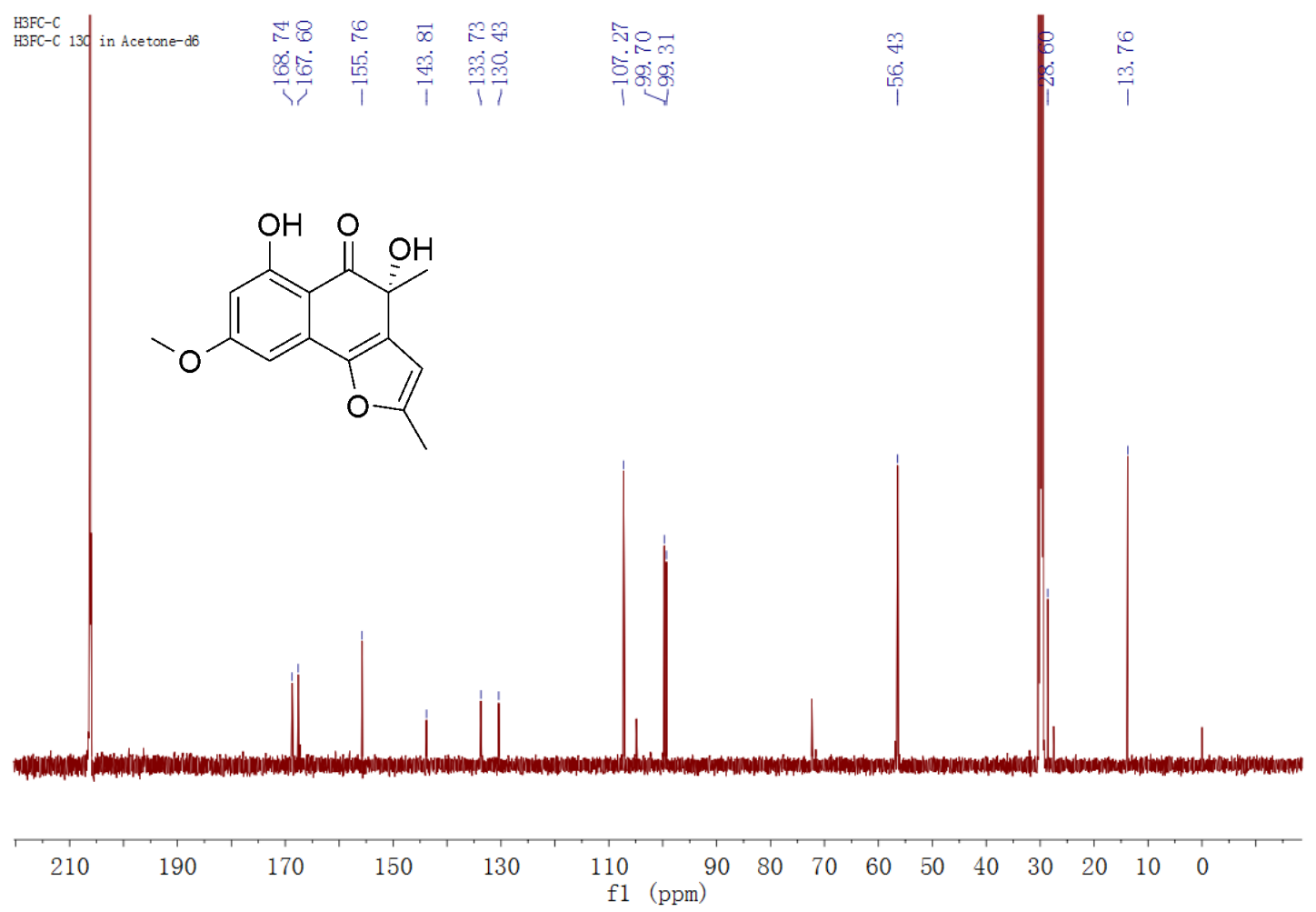

Figure S41. ${ }^{13} \mathrm{C}$ NMR spectrum of 5 in Acetone- $d_{6}$

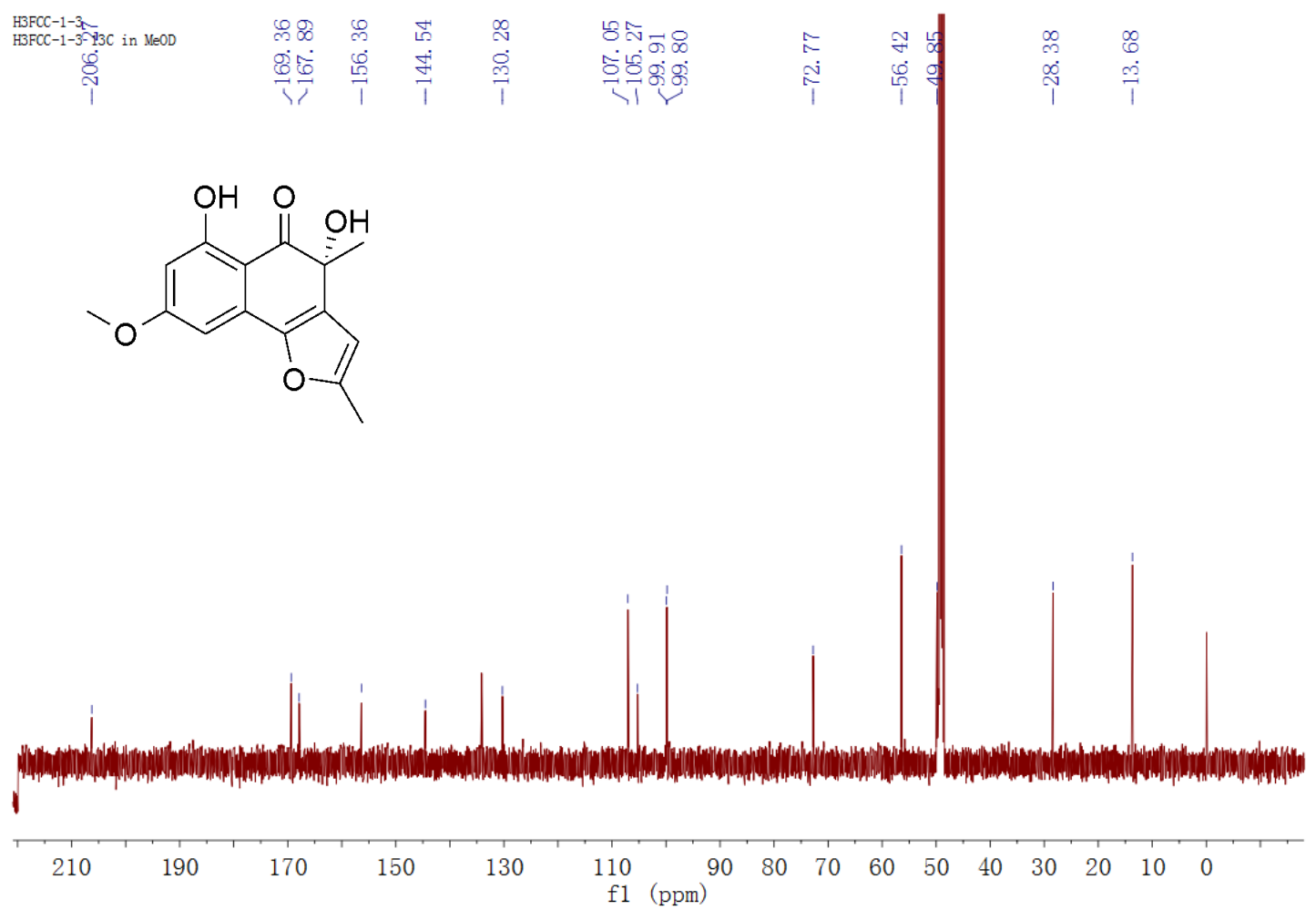

Figure $\mathbf{S 4 2 .}{ }^{13} \mathrm{C}$ NMR spectrum of $\mathbf{5}$ in $\mathrm{CD}_{3} \mathrm{OD}$ 

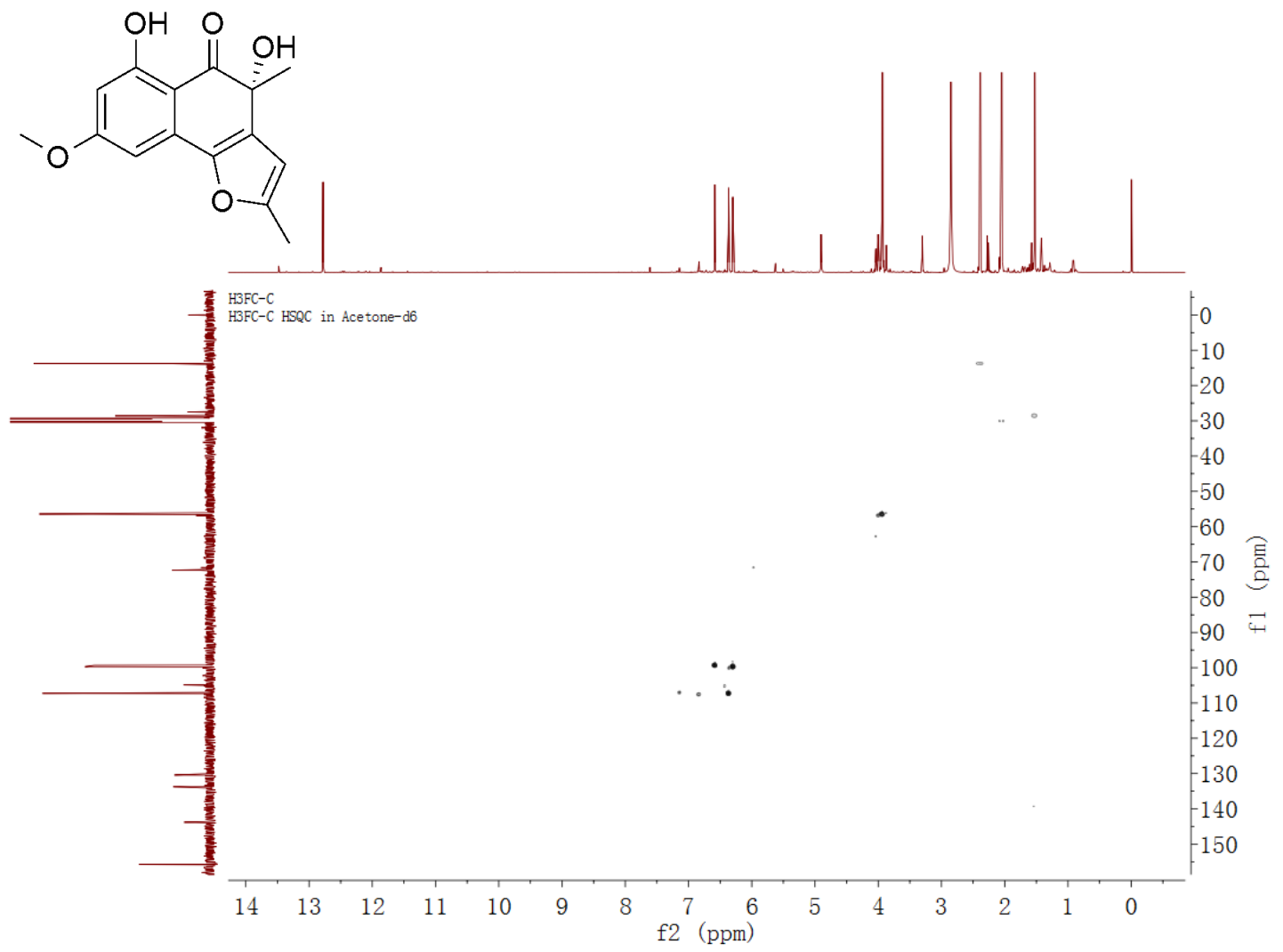

Figure S43. HSQC spectrum of 5 in Acetone- $d_{6}$

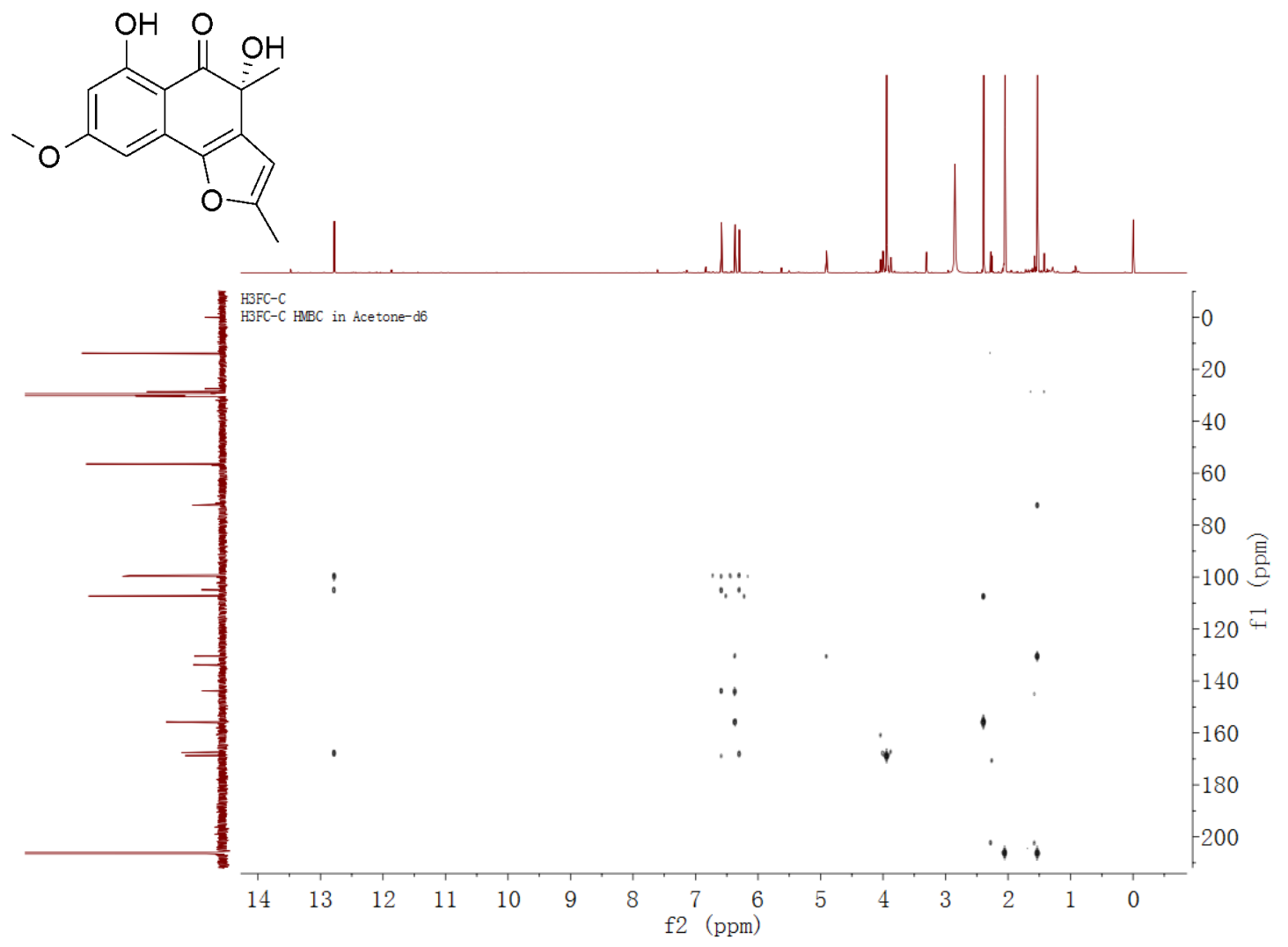

Figure S44. HMBC spectrum of 5 in Acetone- $d_{6}$ 


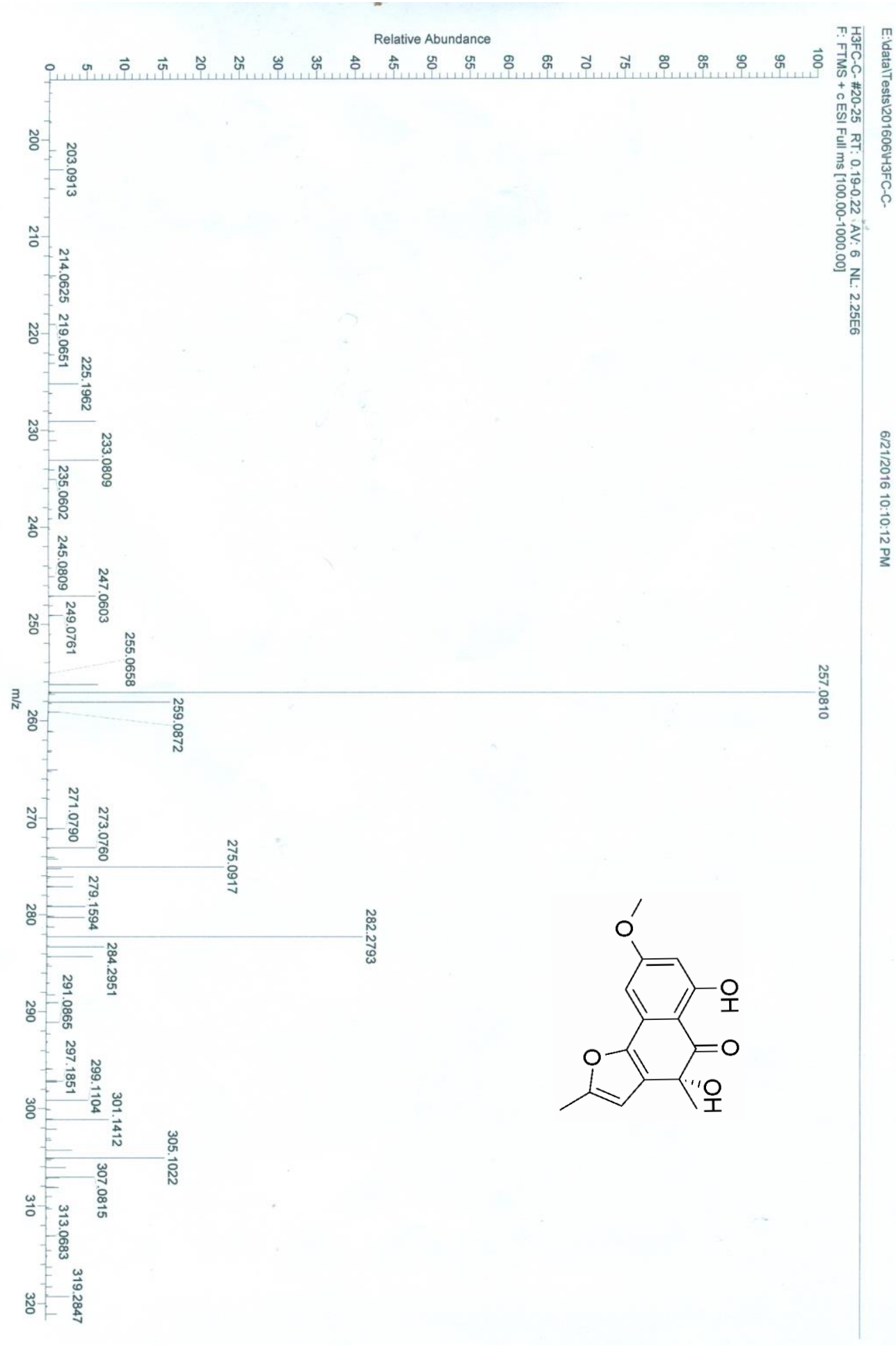

Figure S45. HRESIMS spectrum of $\mathbf{5}$ 


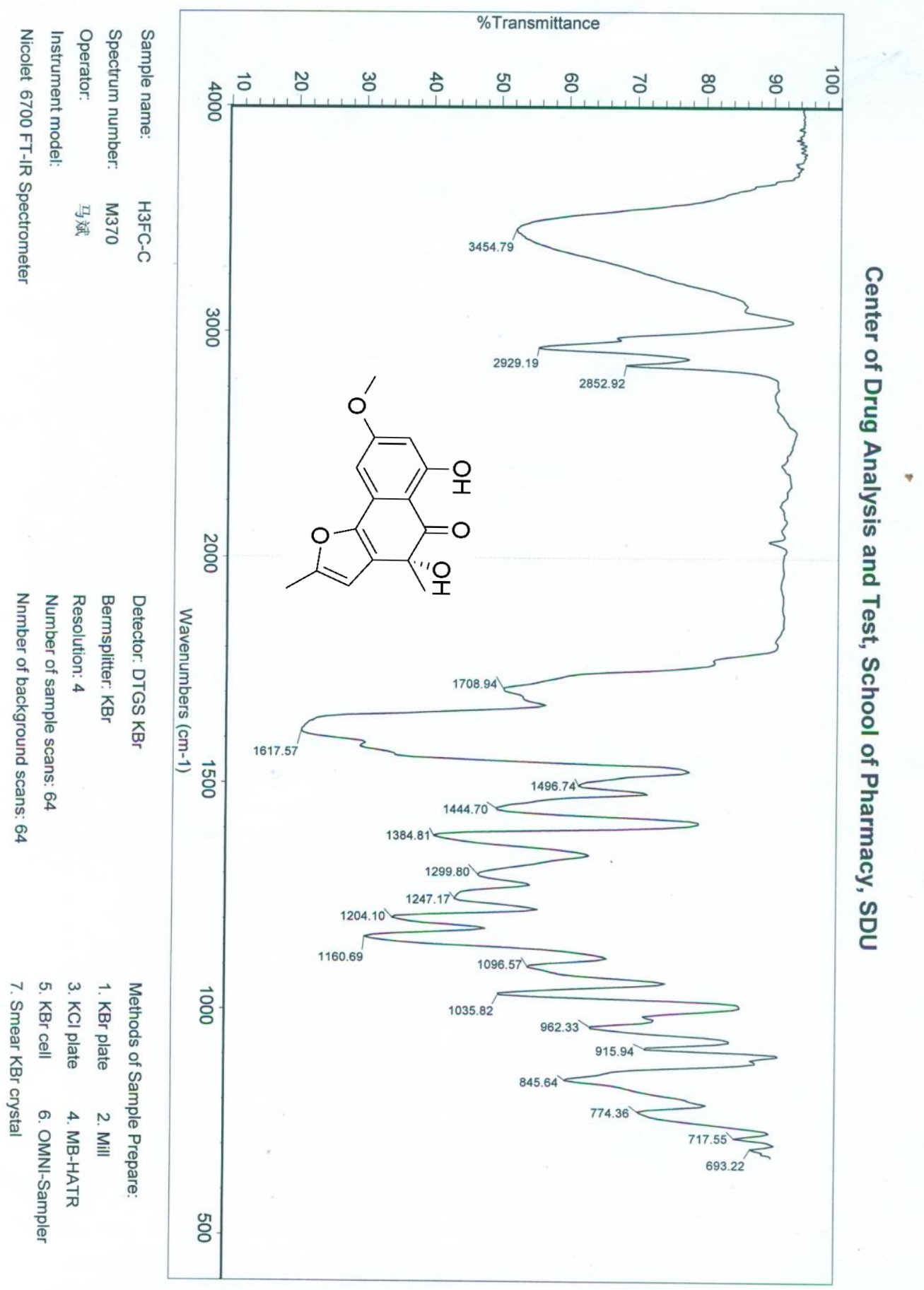

Figure S46. IR ( $\mathrm{KBr}$ disc) spectrum of 5 


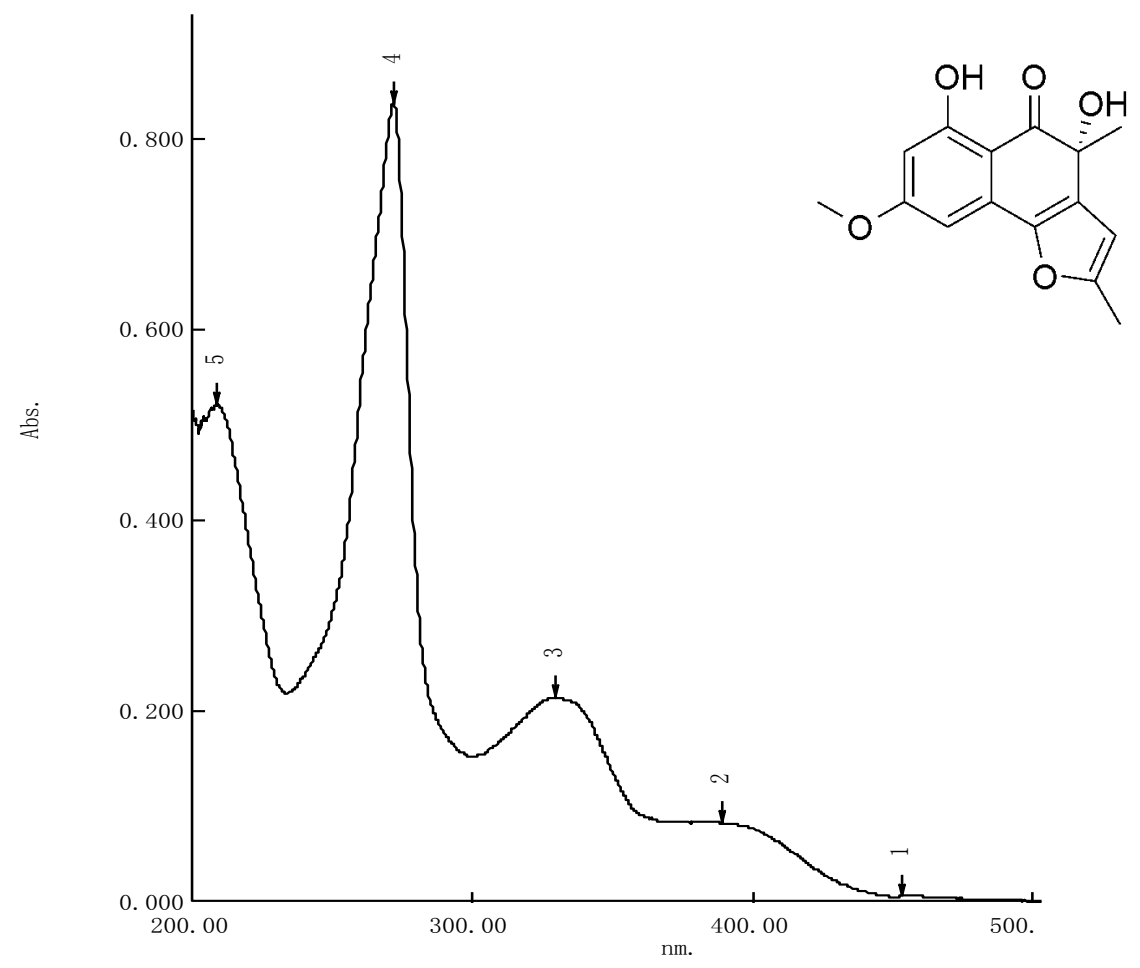

Figure S47. UV spectrum of 5

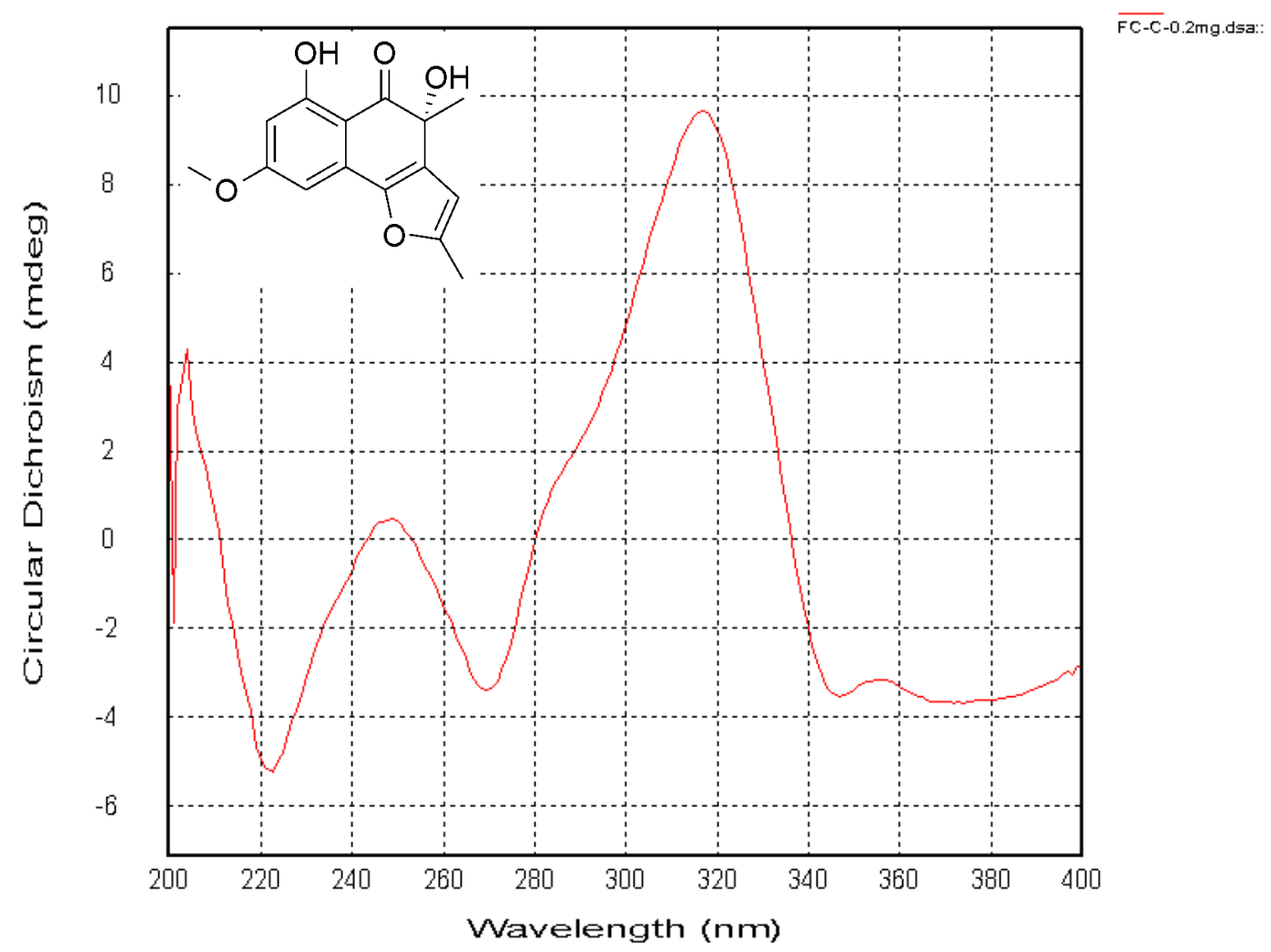

Figure S48. ECD spectrum of 5 


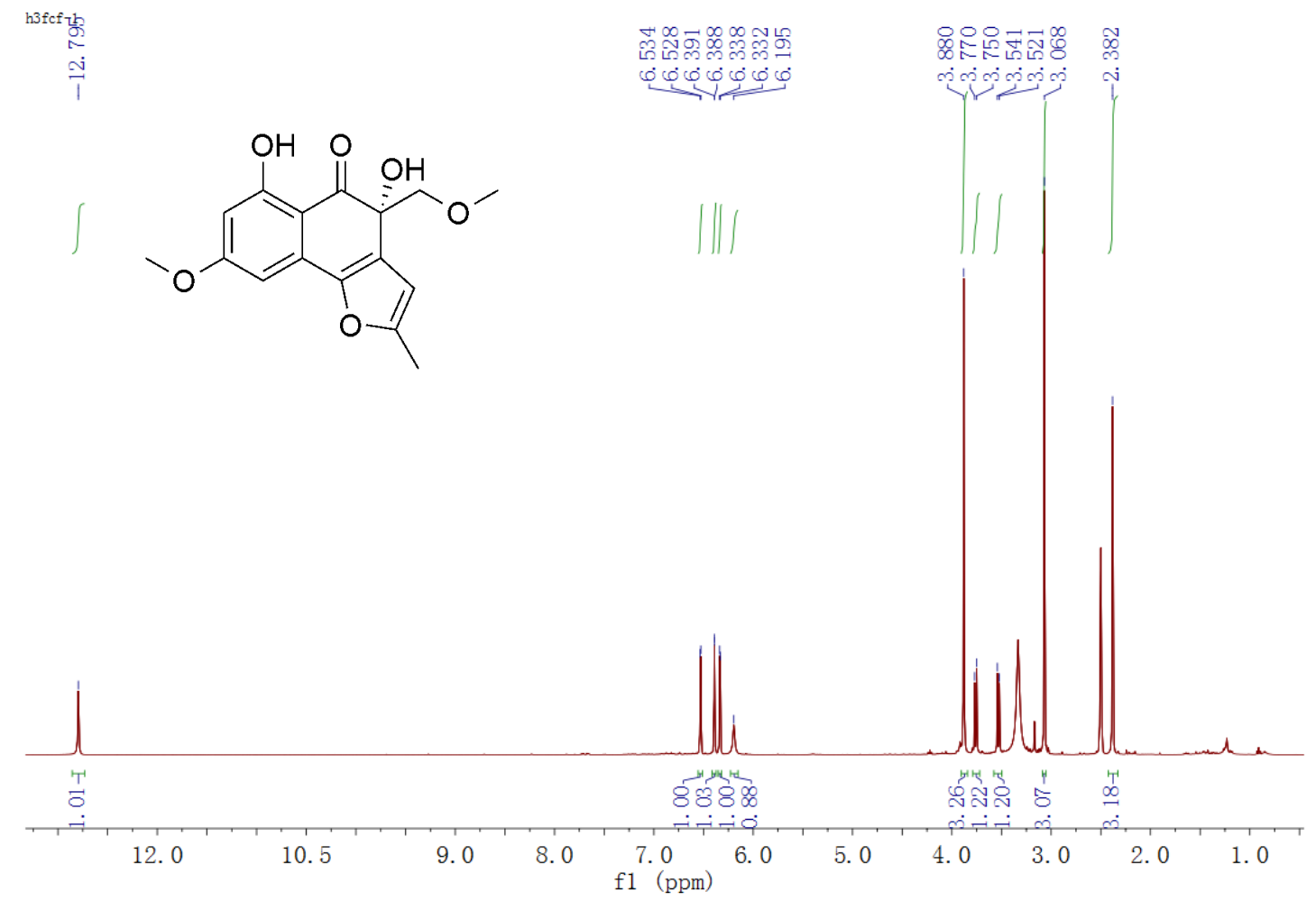

Figure S49. ${ }^{1} \mathrm{H}$ NMR spectrum of 6 in DMSO-d
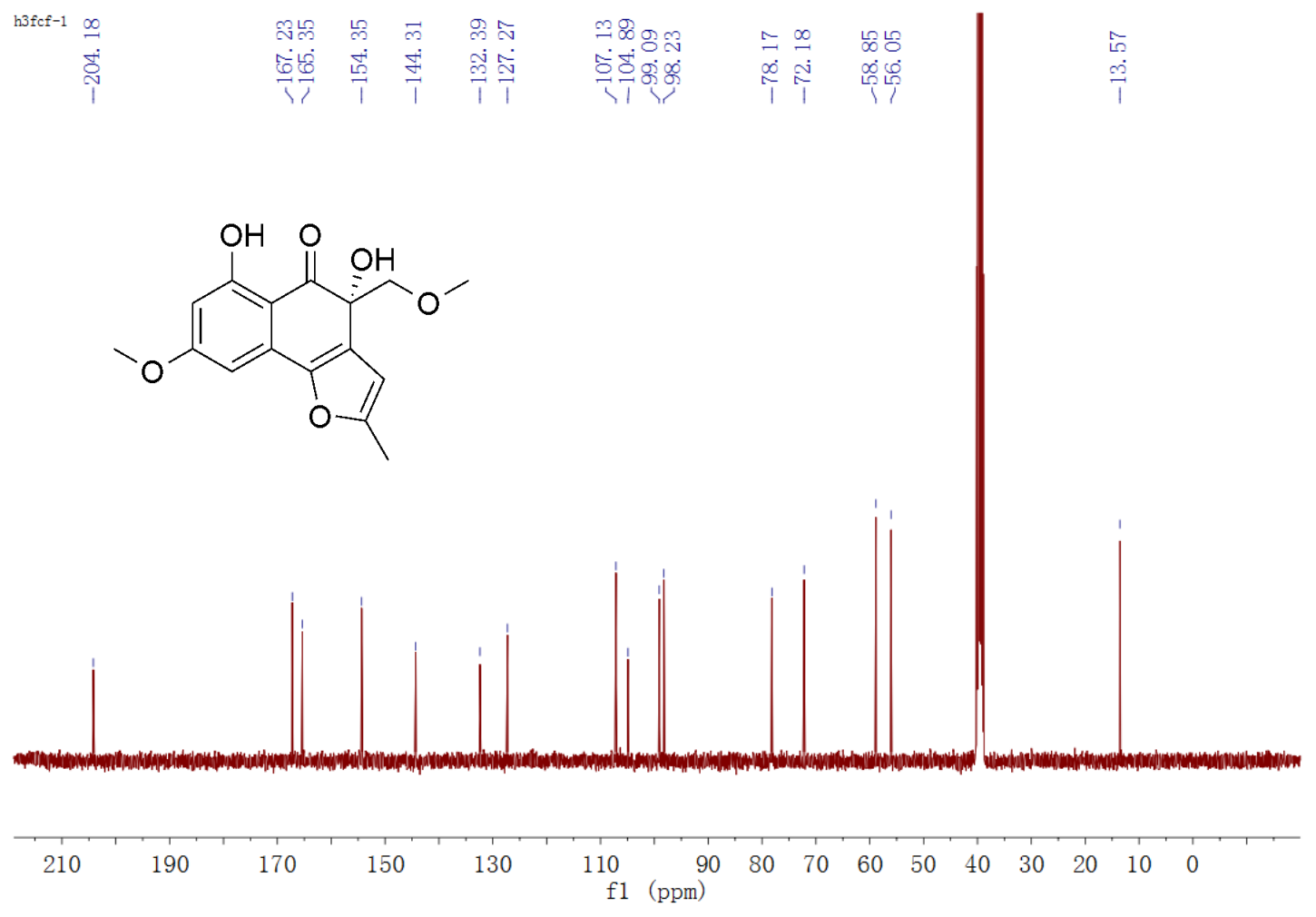

Figure S50. ${ }^{13} \mathrm{C}$ NMR spectrum of 6 in DMSO-d 6 


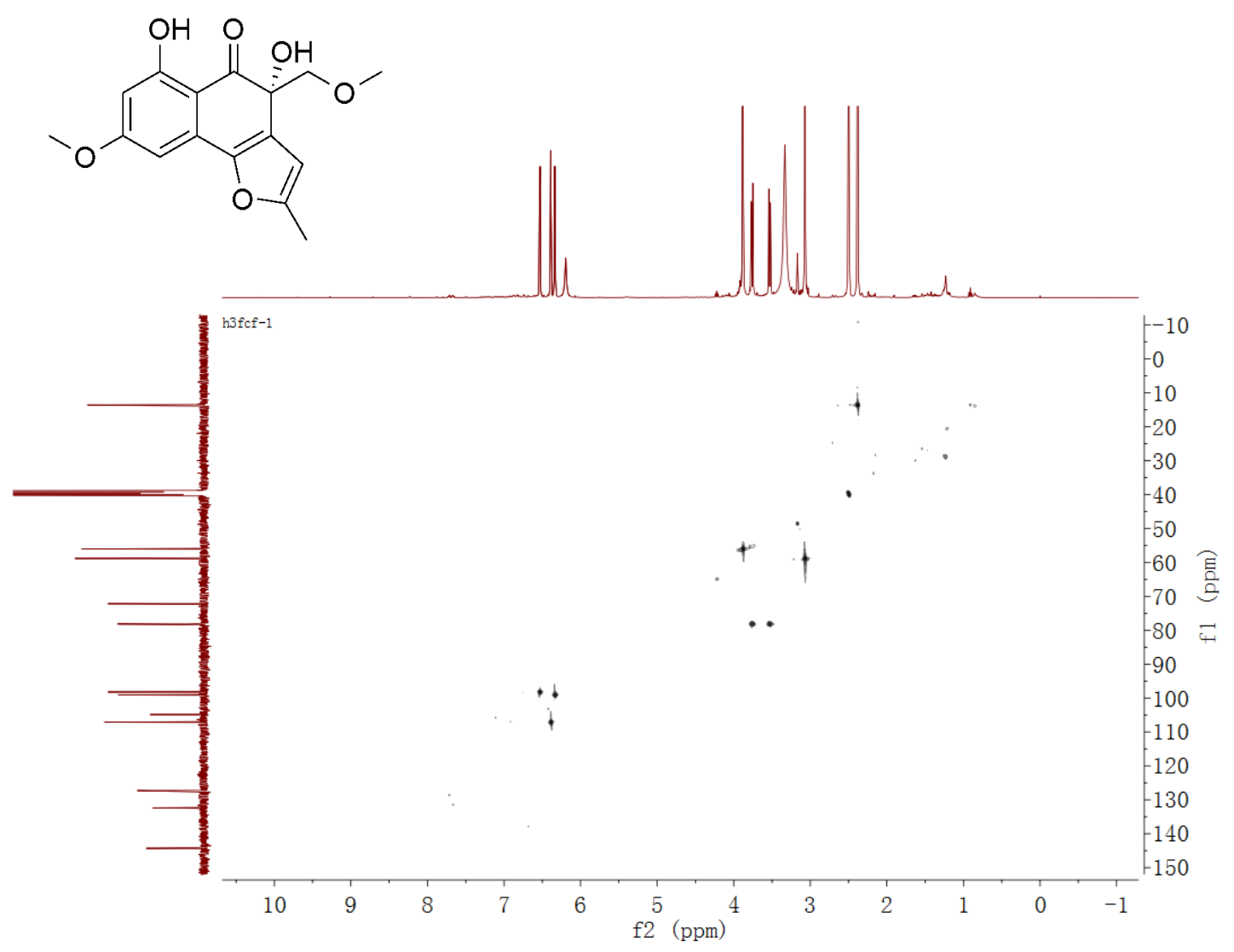

Figure S51. HSQC spectrum of 6 in DMSO- $\mathrm{d}_{6}$

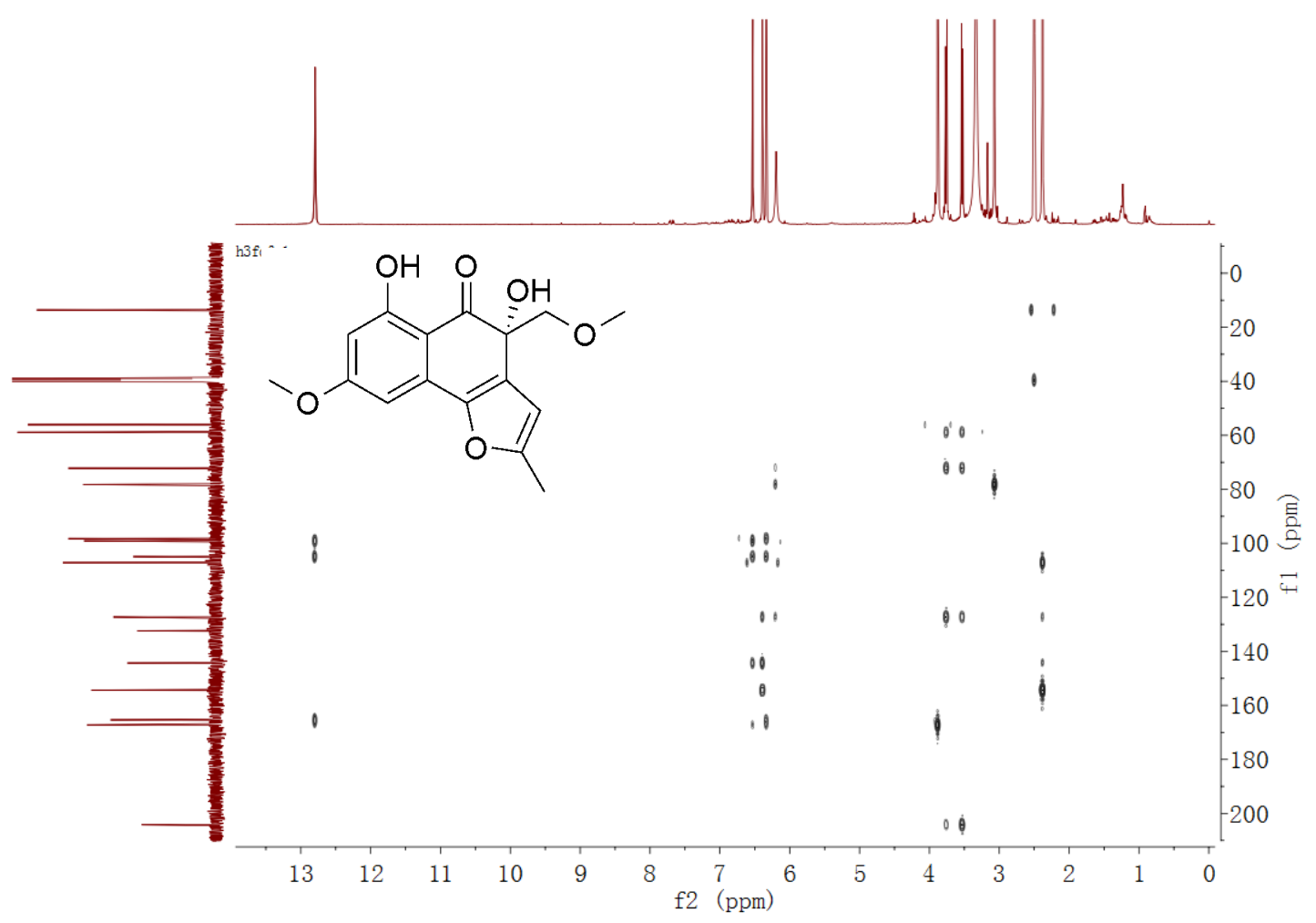

Figure S52. HMBC spectrum of 6 in DMSO- $\mathrm{d}_{6}$ 


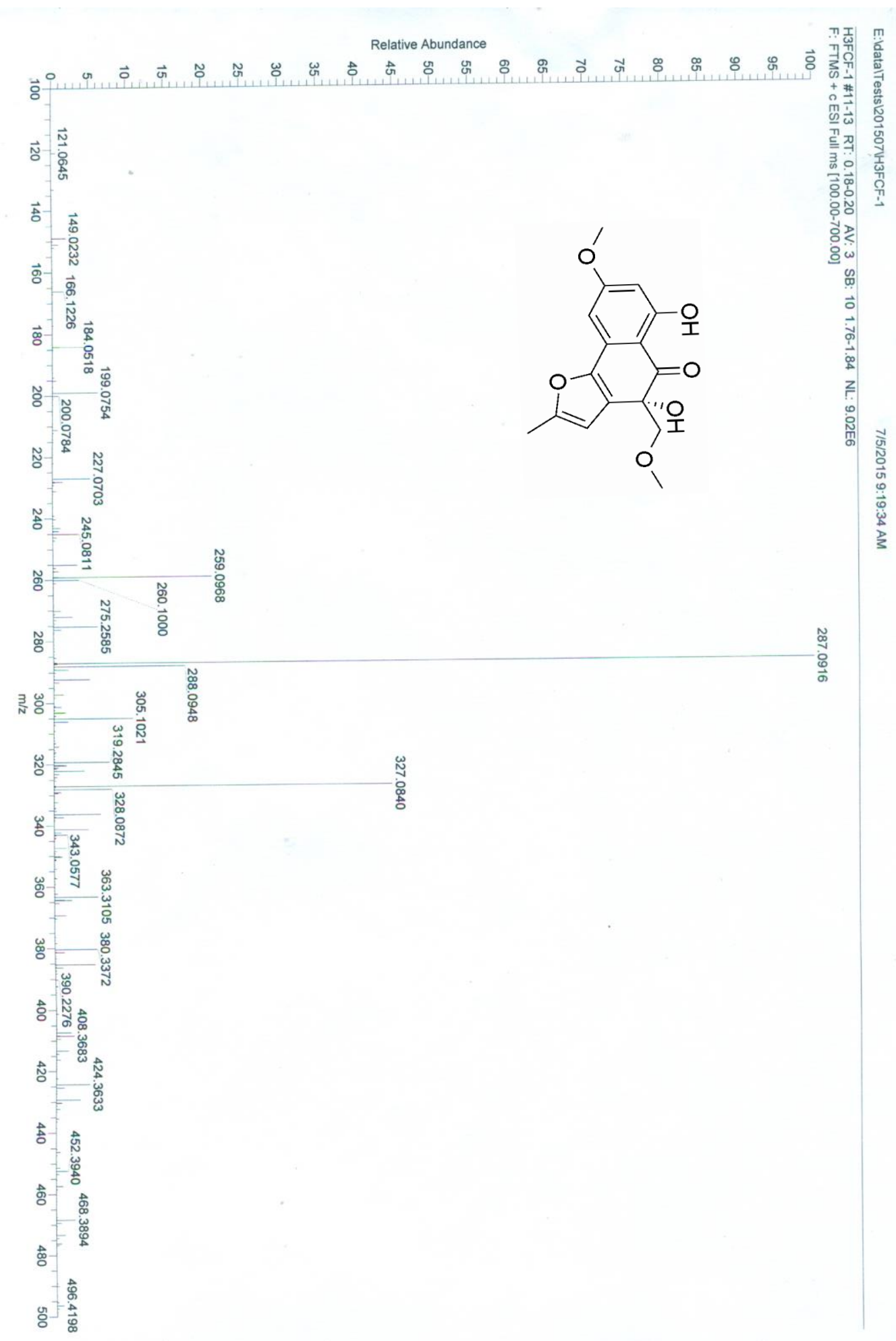

Figure S53. HRESIMS spectrum of 6 


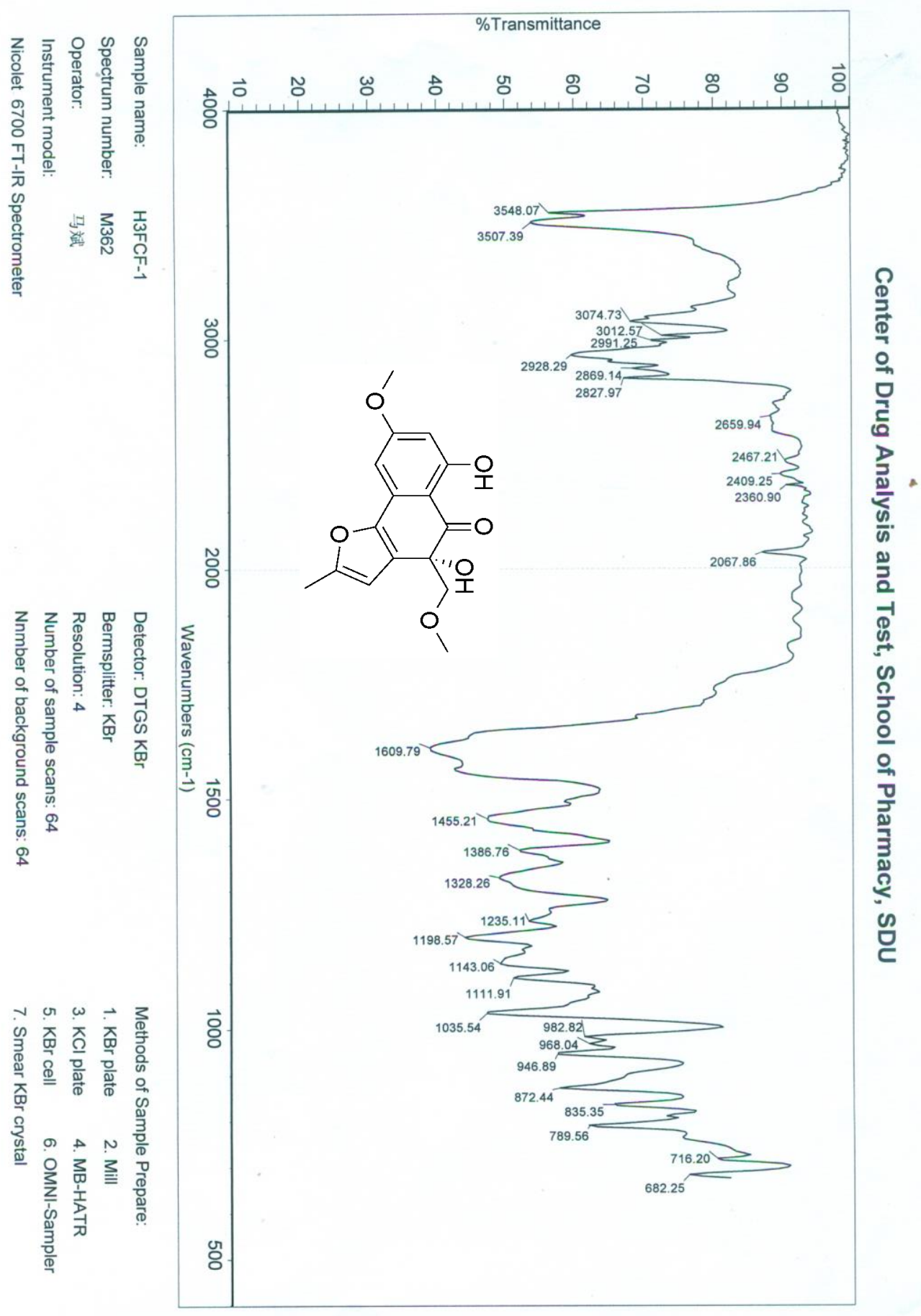

Figure S54. IR ( $\mathrm{KBr}$ disc) spectrum of 6 


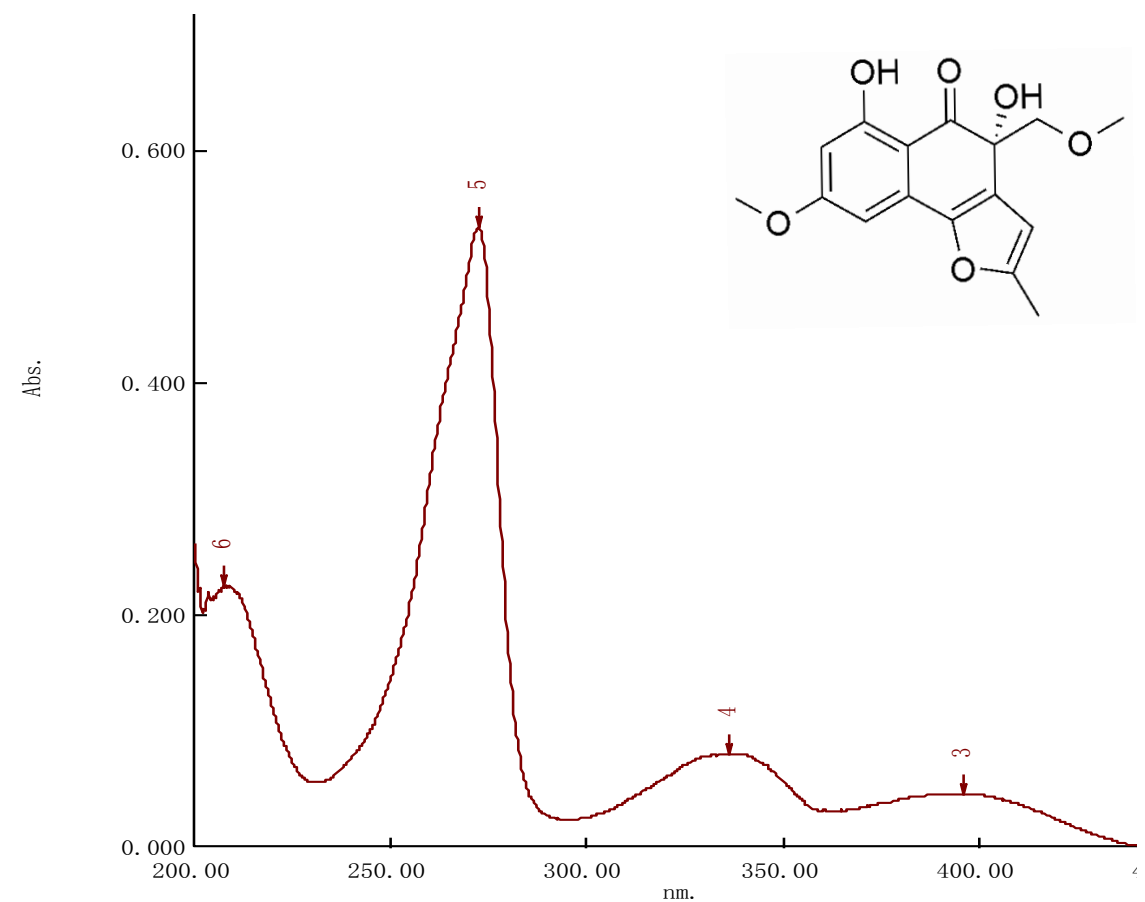

Figure S55. UV spectrum of 6

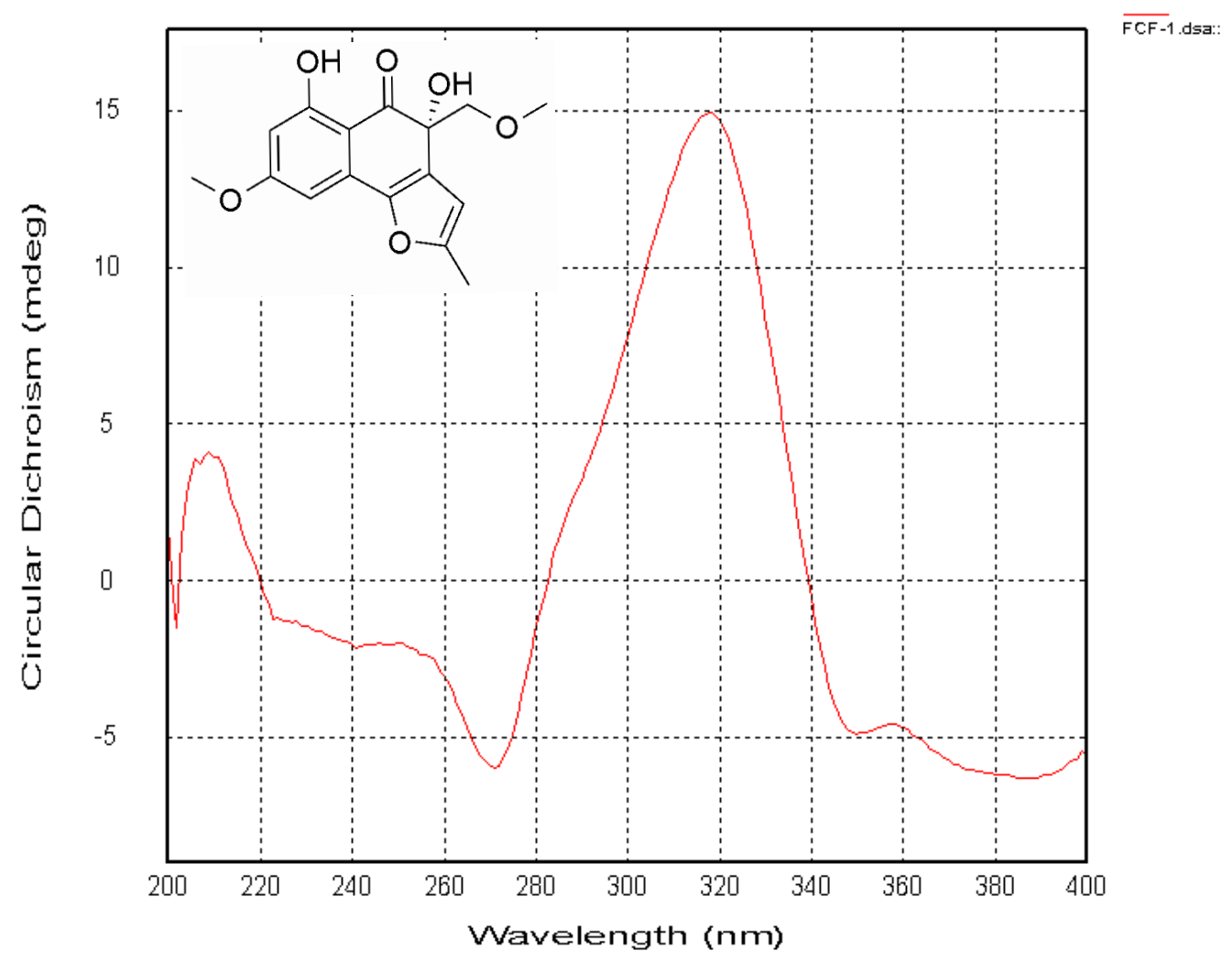

Figure S56. ECD spectrum of 6 


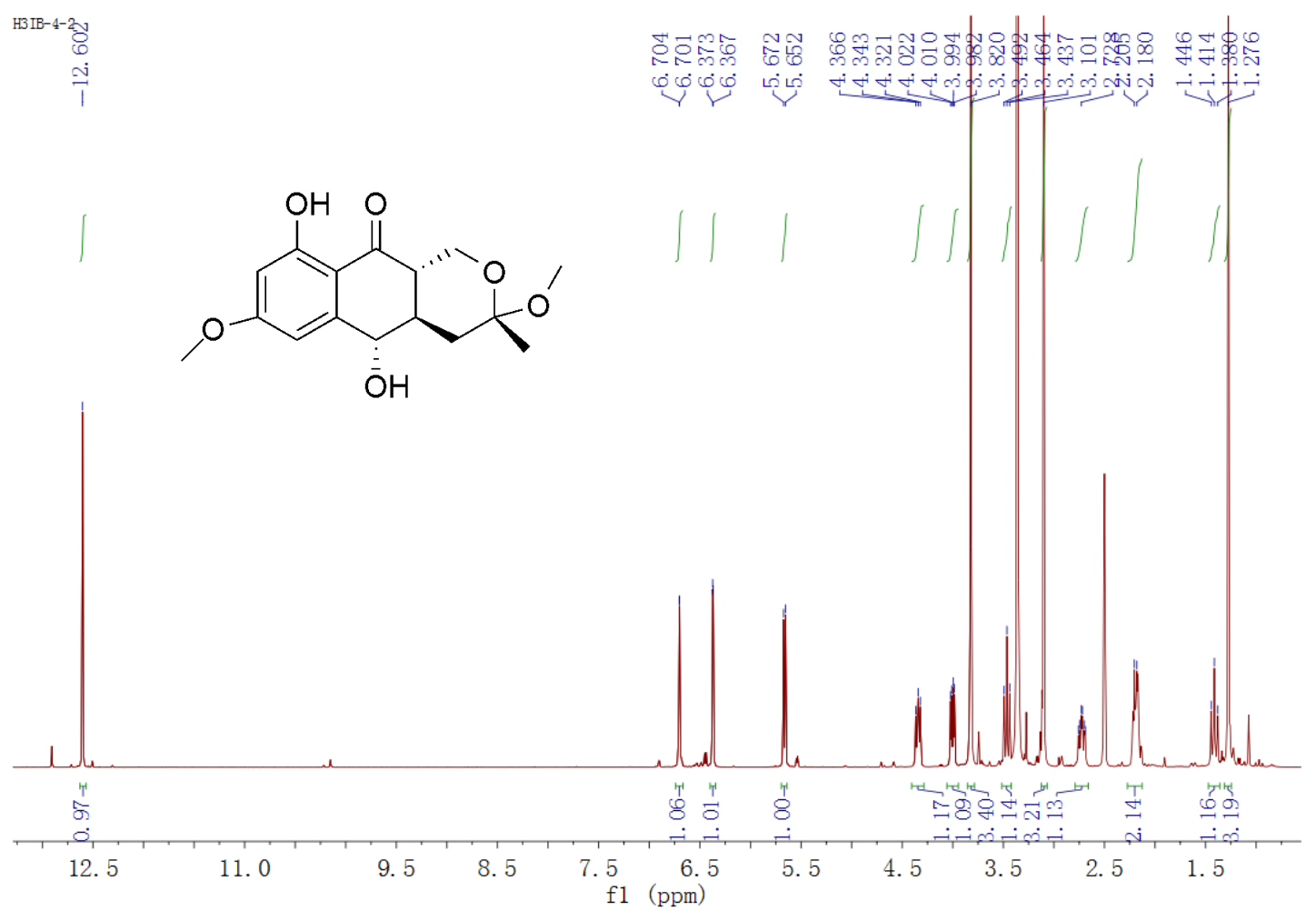

Figure S57. ${ }^{1} \mathrm{H}$ NMR spectrum of 7 in DMSO-d 6
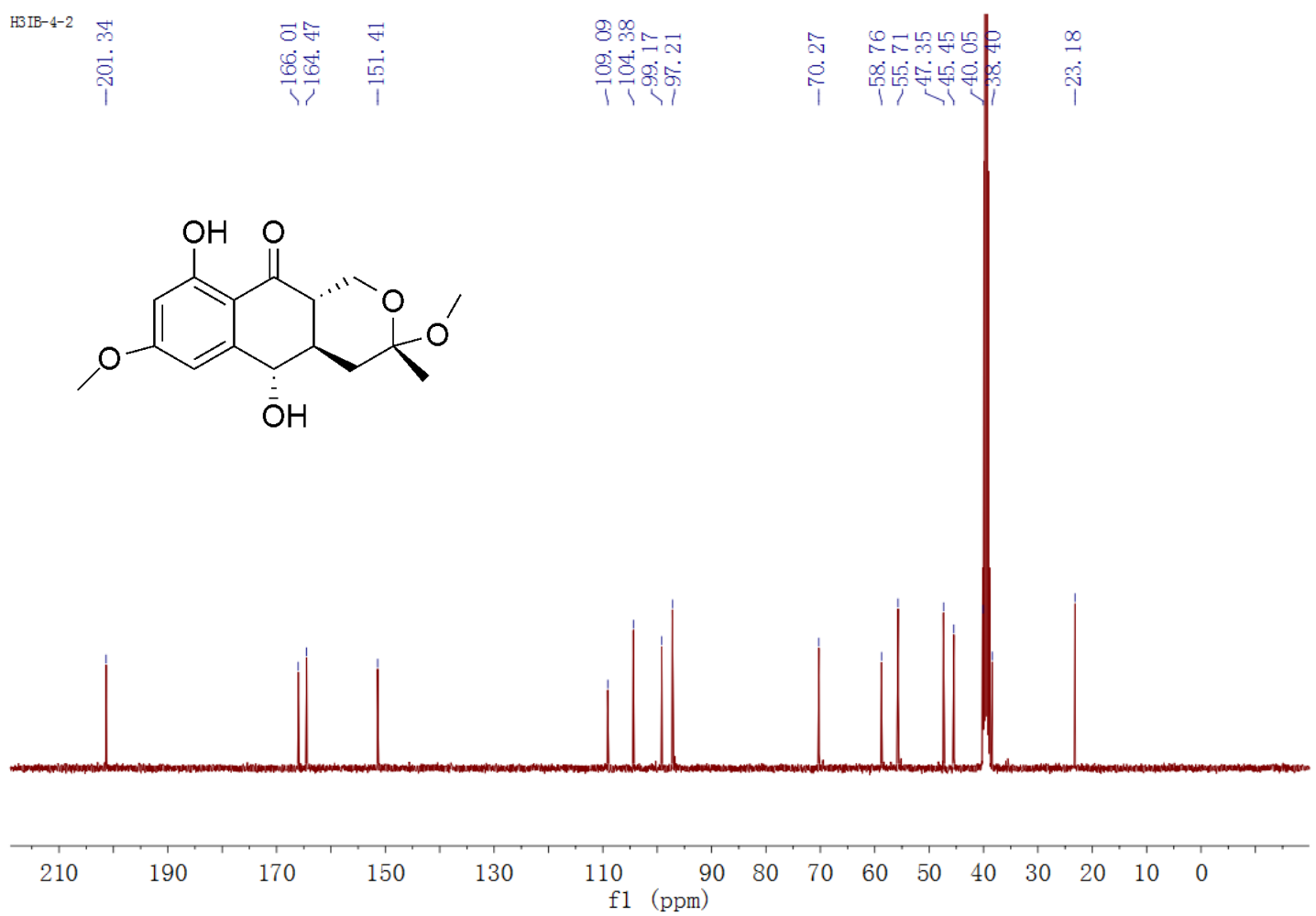

Figure S58. ${ }^{13} \mathrm{C}$ NMR spectrum of 7 in DMSO-d 6 


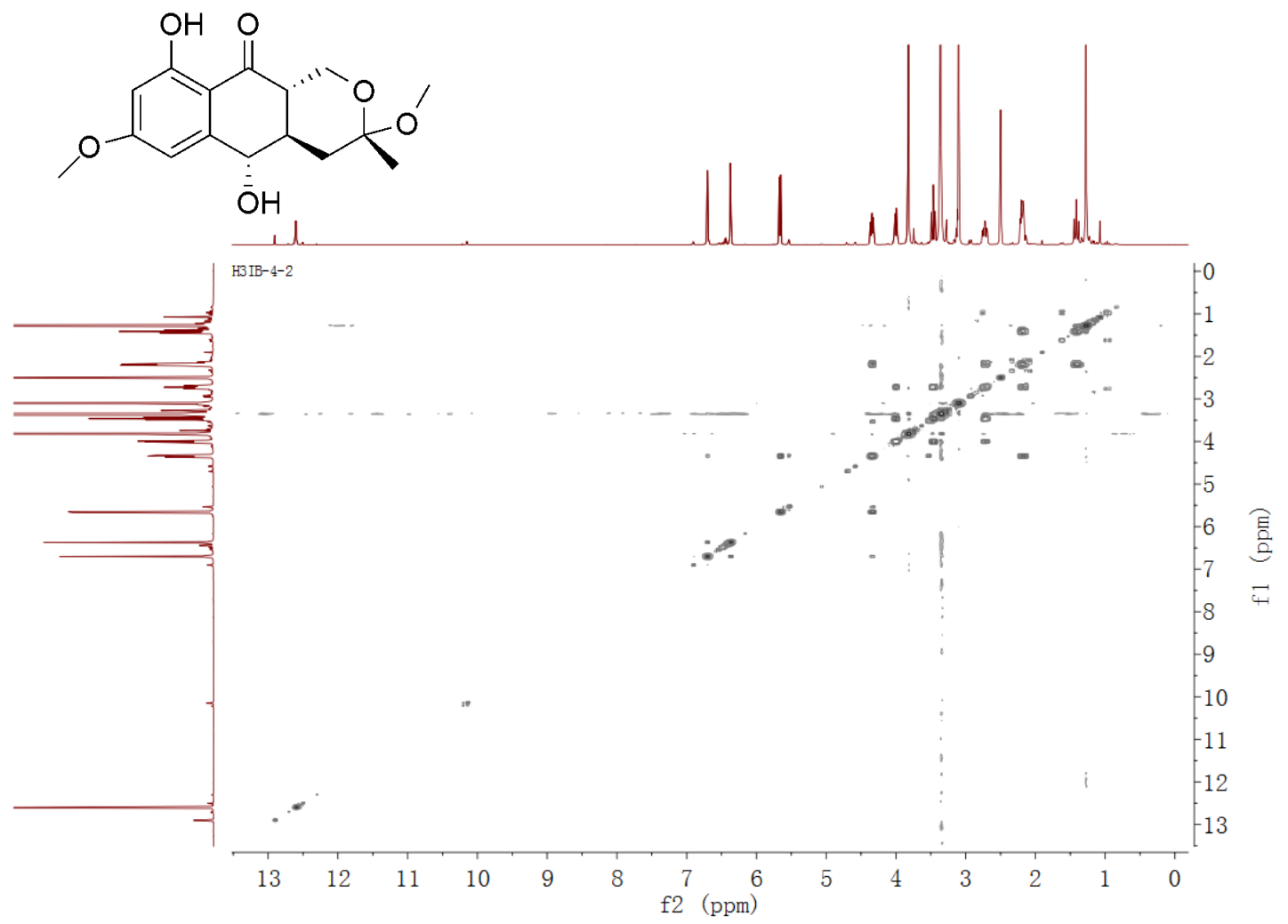

Figure S59. ${ }^{1} \mathrm{H}-{ }^{1} \mathrm{H}$ COSY spectrum of 7 in DMSO- $\mathrm{d}_{6}$

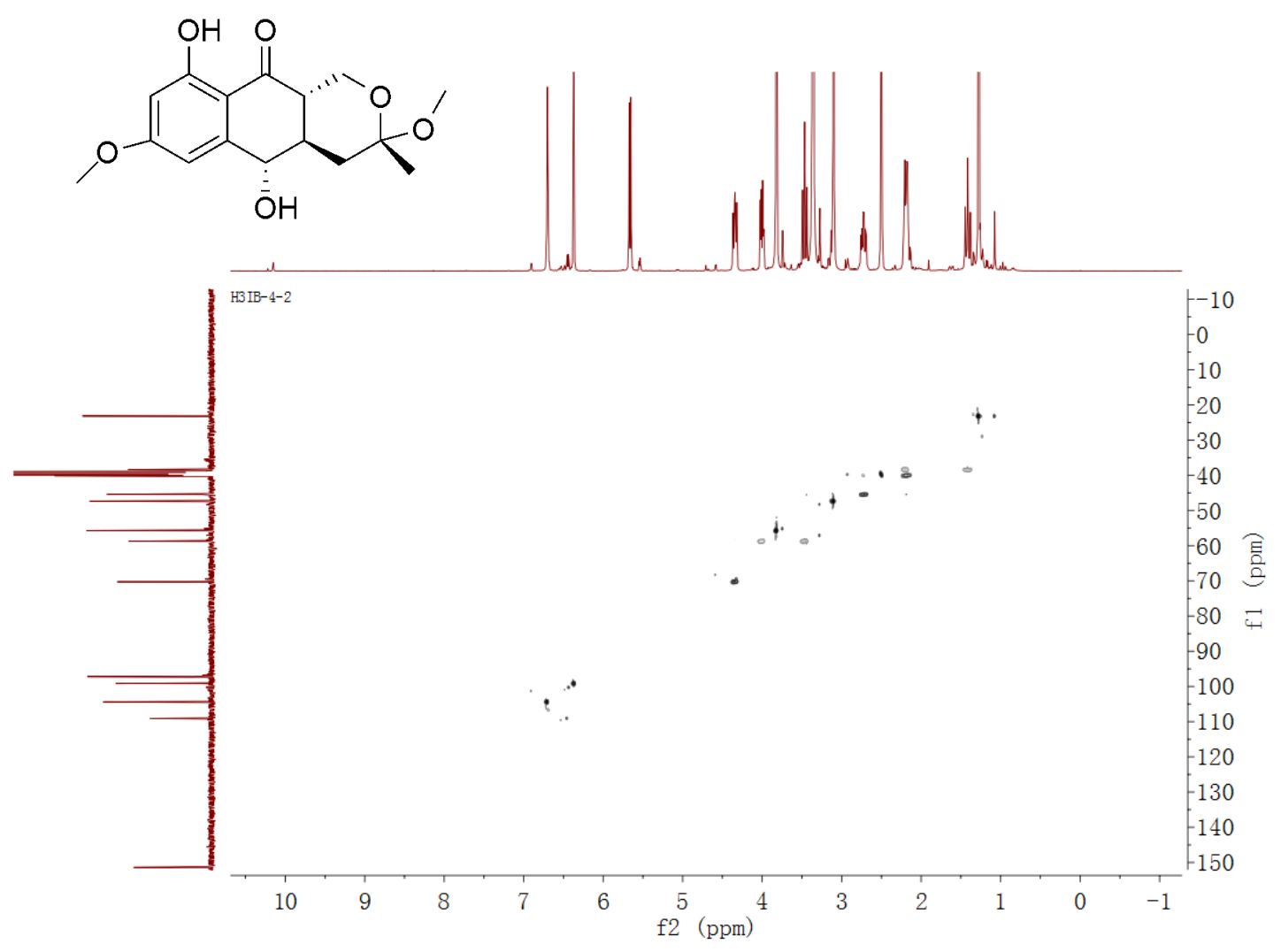

Figure S60. HSQC spectrum of 7 in DMSO- $\mathrm{d}_{6}$ 


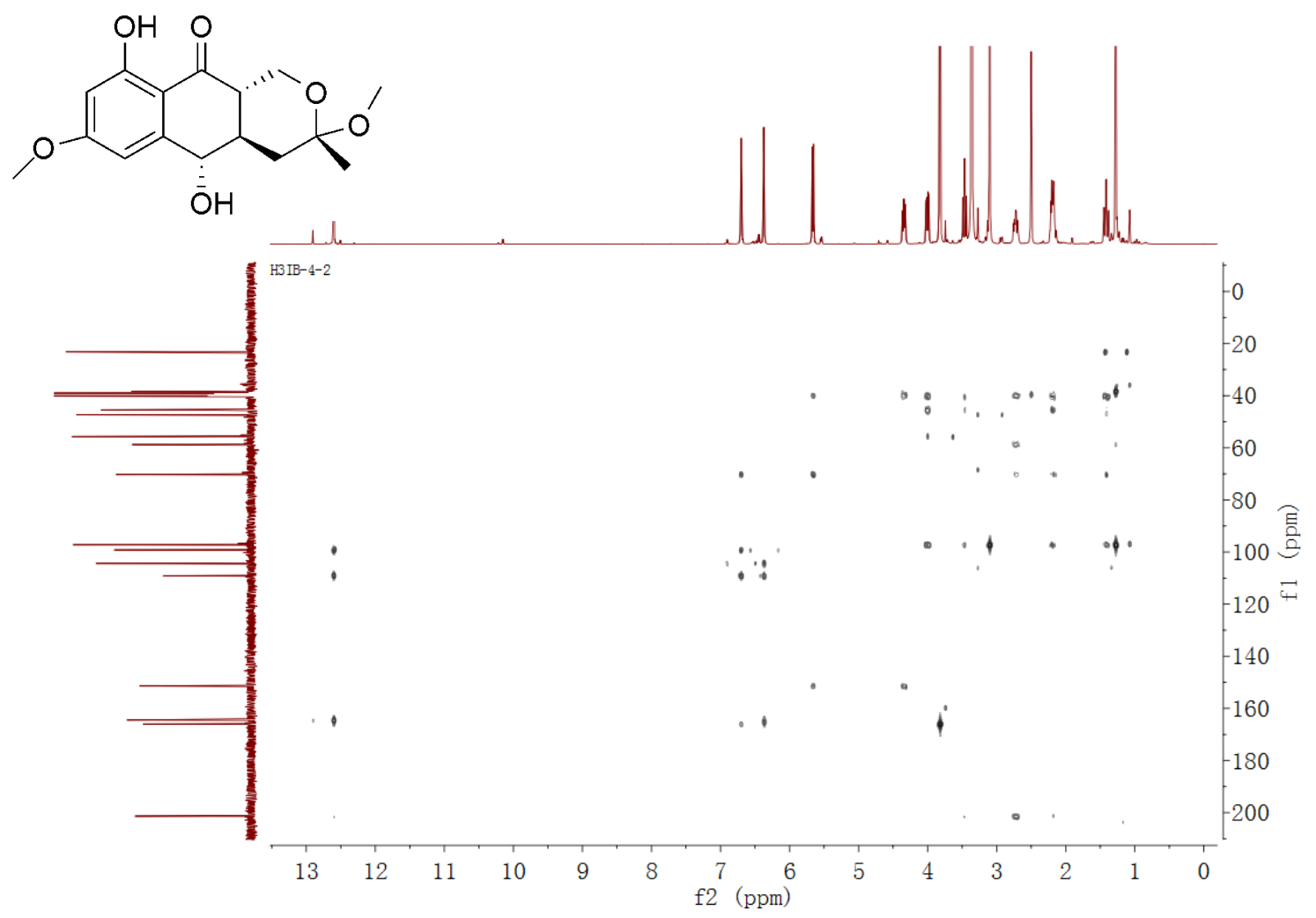

Figure S61. HMBC spectrum of 7 in DMSO-d 6

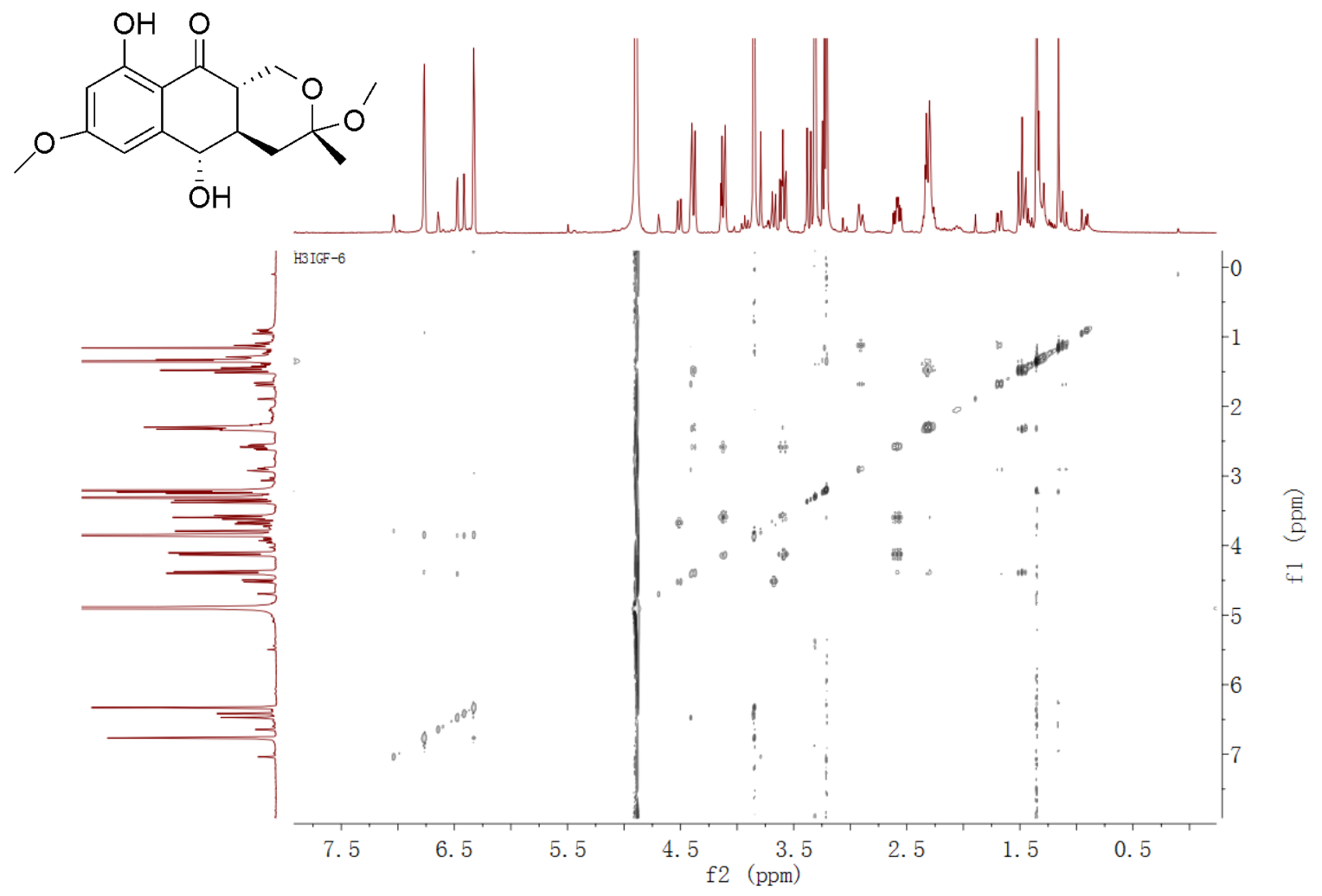

Figure S62. NOESY spectrum of 7 in $\mathrm{CD}_{3} \mathrm{OD}$ 


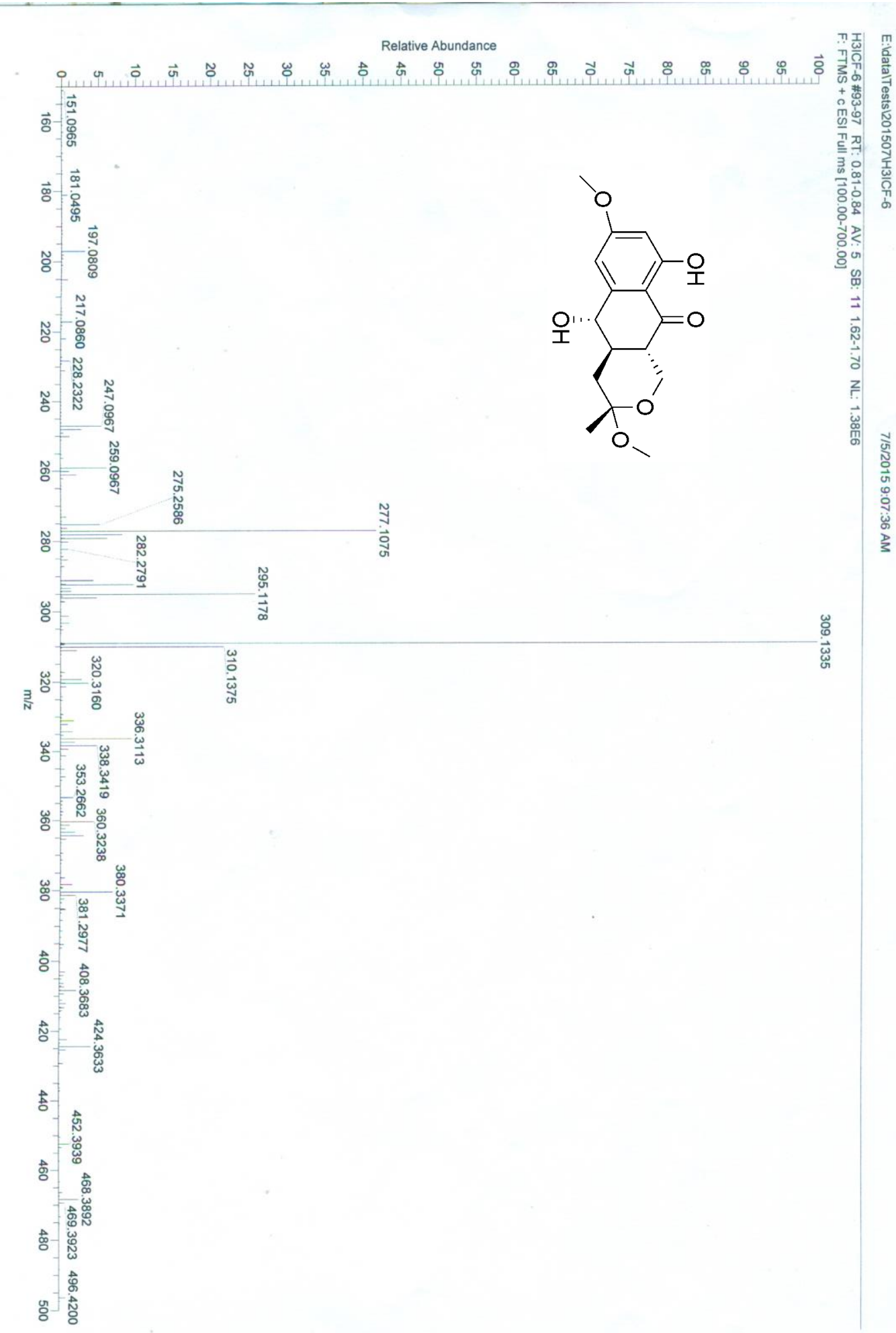

Figure S63. HRESIMS spectrum of 7 


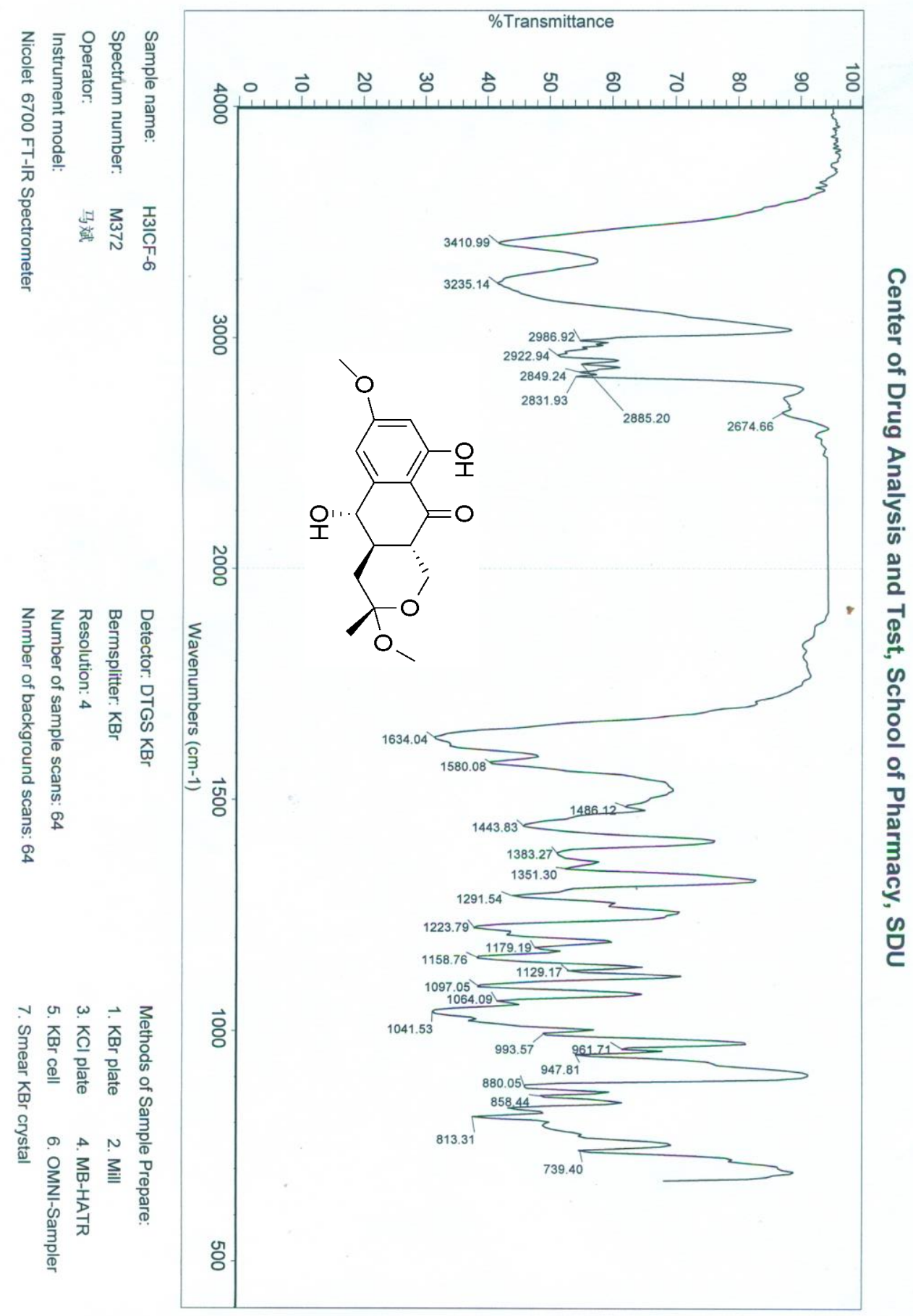

Figure S64. IR ( $\mathrm{KBr}$ disc) spectrum of 7 


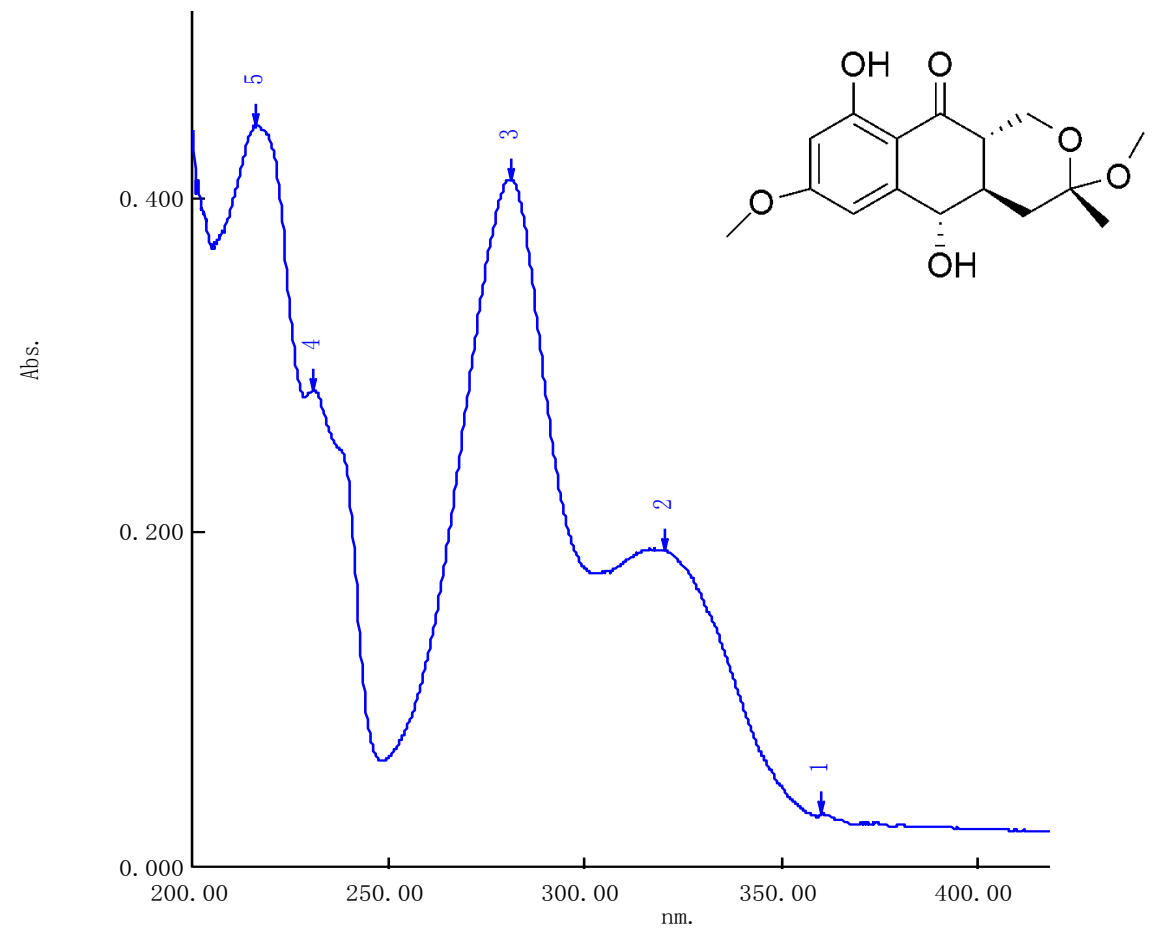

Figure S65. UV spectrum of 7

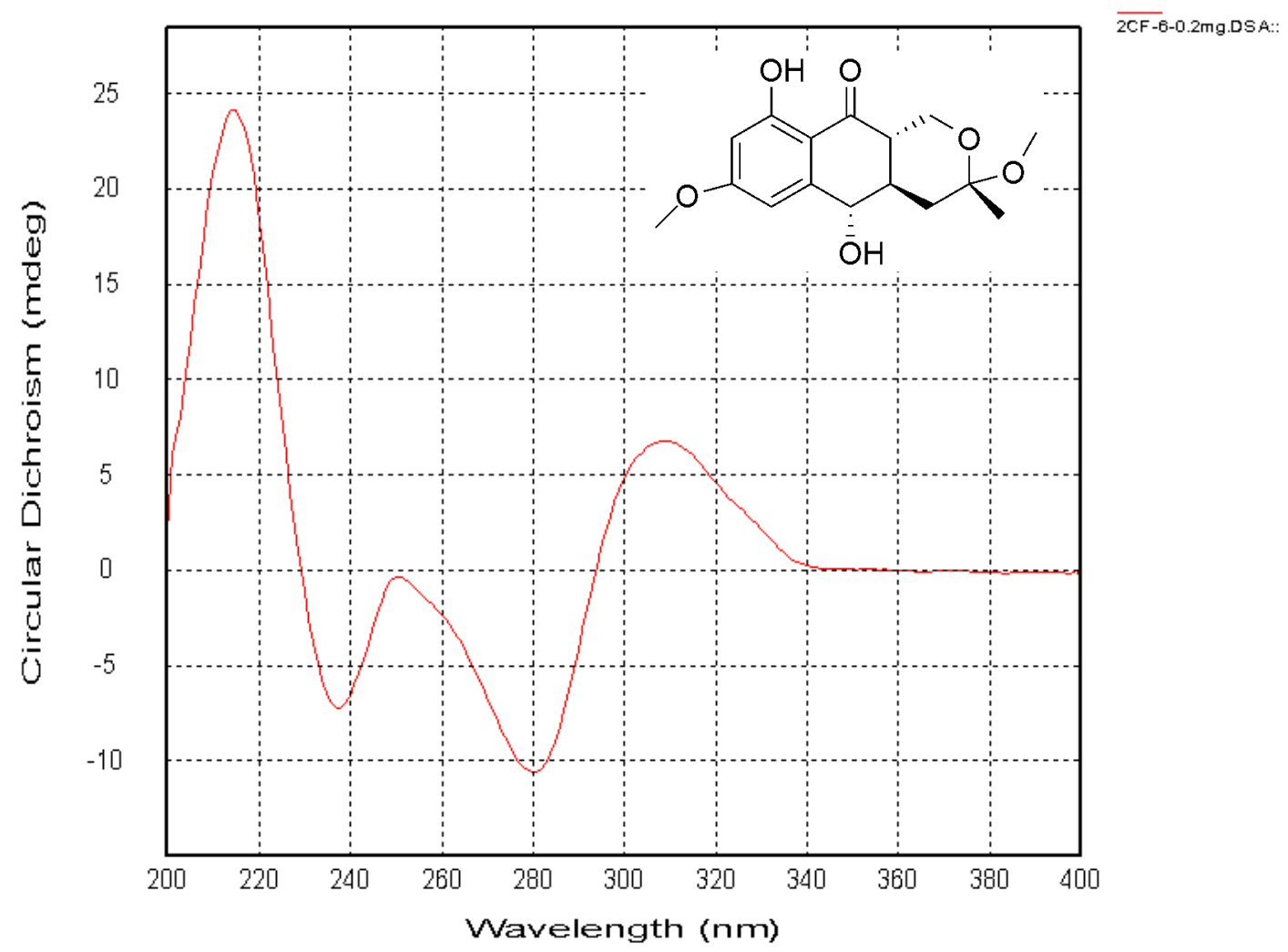

Figure S66. ECD spectrum of 7 


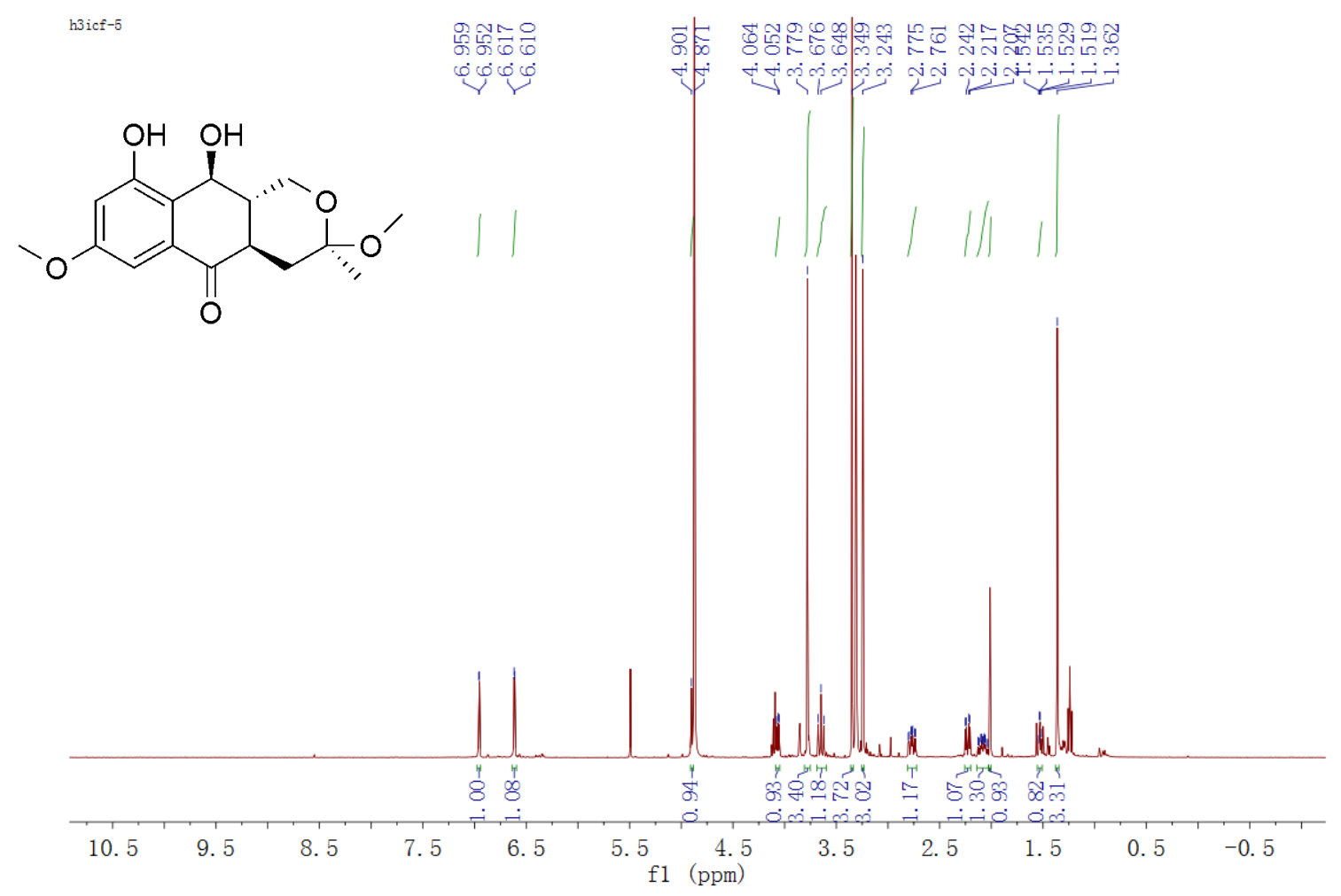

Figure S67. ${ }^{1} \mathrm{H}$ NMR spectrum of 8 in $\mathrm{CD}_{3} \mathrm{OD}$

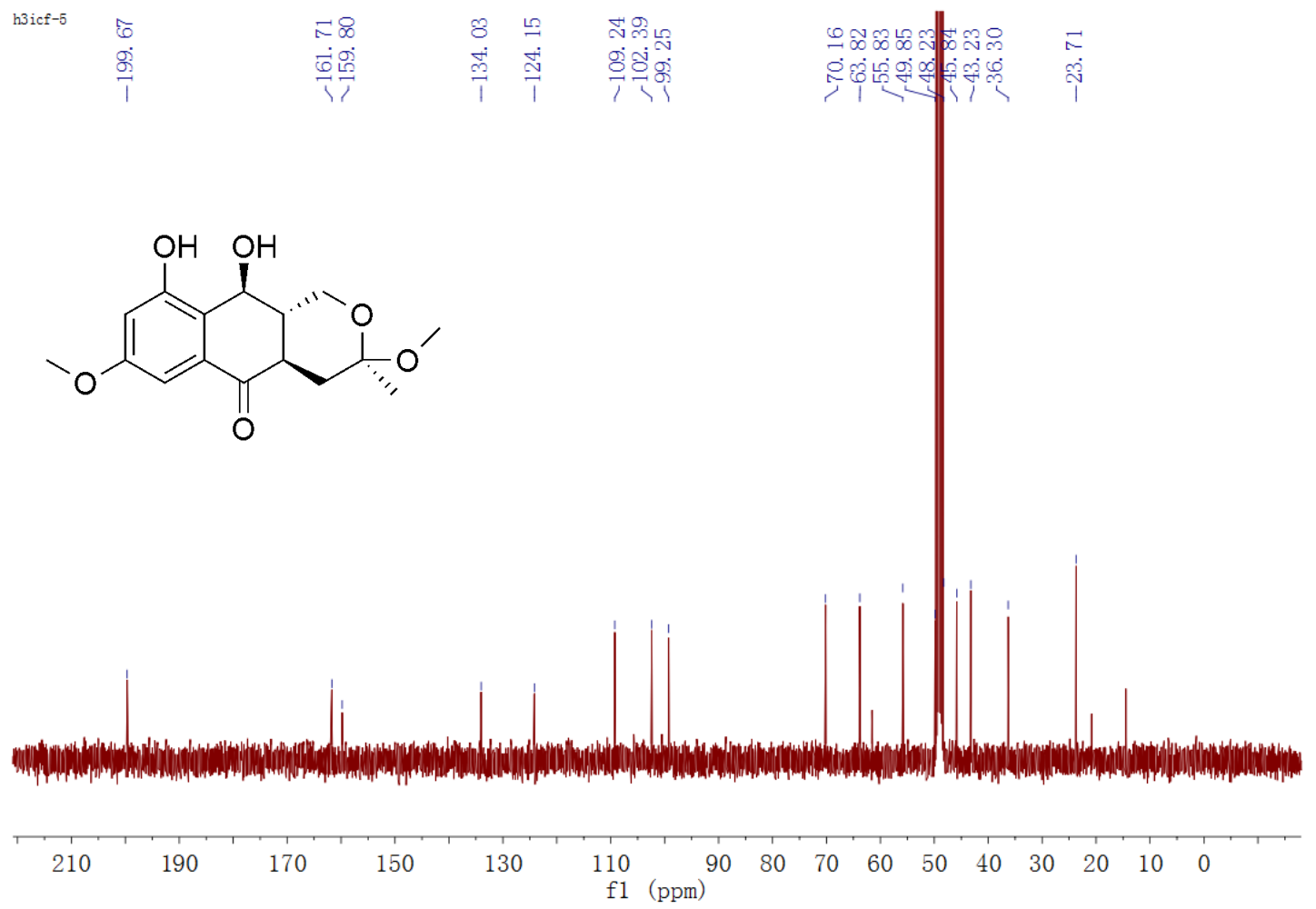

Figure S68. ${ }^{13} \mathrm{C}$ NMR spectrum of $\mathbf{8}$ in $\mathrm{CD}_{3} \mathrm{OD}$ 


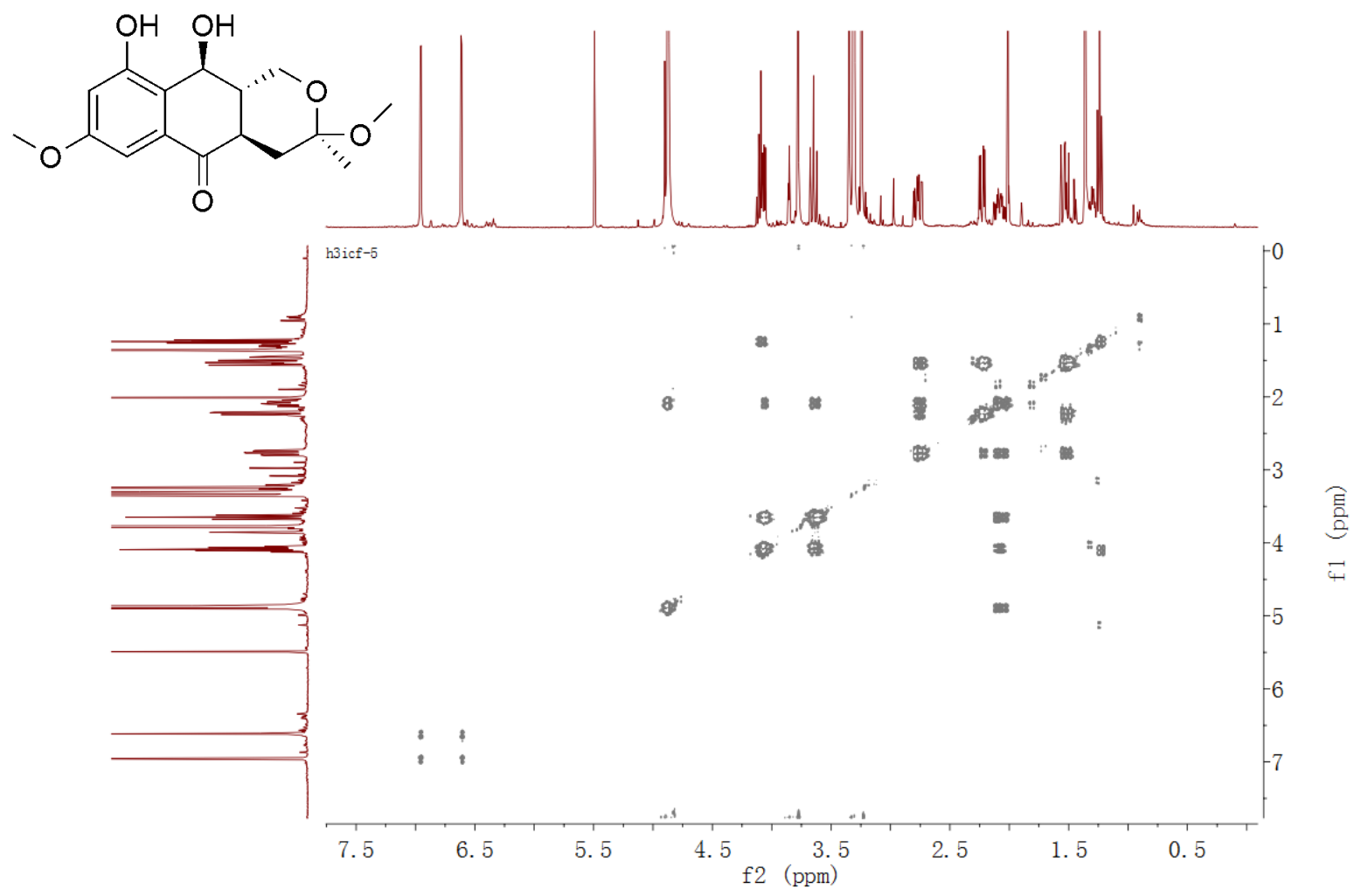

Figure S69. ${ }^{1} \mathrm{H}-{ }^{1} \mathrm{H}$ COSY spectrum of 8 in $\mathrm{CD}_{3} \mathrm{OD}$<smiles>COc1cc(O)c2c(c1)C(=O)C1C[C@@](C)(OC)OC[C@H]1C2O</smiles>
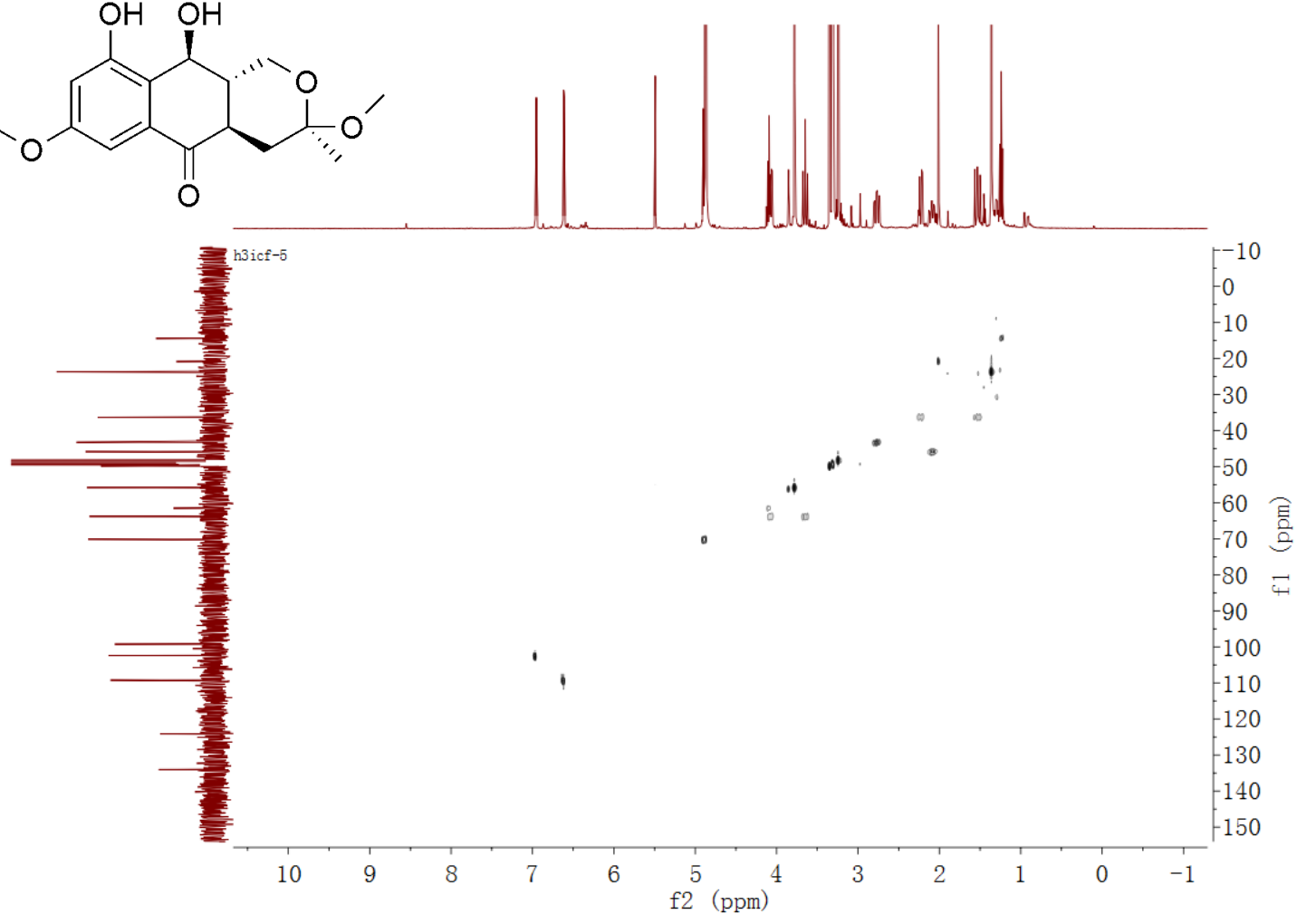

Figure S70. HSQC spectrum of 8 in $\mathrm{CD}_{3} \mathrm{OD}$ 


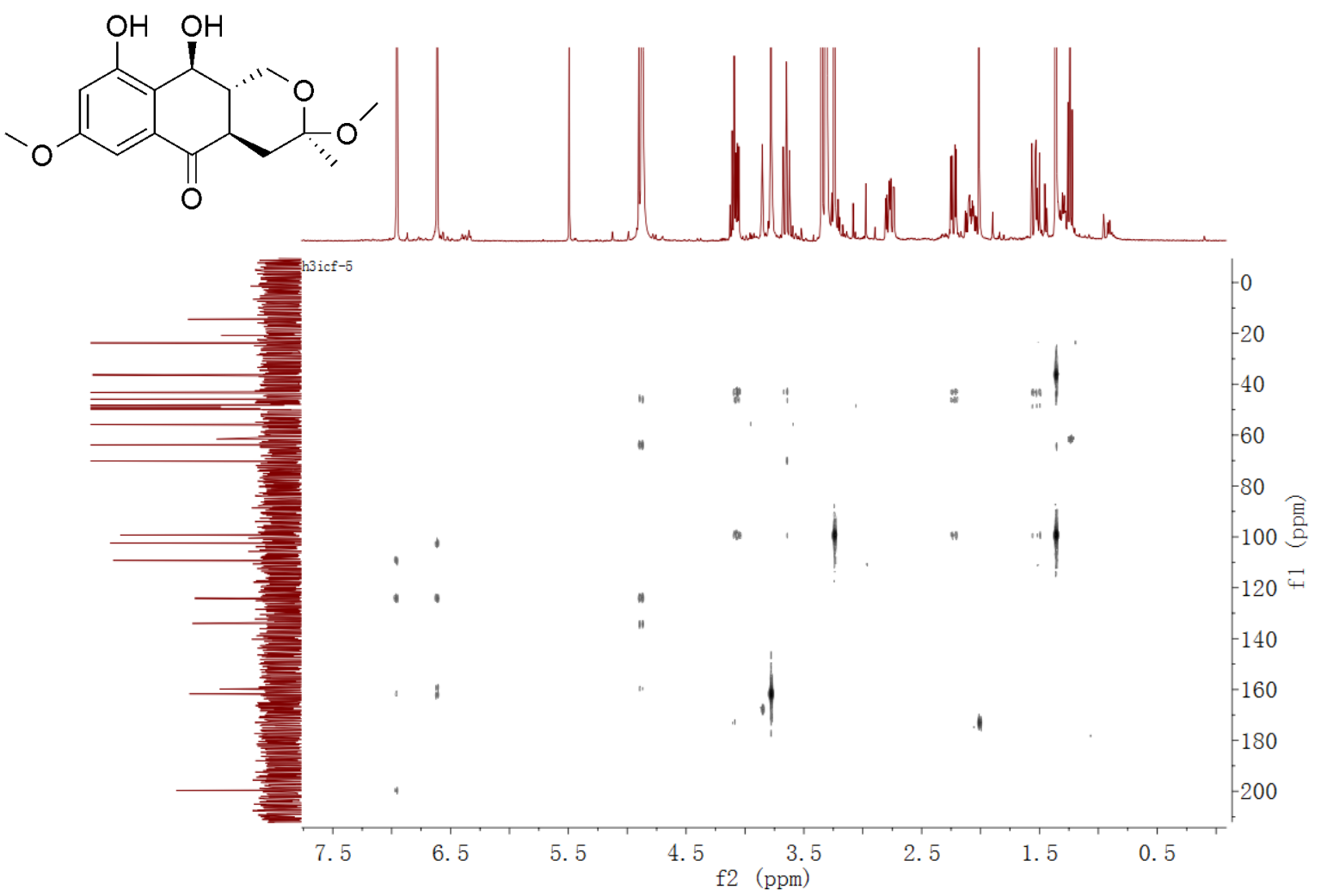

Figure S71. $\mathrm{HMBC}$ spectrum of 8 in $\mathrm{CD}_{3} \mathrm{OD}$

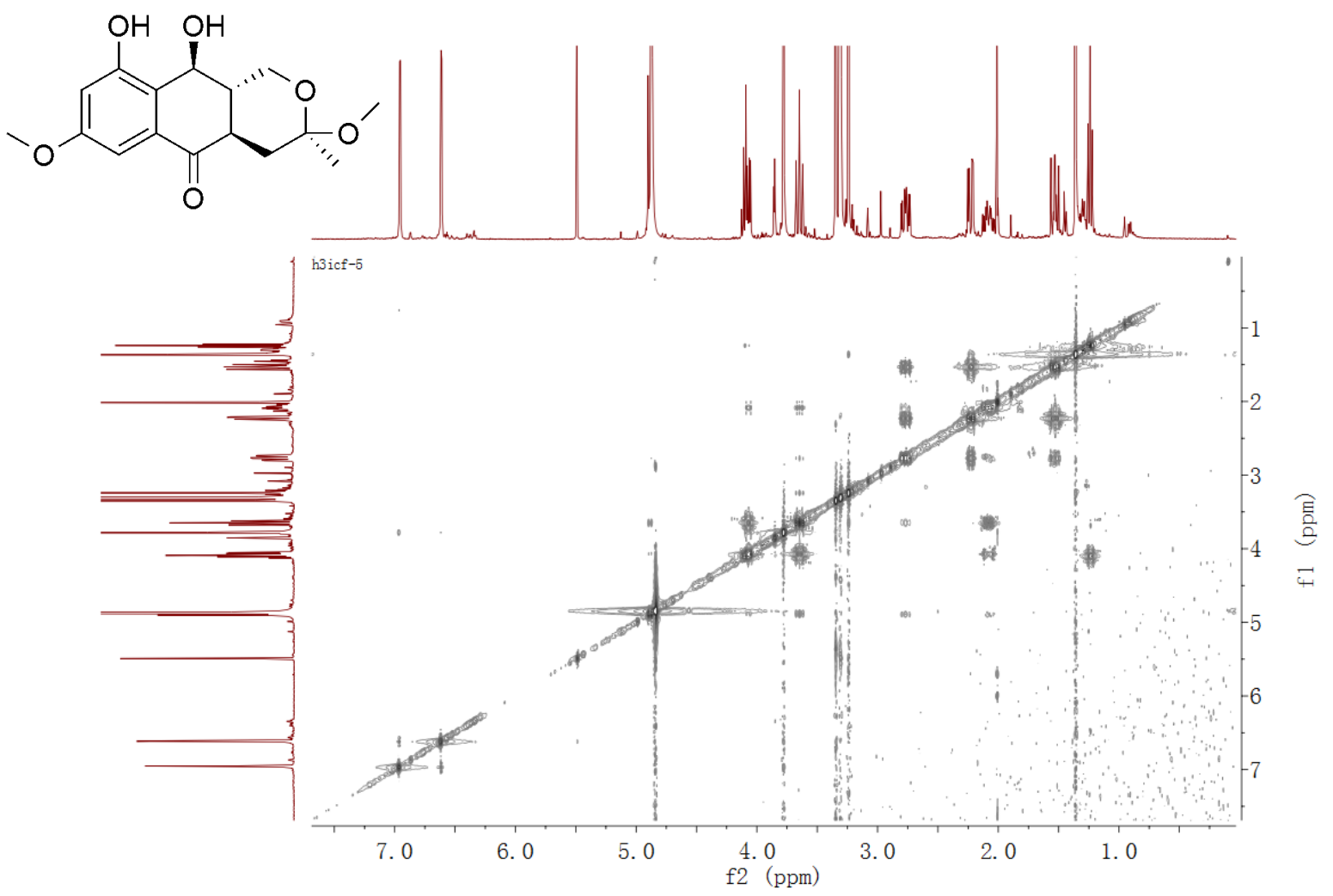

Figure S72. NOESY spectrum of $\mathbf{8}$ in $\mathrm{CD}_{3} \mathrm{OD}$ 


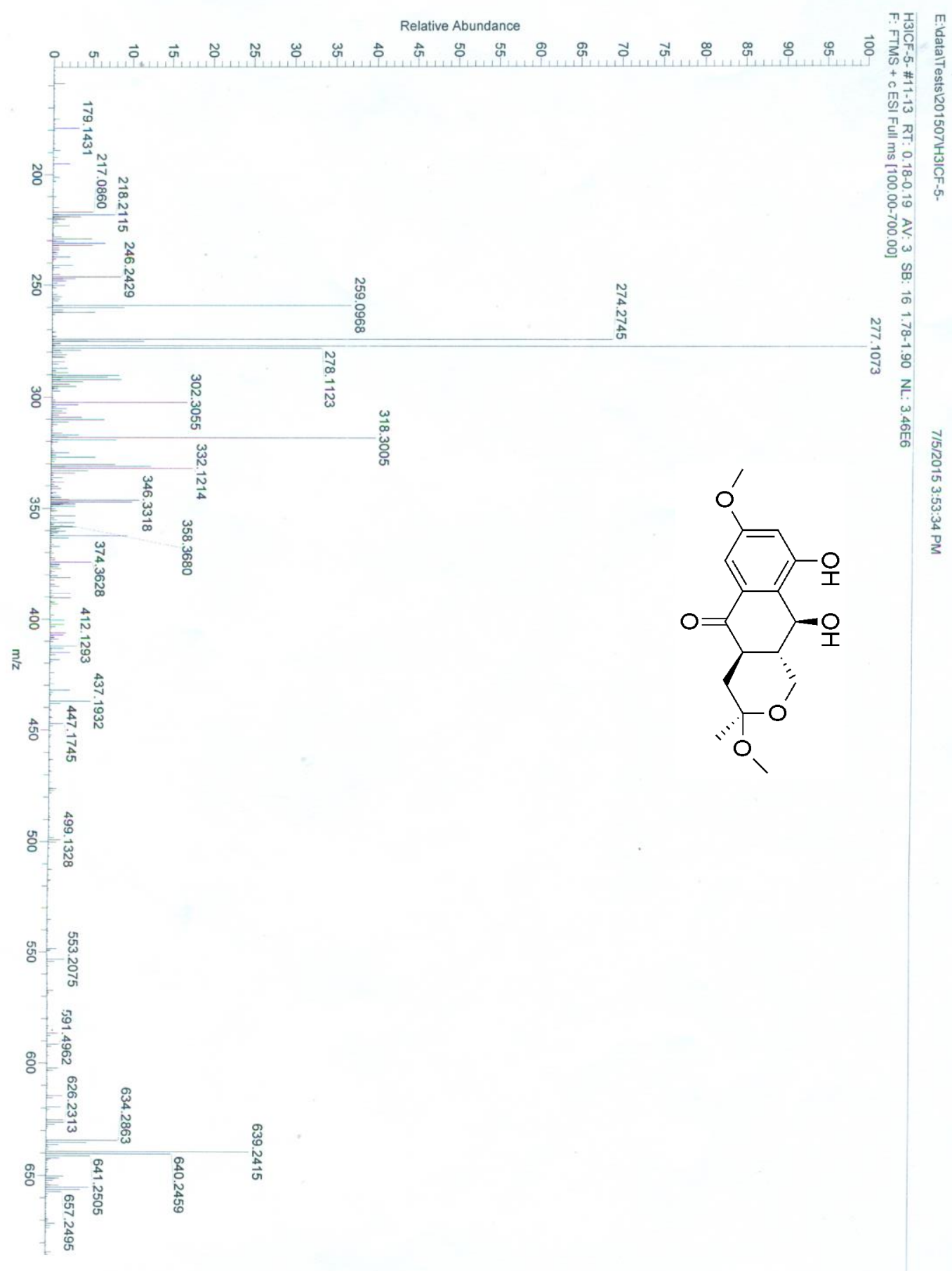

Figure S73. HRESIMS spectrum of 8 


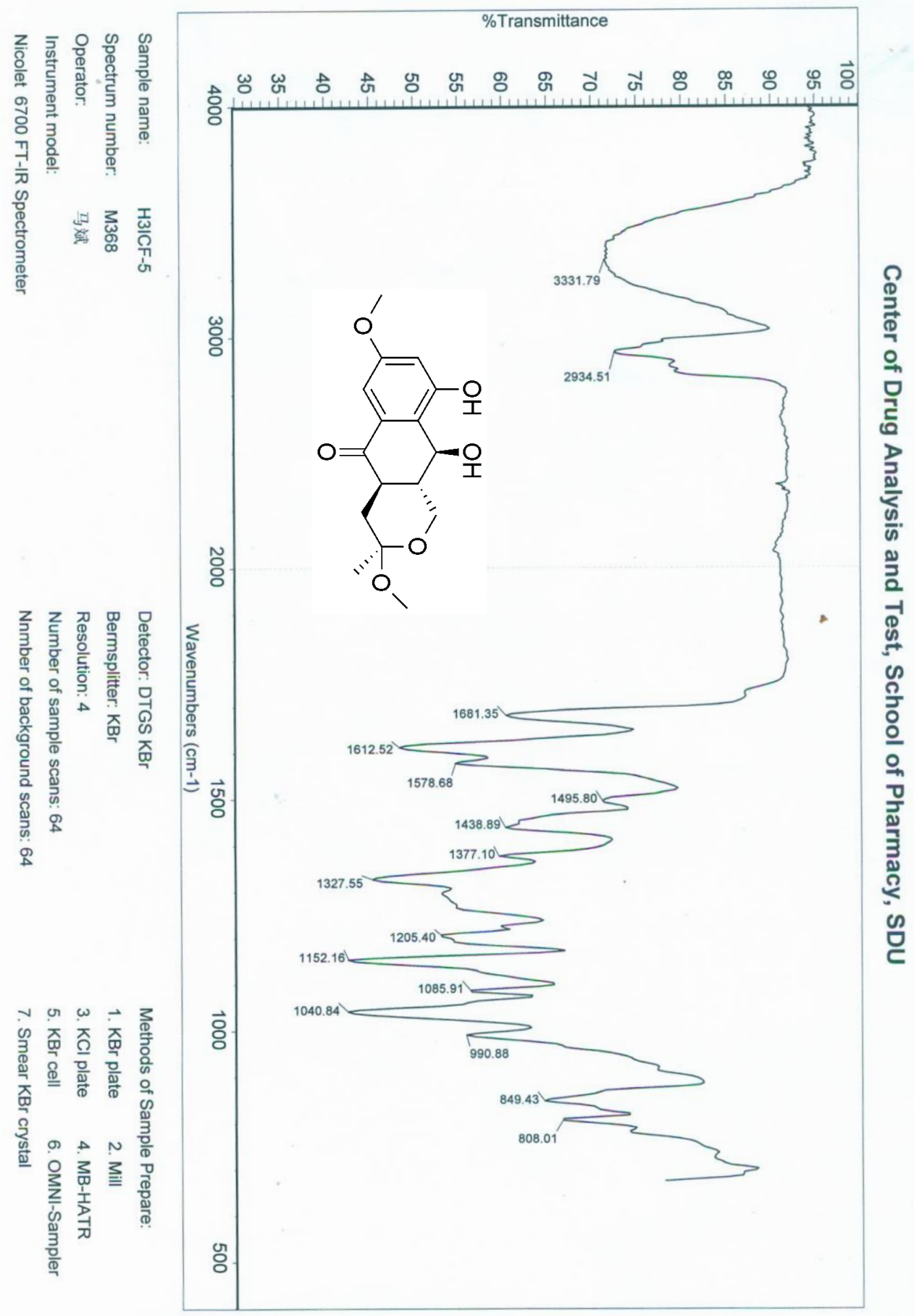

Figure S74. IR ( $\mathrm{KBr}$ disc) spectrum of 8 


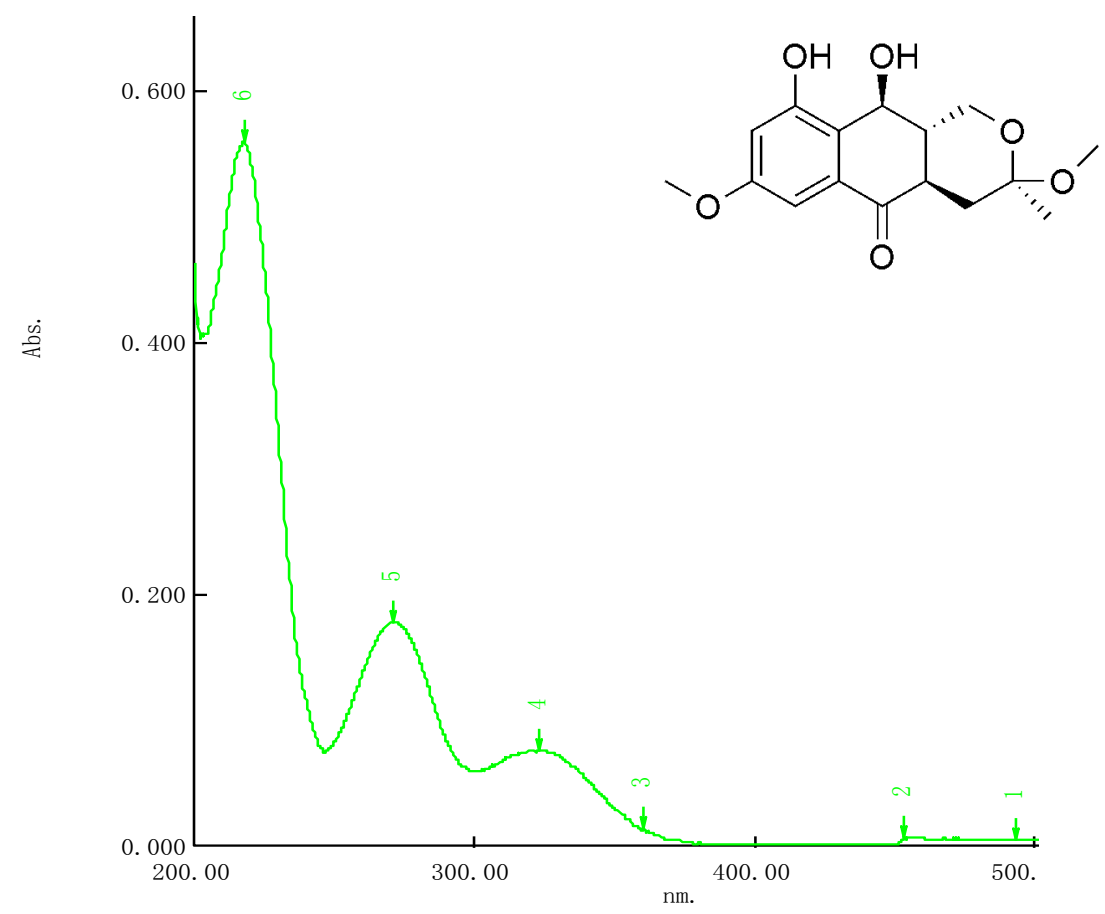

Figure S75. UV spectrum of 8

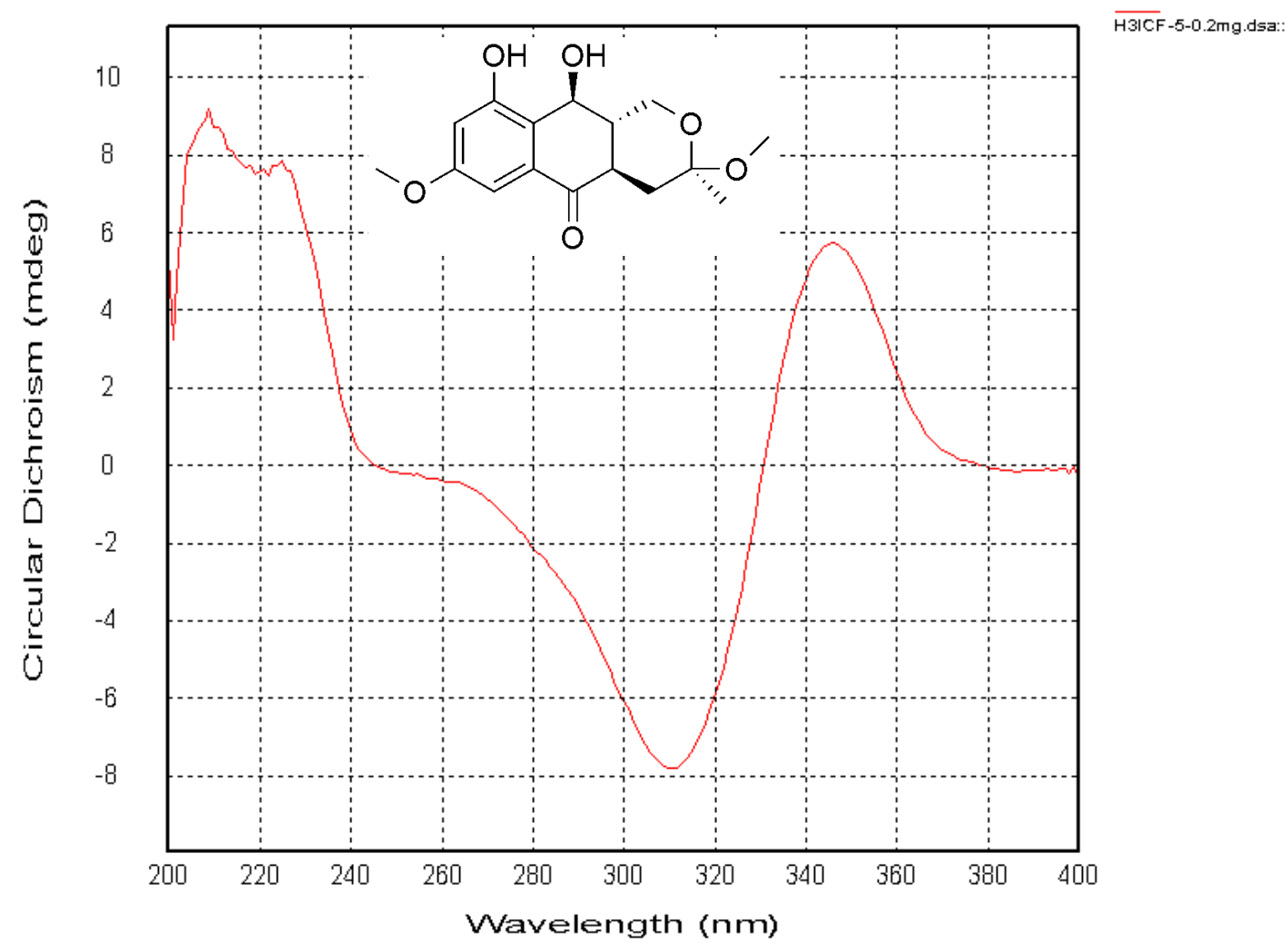

Figure S76. ECD spectrum of 8 


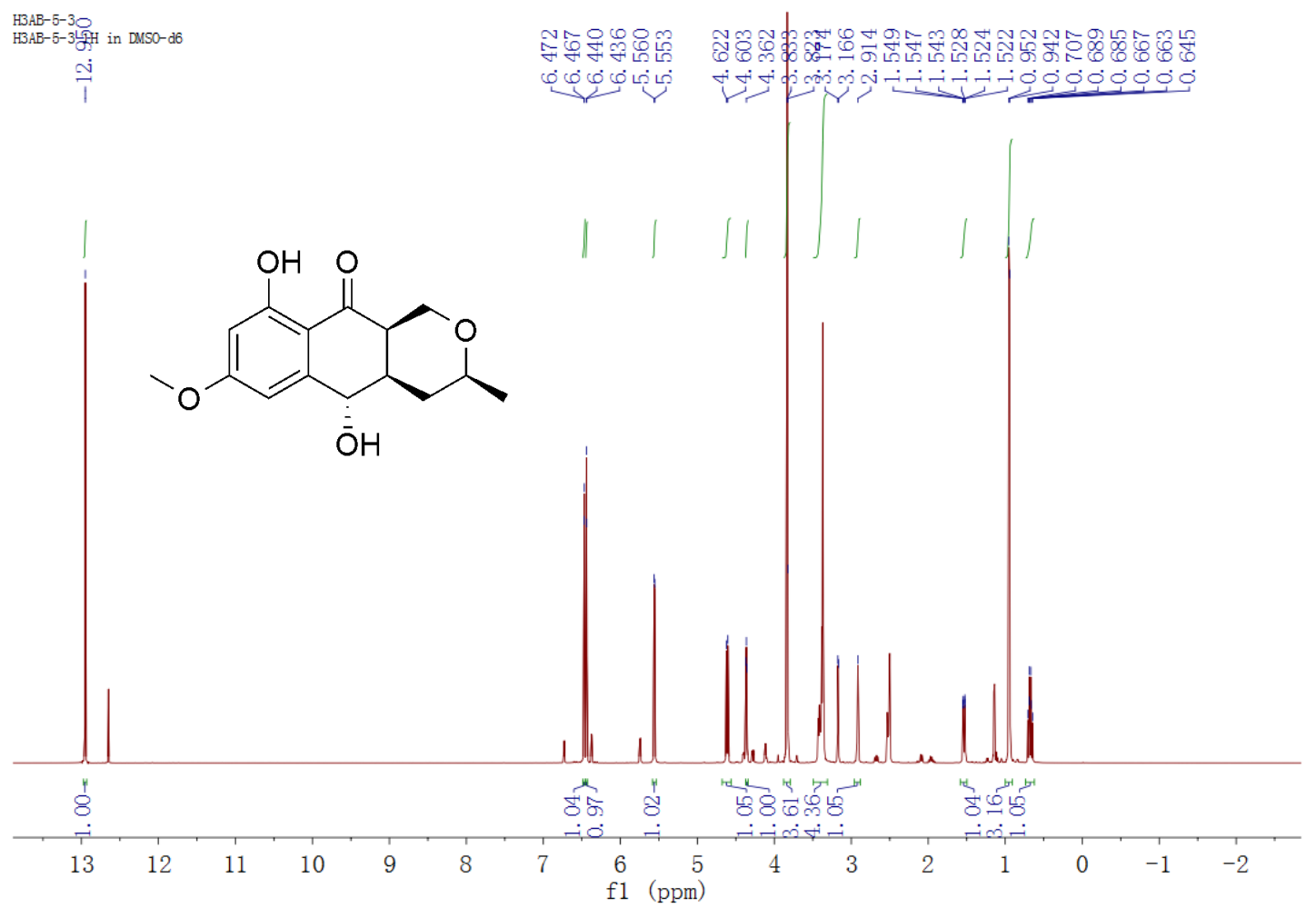

Figure S77. ${ }^{1} \mathrm{H}$ NMR spectrum of 9 in DMSO-d 6

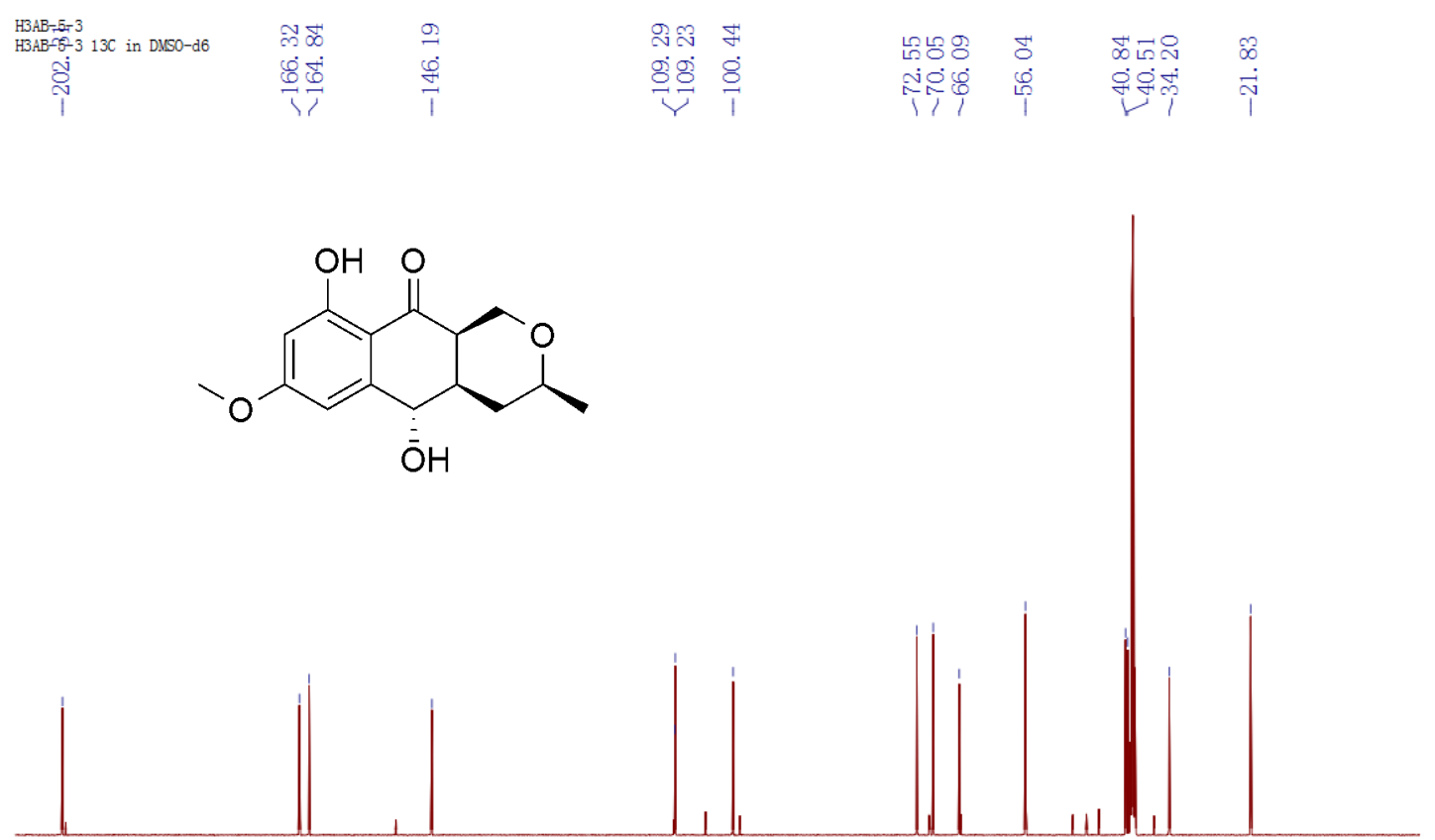

190

170

130 110 (ppm)

$\begin{array}{llllllllll}0 & 80 & 70 & 60 & 50 & 40 & 30 & 20 & 10 & 0\end{array}$

Figure S78. ${ }^{13} \mathrm{C}$ NMR spectrum of 9 in DMSO-d 6 


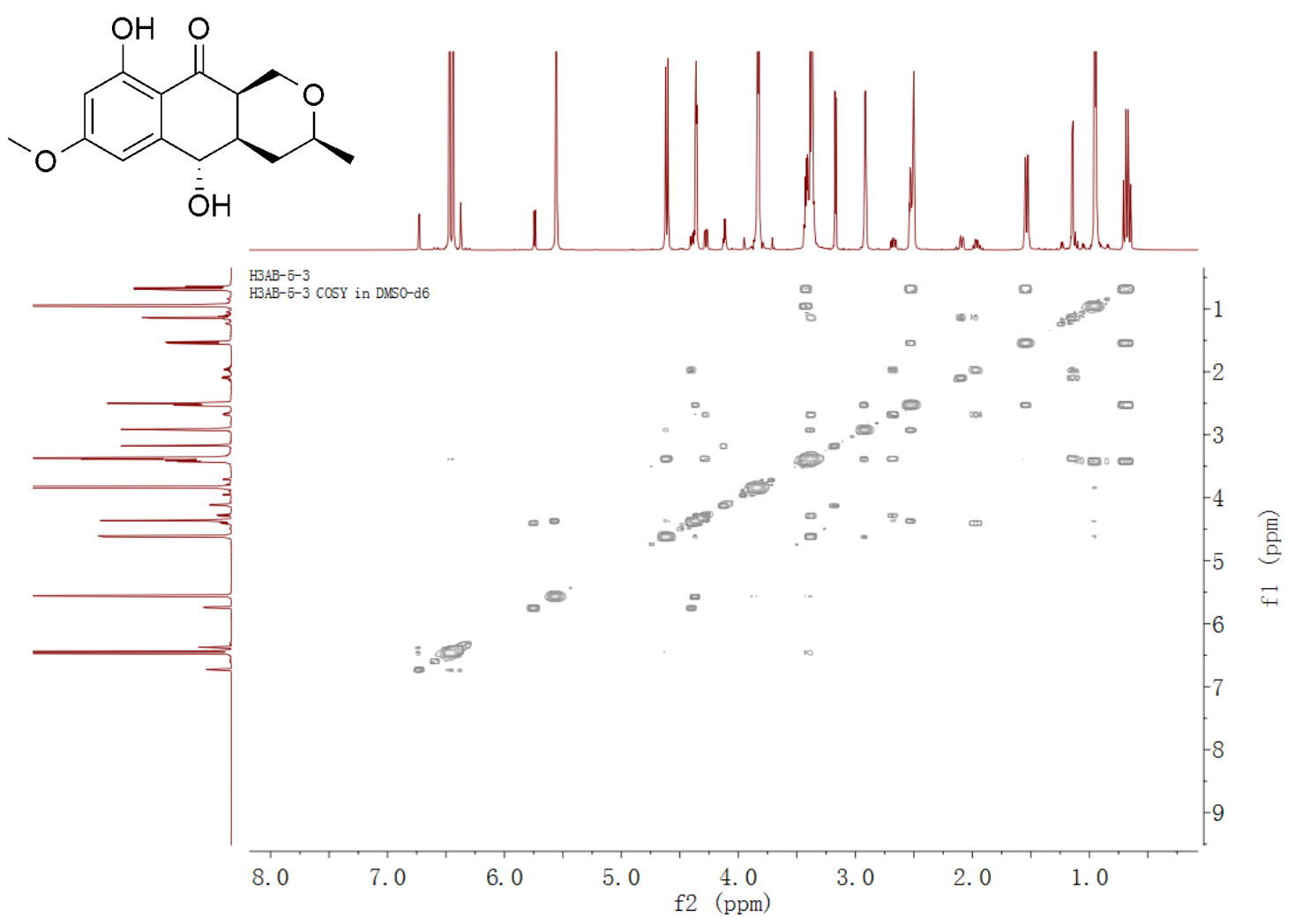

Figure S79. ${ }^{1} \mathrm{H}-{ }^{1} \mathrm{H}$ COSY spectrum of 9 in DMSO-d ${ }_{6}$

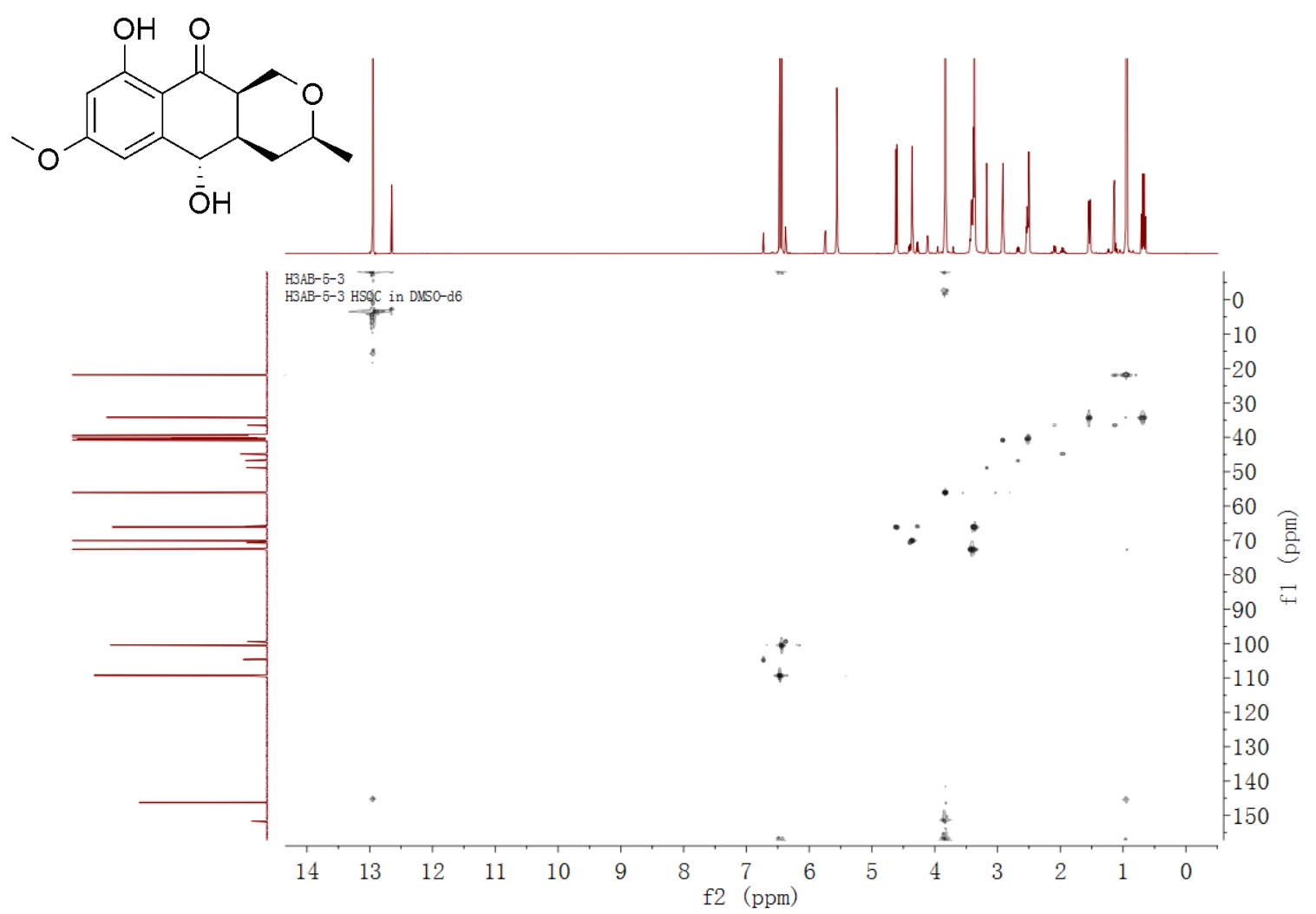

Figure S80. HSQC spectrum of 9 in DMSO- $\mathrm{d}_{6}$ 


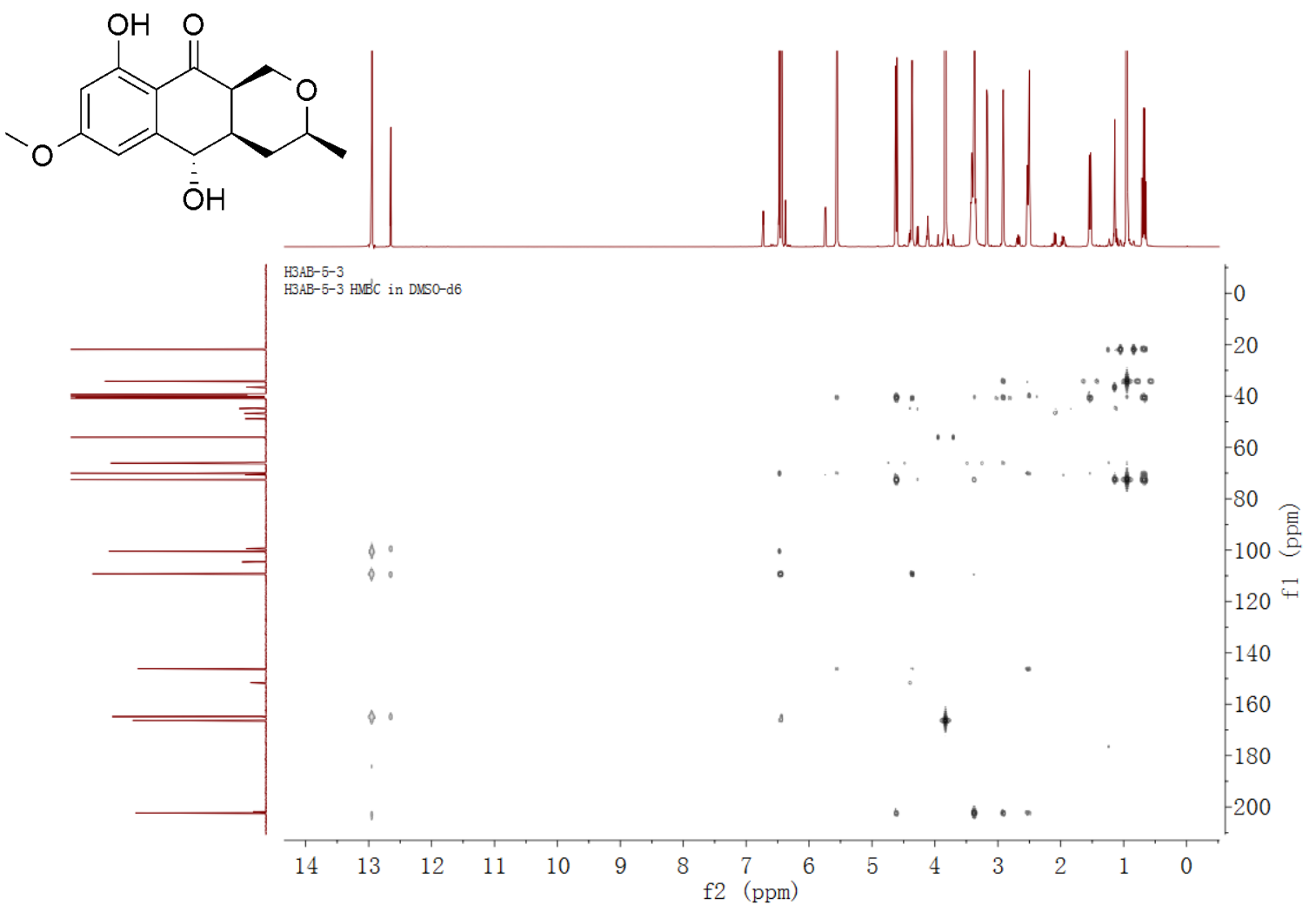

Figure S81. HMBC spectrum of 9 in DMSO-d 6

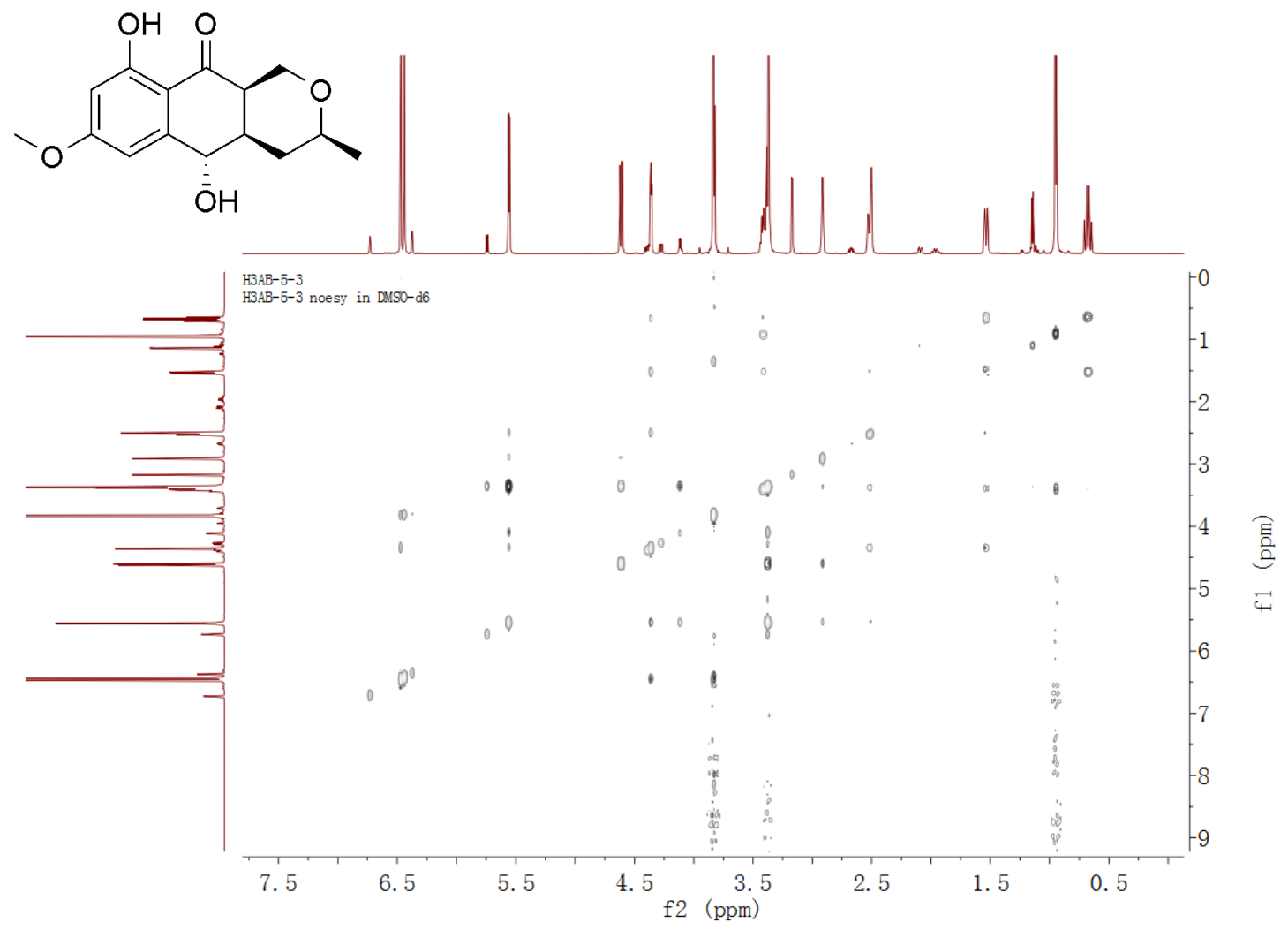

Figure S82. NOESY spectrum of 9 in DMSO- $\mathrm{d}_{6}$ 


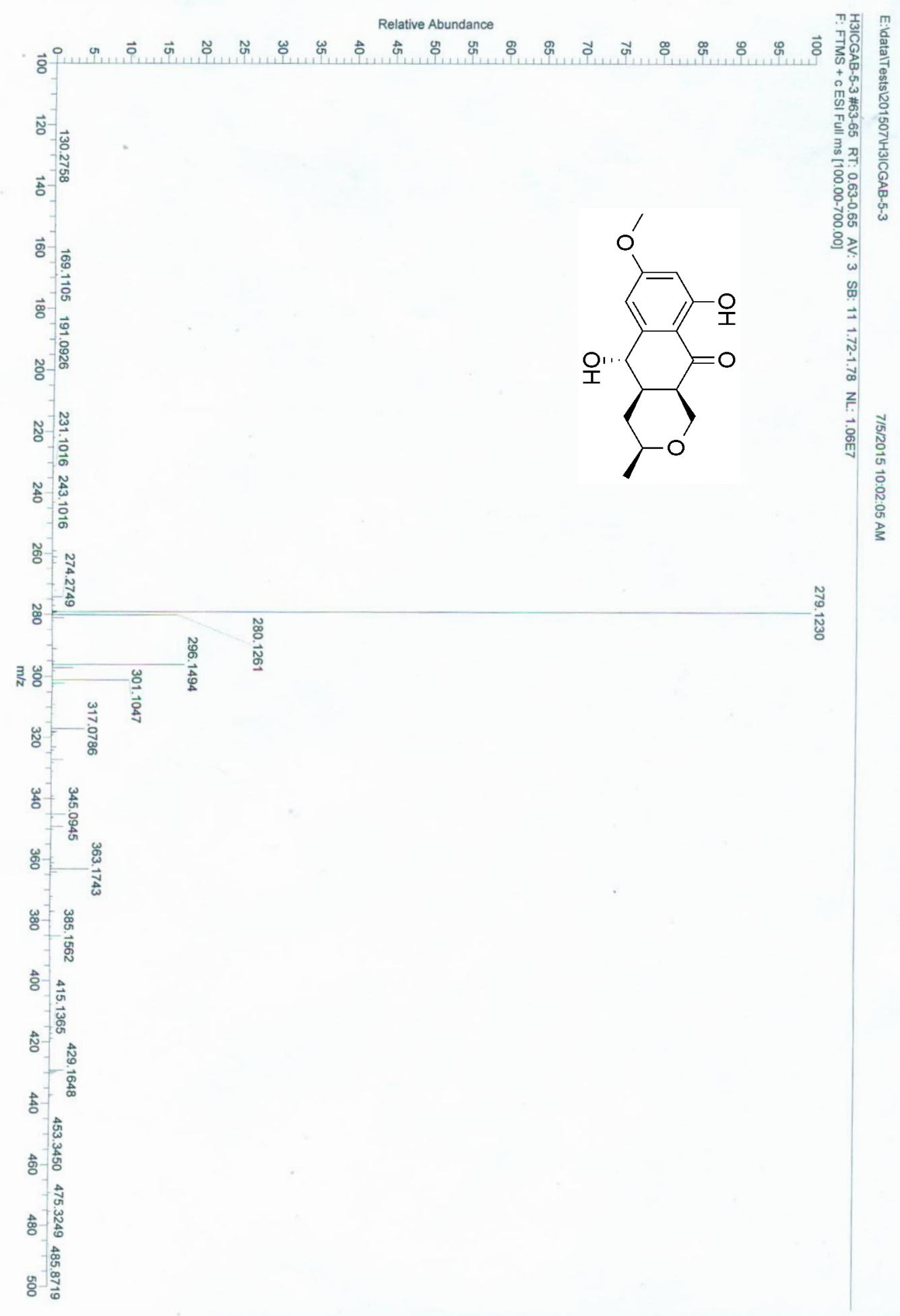

Figure S83. HRESIMS spectrum of 9 


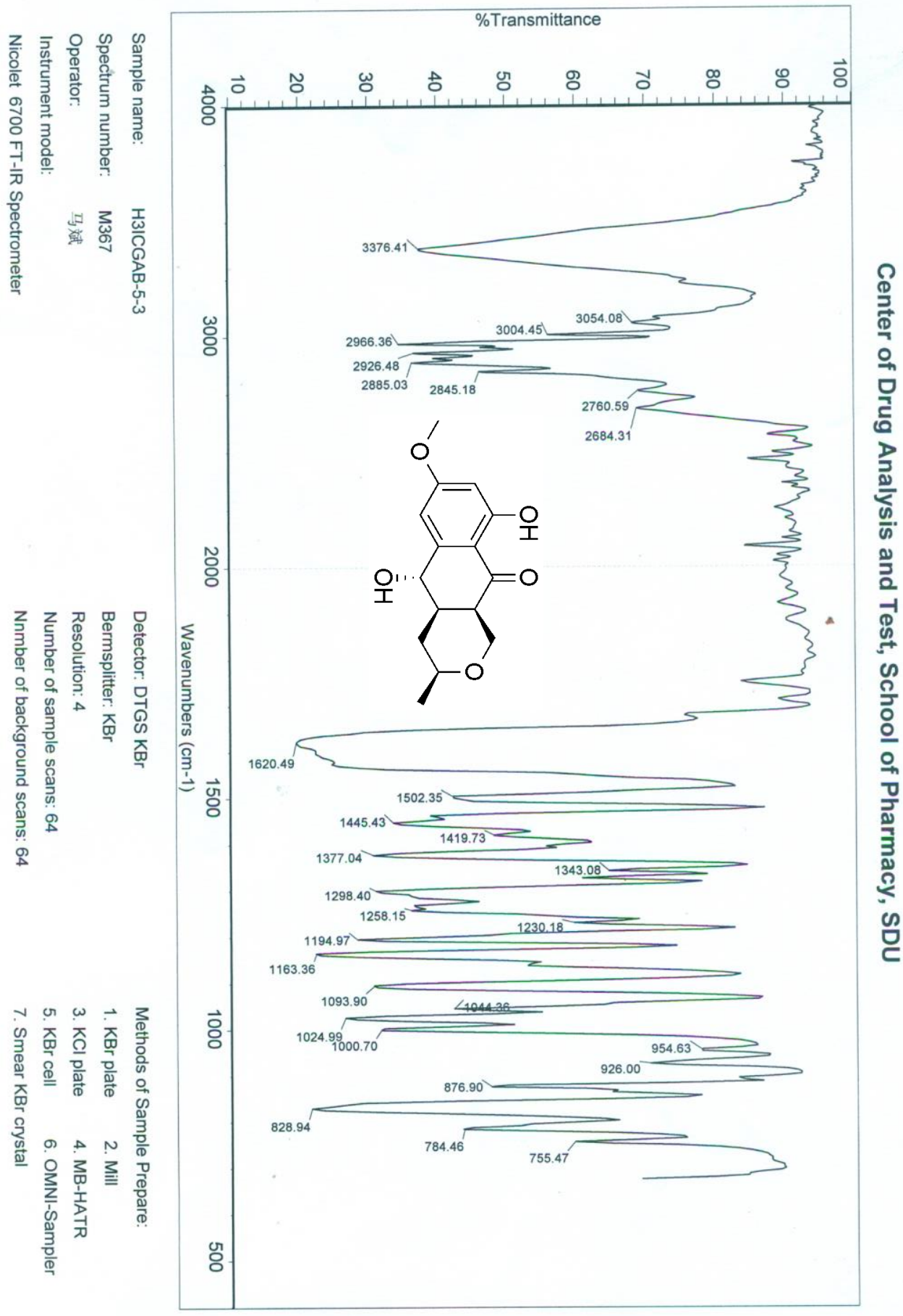

Figure S84. IR ( $\mathrm{KBr}$ disc) spectrum of 9 


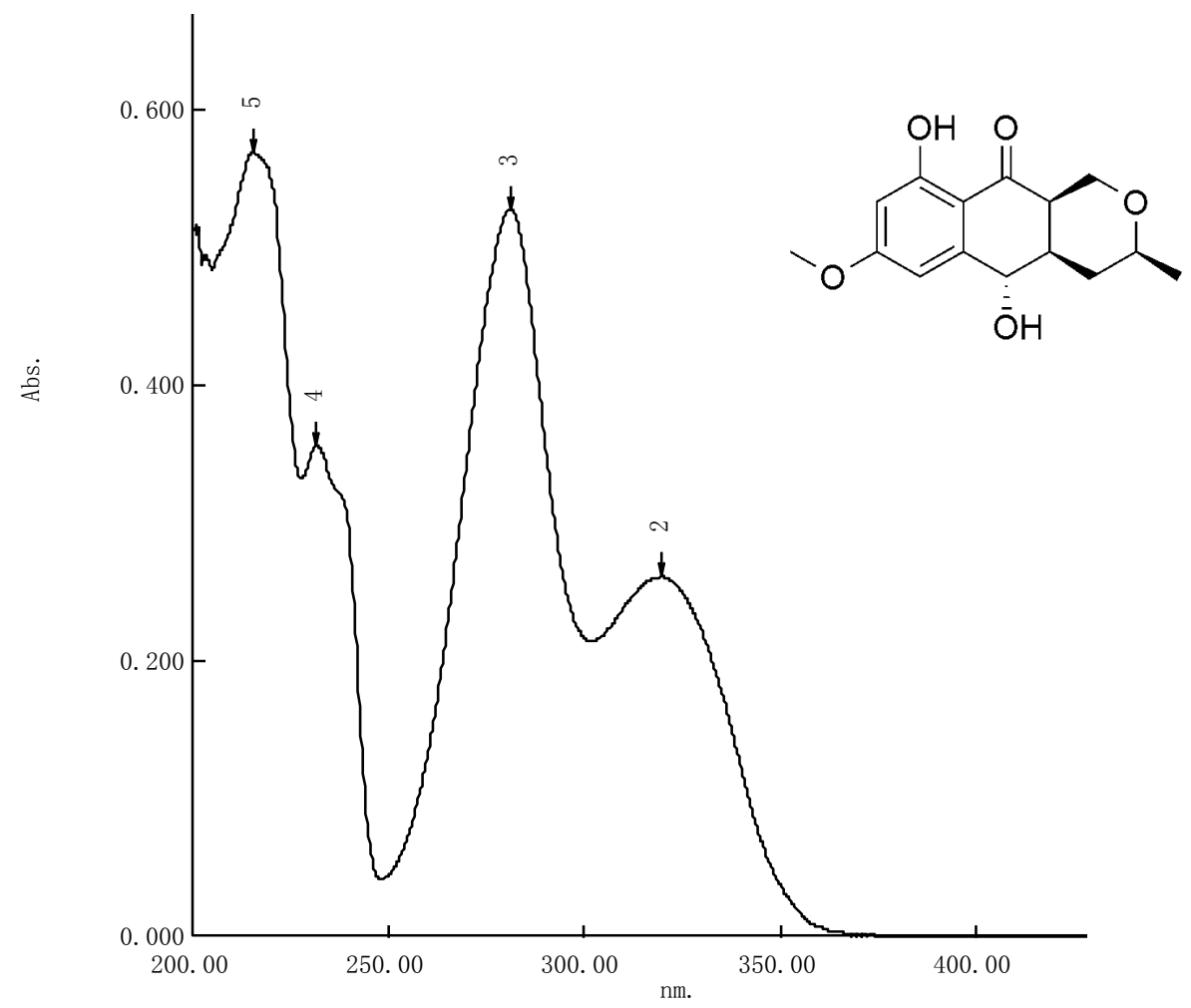

Figure S85. UV spectrum of 9

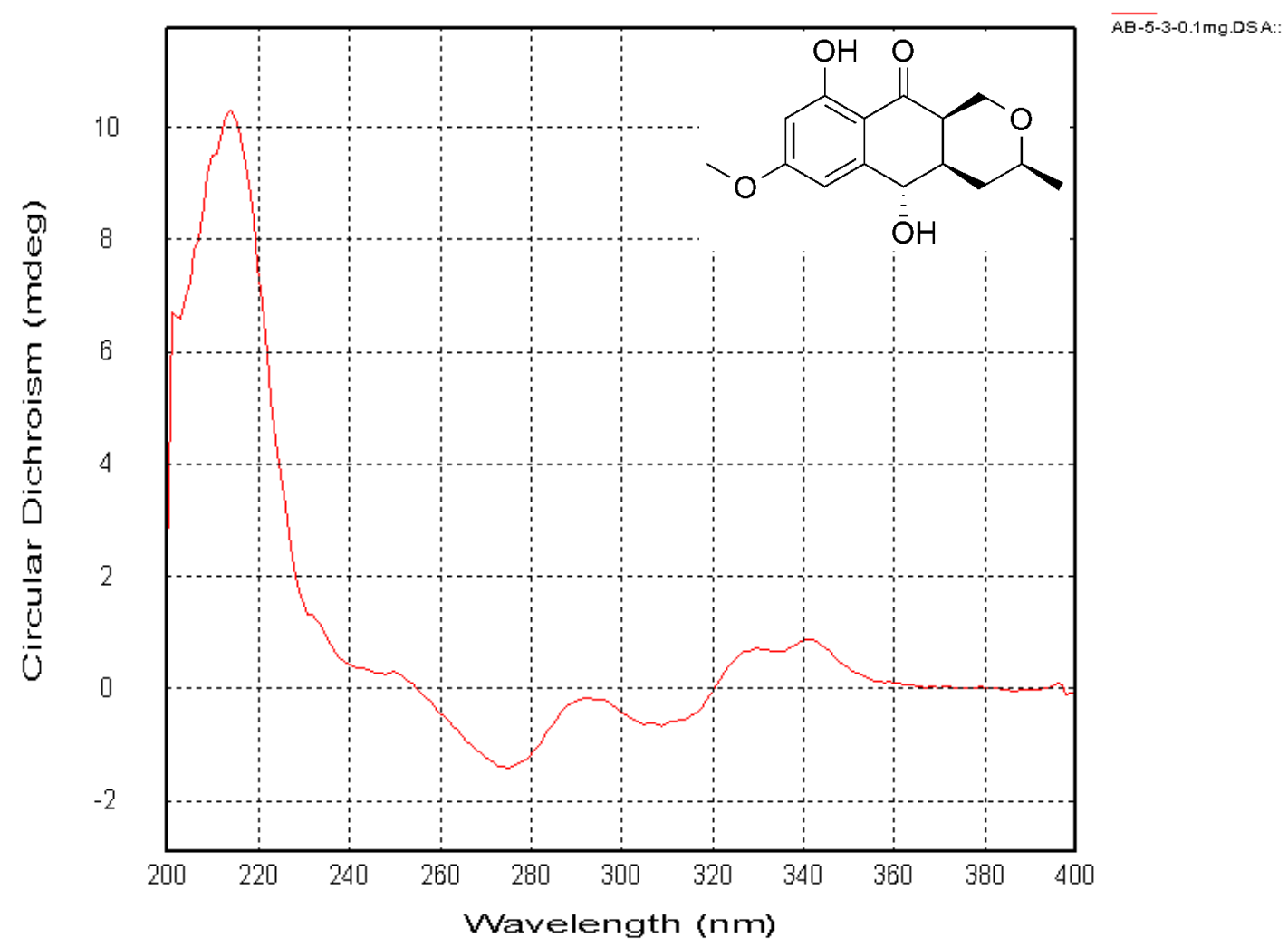

Figure S86. ECD spectrum of 9 


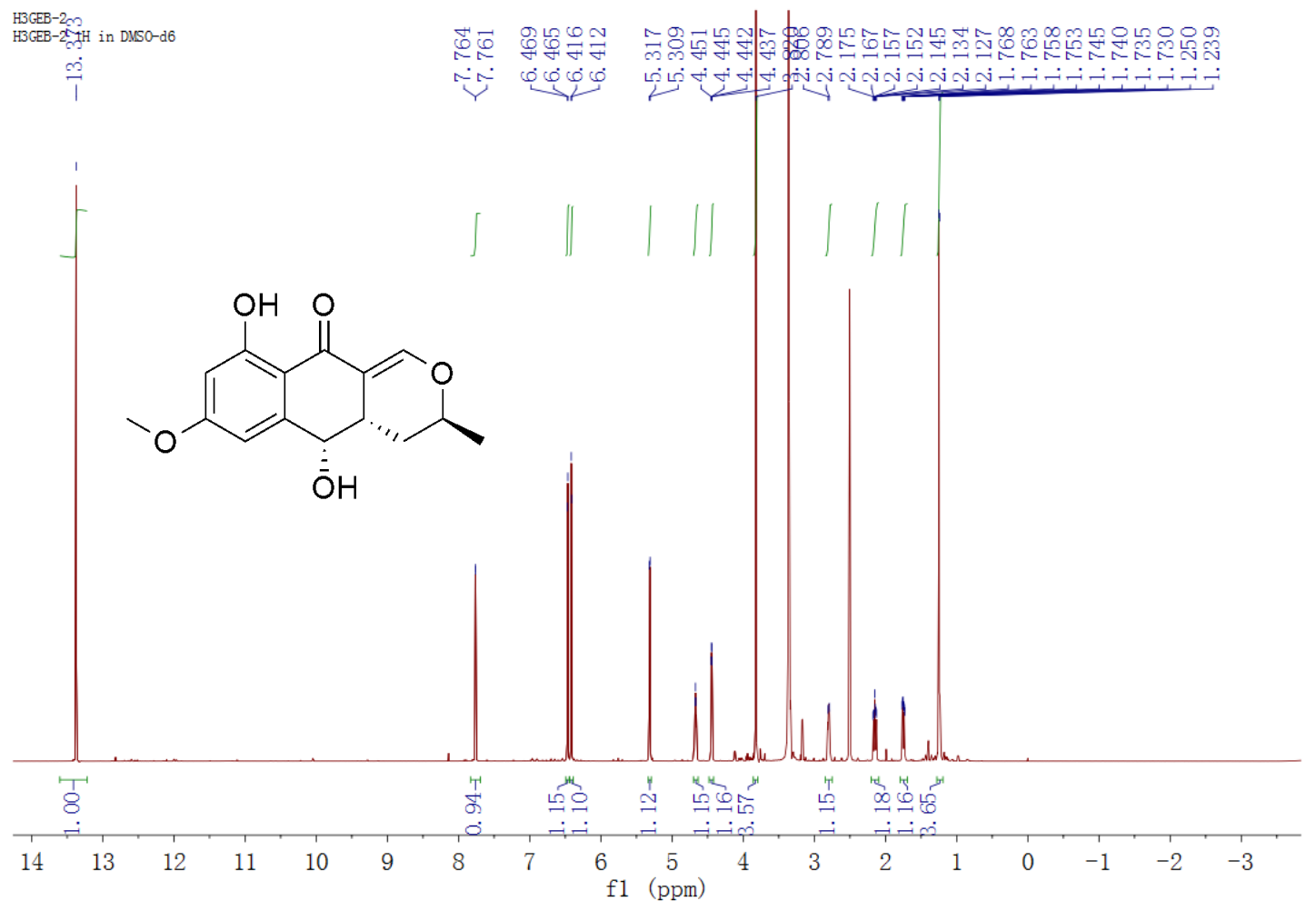

Figure S87. ${ }^{1} \mathrm{H}$ NMR spectrum of $\mathbf{1 0}$ in DMSO-d $\mathrm{d}_{6}$

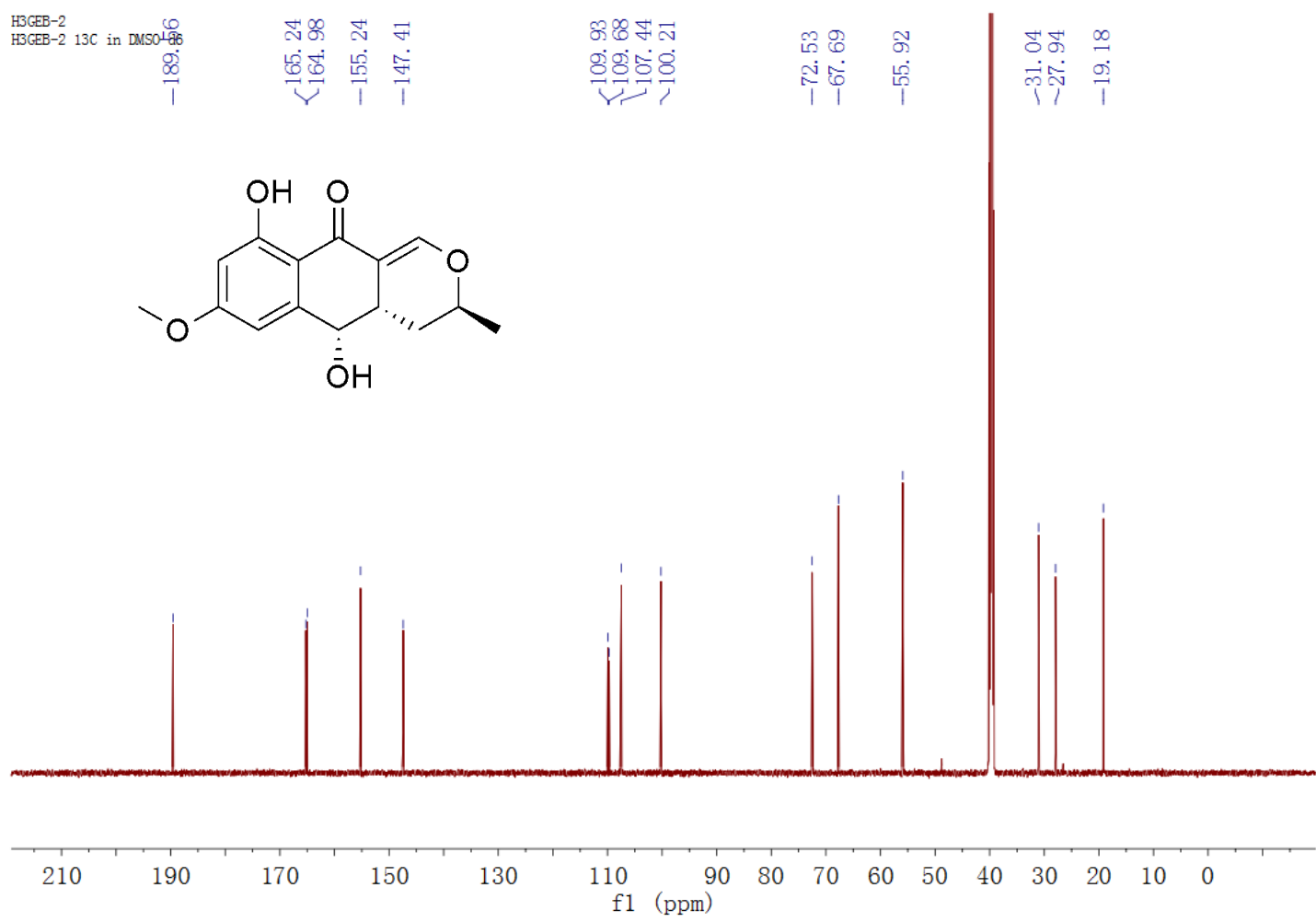

Figure S88. ${ }^{13} \mathrm{C}$ NMR spectrum of $\mathbf{1 0}$ in DMSO-d 6 


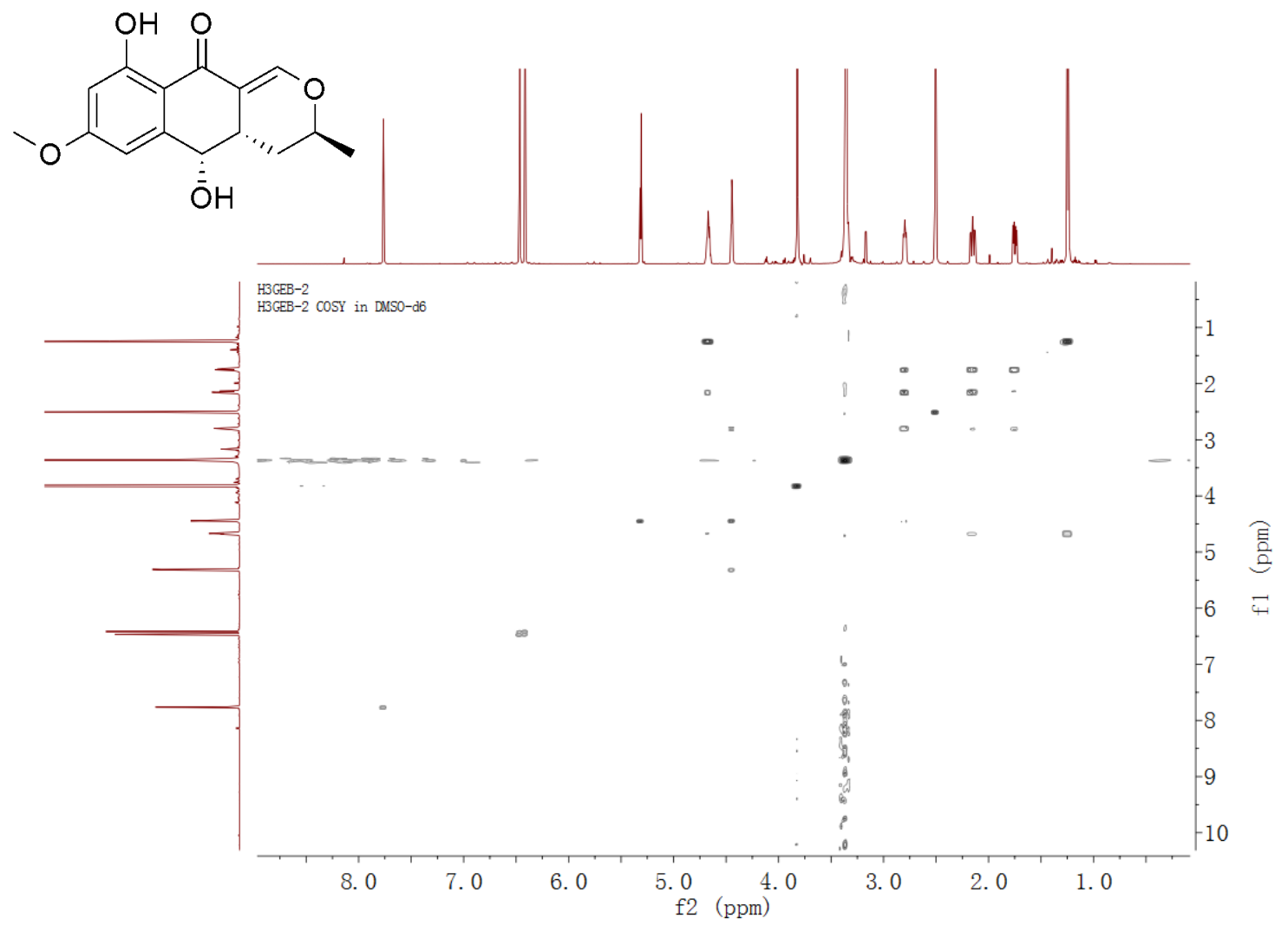

Figure S89. ${ }^{1} \mathrm{H}-{ }^{1} \mathrm{H}$ COSY spectrum of $\mathbf{1 0}$ in DMSO- $\mathrm{d}_{6}$

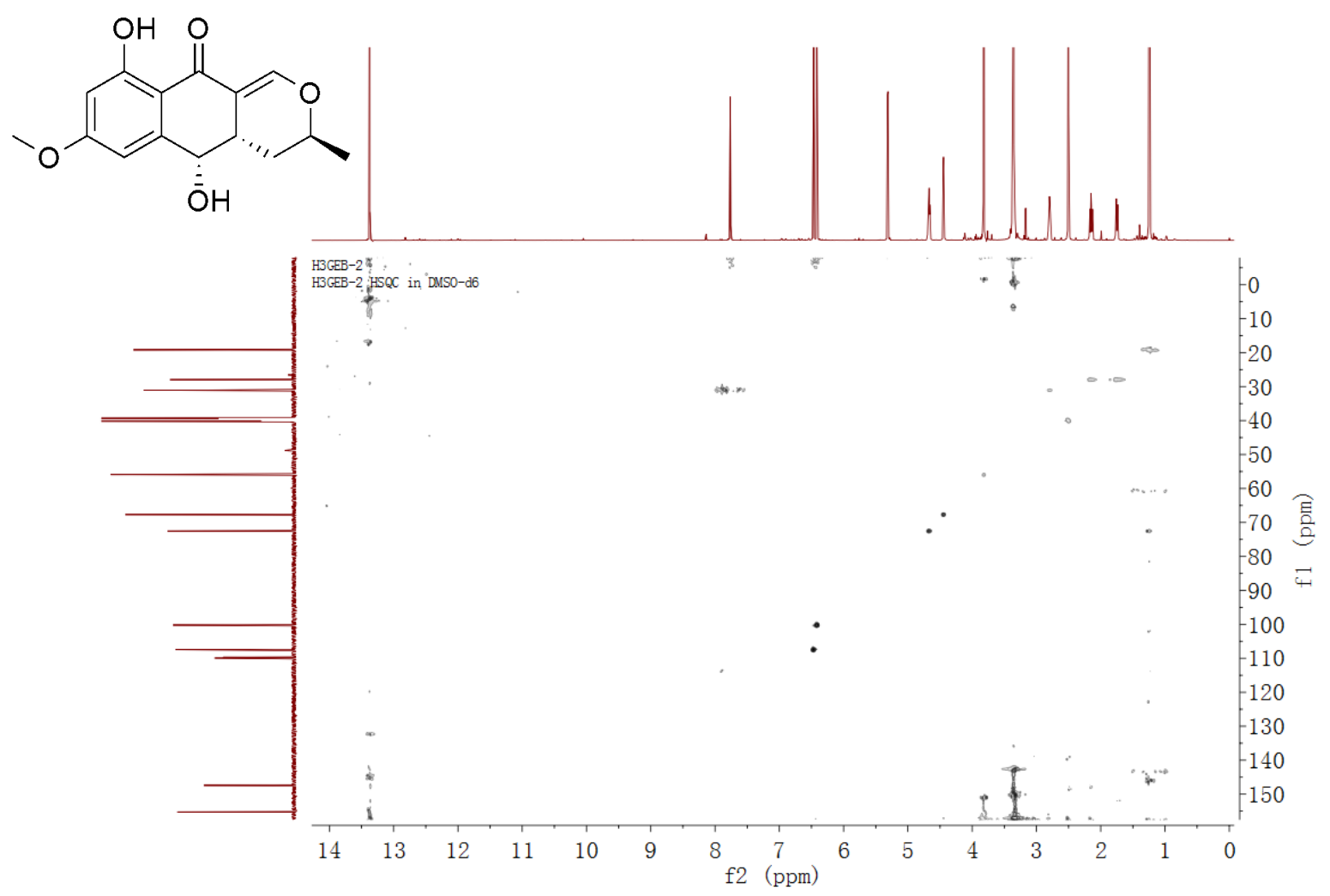

Figure S90. HSQC spectrum of $\mathbf{1 0}$ in DMSO- $\mathrm{d}_{6}$ 


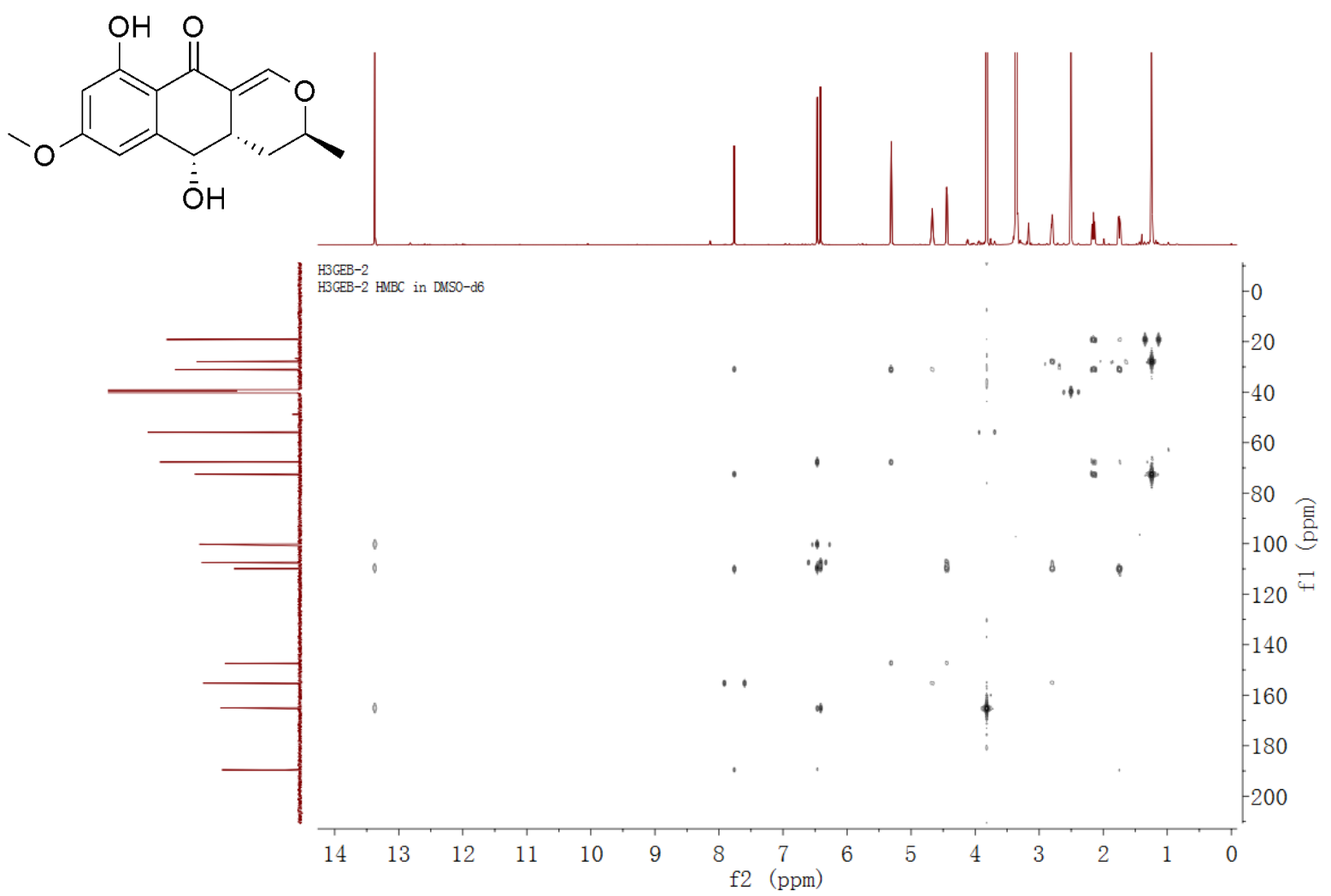

Figure S91. HMBC spectrum of $\mathbf{1 0}$ in DMSO-d $\mathrm{d}_{6}$

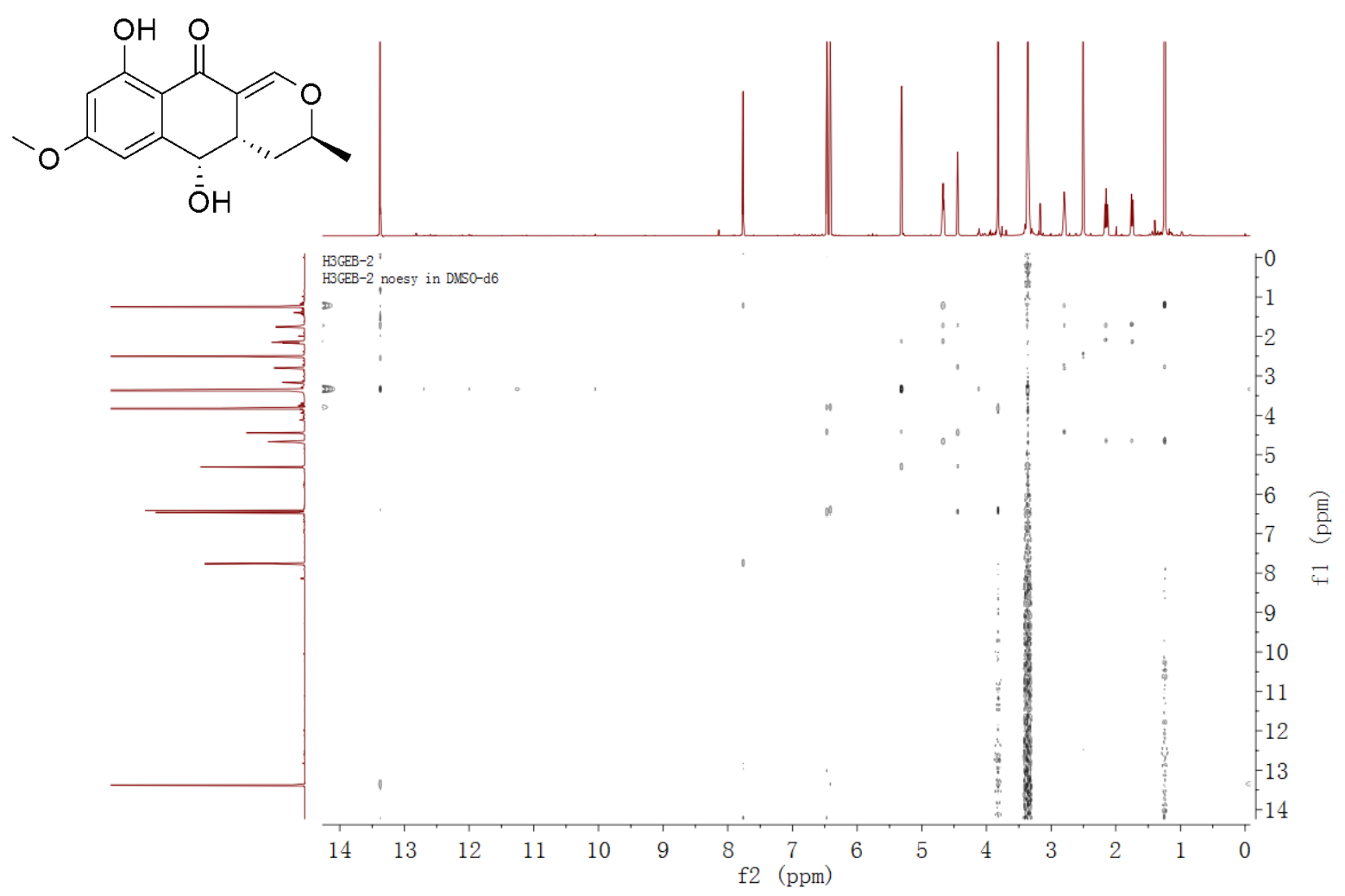

Figure S92. NOESY spectrum of $\mathbf{1 0}$ in DMSO-d 6 


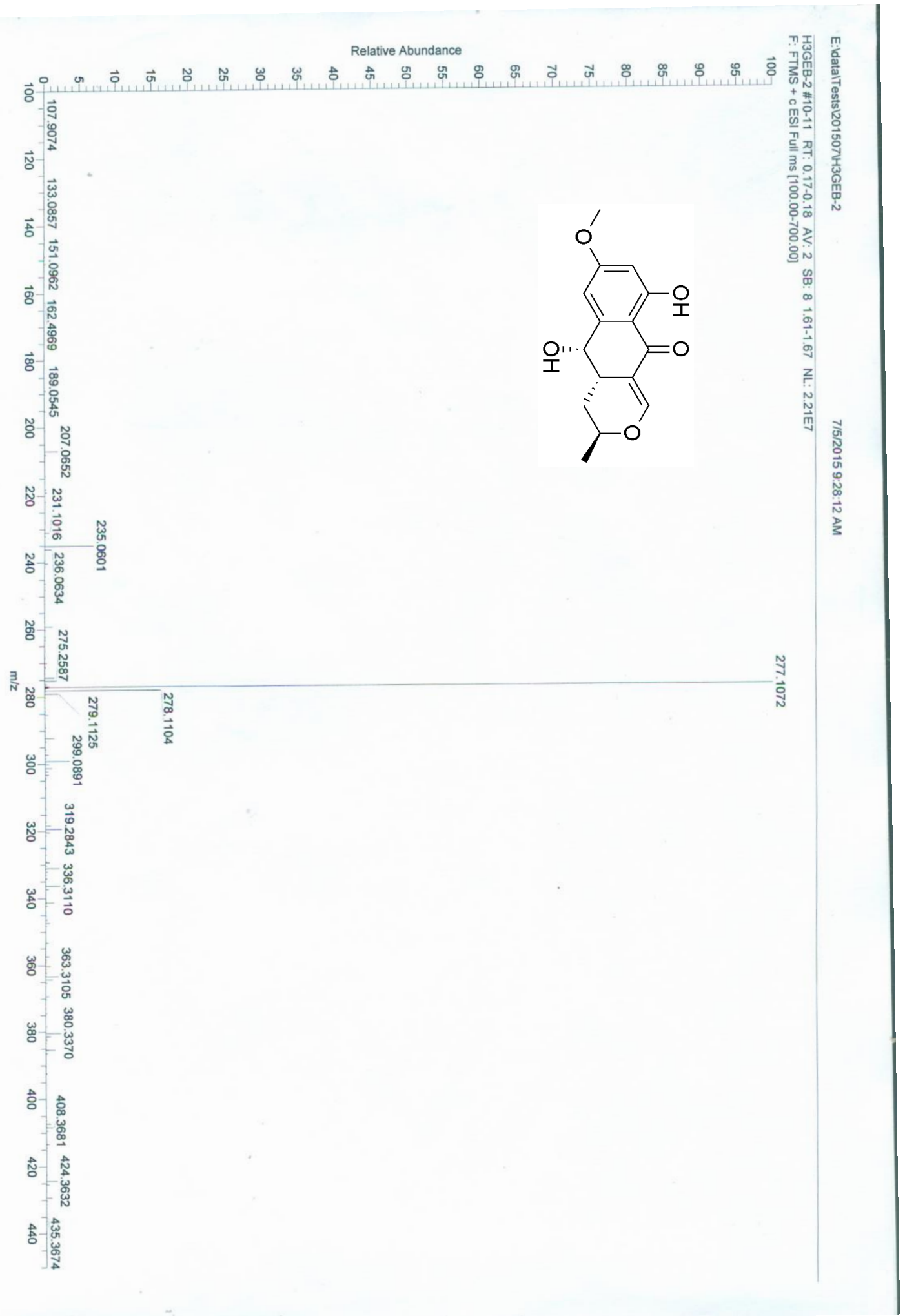

Figure S93. HRESIMS spectrum of $\mathbf{1 0}$ 


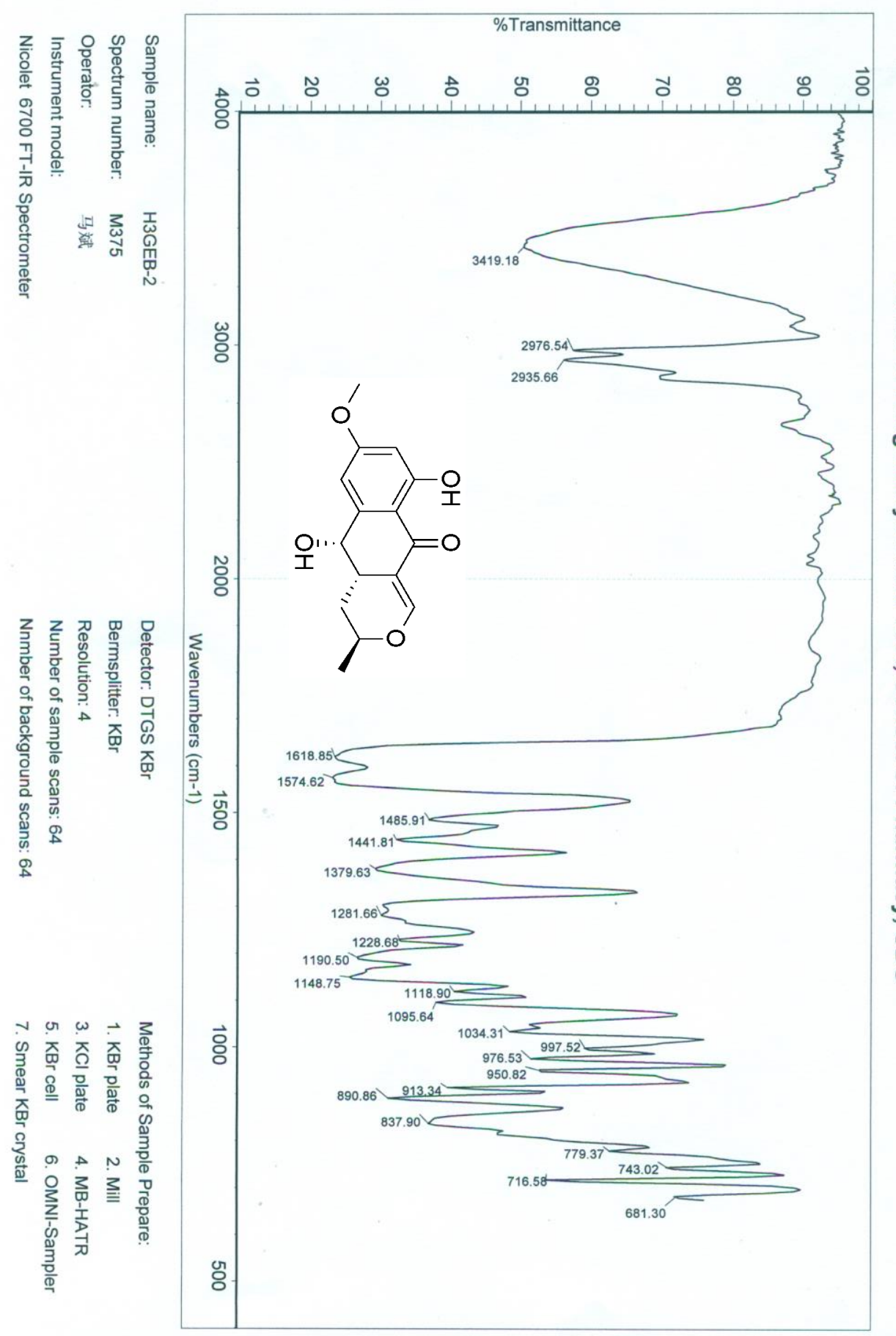

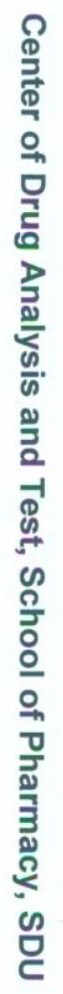

Figure S94. IR ( $\mathrm{KBr}$ disc) spectrum of $\mathbf{1 0}$ 


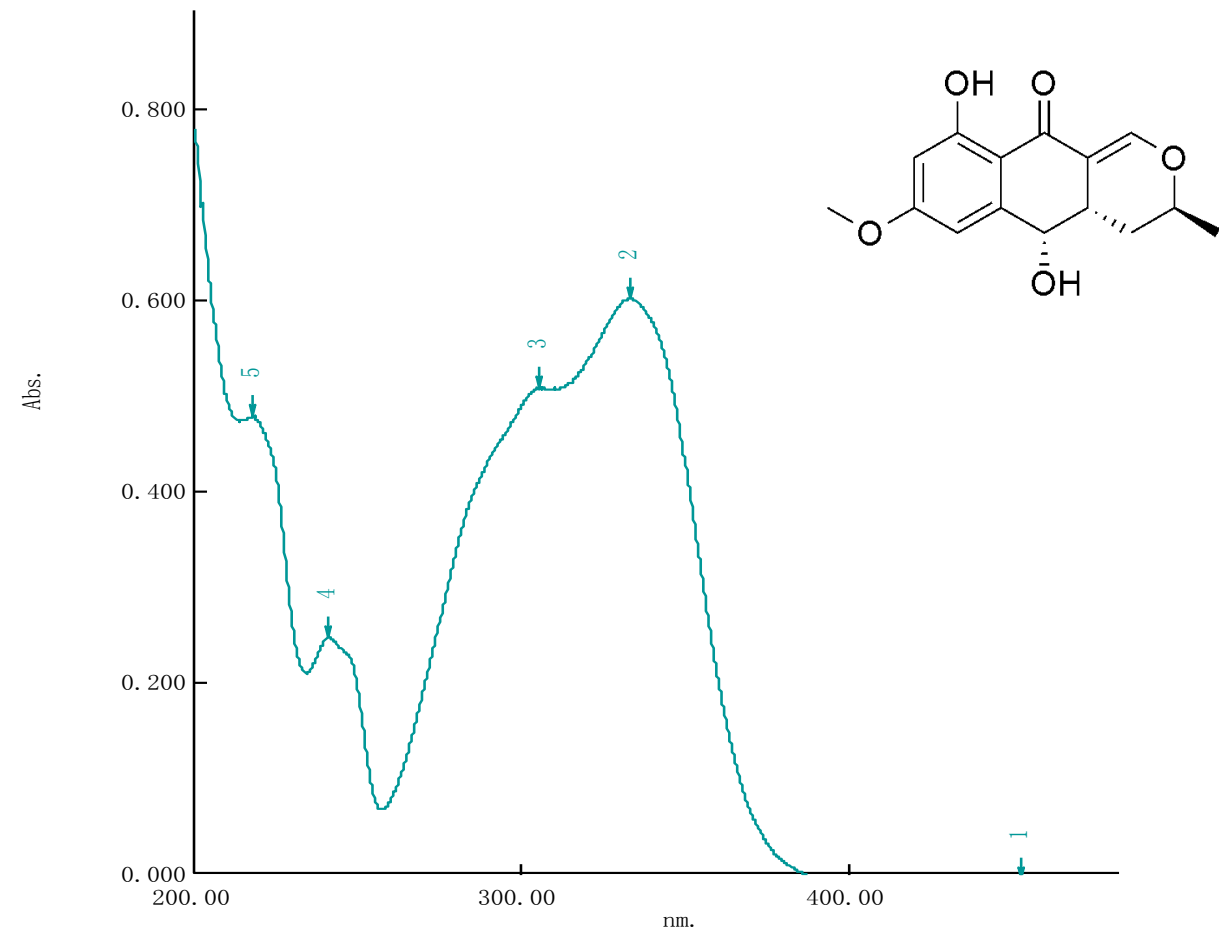

Figure S95. UV spectrum of $\mathbf{1 0}$

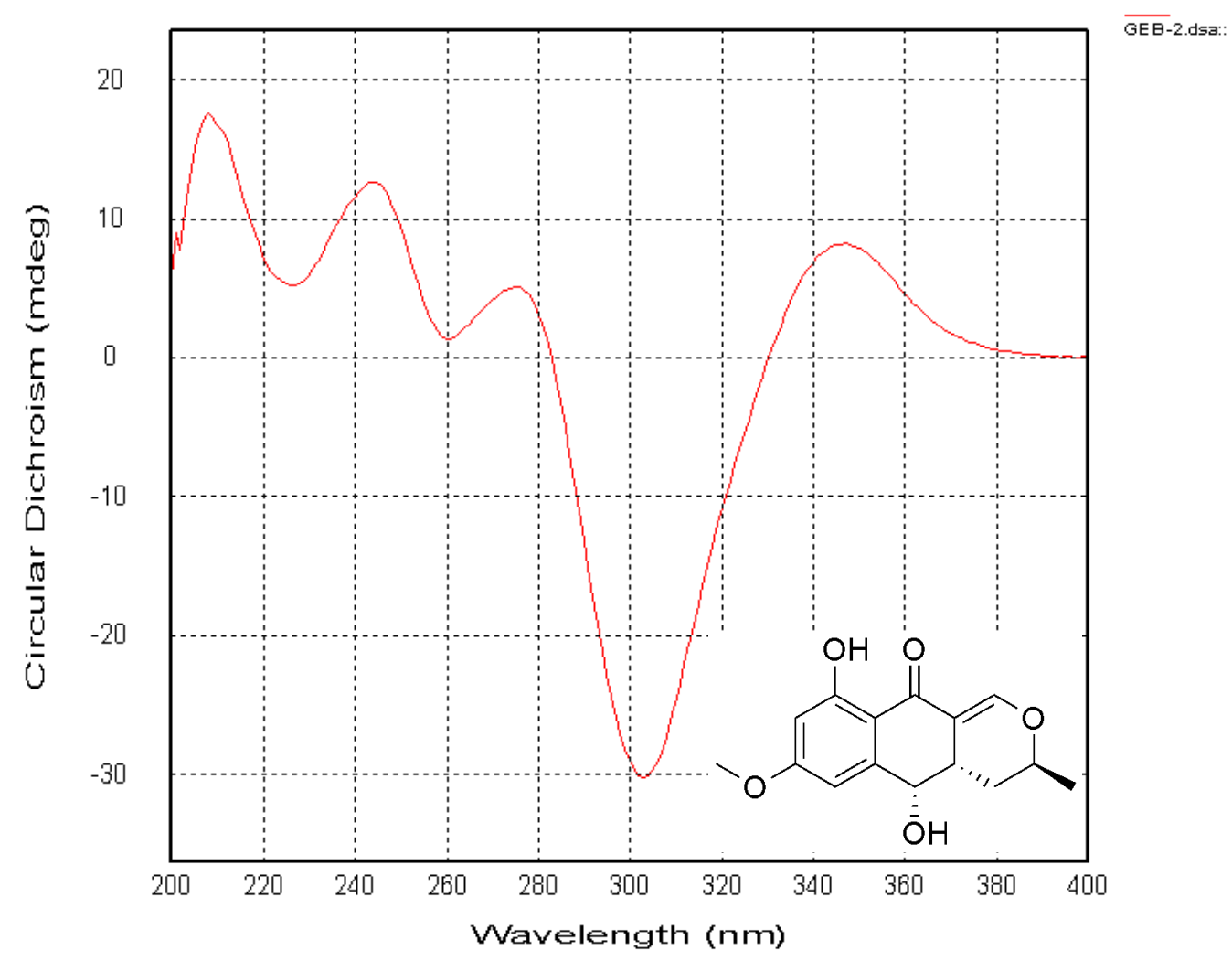

Figure S96. ECD spectrum of $\mathbf{1 0}$ 


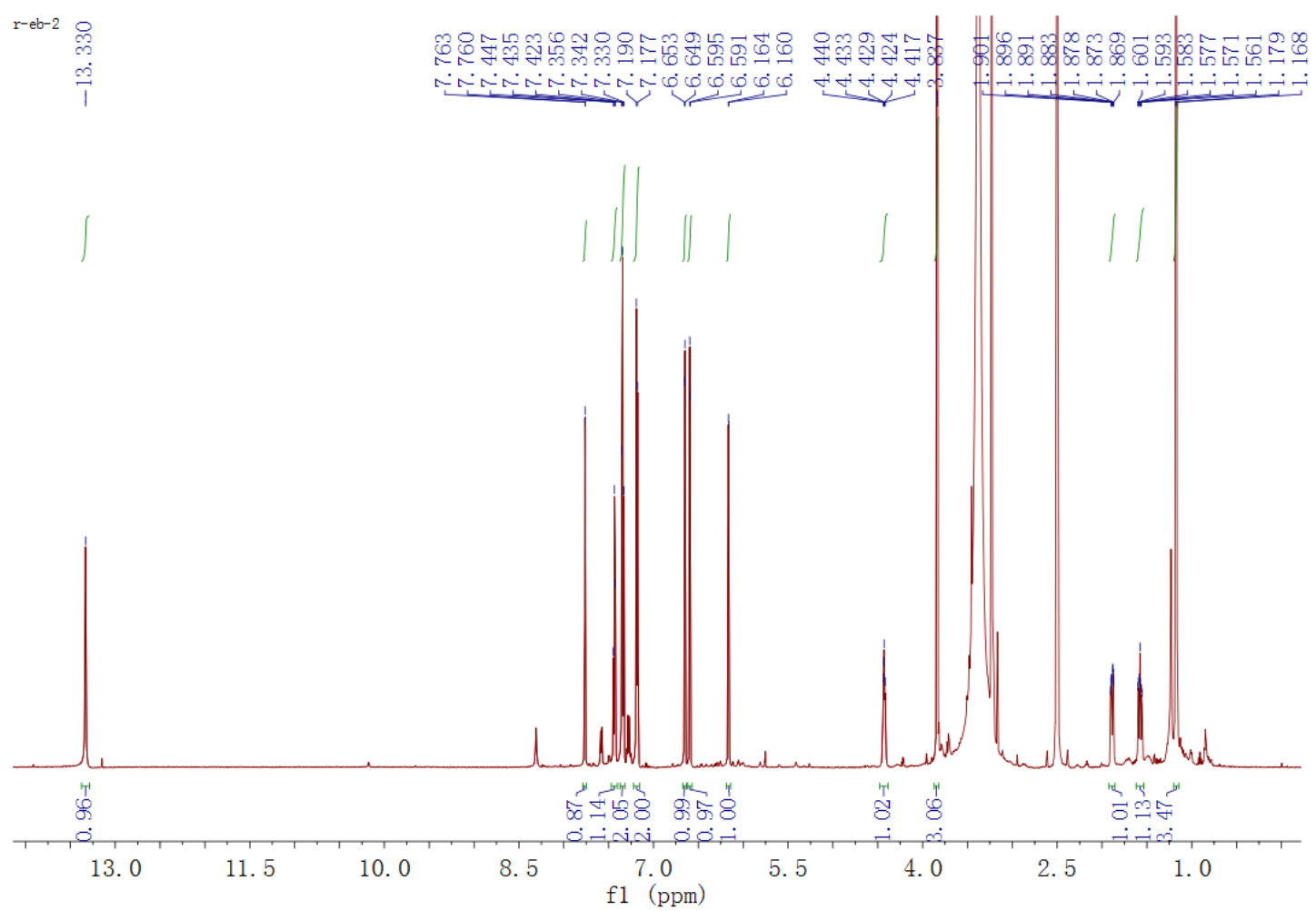

Figure S97. ${ }^{1} \mathrm{H}$ NMR spectrum of 10a in DMSO-d 6

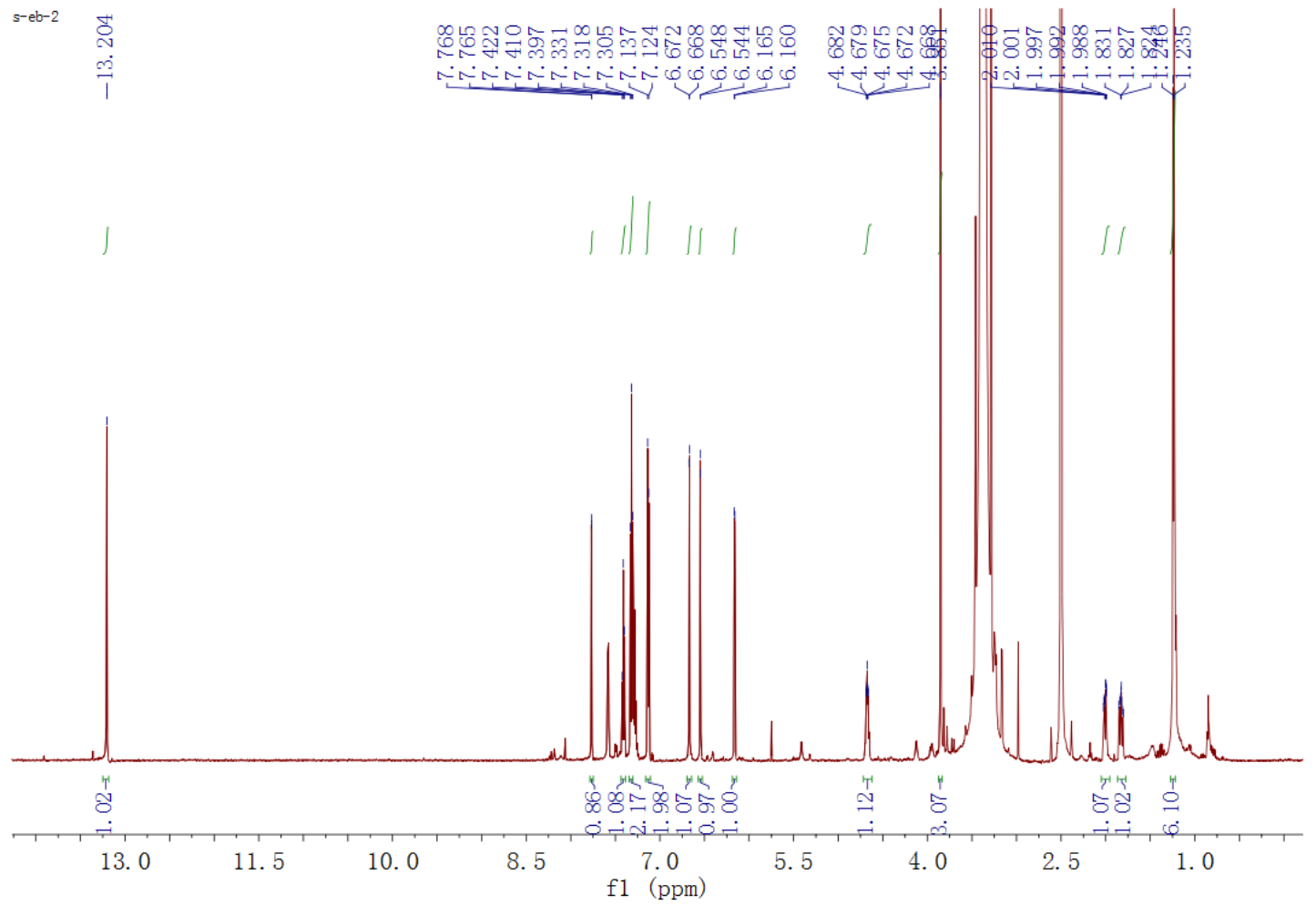

Figure S98. ${ }^{1} \mathrm{H}$ NMR spectrum of $\mathbf{1 0 b}$ in DMSO- $\mathrm{d}_{6}$ 


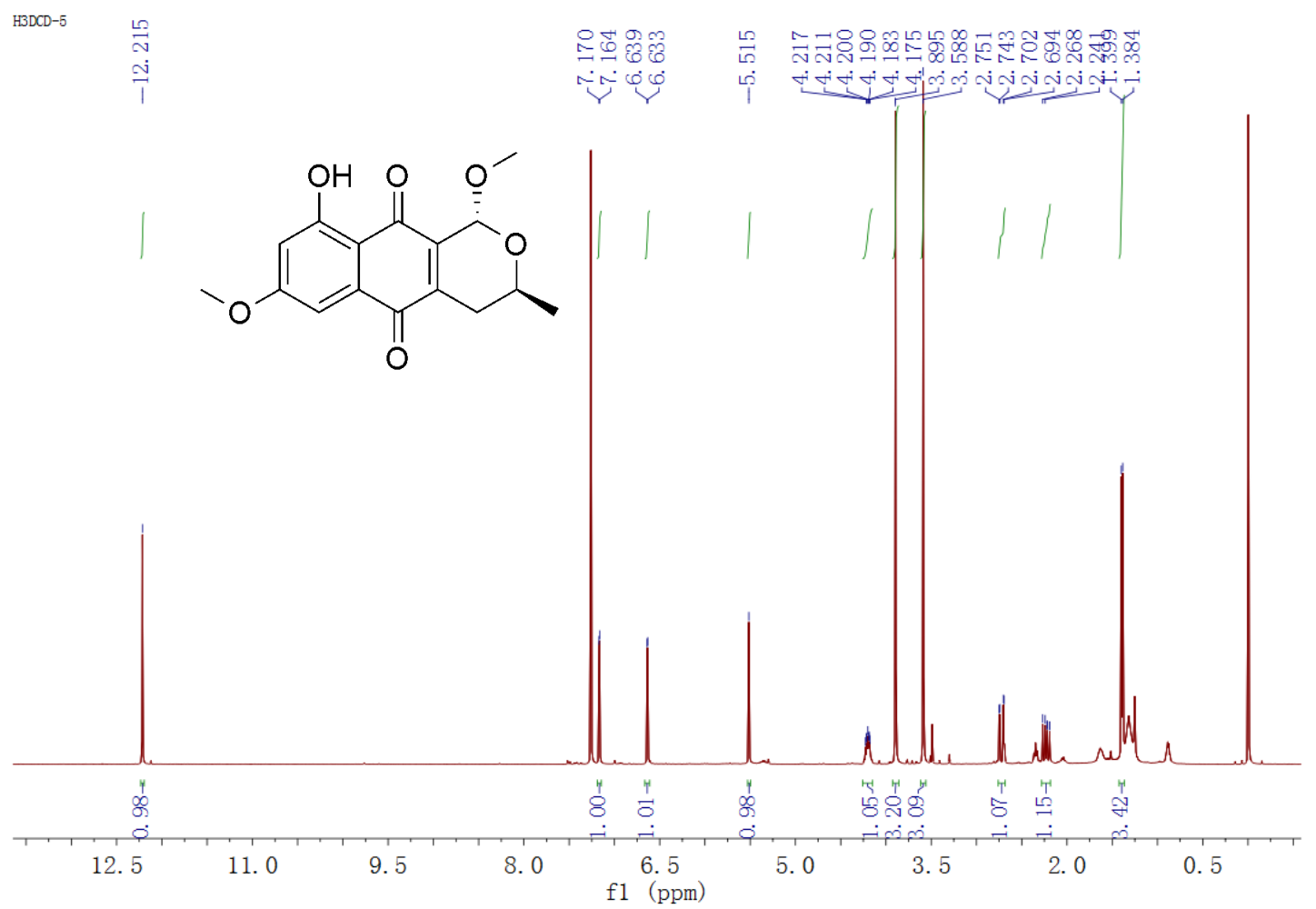

Figure S99. ${ }^{1} \mathrm{H}$ NMR spectrum of $\mathbf{1 1}$ in $\mathrm{CDCl}_{3}$

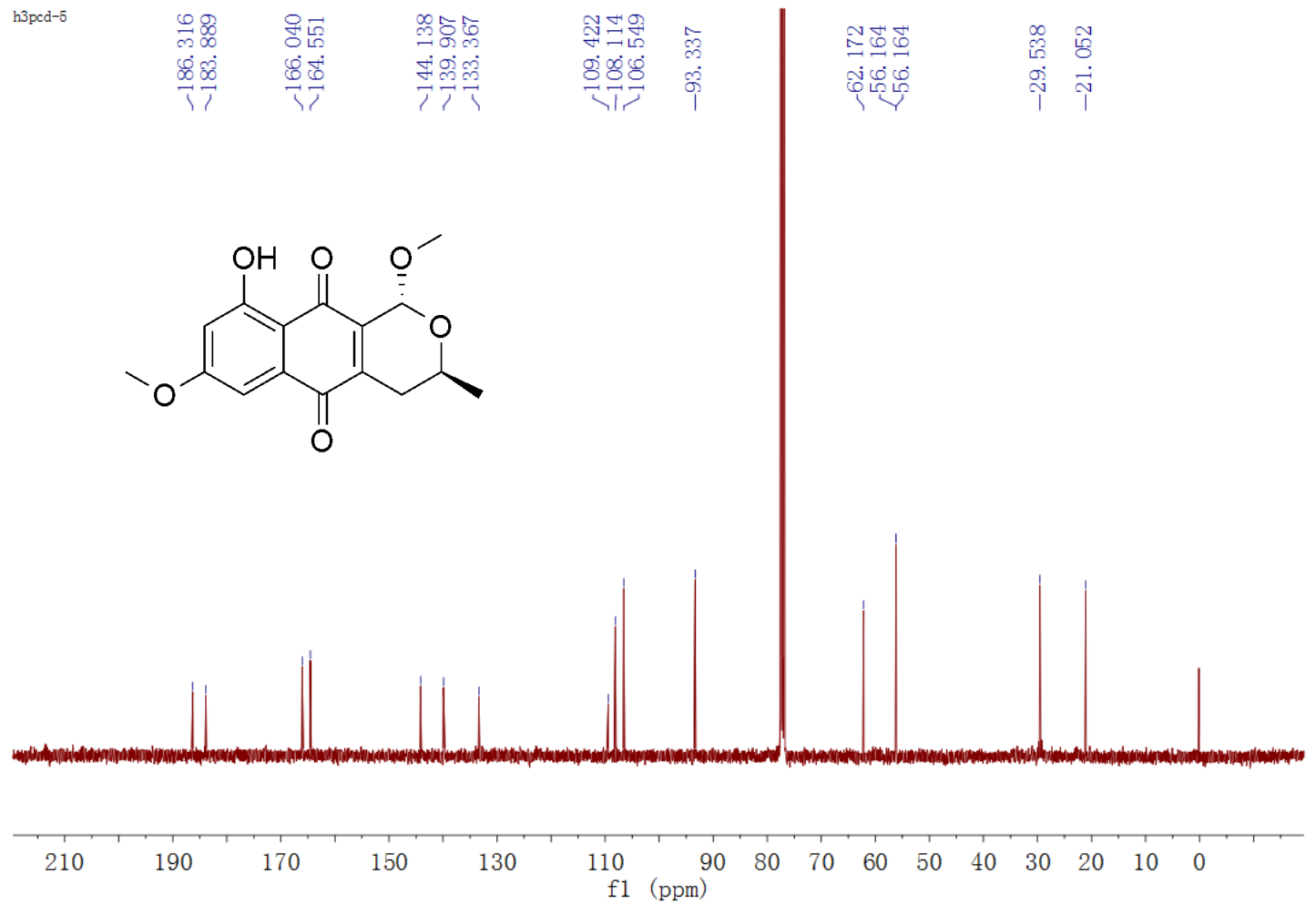

Figure S100. ${ }^{13} \mathrm{C}$ NMR spectrum of $\mathbf{1 1}$ in $\mathrm{CDCl}_{3}$ 


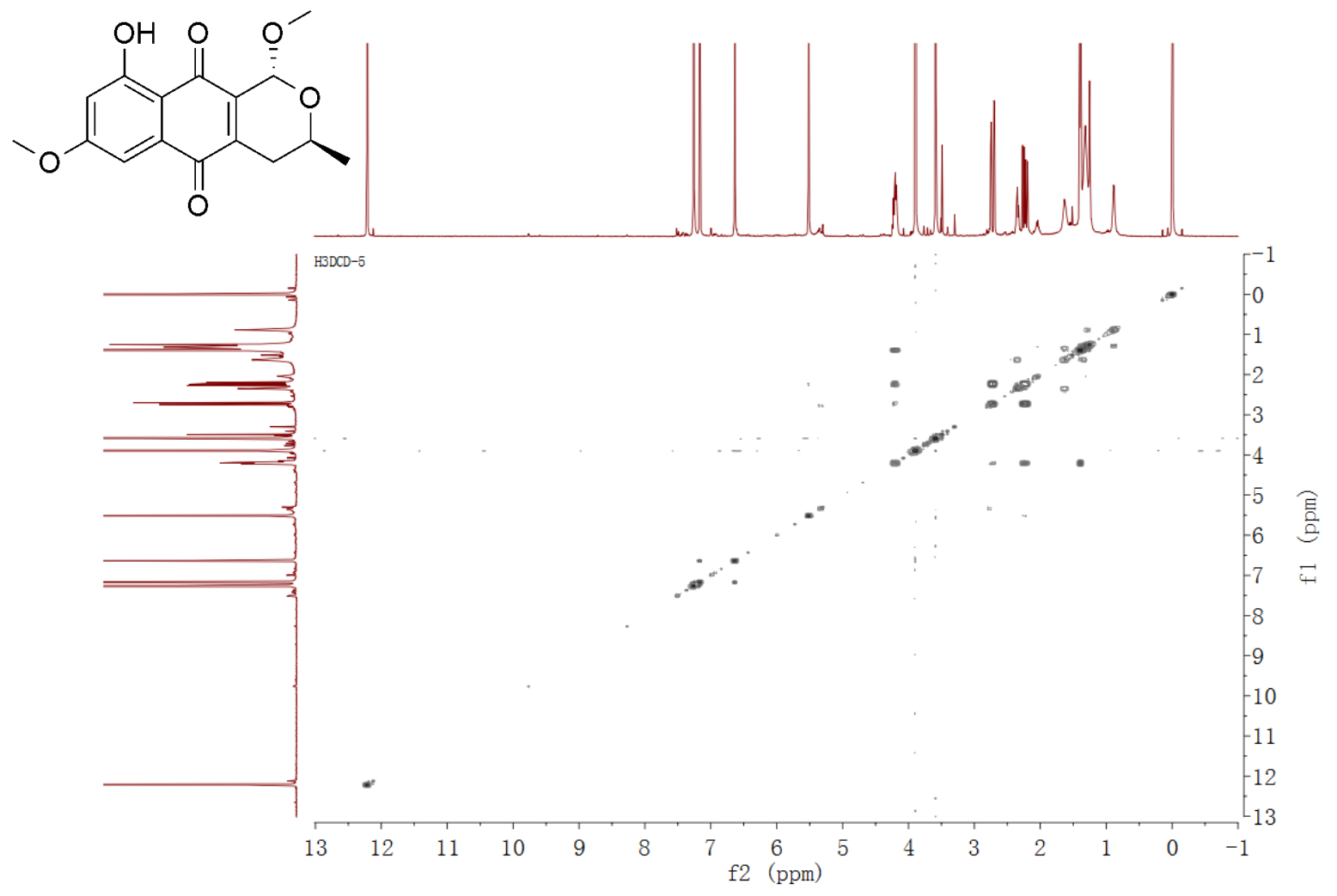

Figure S101. ${ }^{1} \mathrm{H}-{ }^{1} \mathrm{H}$ COSY spectrum of $\mathbf{1 1}$ in $\mathrm{CDCl}_{3}$<smiles>COc1cc(O)c2c(c1)C(=O)C1=C(C2=O)C(OC)OC(C)C1</smiles>

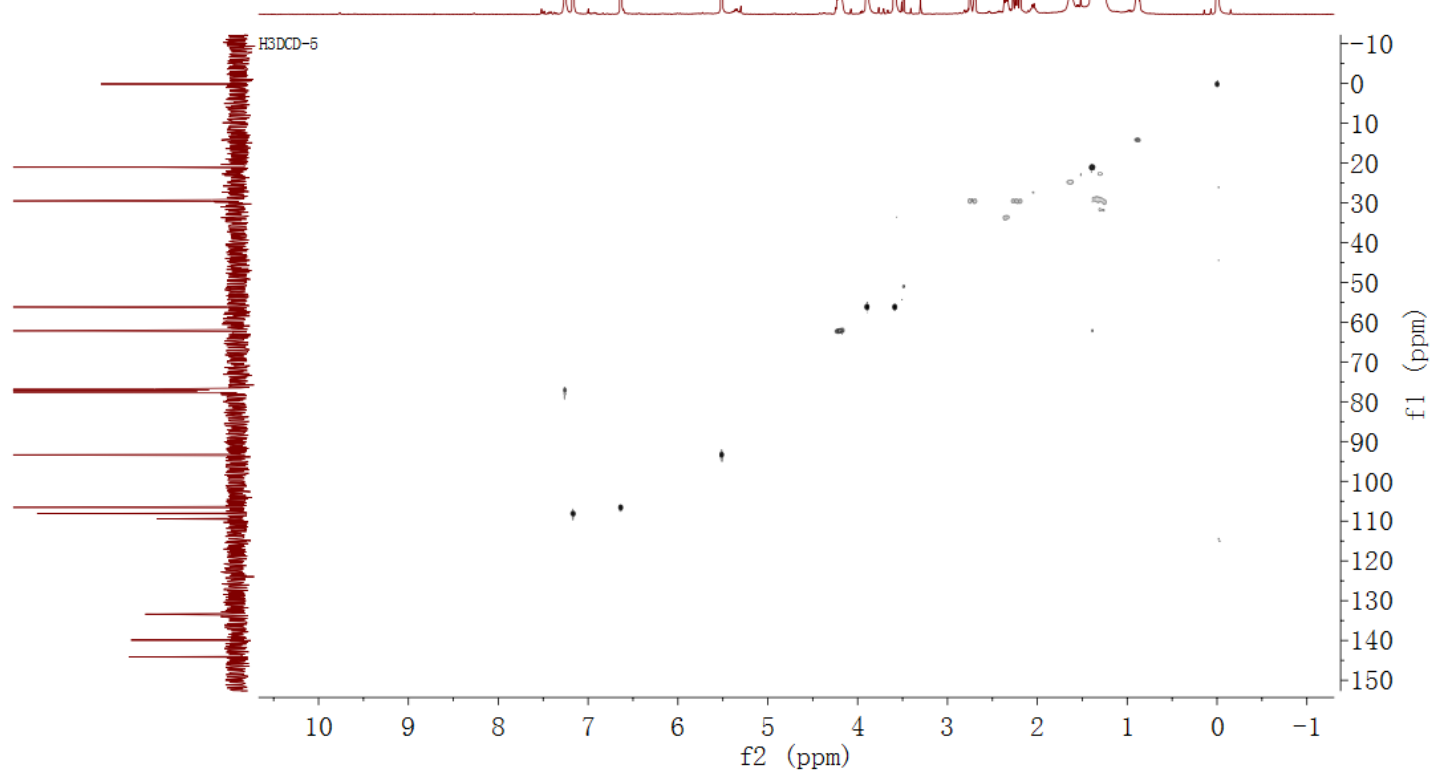

Figure S102. HSQC spectrum of $\mathbf{1 1}$ in $\mathrm{CDCl}_{3}$ 


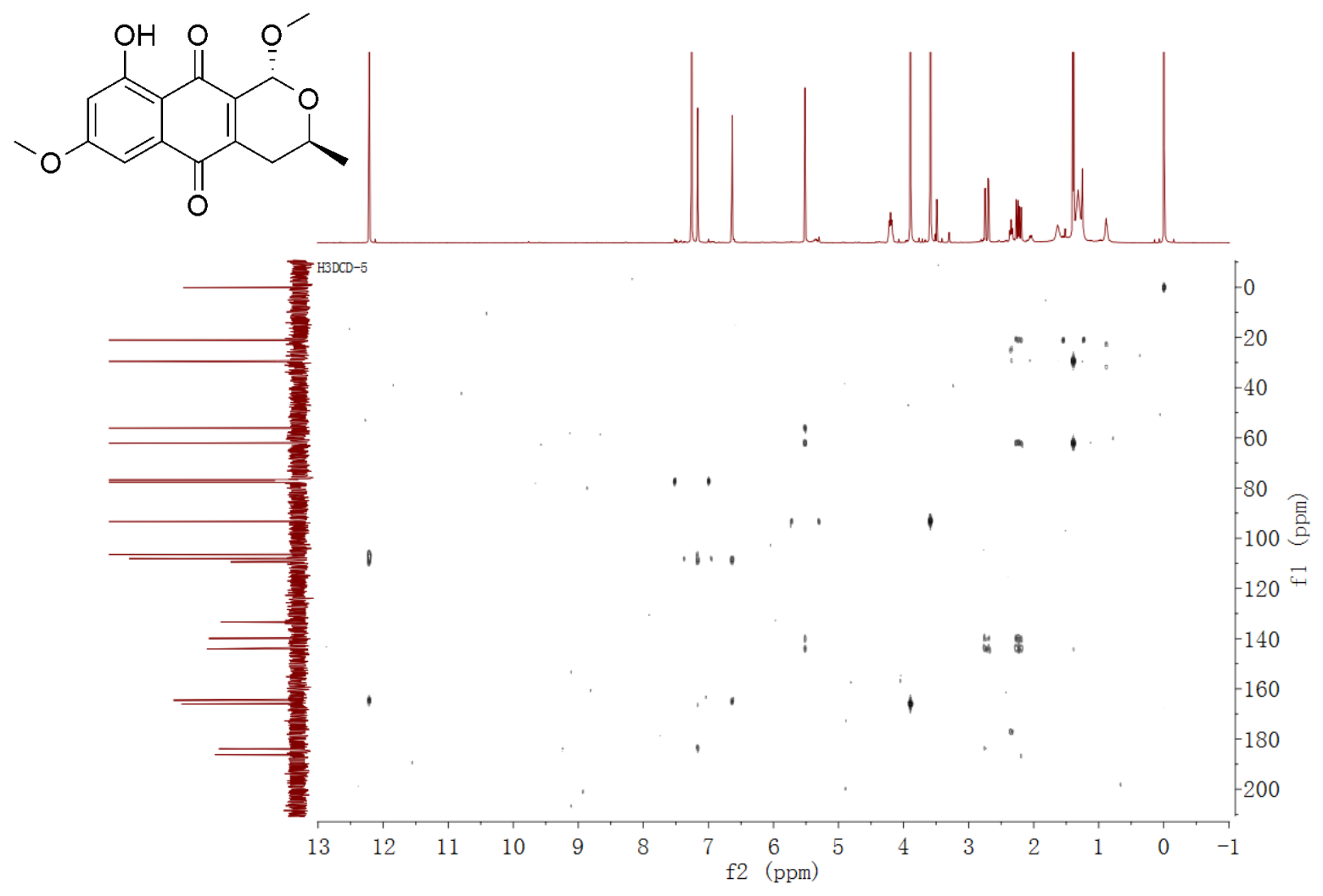

Figure S103.HMBC spectrum of $\mathbf{1 1}$ in $\mathrm{CDCl}_{3}$

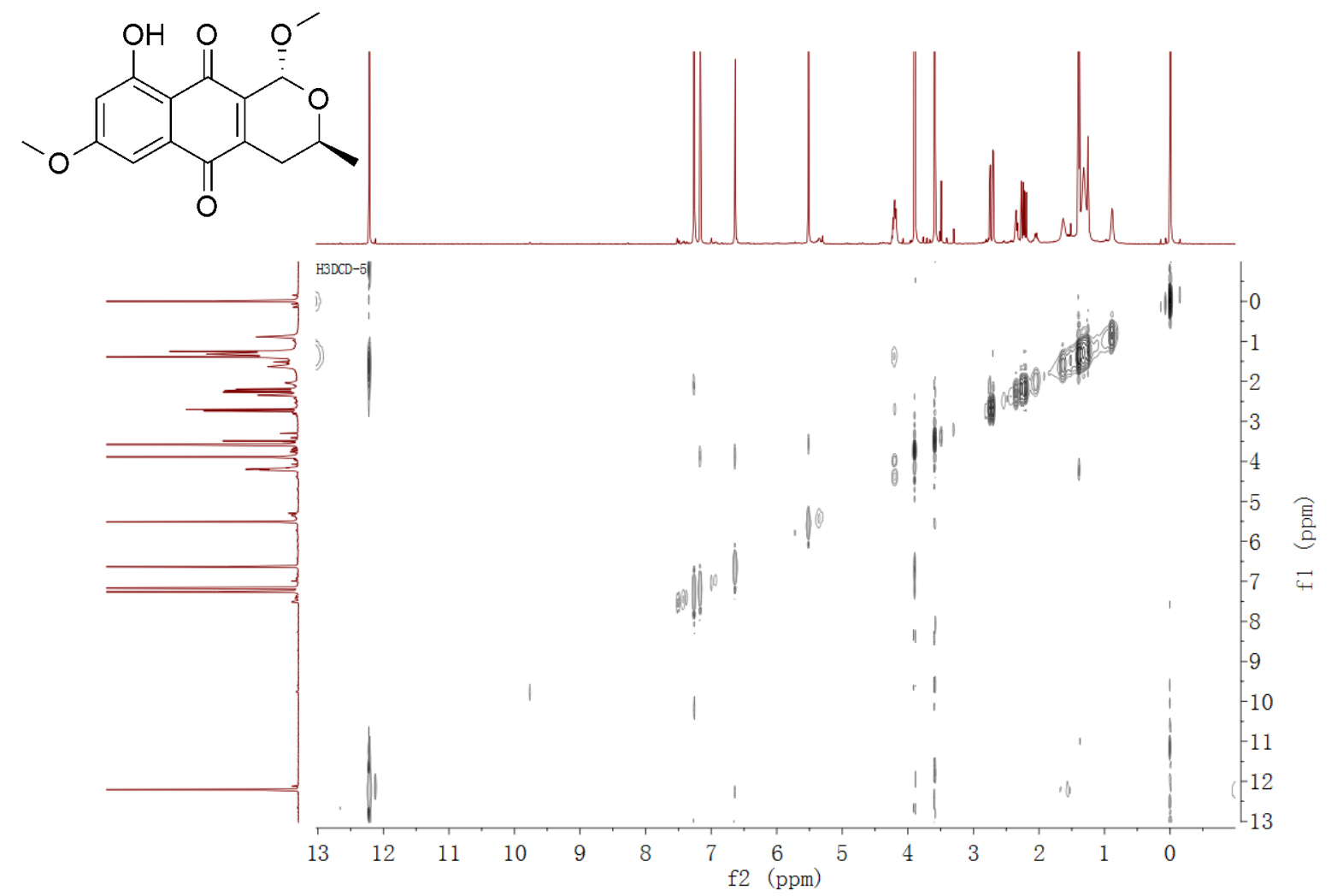

Figure S104. NOESY spectrum of $\mathbf{1 1}$ in $\mathrm{CDCl}_{3}$ 


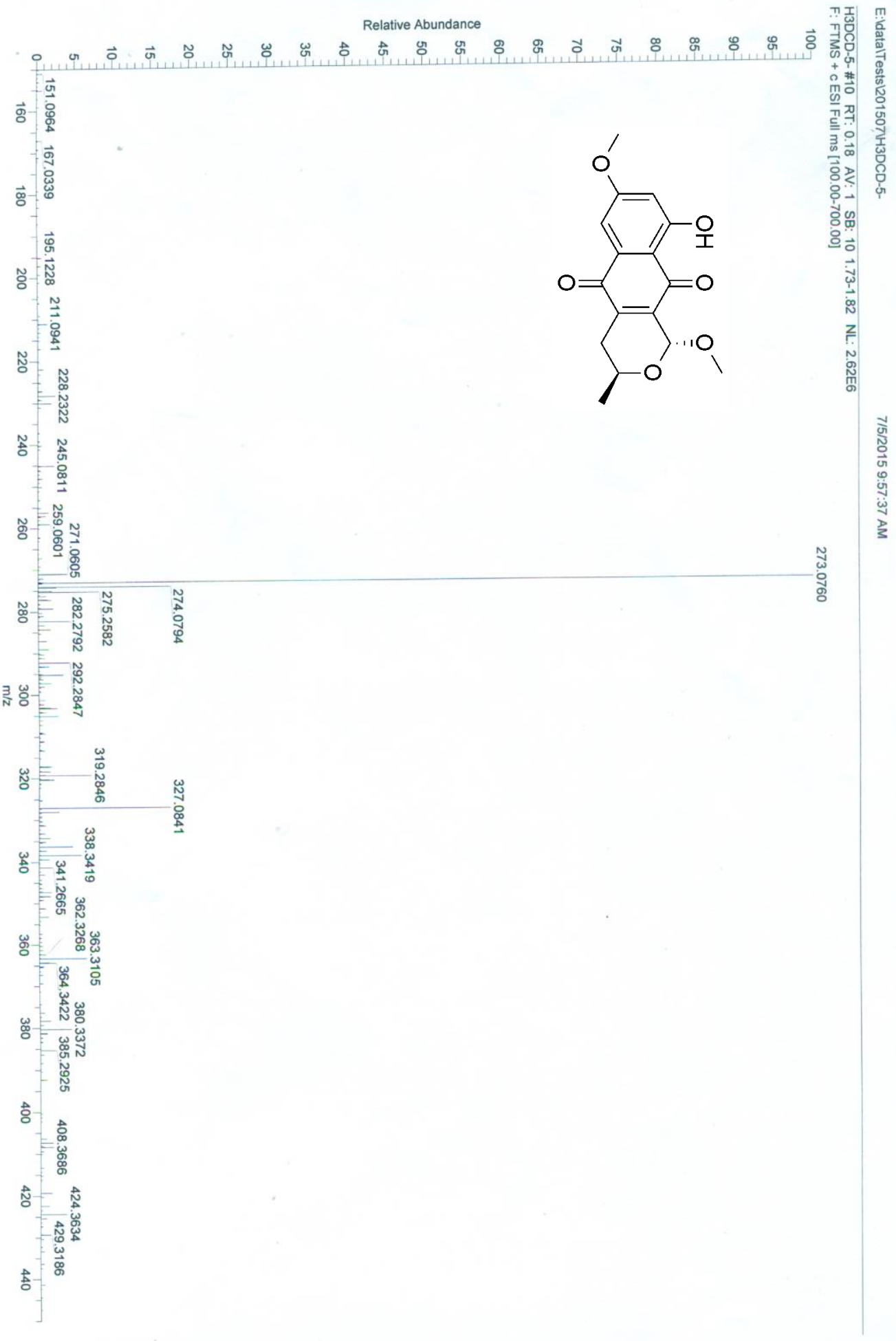

Figure S105. HRESIMS spectrum of $\mathbf{1 1}$ 


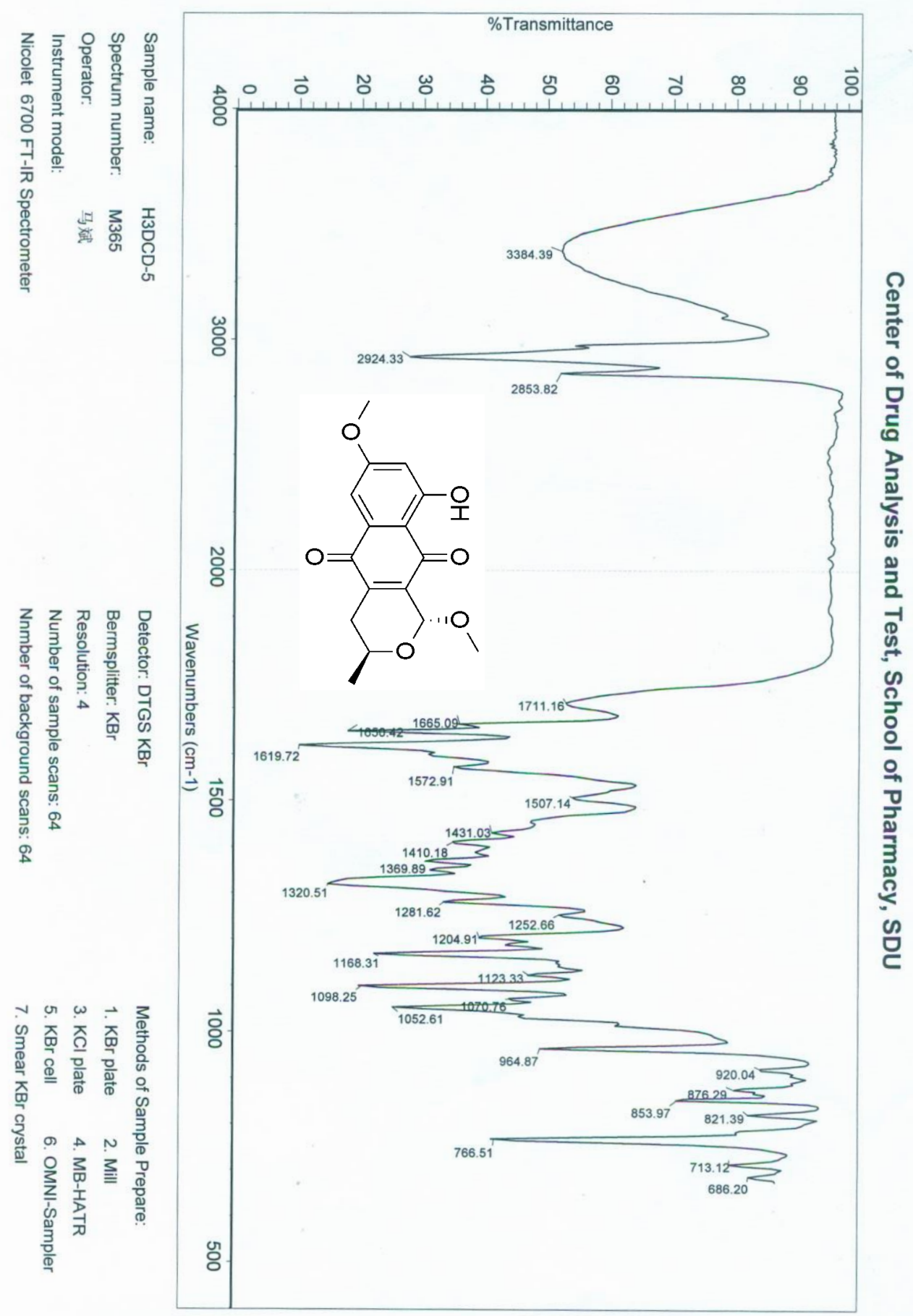

Figure S106. IR (KBr disc) spectrum of $\mathbf{1 1}$ 


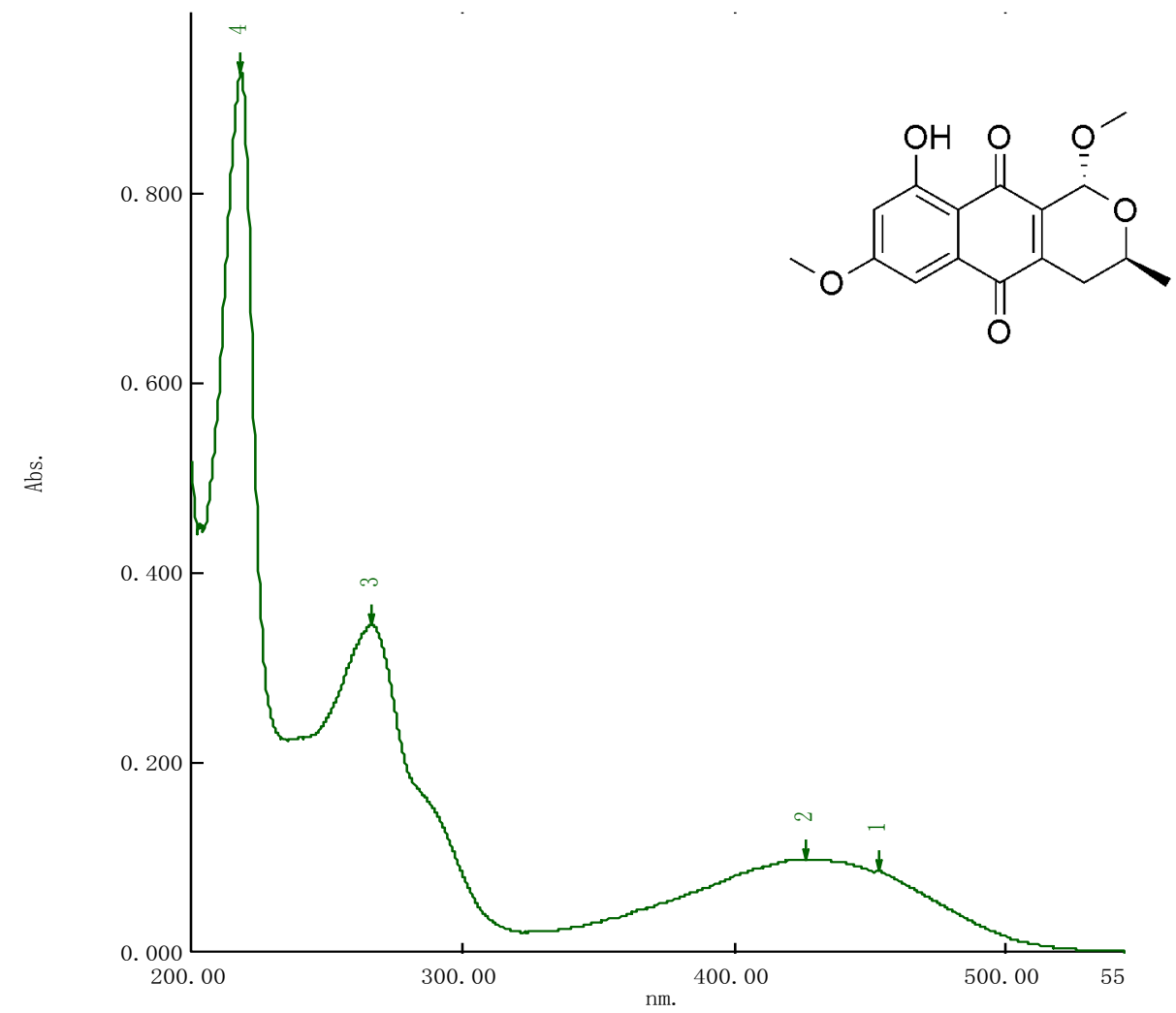

Figure S107. UV spectrum of $\mathbf{1 1}$

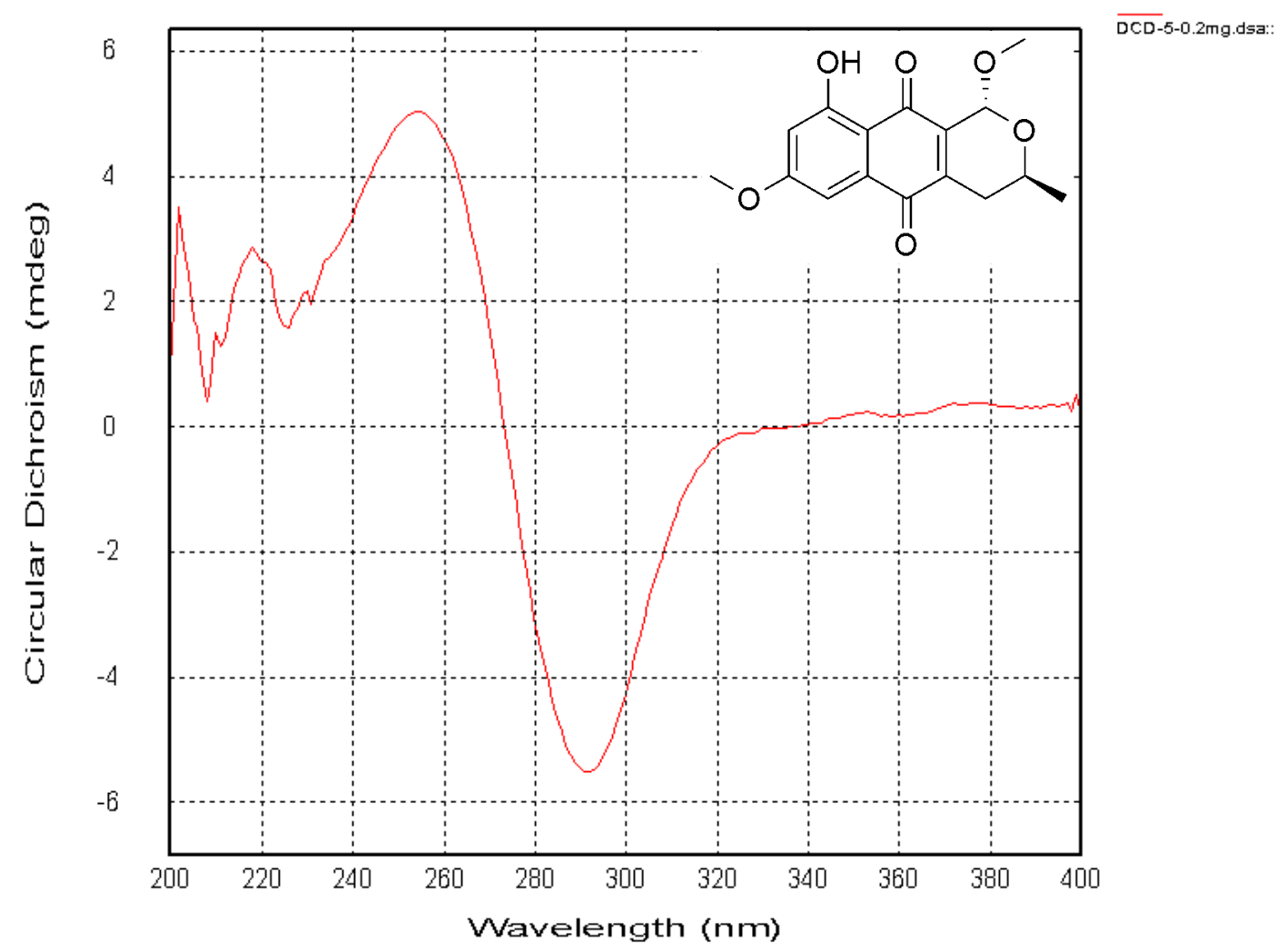

Figure S108. ECD spectrum of $\mathbf{1 1}$ 


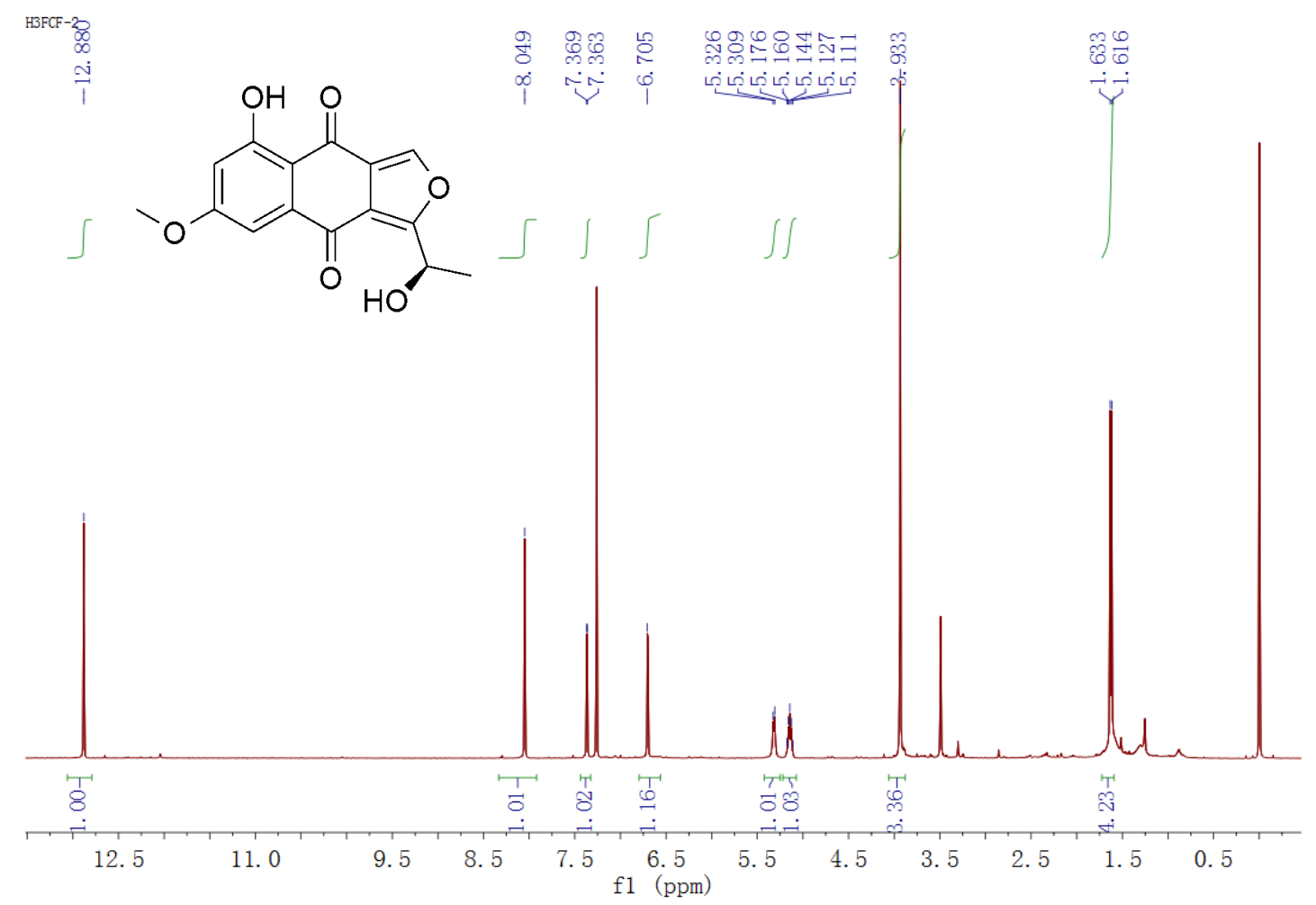

Figure S109. ${ }^{1} \mathrm{H}$ NMR spectrum of 12 in $\mathrm{CDCl}_{3}$

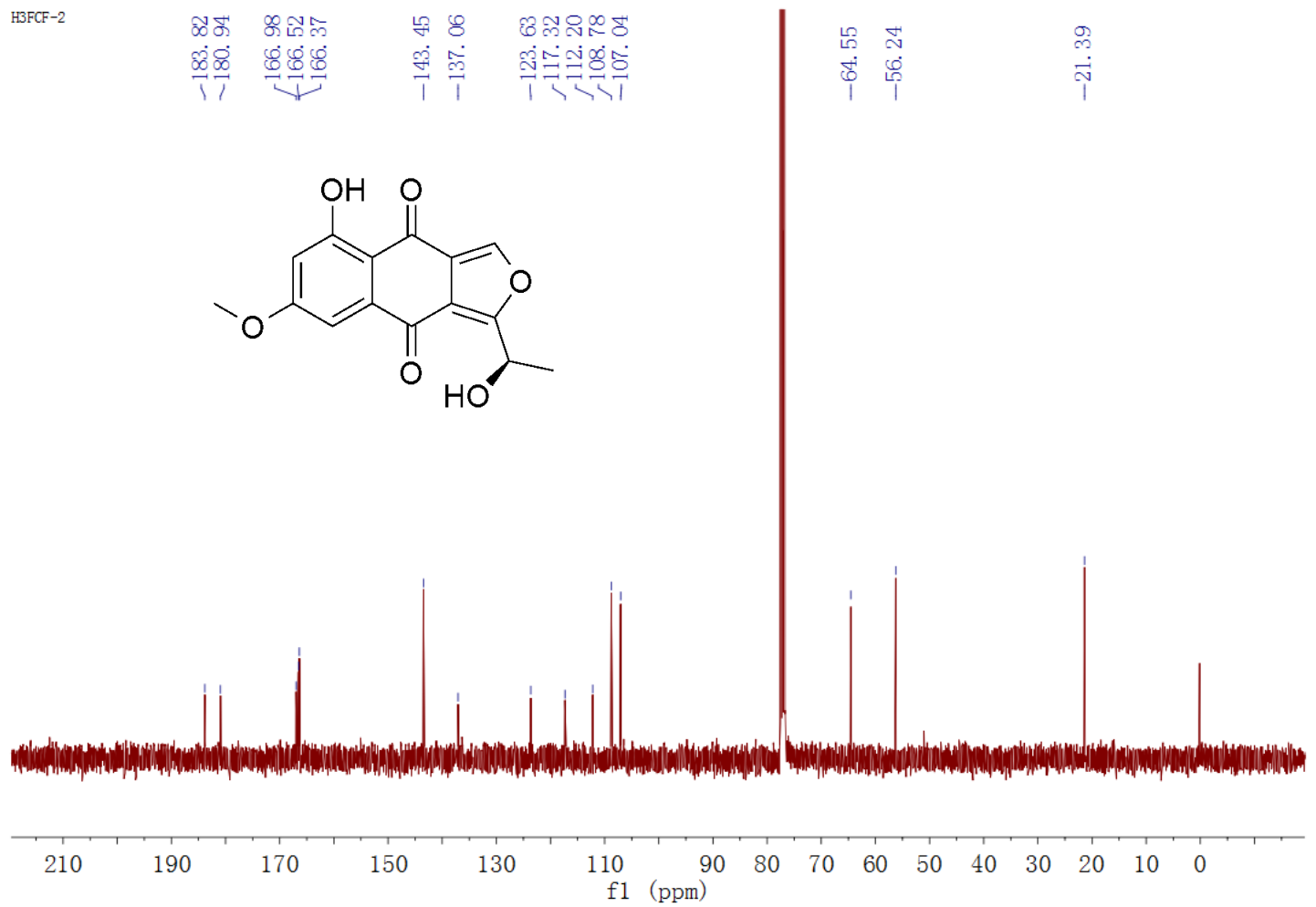

Figure S110. ${ }^{13} \mathrm{C}$ NMR spectrum of 12 in $\mathrm{CDCl}_{3}$ 


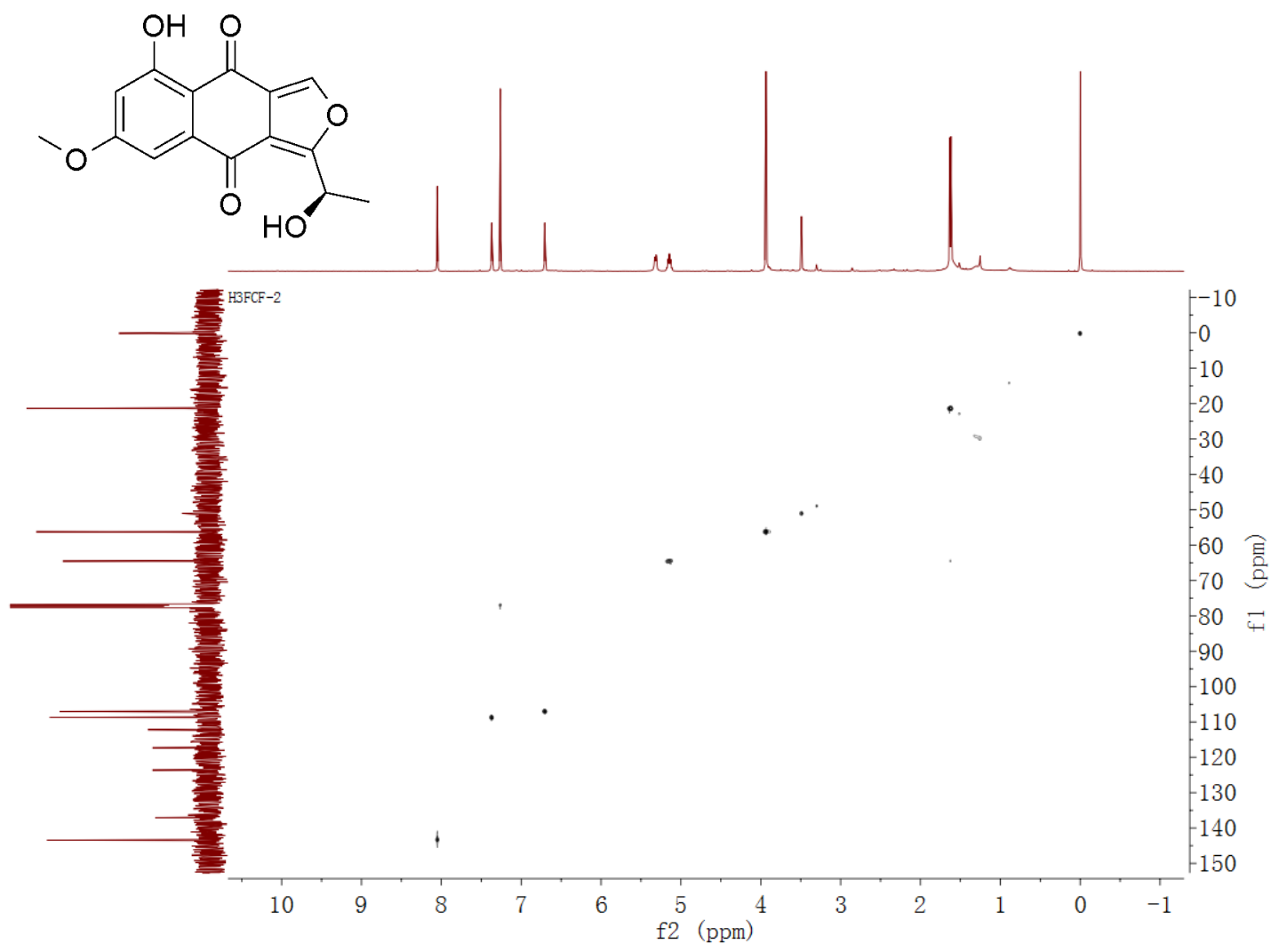

Figure S111. ${ }^{1} \mathrm{H}-{ }^{1} \mathrm{H}$ COSY spectrum of 12 in $\mathrm{CDCl}_{3}$

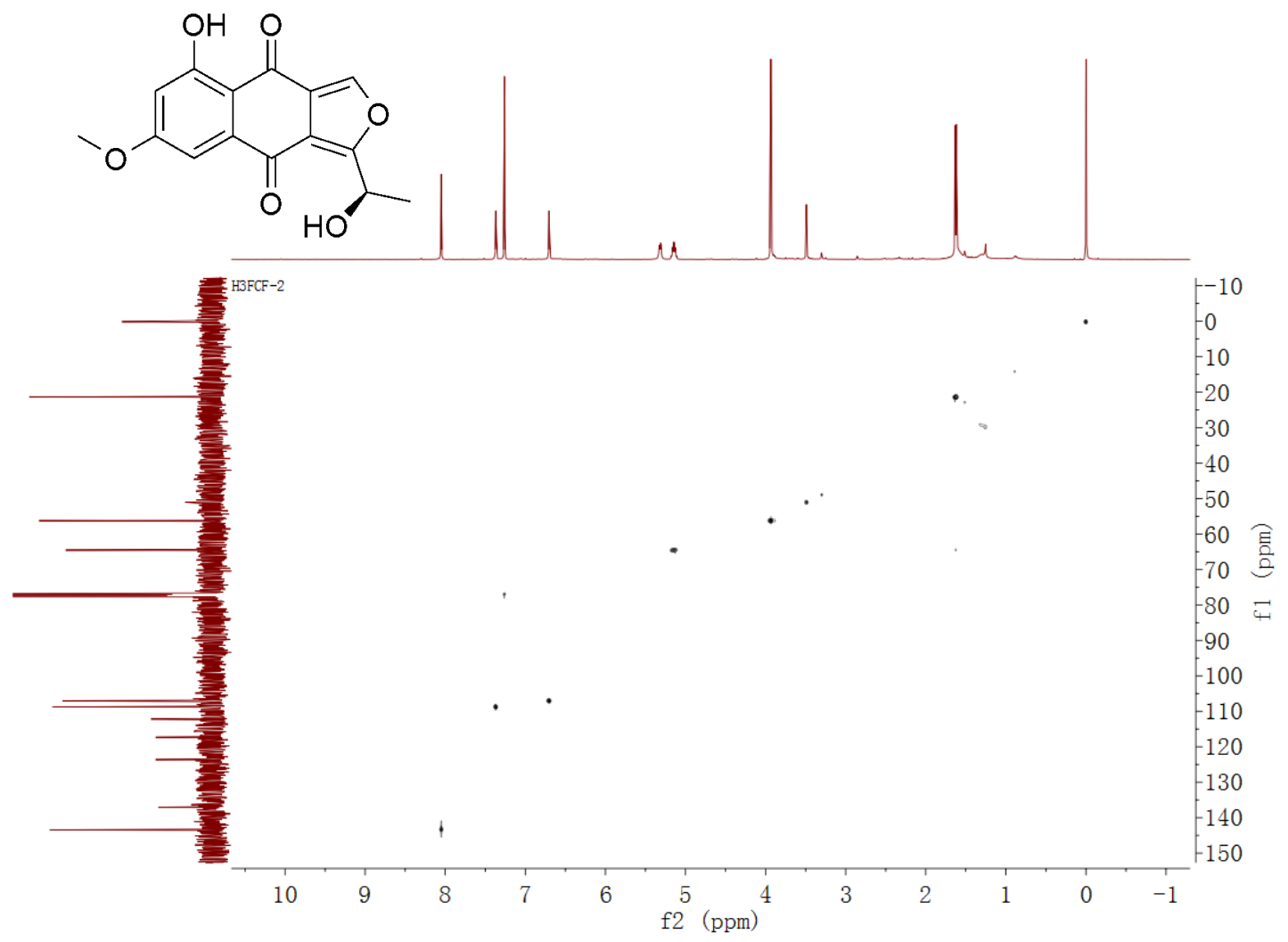

Figure S112. HSQC spectrum of 12 in $\mathrm{CDCl}_{3}$ 


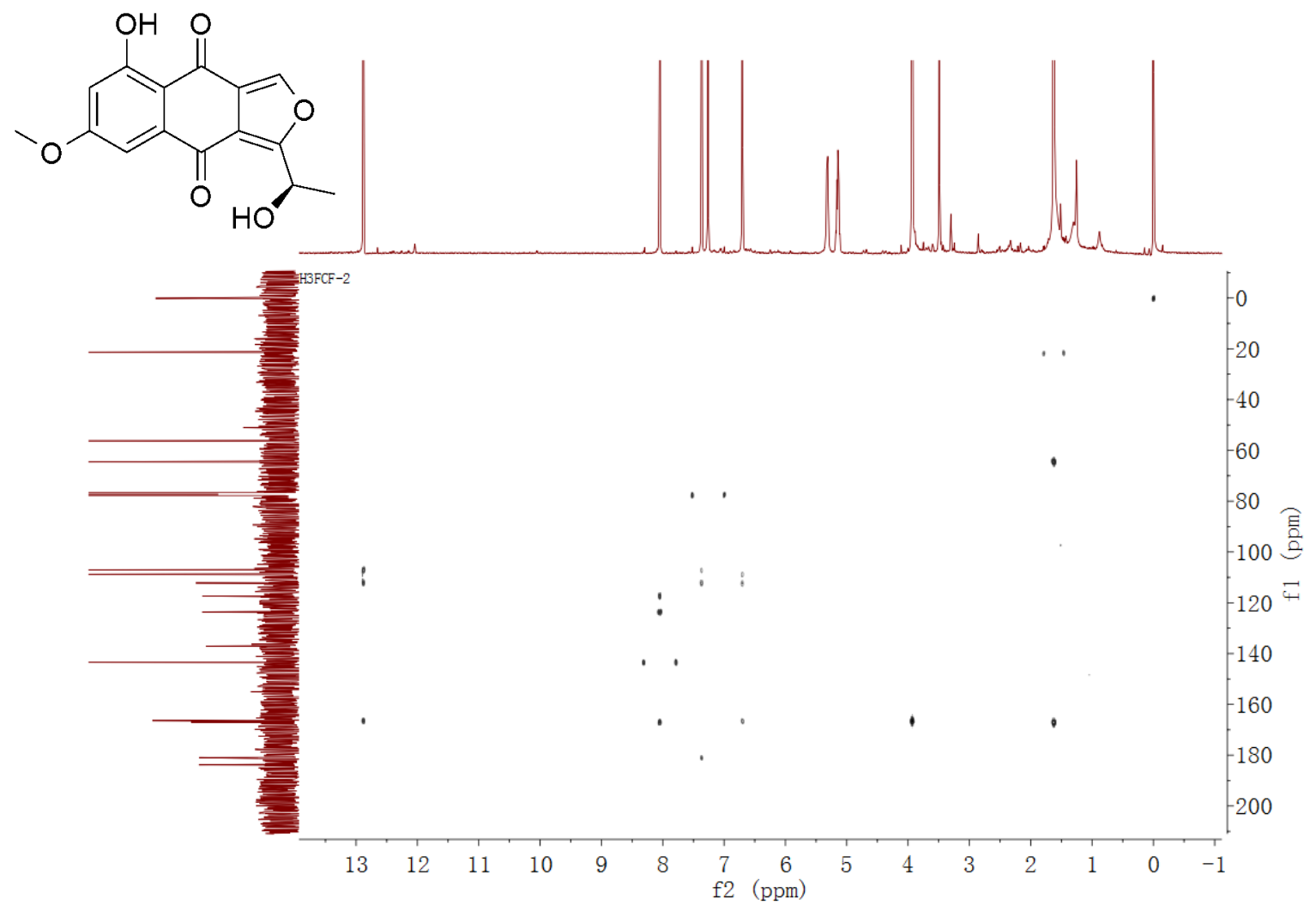

Figure S113. $\mathrm{HMBC}$ spectrum of 12 in $\mathrm{CDCl}_{3}$

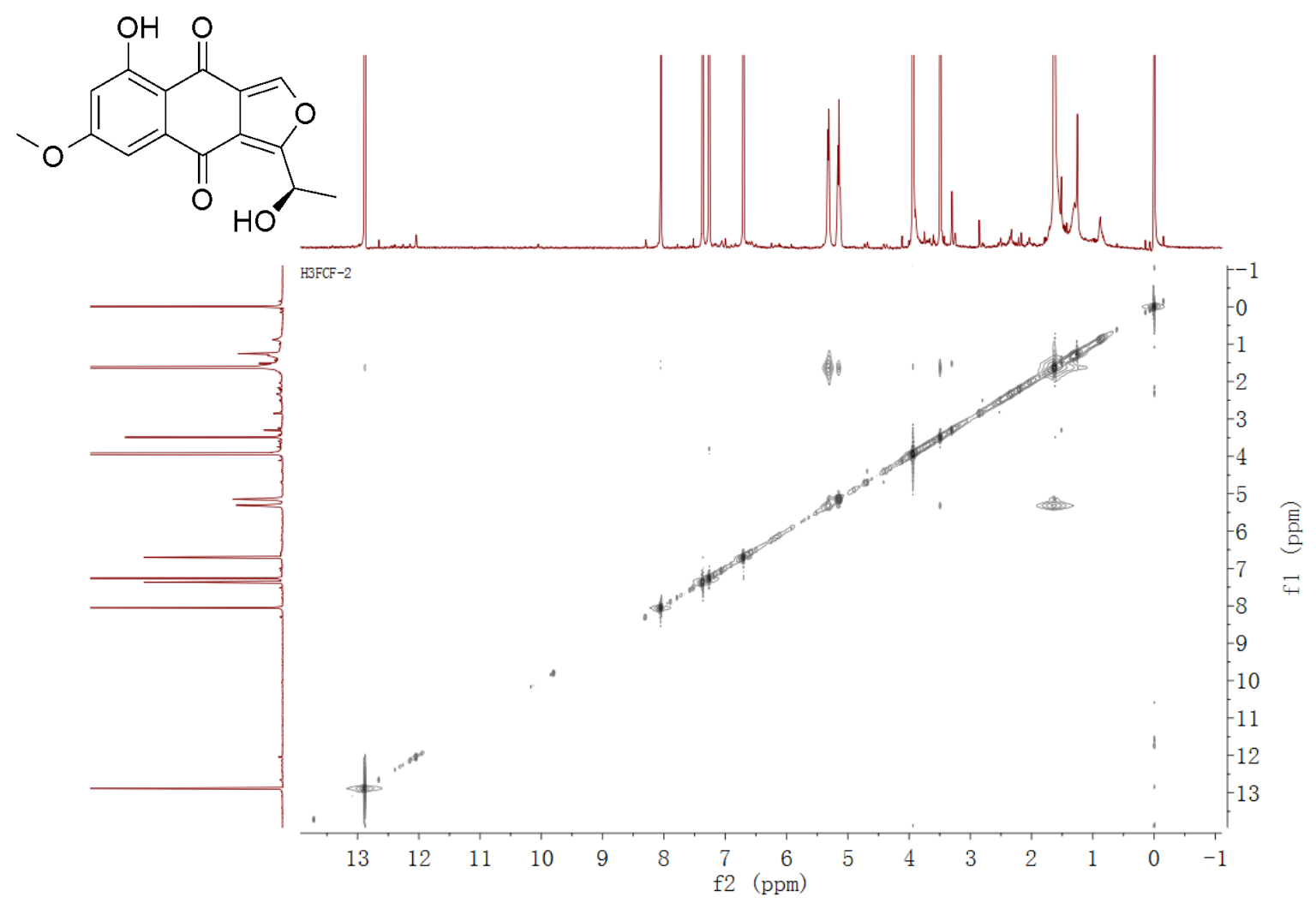

Figure S114. NOESY spectrum of 12 in $\mathrm{CDCl}_{3}$ 


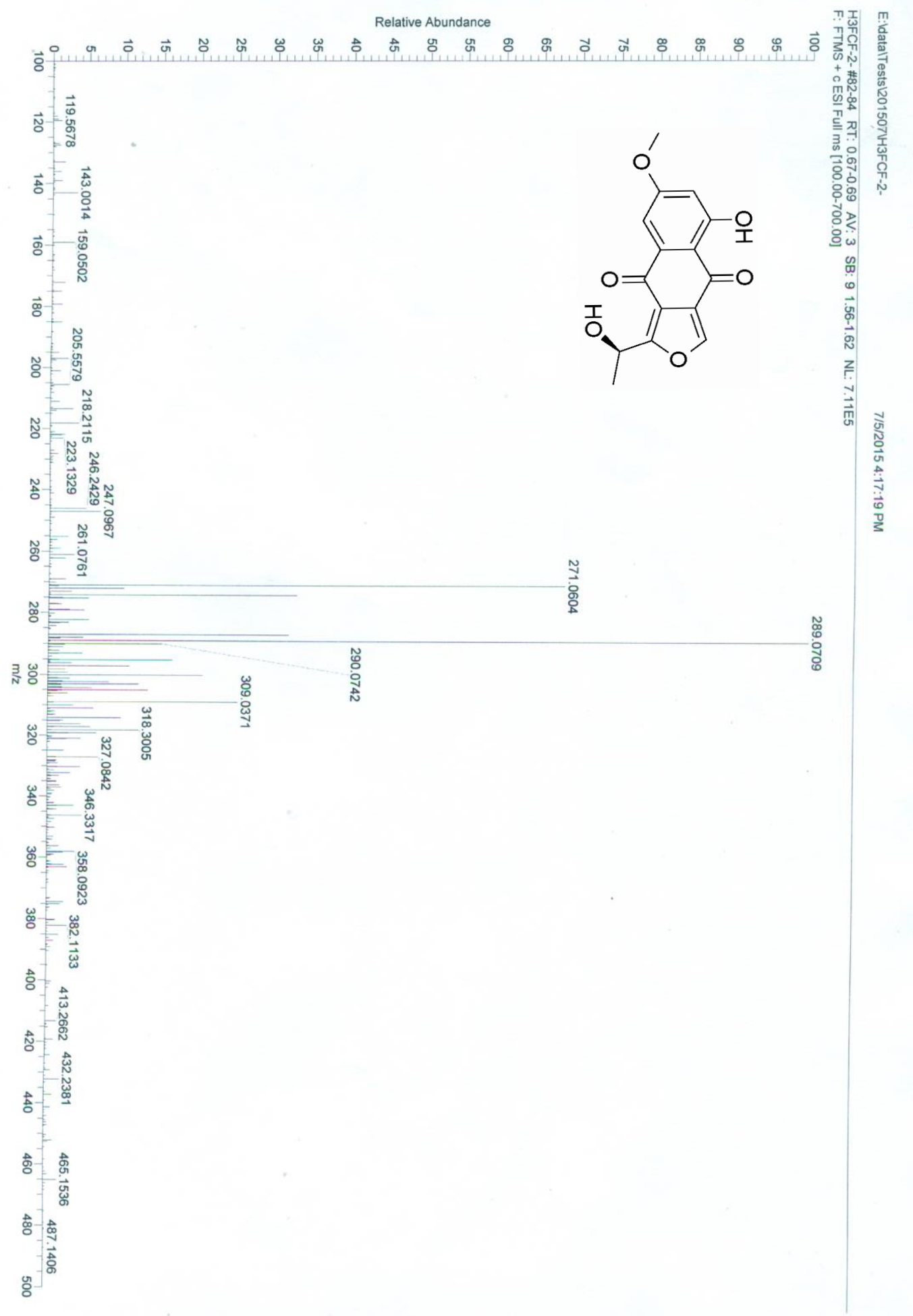

Figure S115. HRESIMS spectrum of 12 


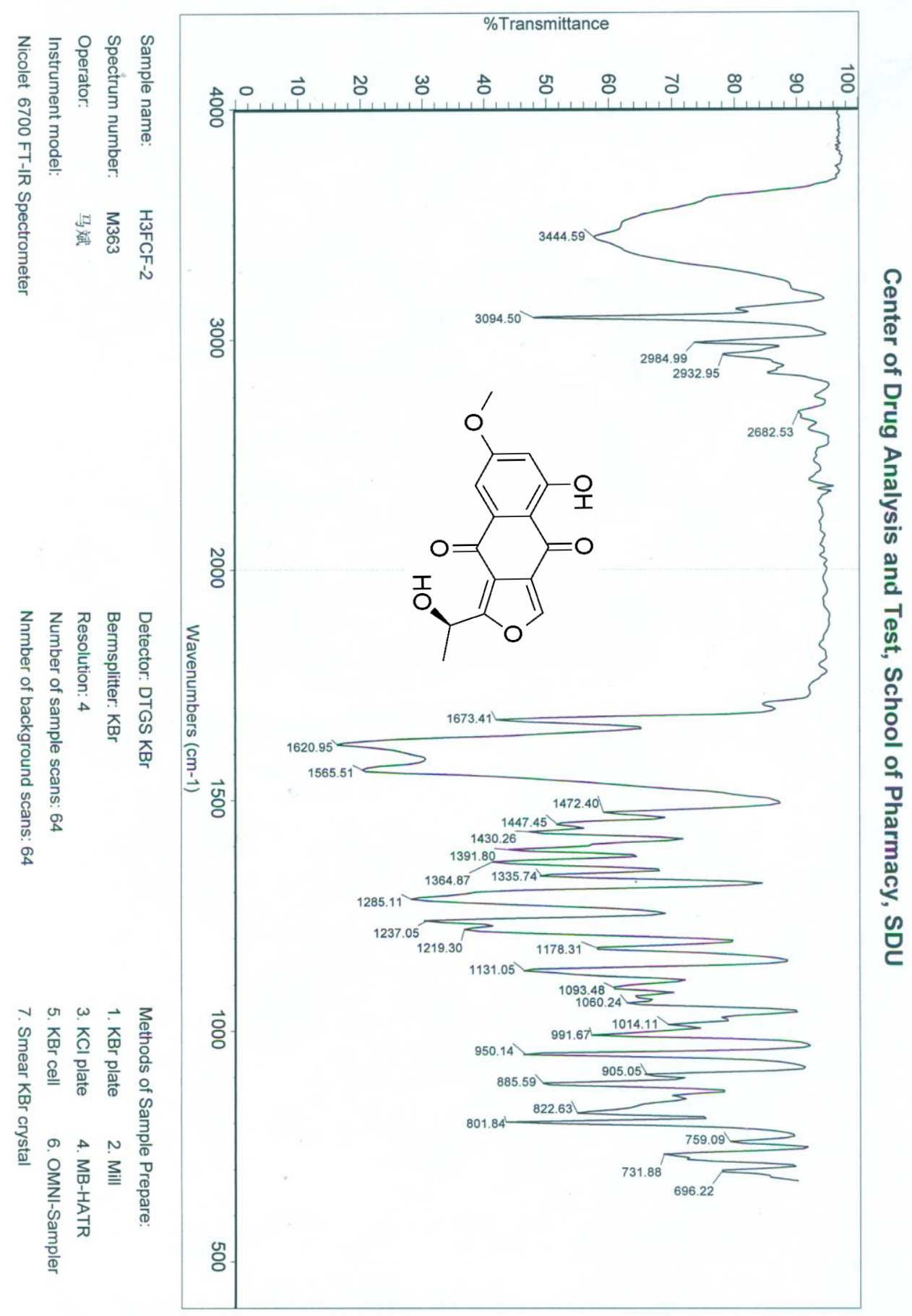

Figure S116. IR ( $\mathrm{KBr}$ disc) spectrum of 12 


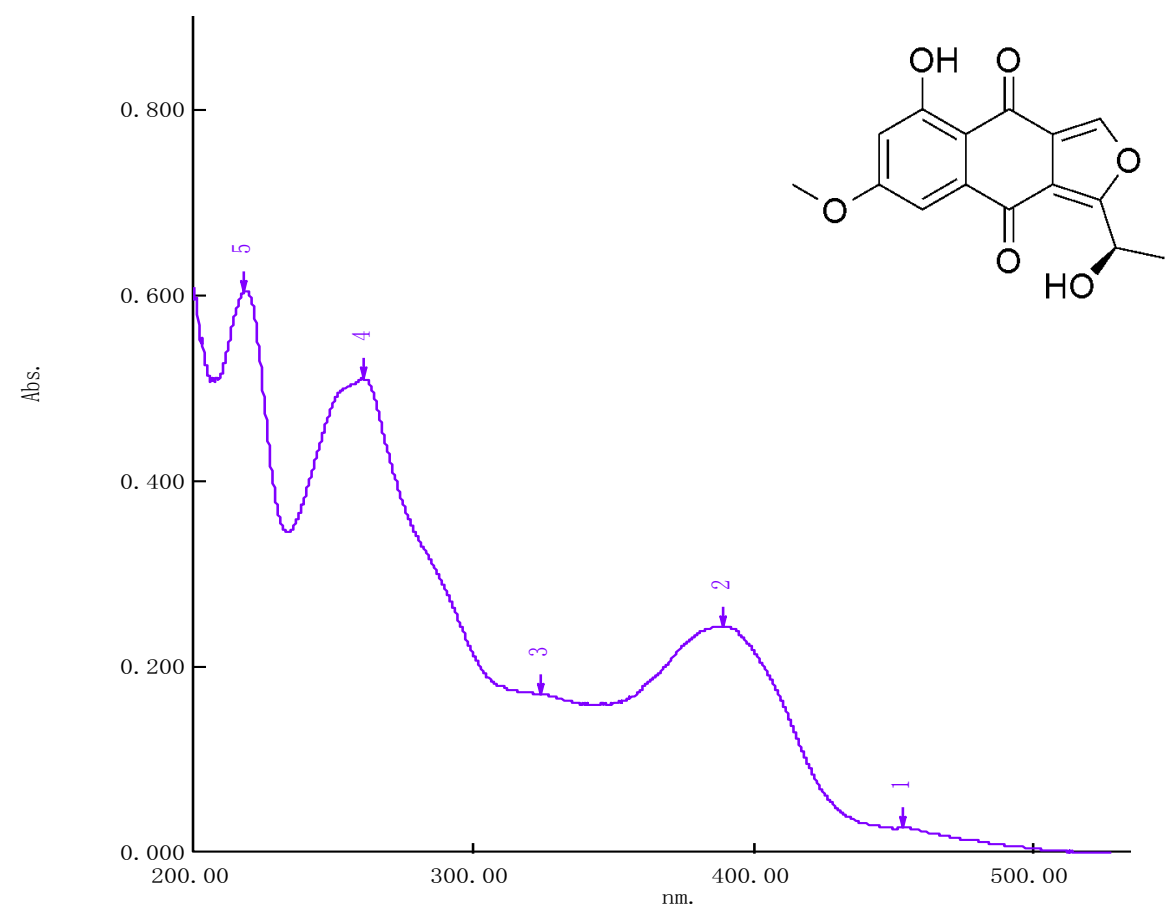

Figure S117. UV spectrum of $\mathbf{1 2}$

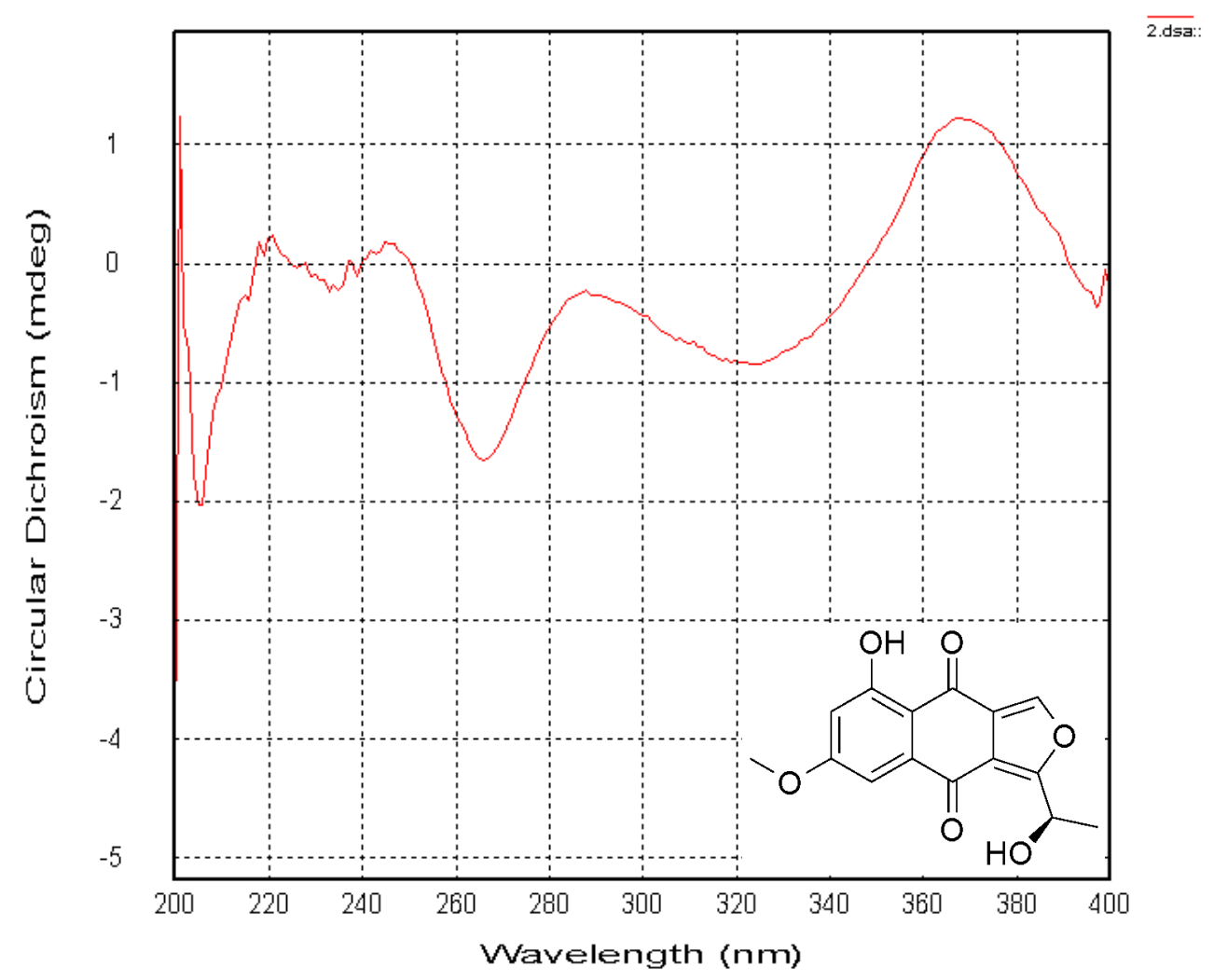

Figure S118. ECD spectrum of $\mathbf{1 2}$ 


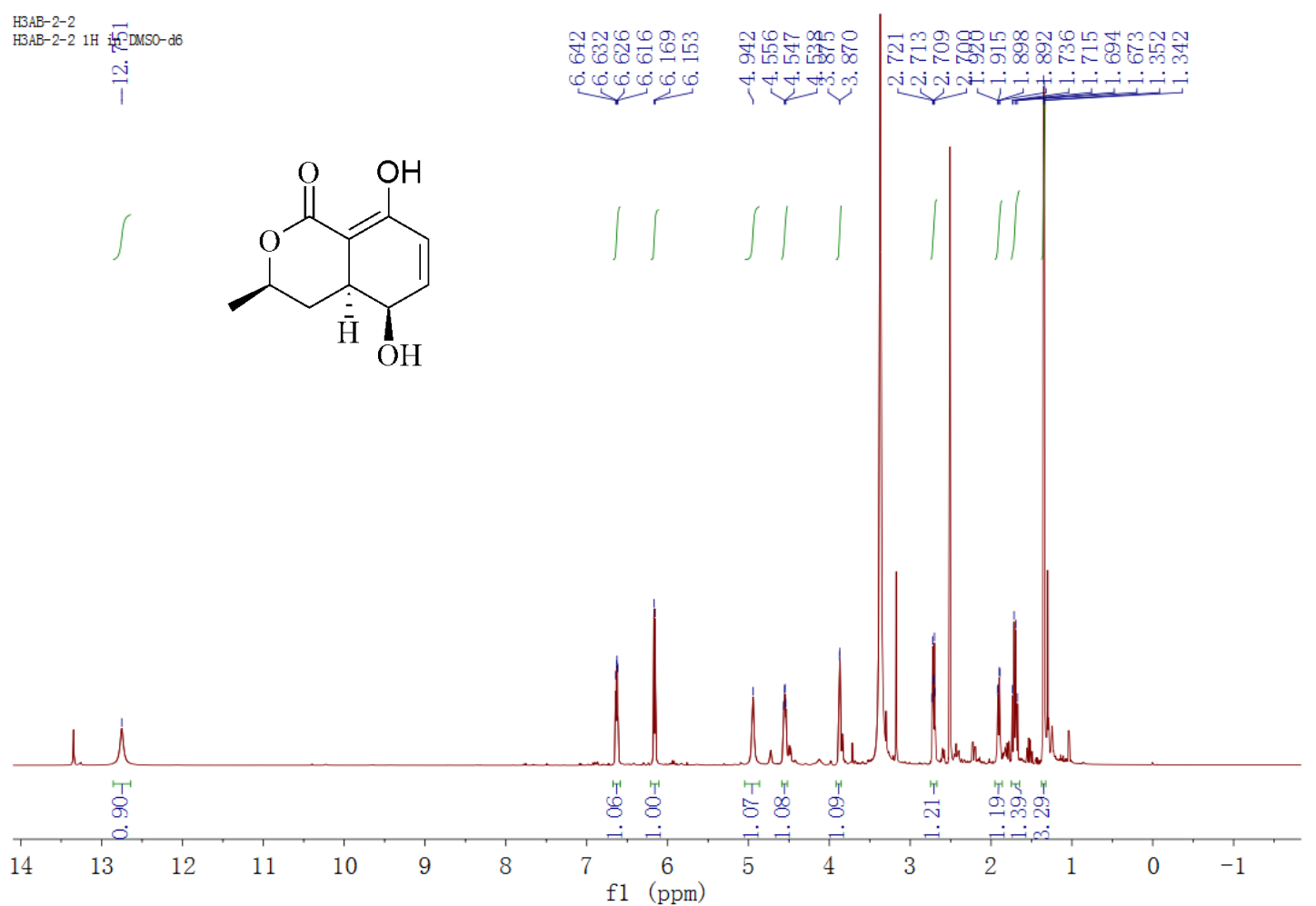

Figure S119. ${ }^{1} \mathrm{H}$ NMR spectrum of $\mathbf{1 3}$ in DMSO-d 6
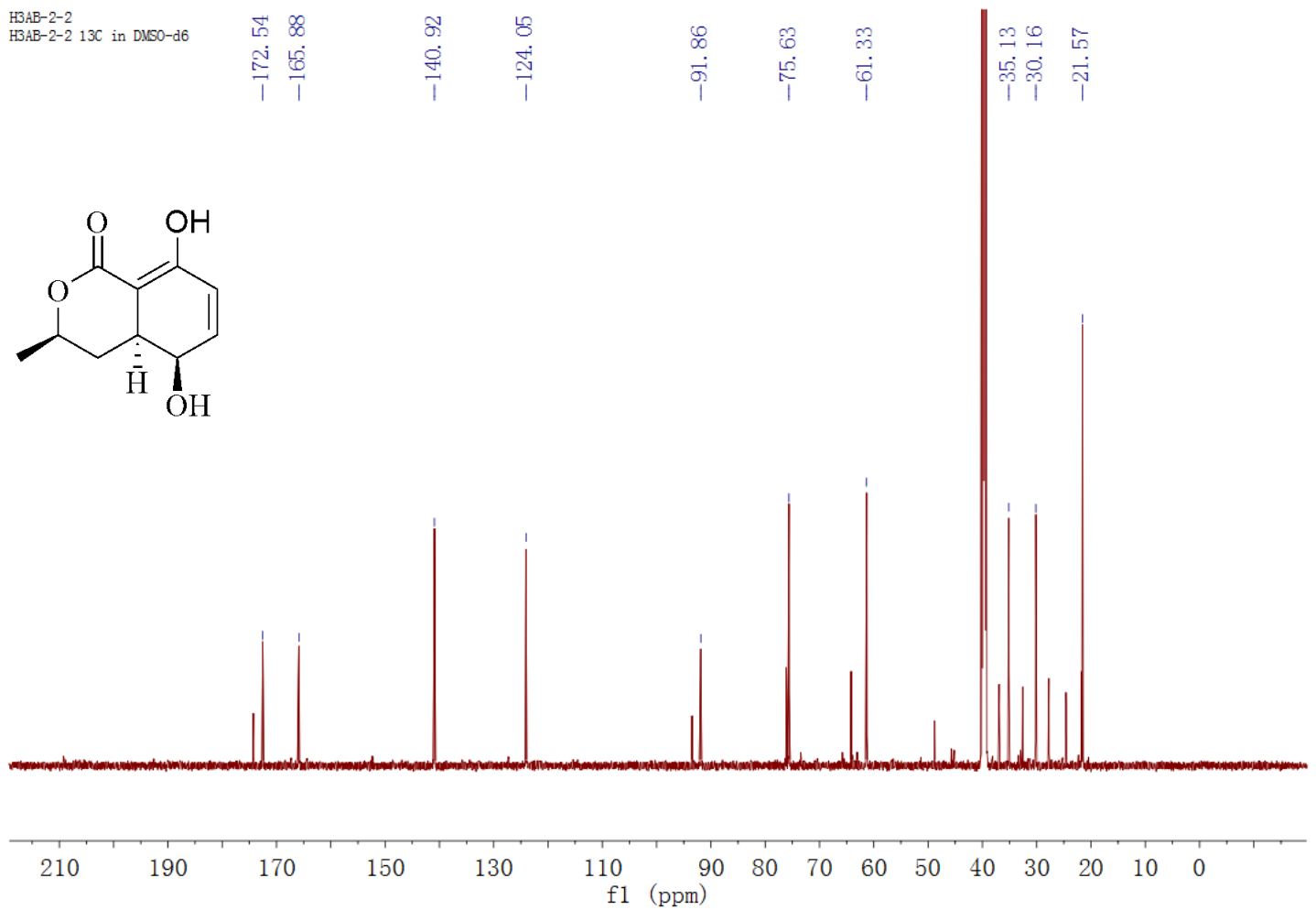

Figure S120. ${ }^{13} \mathrm{C}$ NMR spectrum of $\mathbf{1 3}$ in DMSO-d 6 


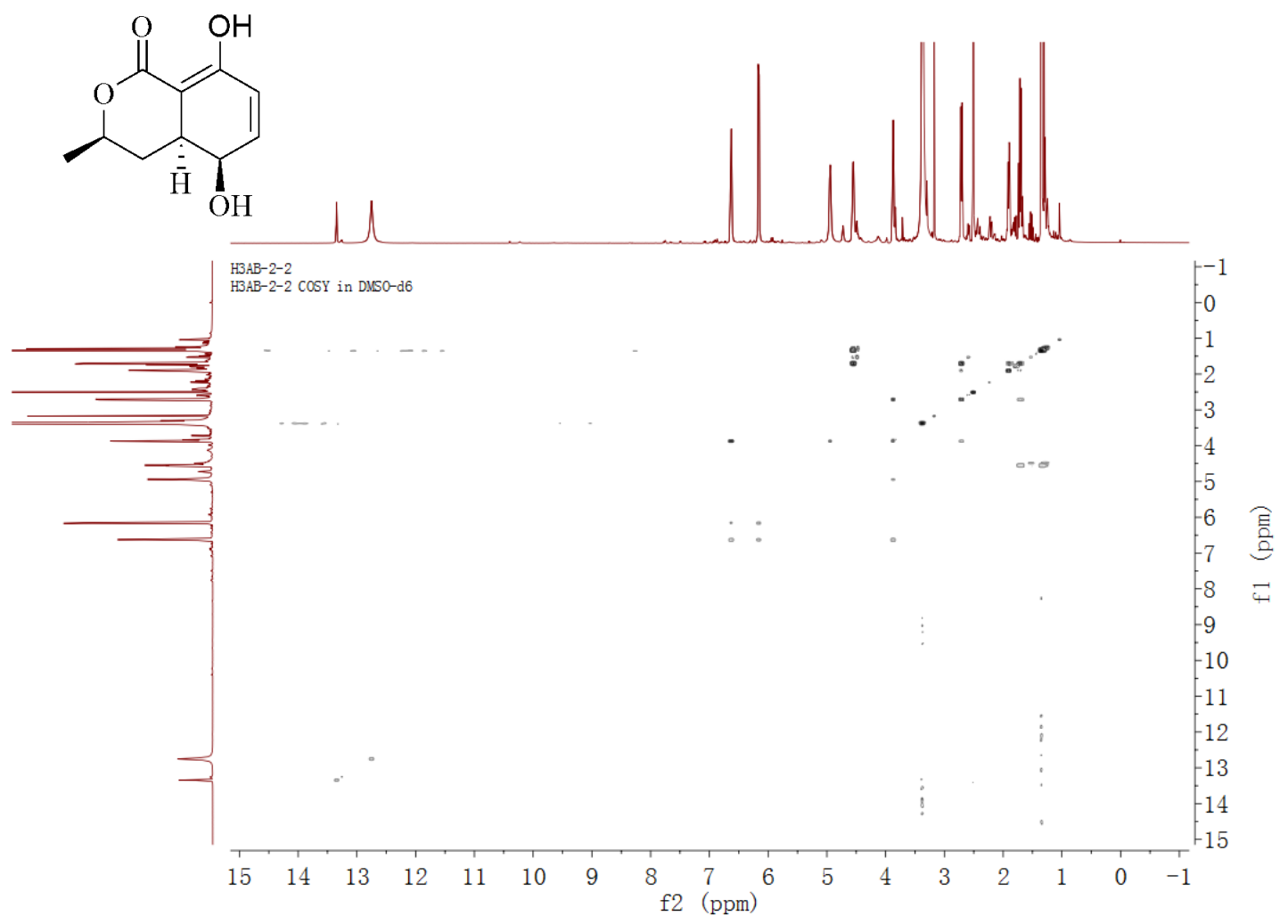

Figure S121. ${ }^{1} \mathrm{H}-{ }^{1} \mathrm{H}$ COSY spectrum of $\mathbf{1 3}$ in DMSO-d 6<smiles>CC1C[C@H]2C(=C(O)C=CC2O)C(=O)O1</smiles>

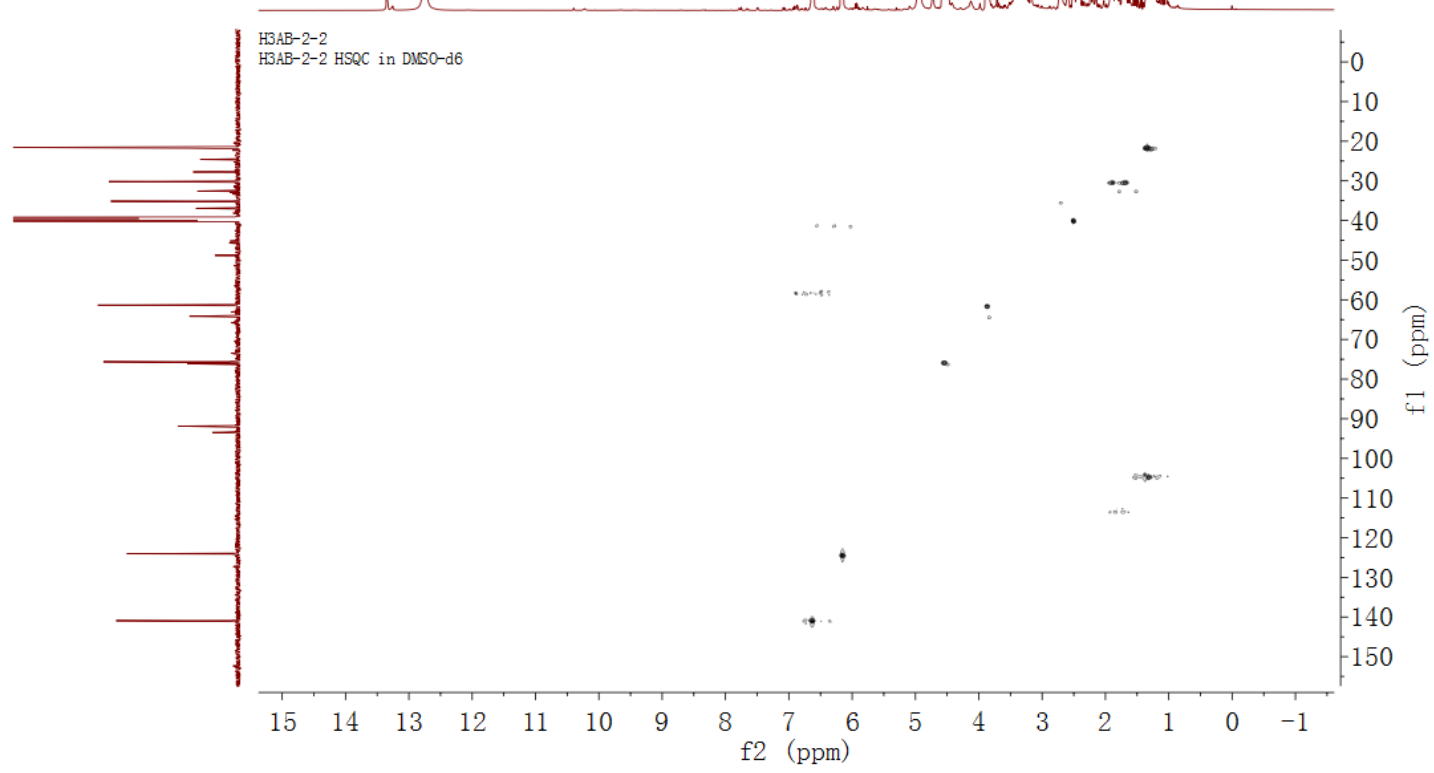

Figure S122. HSQC spectrum of $\mathbf{1 3}$ in DMSO-d 6 


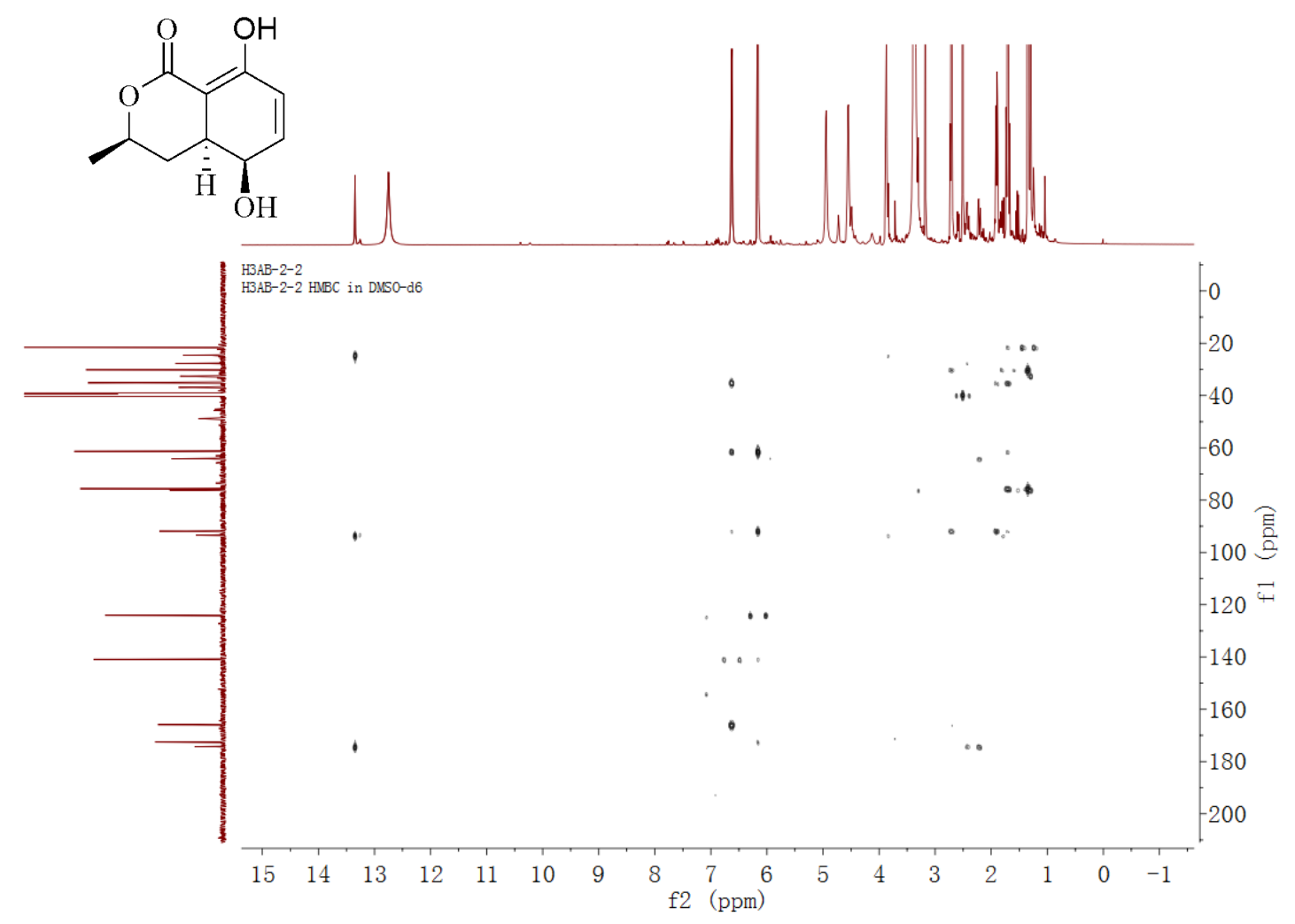

Figure S123. HMBC spectrum of $\mathbf{1 3}$ in DMSO- $\mathrm{d}_{6}$

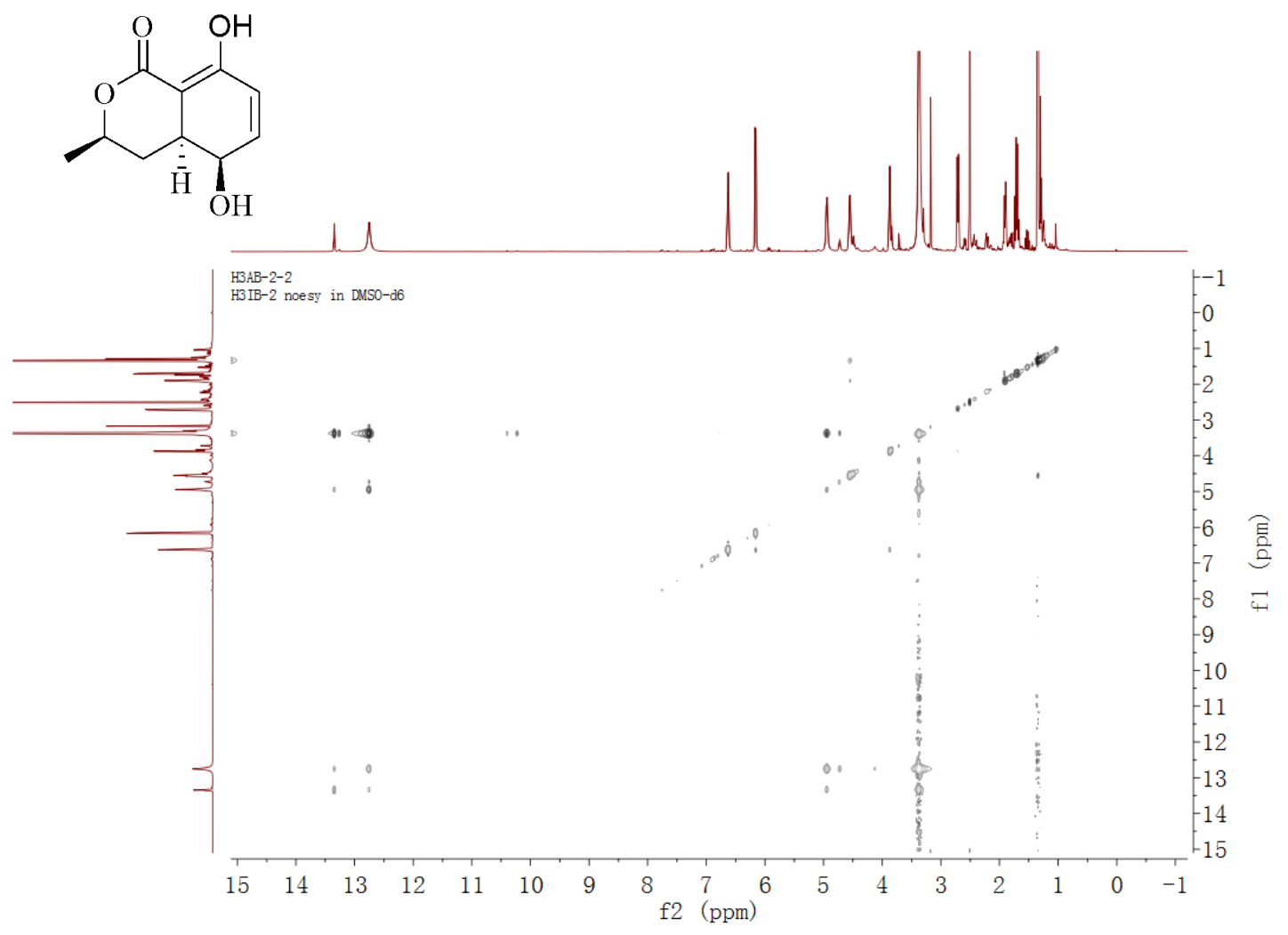

Figure S124. NOESY spectrum of $\mathbf{1 3}$ in DMSO-d 6 


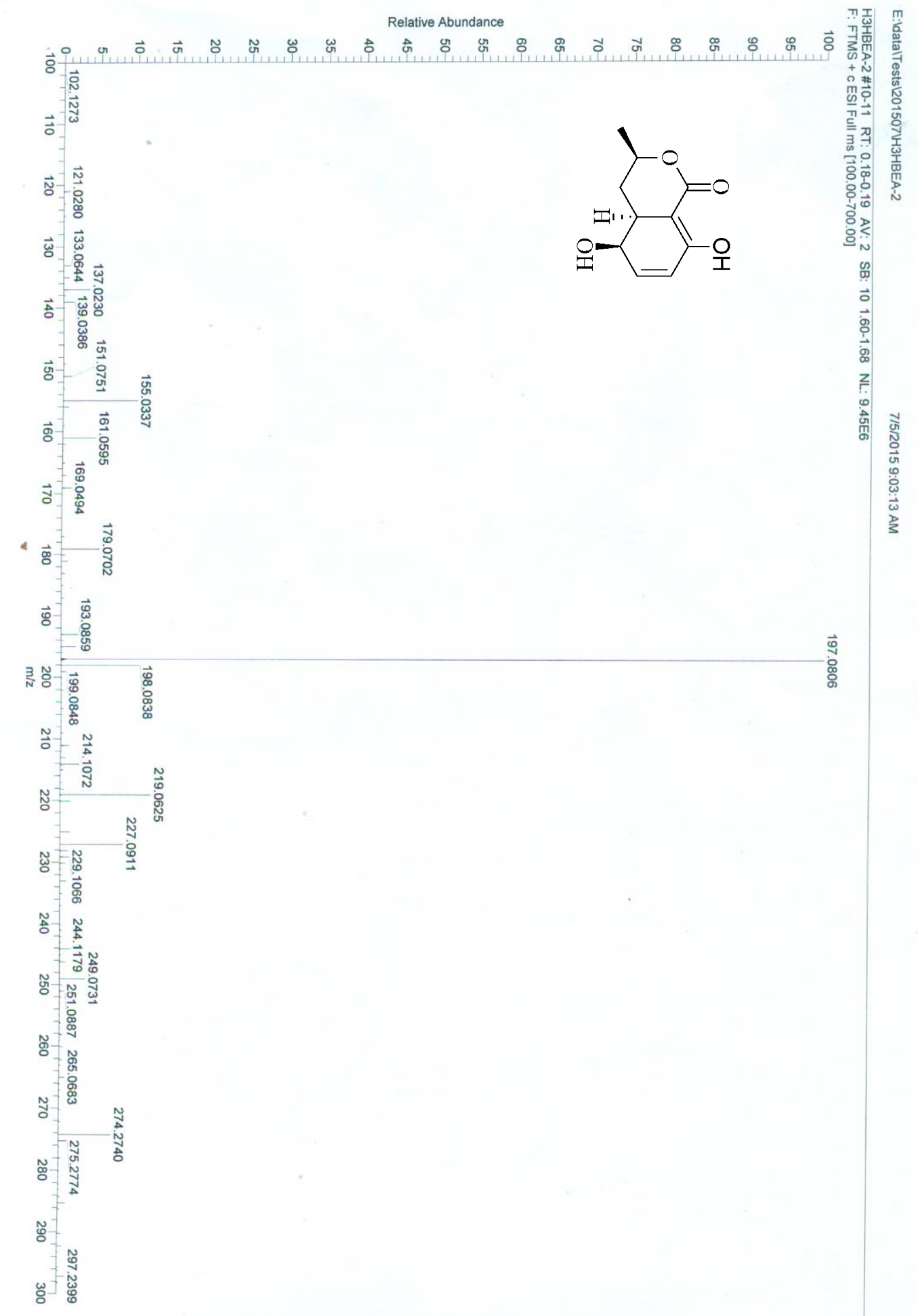

Figure S125. HRESIMS spectrum of $\mathbf{1 3}$ 


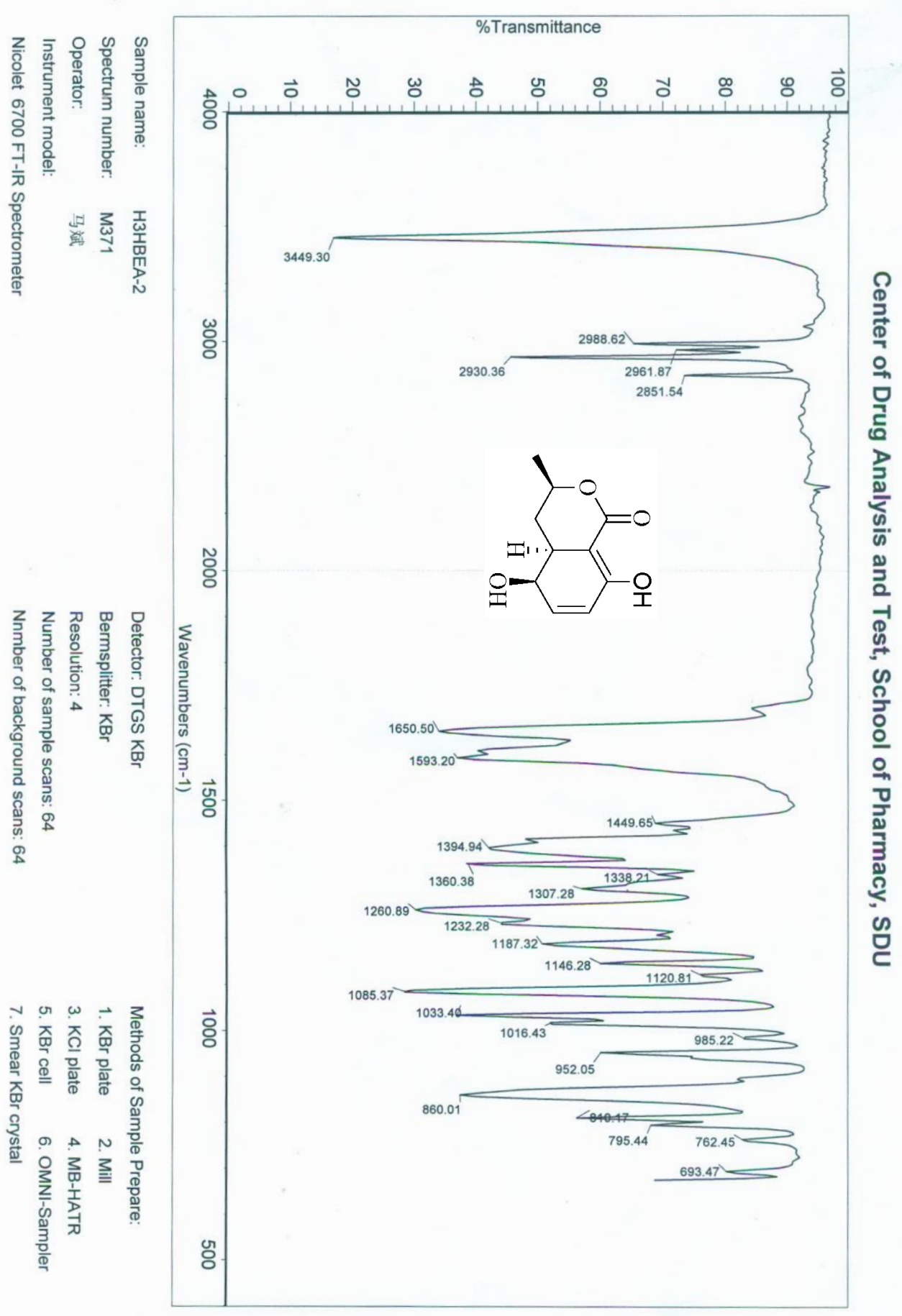

Figure S126. IR ( $\mathrm{KBr}$ disc) spectrum of $\mathbf{1 3}$ 


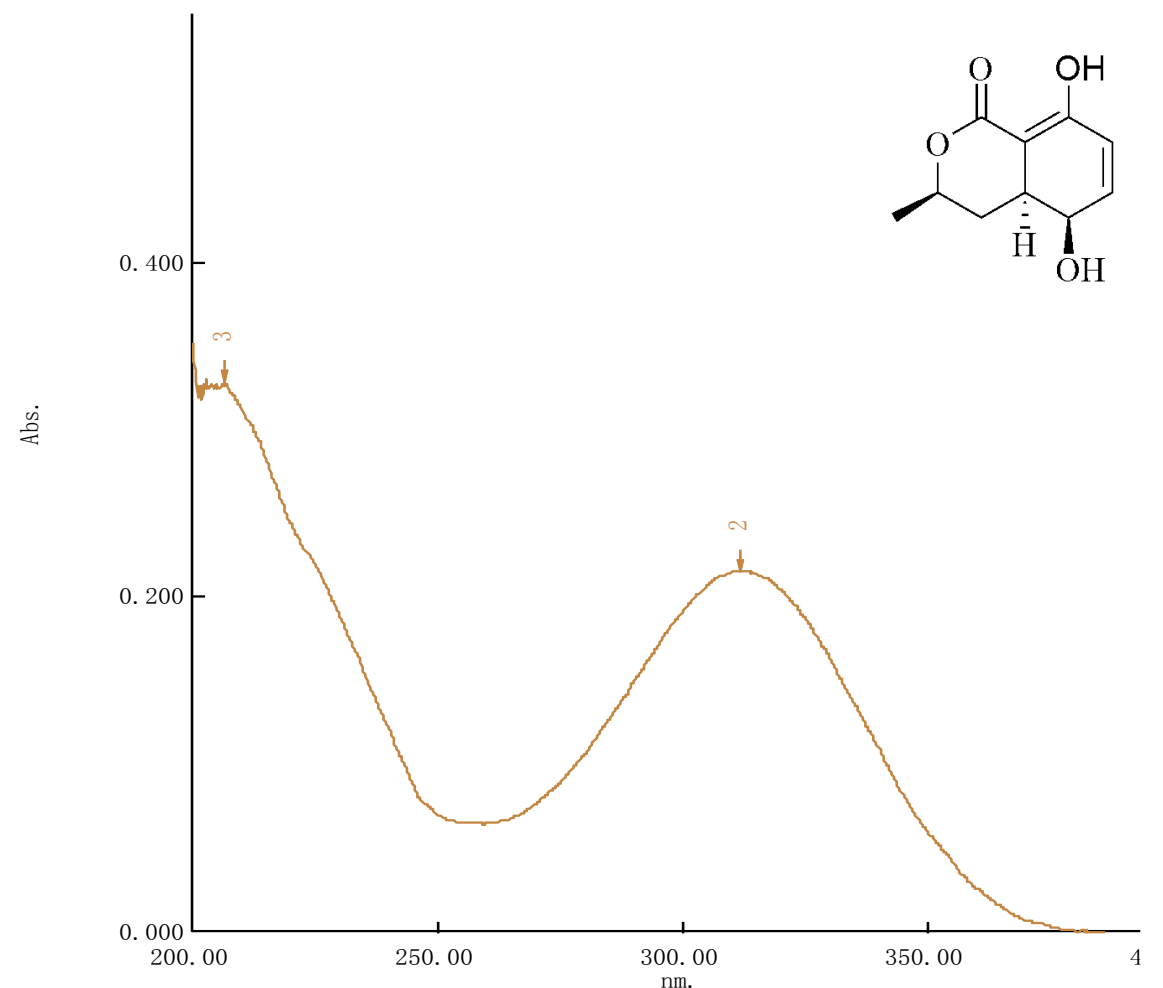

Figure S127. UV spectrum of $\mathbf{1 3}$

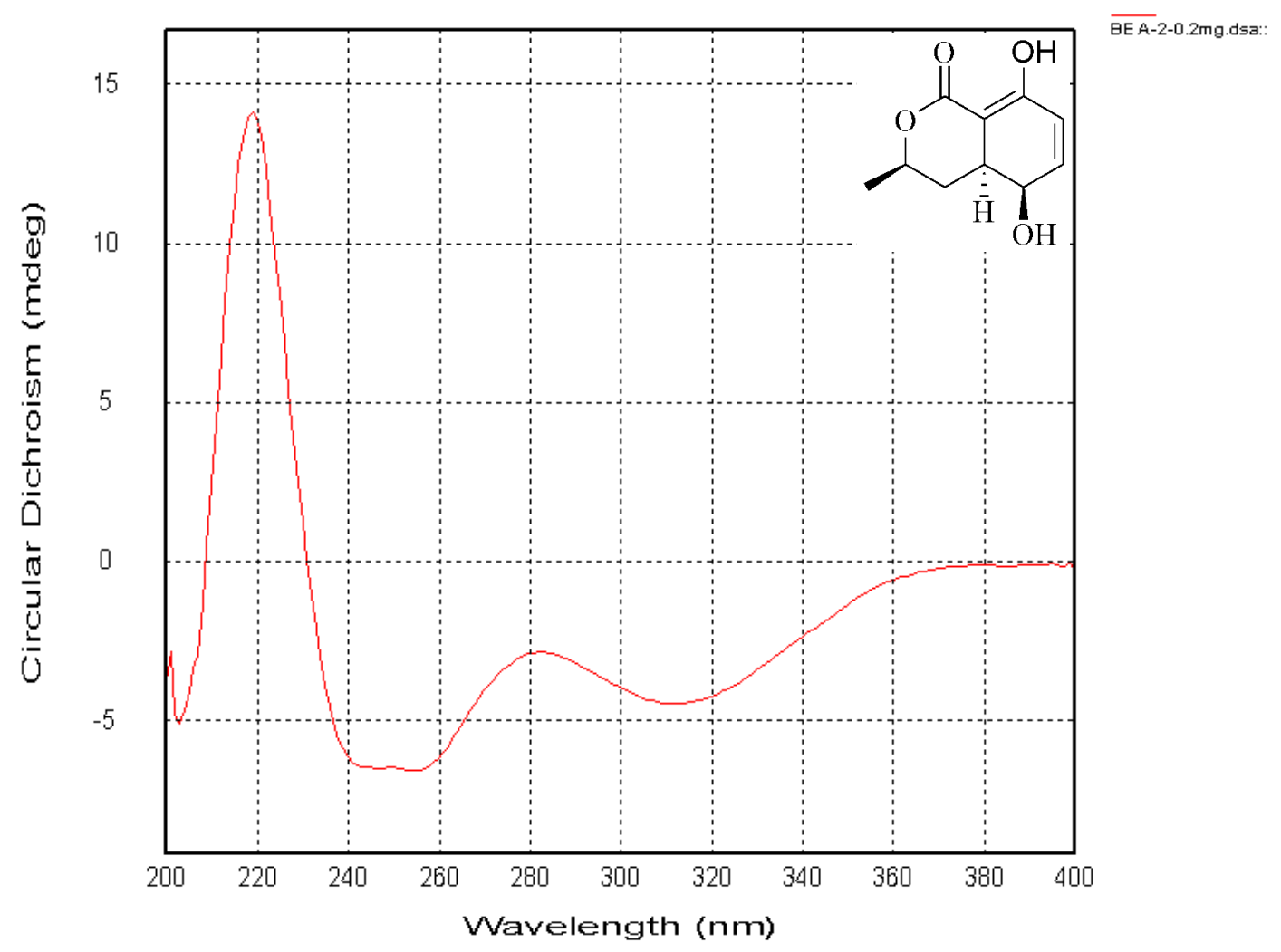

Figure S128. ECD spectrum of $\mathbf{1 3}$ 


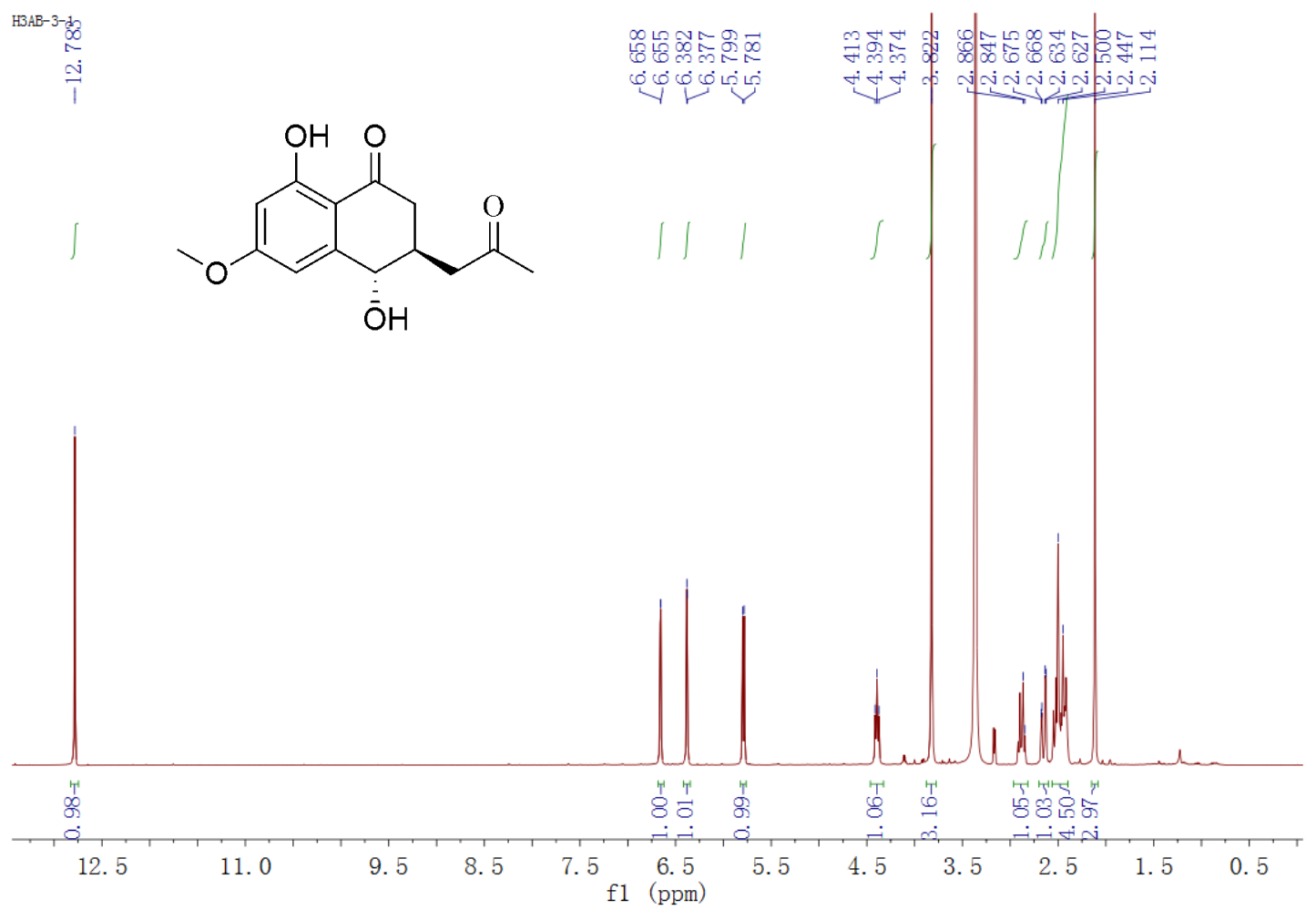

Figure S129. ${ }^{1} \mathrm{H}$ NMR spectrum of $\mathbf{1 4}$ in DMSO-d 6

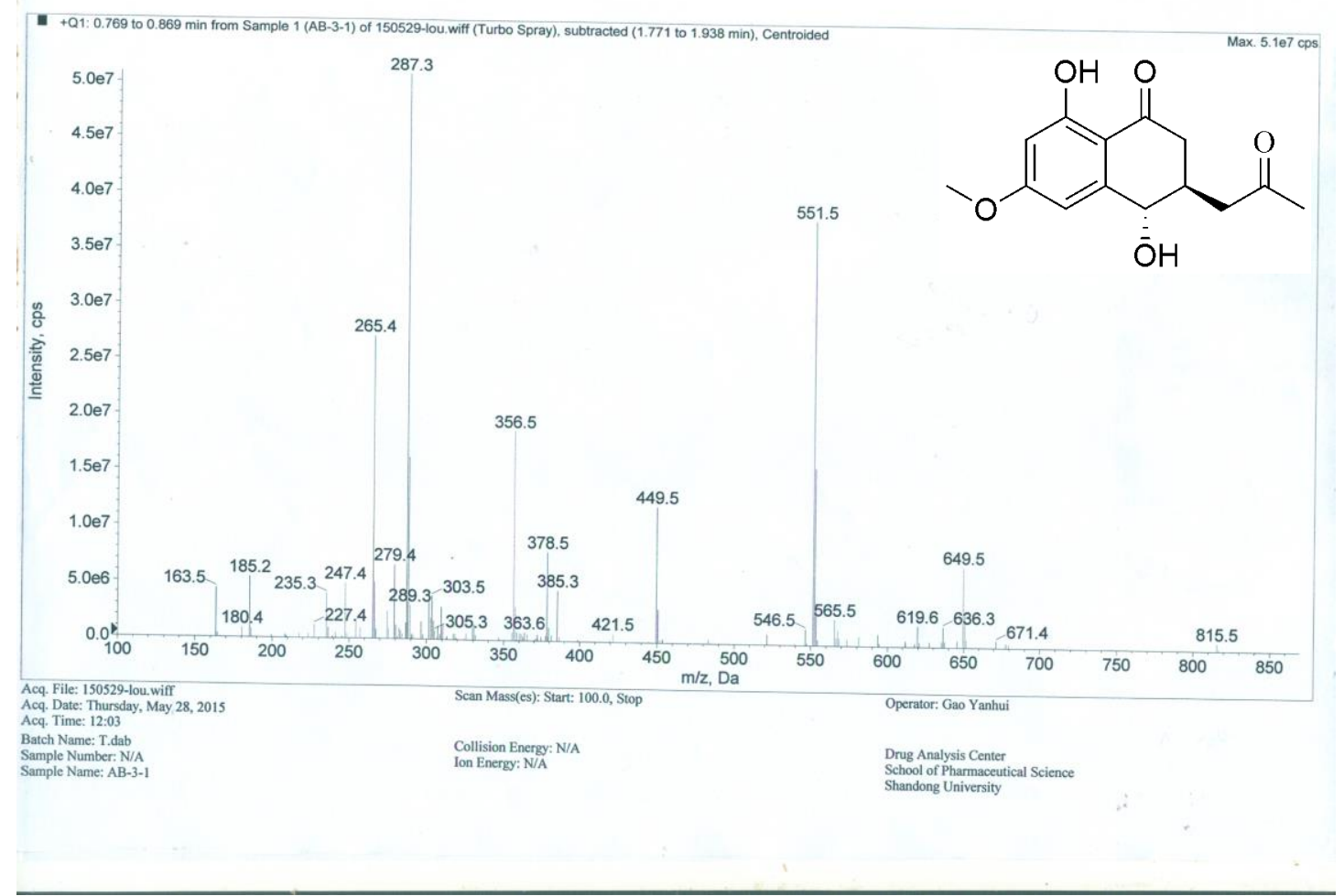

Figure S130. ESIMS spectrum of 14 


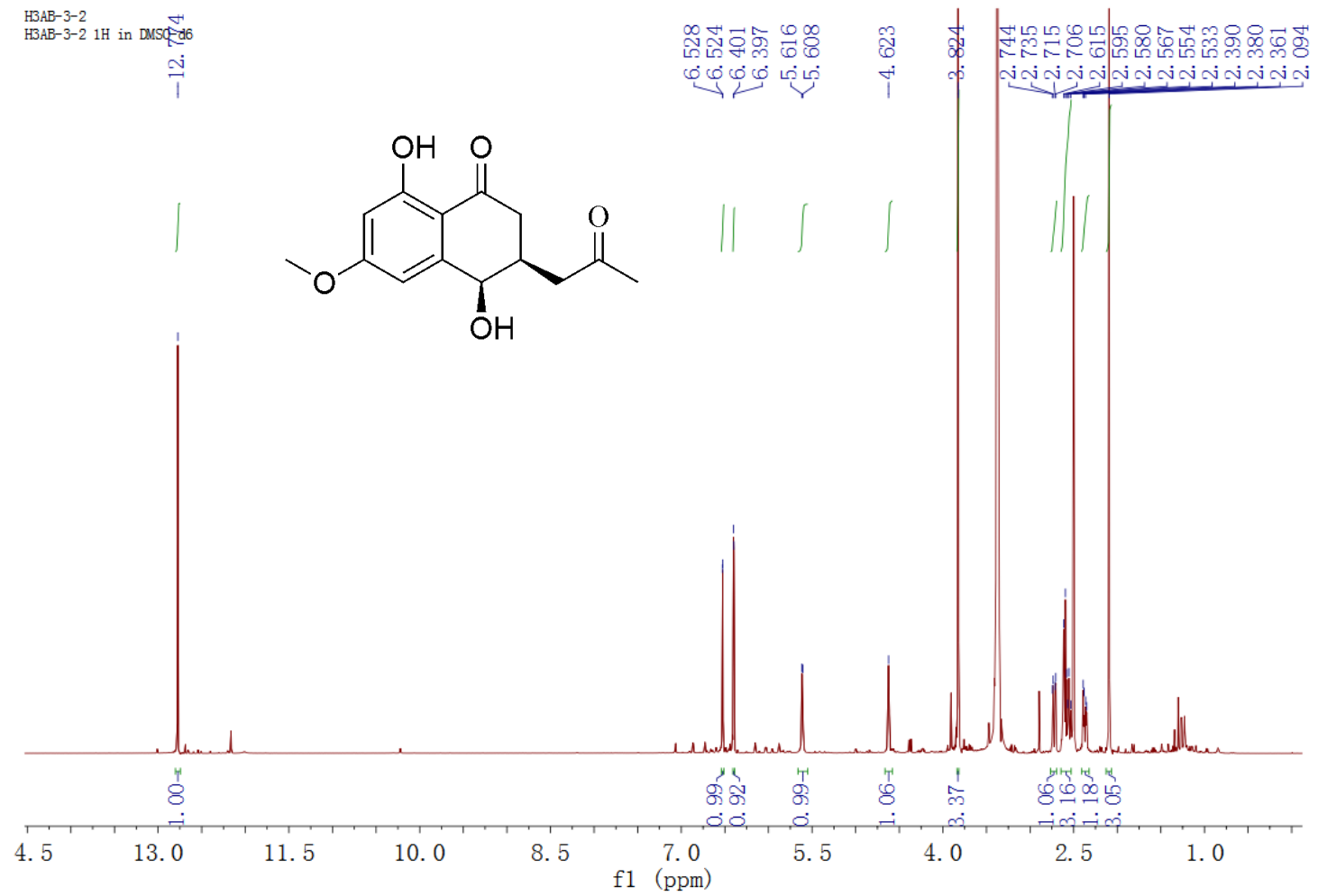

Figure S131. ${ }^{1} \mathrm{H}$ NMR spectrum of $\mathbf{1 5}$ in DMSO-d 6

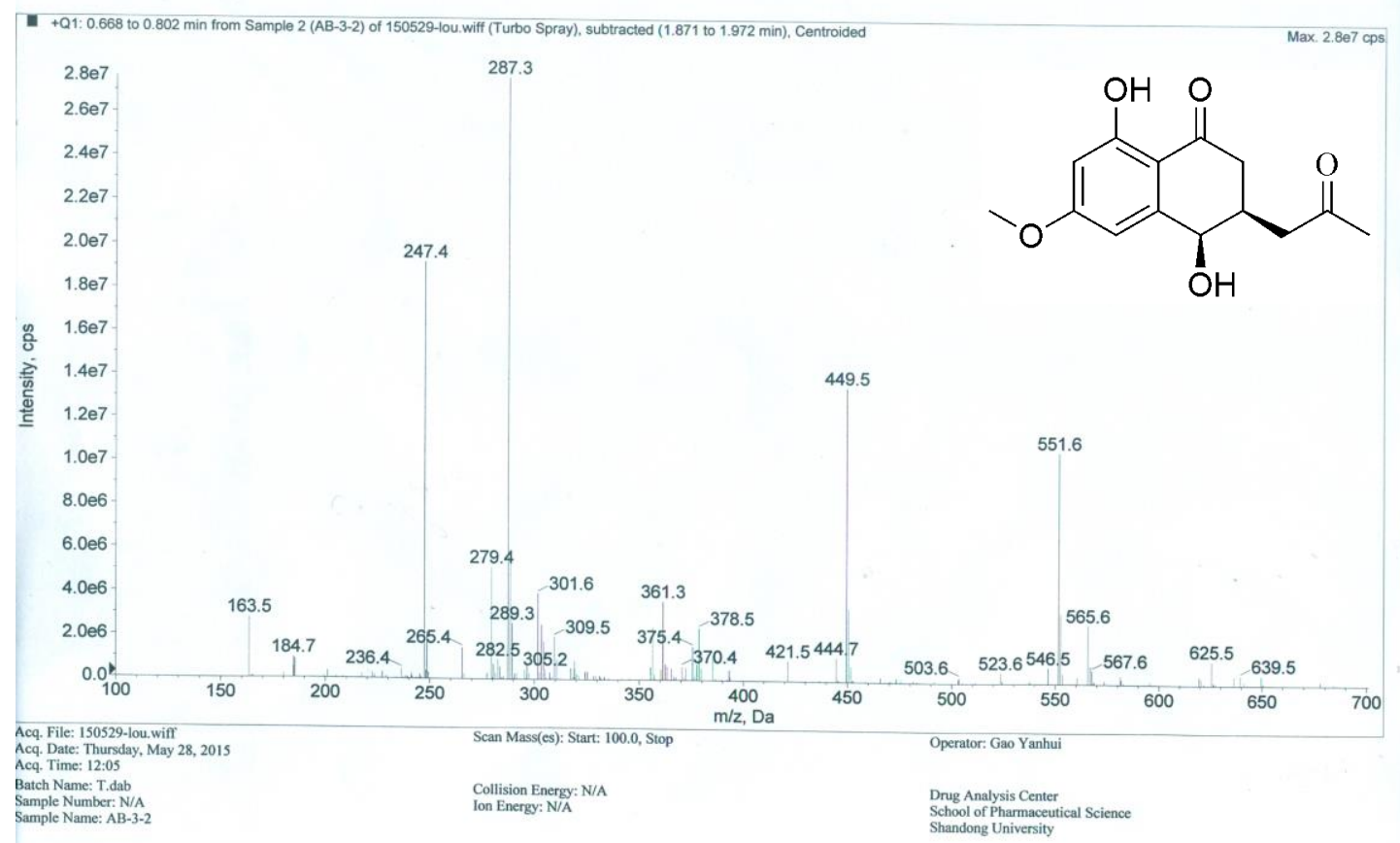

Figure S132. ESIMS spectrum of 15 


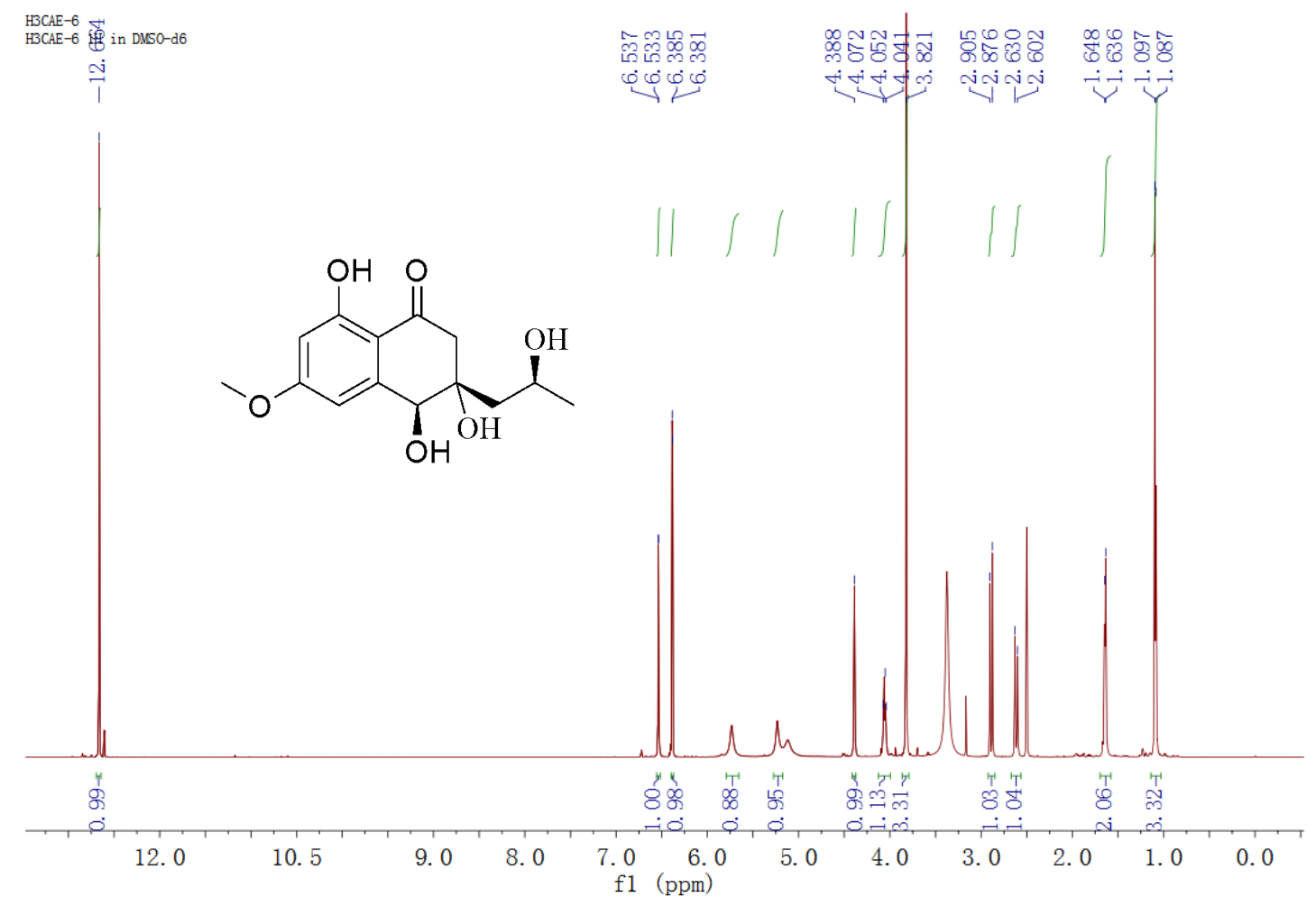

Figure S133. ${ }^{1} \mathrm{H}$ NMR spectrum of 16 in DMSO- $\mathrm{d}_{6}$

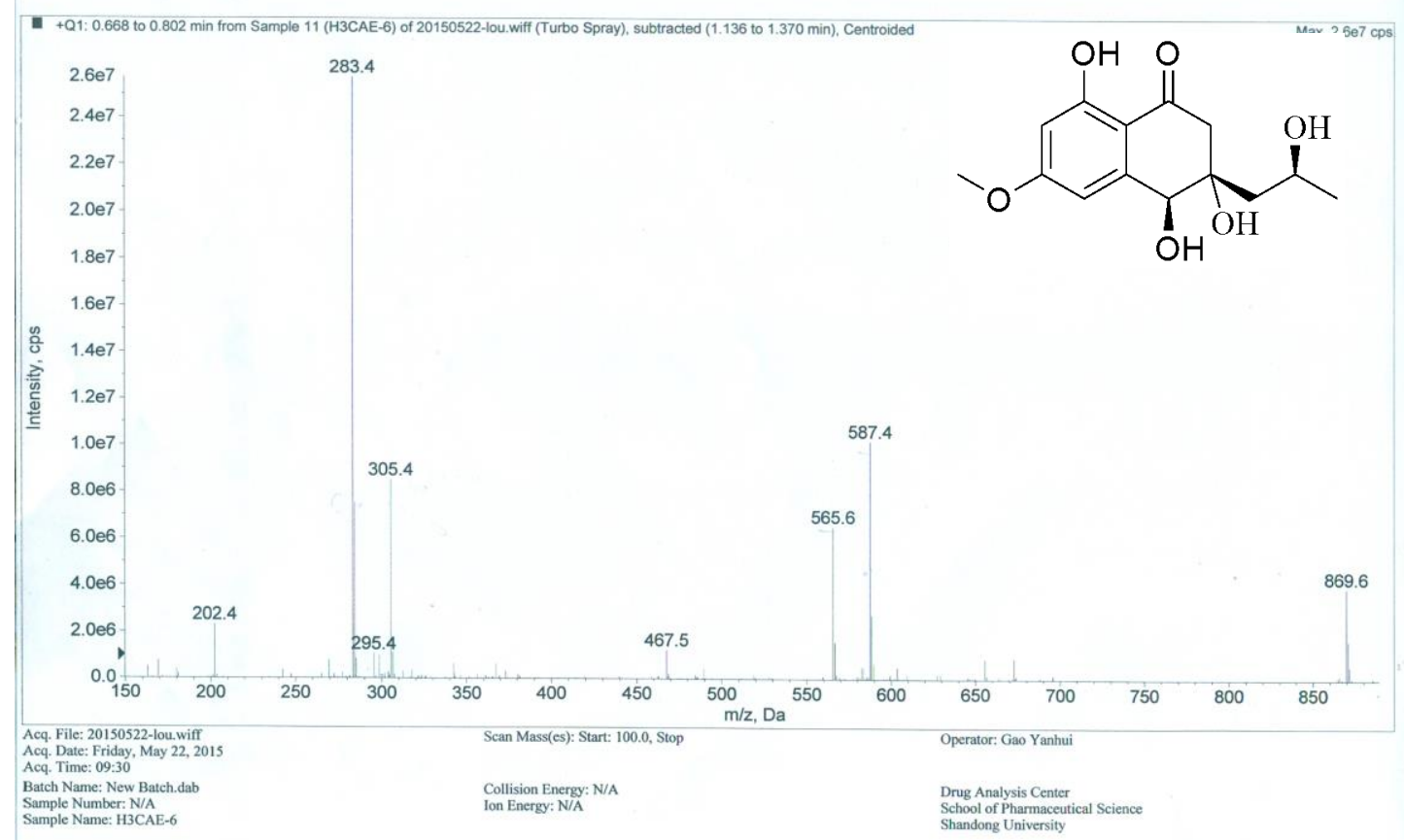

Figure S134. ESIMS spectrum of $\mathbf{1 6}$ 


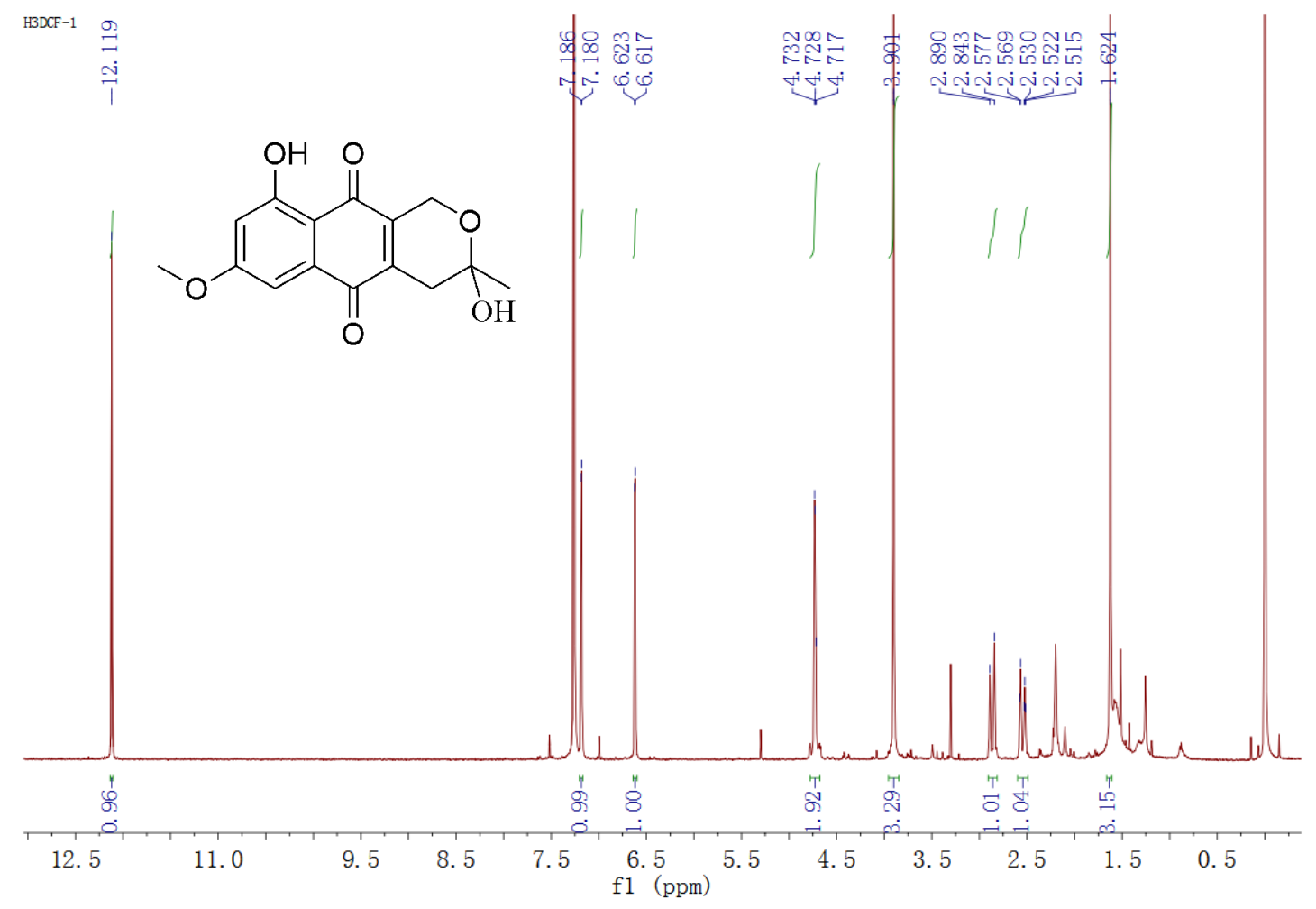

Figure S135. ${ }^{1} \mathrm{H}$ NMR spectrum of $\mathbf{1 7}$ in $\mathrm{CDCl}_{3}$

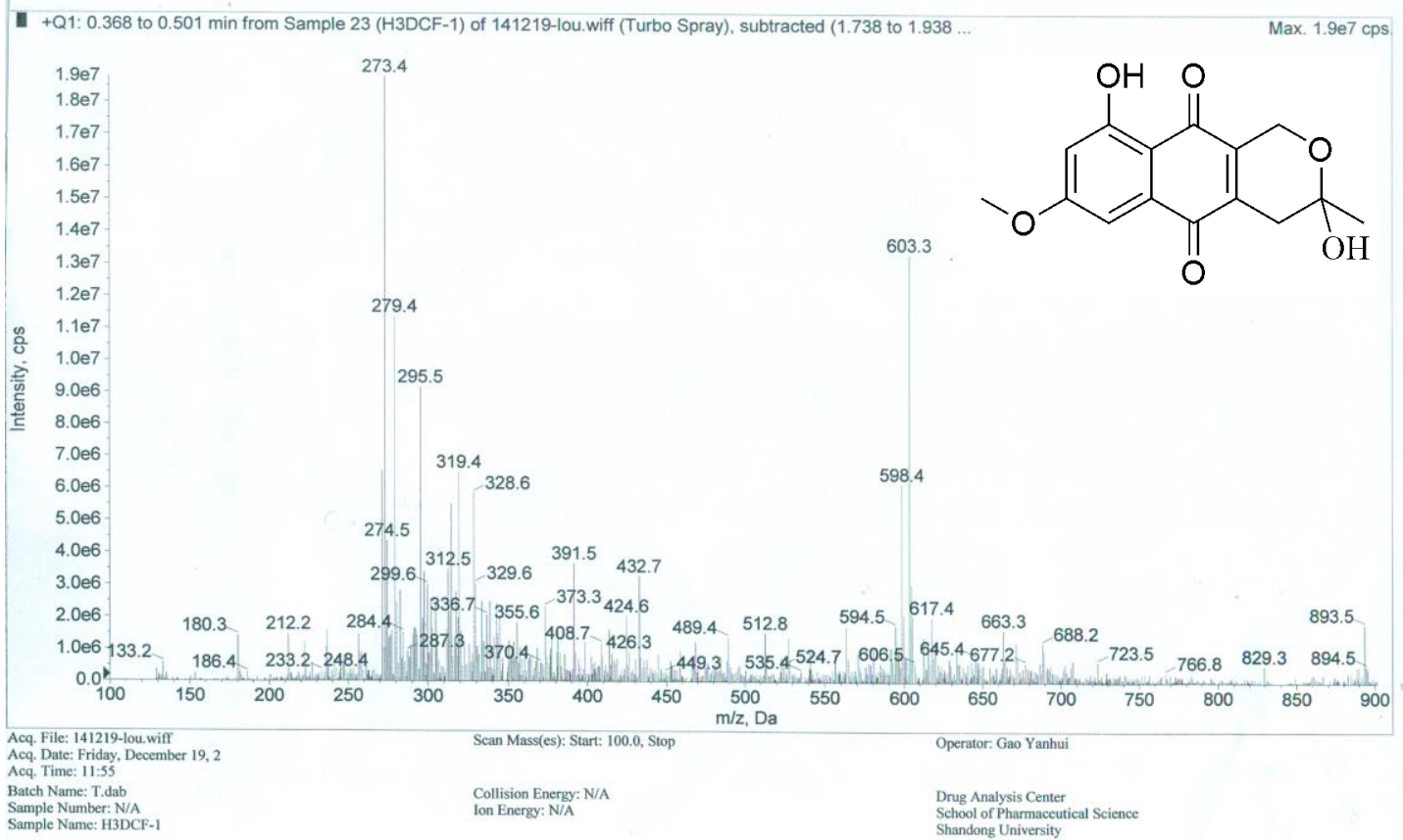

Figure S136. ESIMS spectrum of 17 


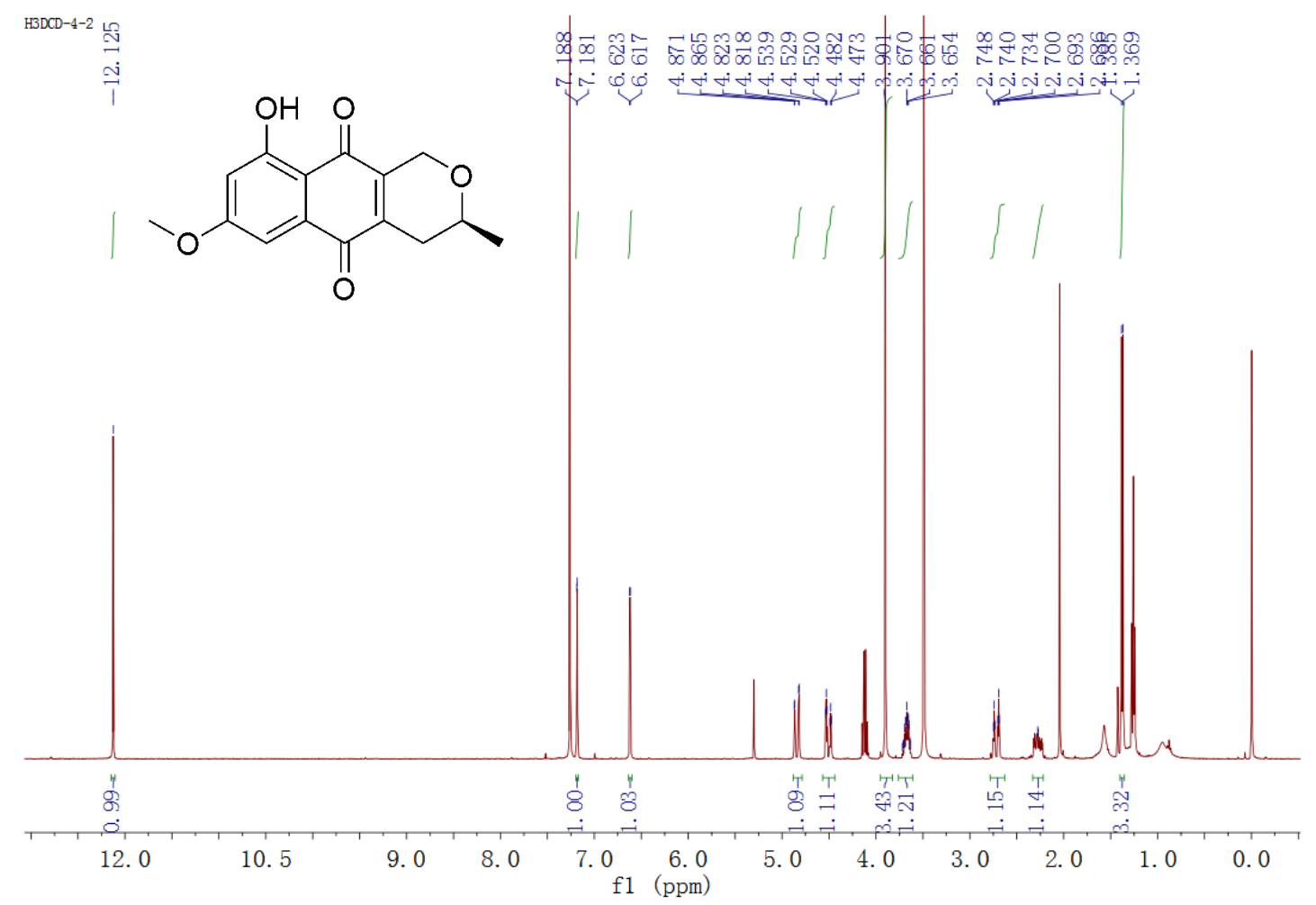

Figure S137. ${ }^{1} \mathrm{H}$ NMR spectrum of 18 in $\mathrm{CDCl}_{3}$

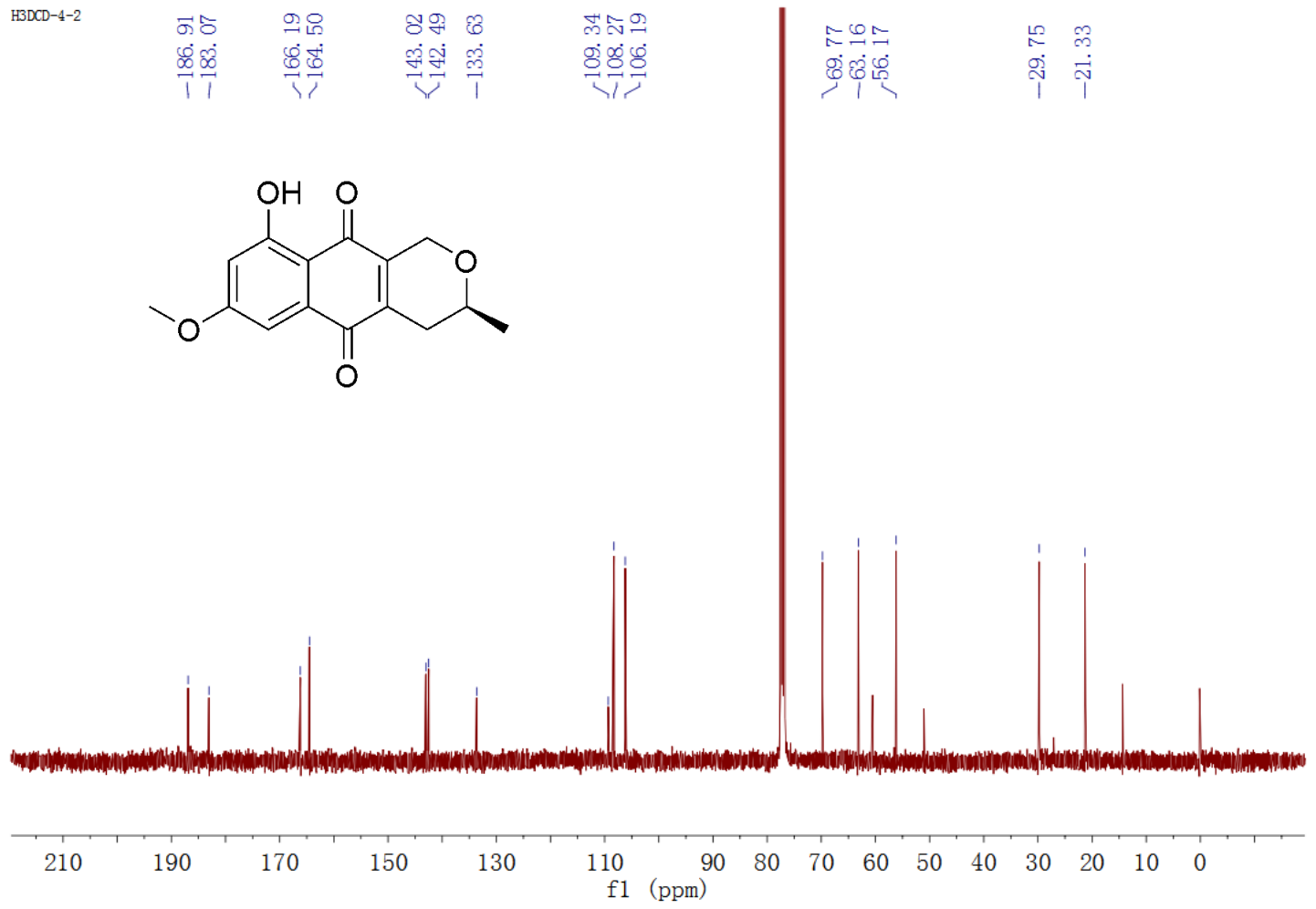

Figure S138. ${ }^{13} \mathrm{C}$ NMR spectrum of 18 in $\mathrm{CDCl}_{3}$ 


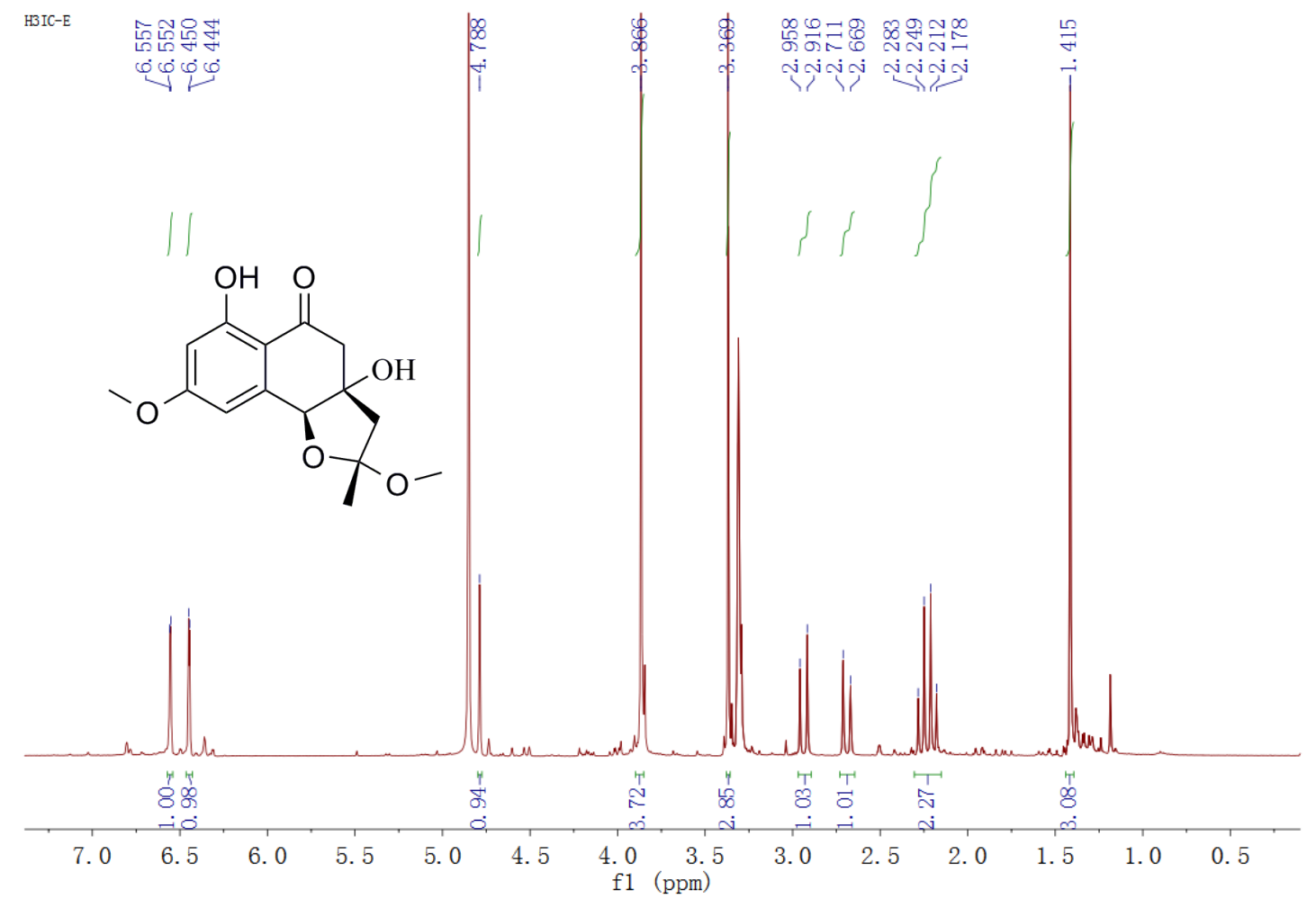

Figure S139. ${ }^{1} \mathrm{H}$ NMR spectrum of 19 in $\mathrm{CD}_{3} \mathrm{OD}$

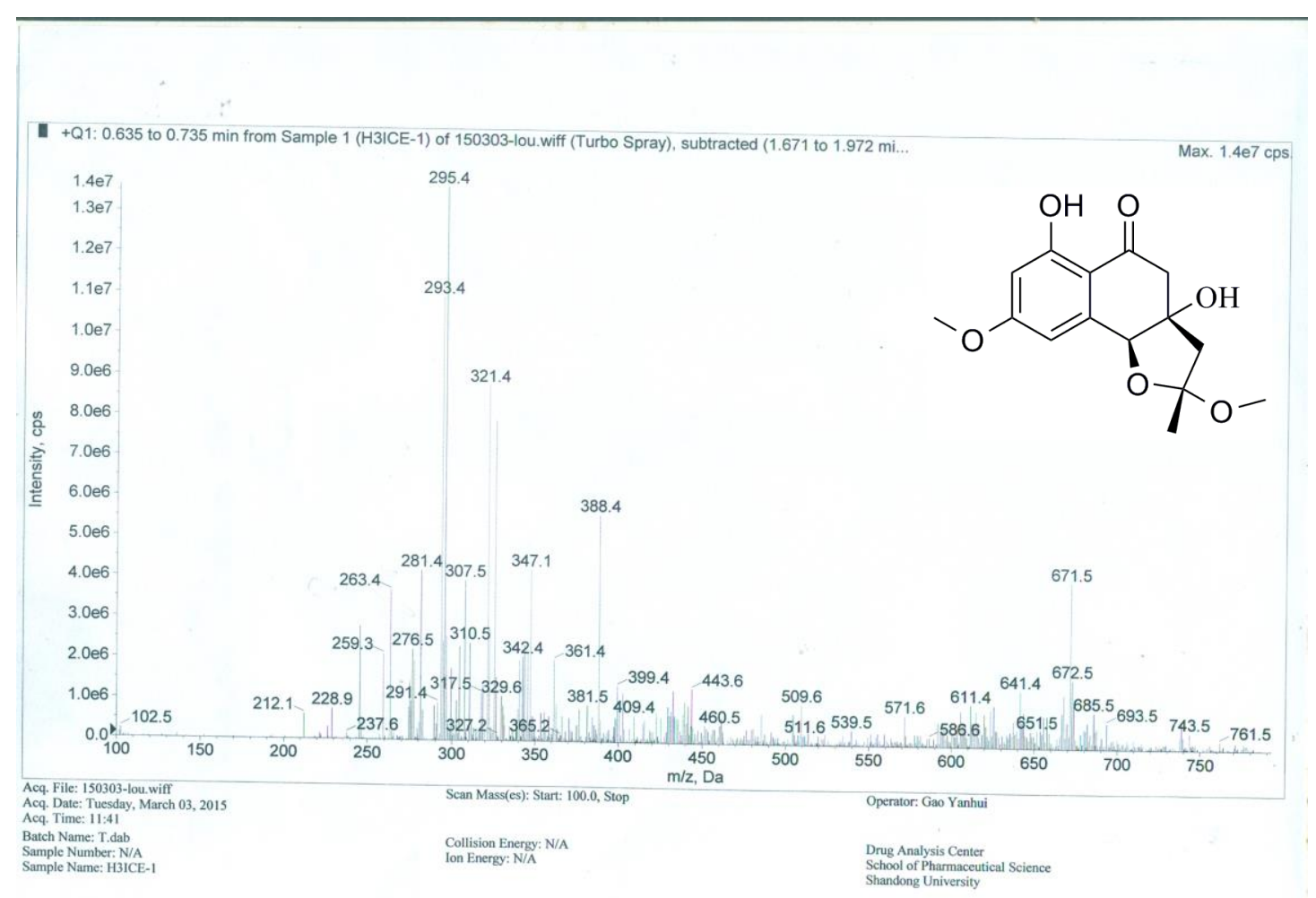

Figure S140. ESIMS spectrum of 19 


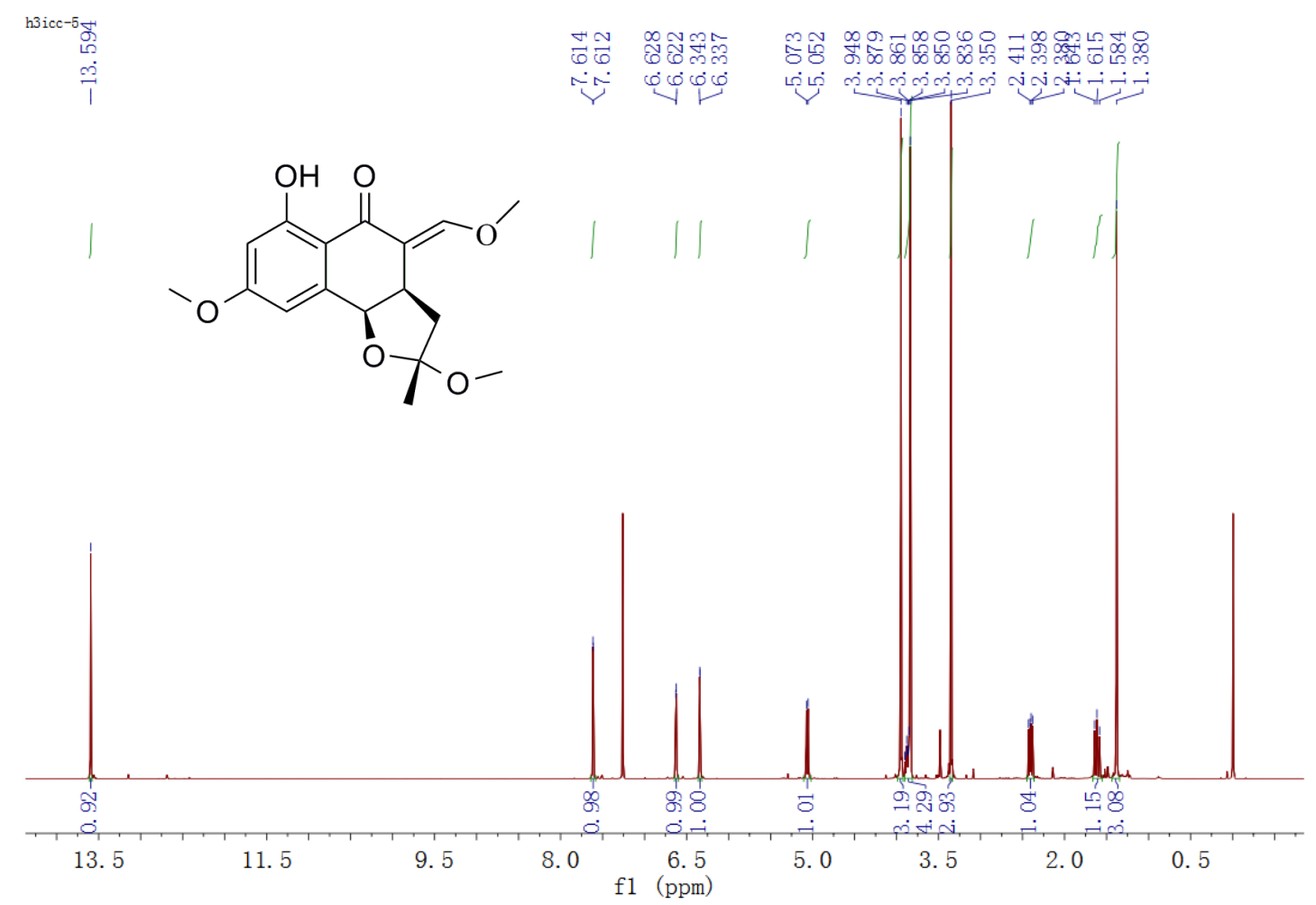

Figure S141. ${ }^{1} \mathrm{H}$ NMR spectrum of 20 in $\mathrm{CDCl}_{3}$

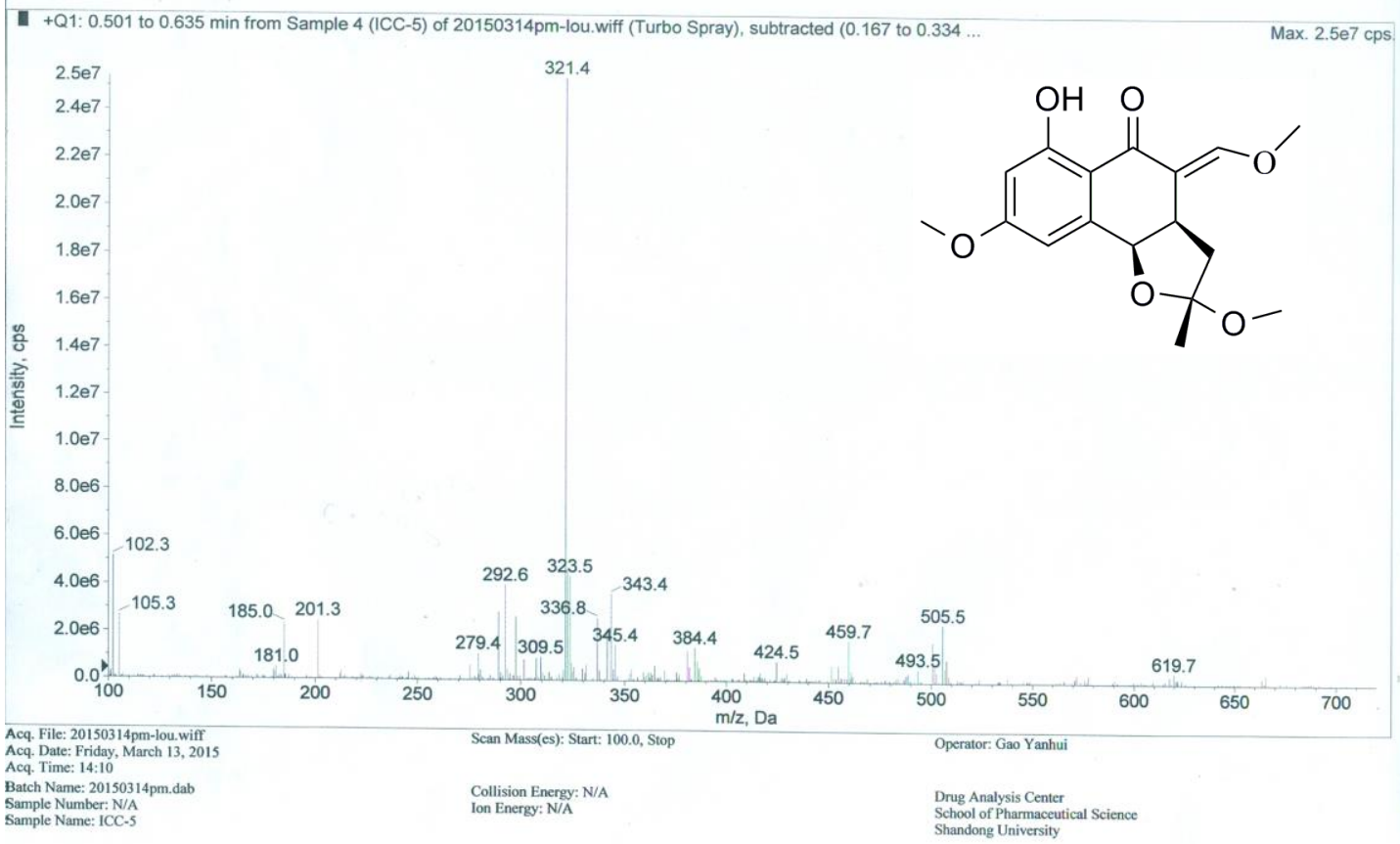

Figure S142. ESIMS spectrum of 20 


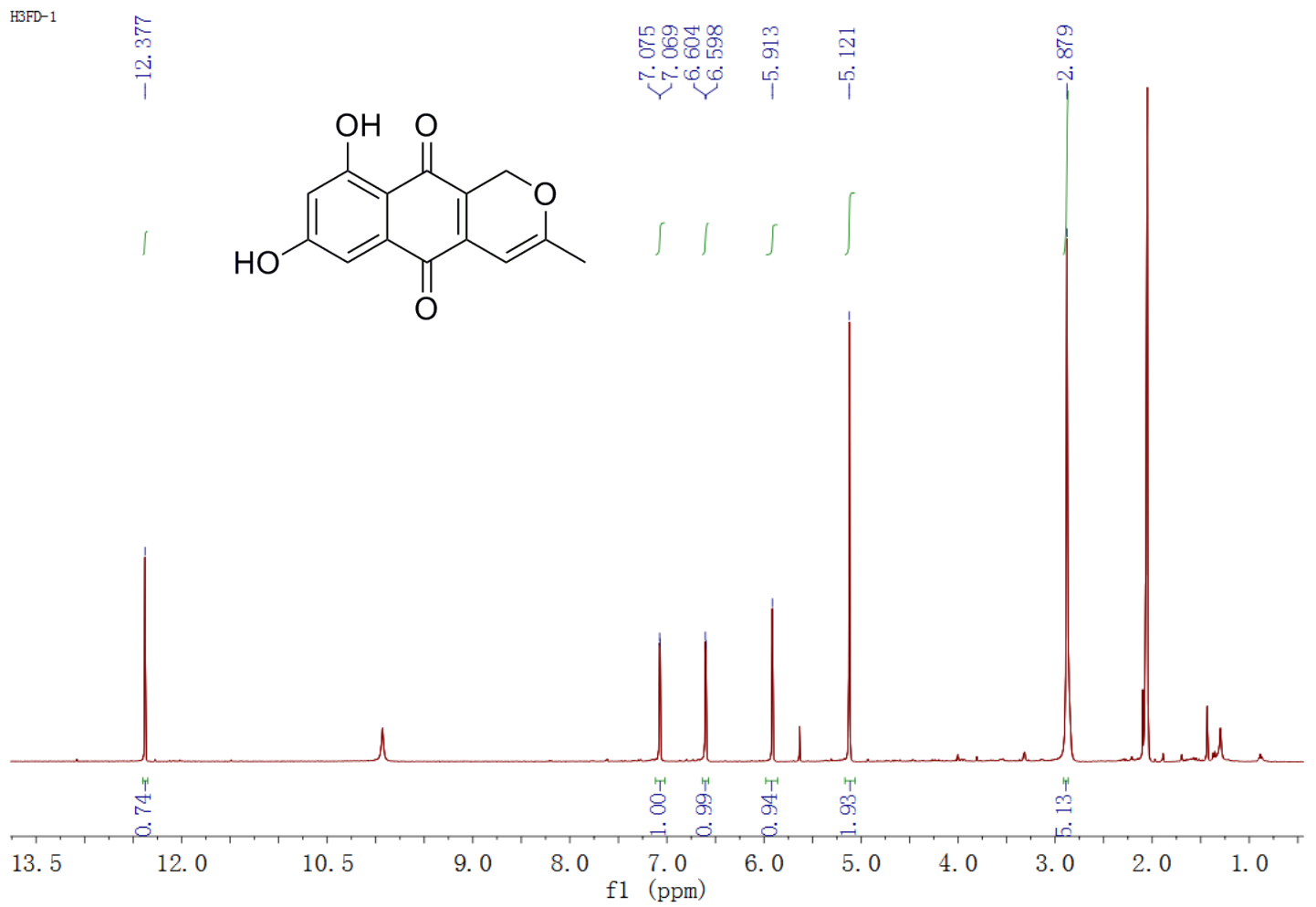

Figure S143. ${ }^{1} \mathrm{H}$ NMR spectrum of 21 in Acetone- $d_{6}$

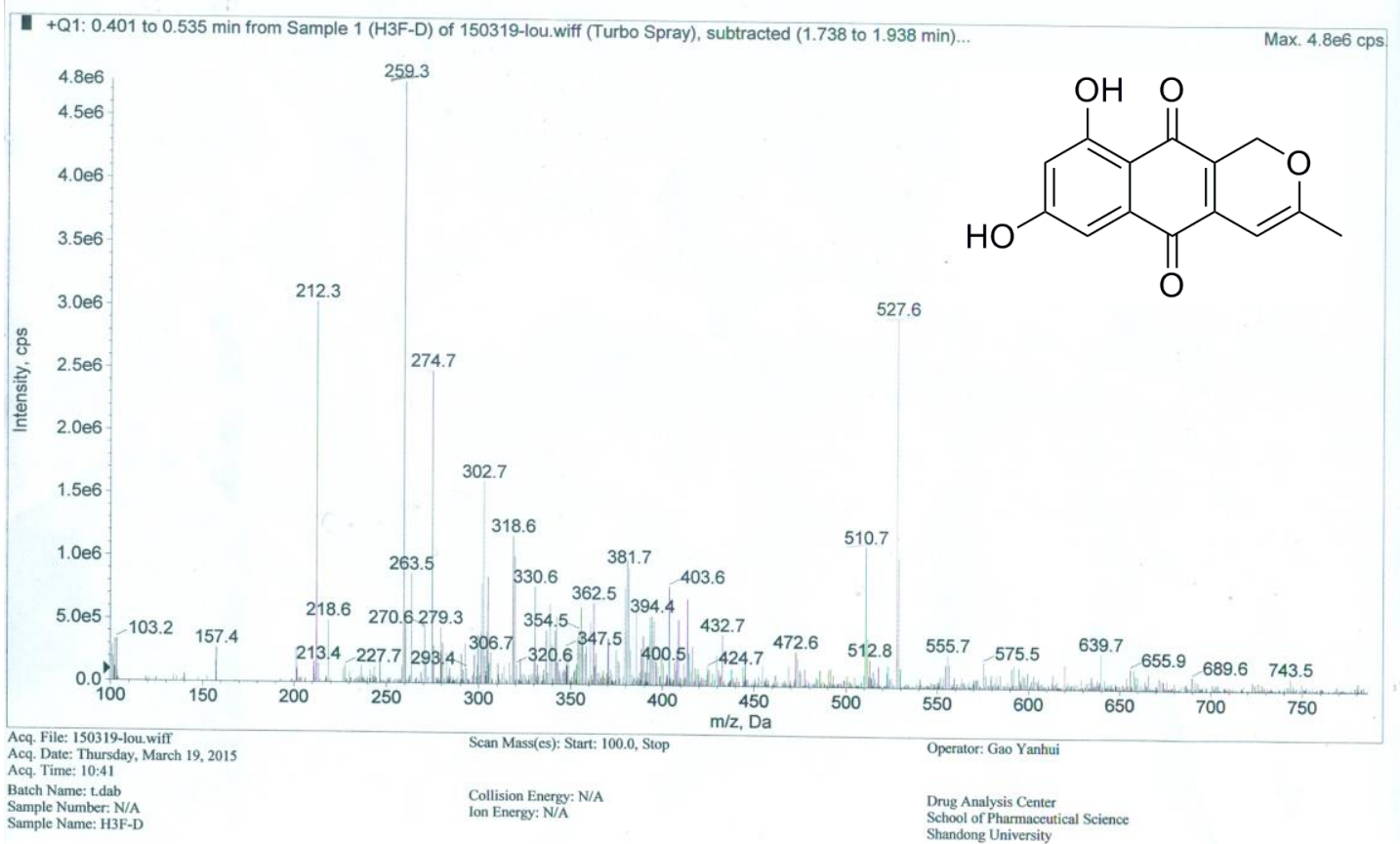

Figure S144. ESIMS spectrum of 21 


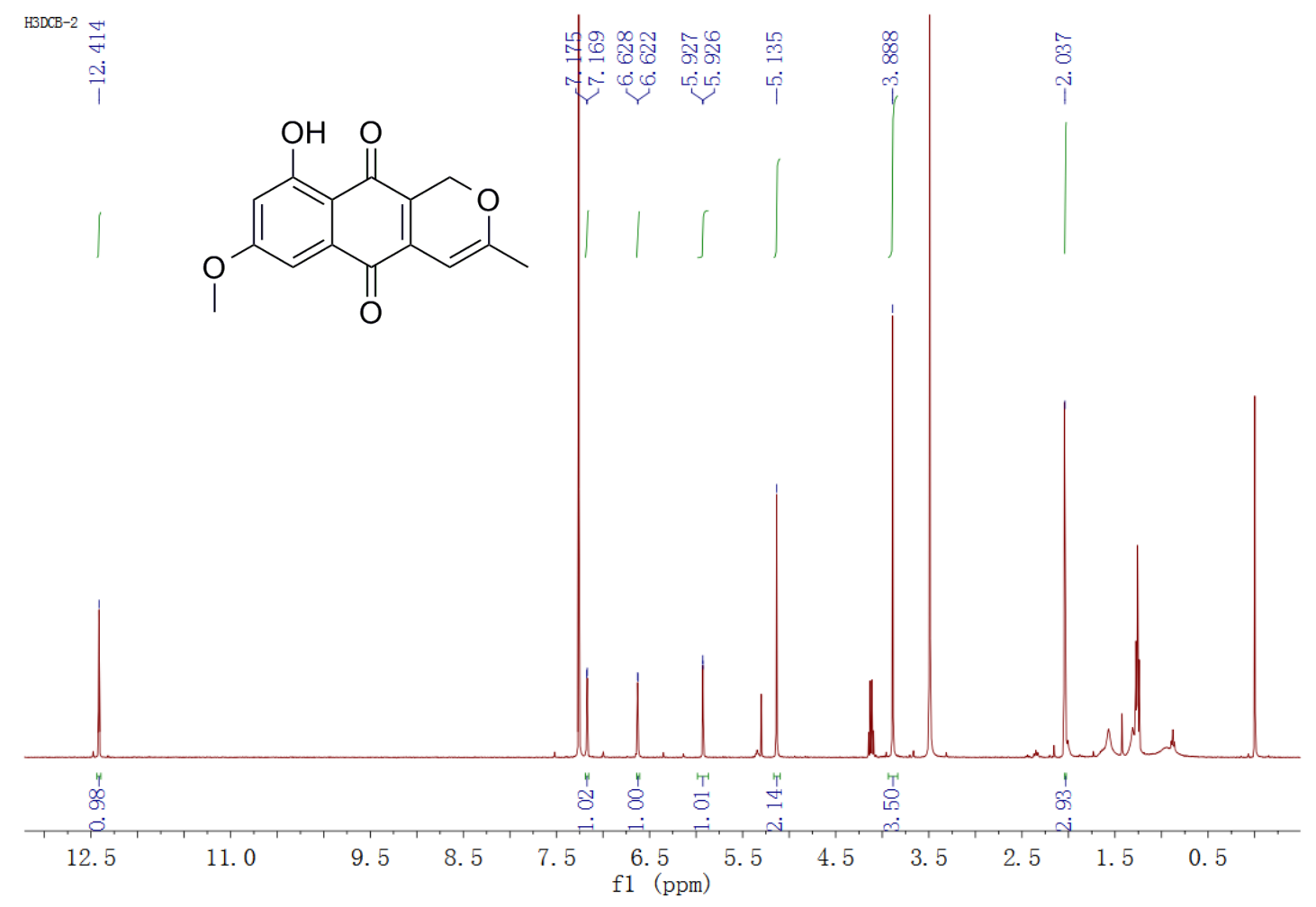

Figure S145. ${ }^{1} \mathrm{H}$ NMR spectrum of 22 in $\mathrm{CDCl}_{3}$

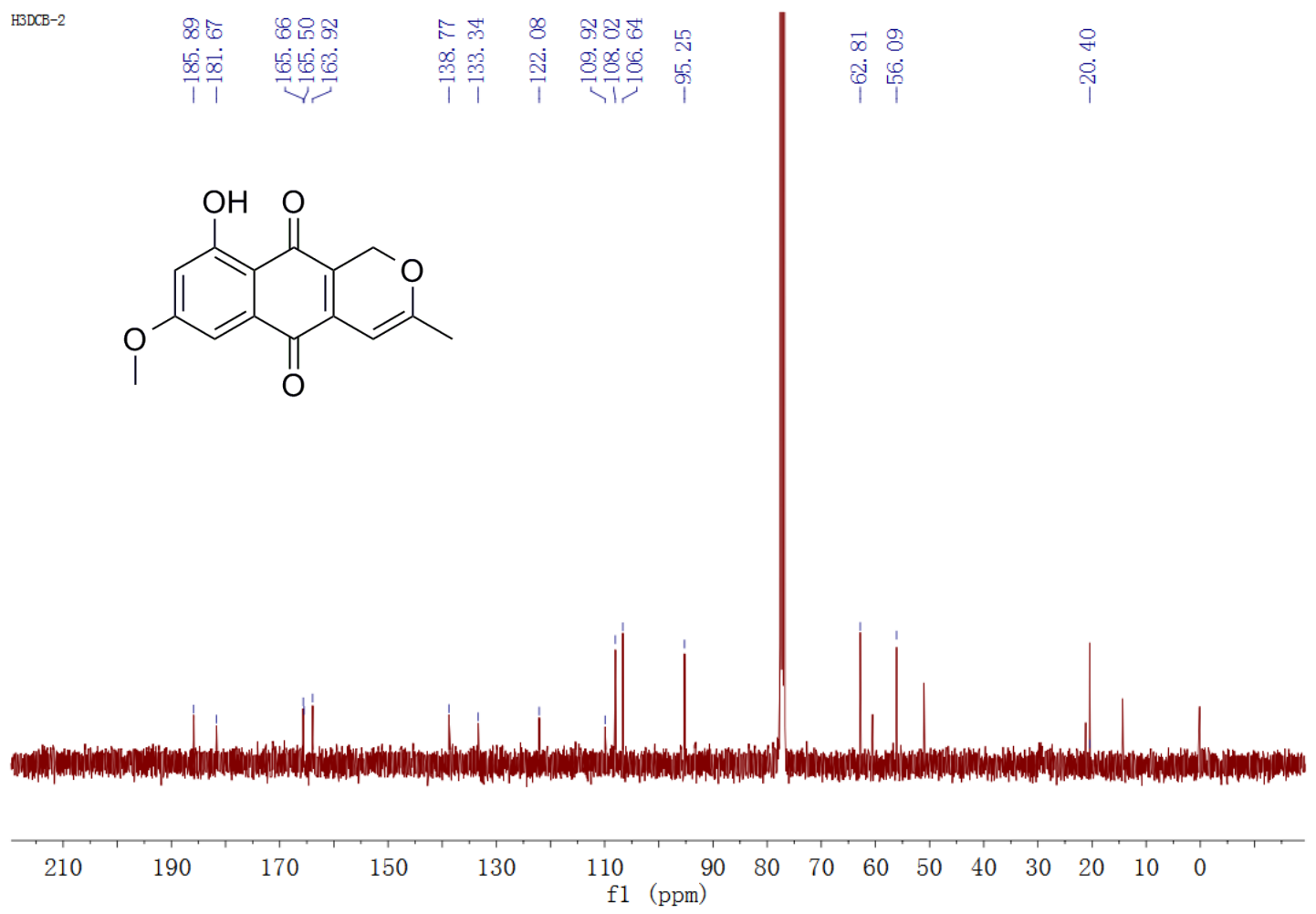

Figure S146. ${ }^{13} \mathrm{C}$ NMR spectrum of 22 in $\mathrm{CDCl}_{3}$ 


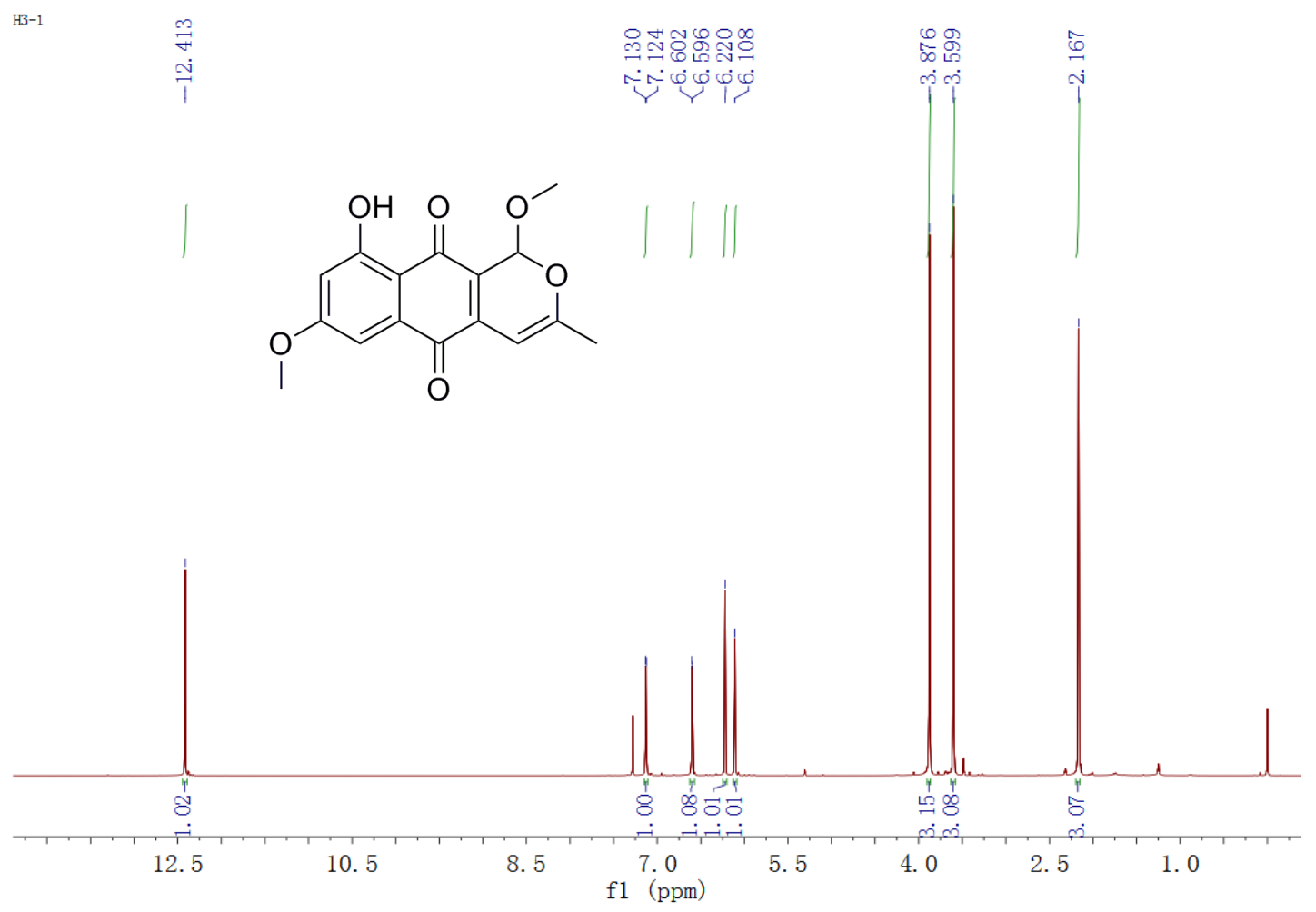

Figure S147. ${ }^{1} \mathrm{H}$ NMR spectrum of 23 in $\mathrm{CDCl}_{3}$

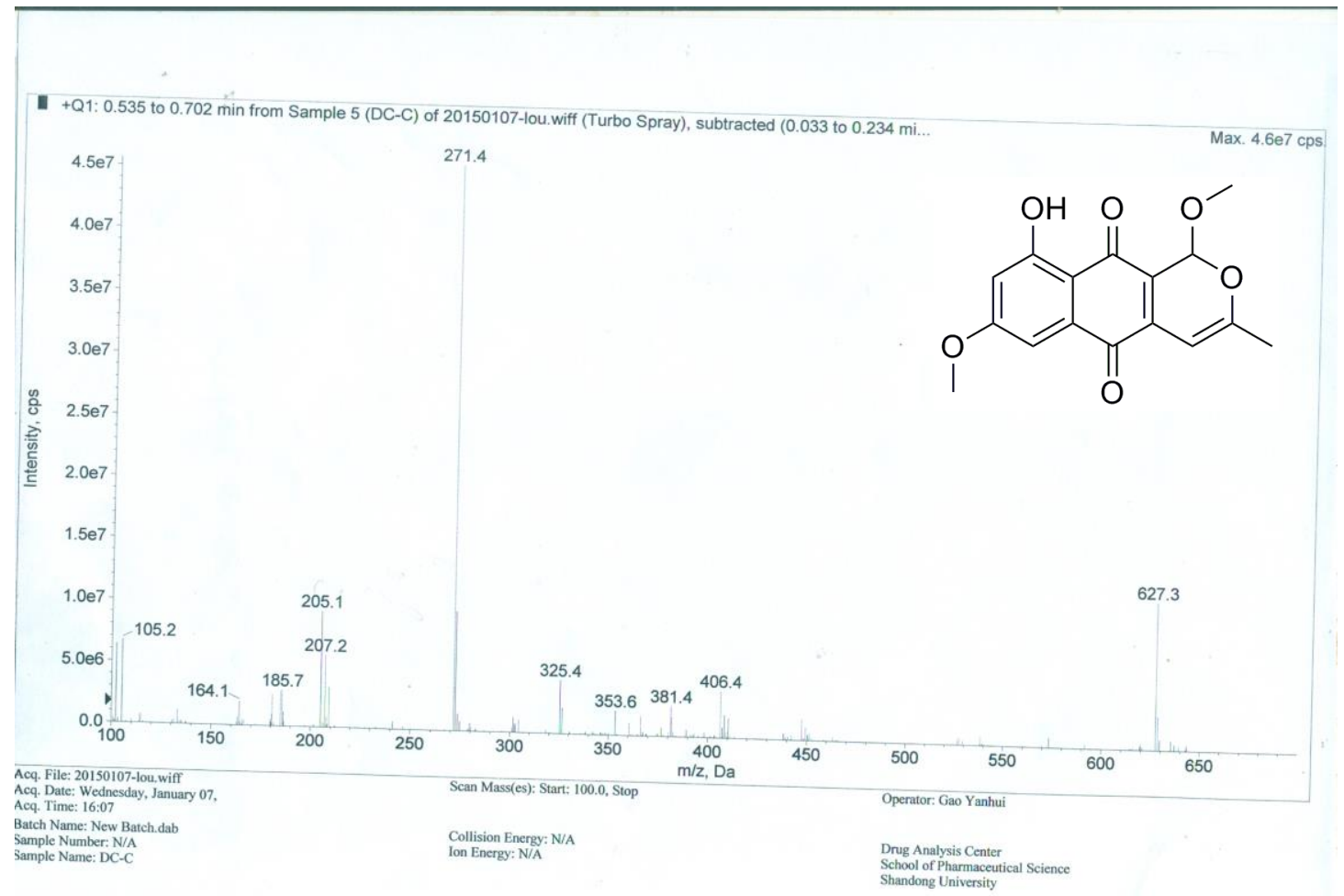

Figure S148. ESIMS spectrum of $\mathbf{2 3}$ 


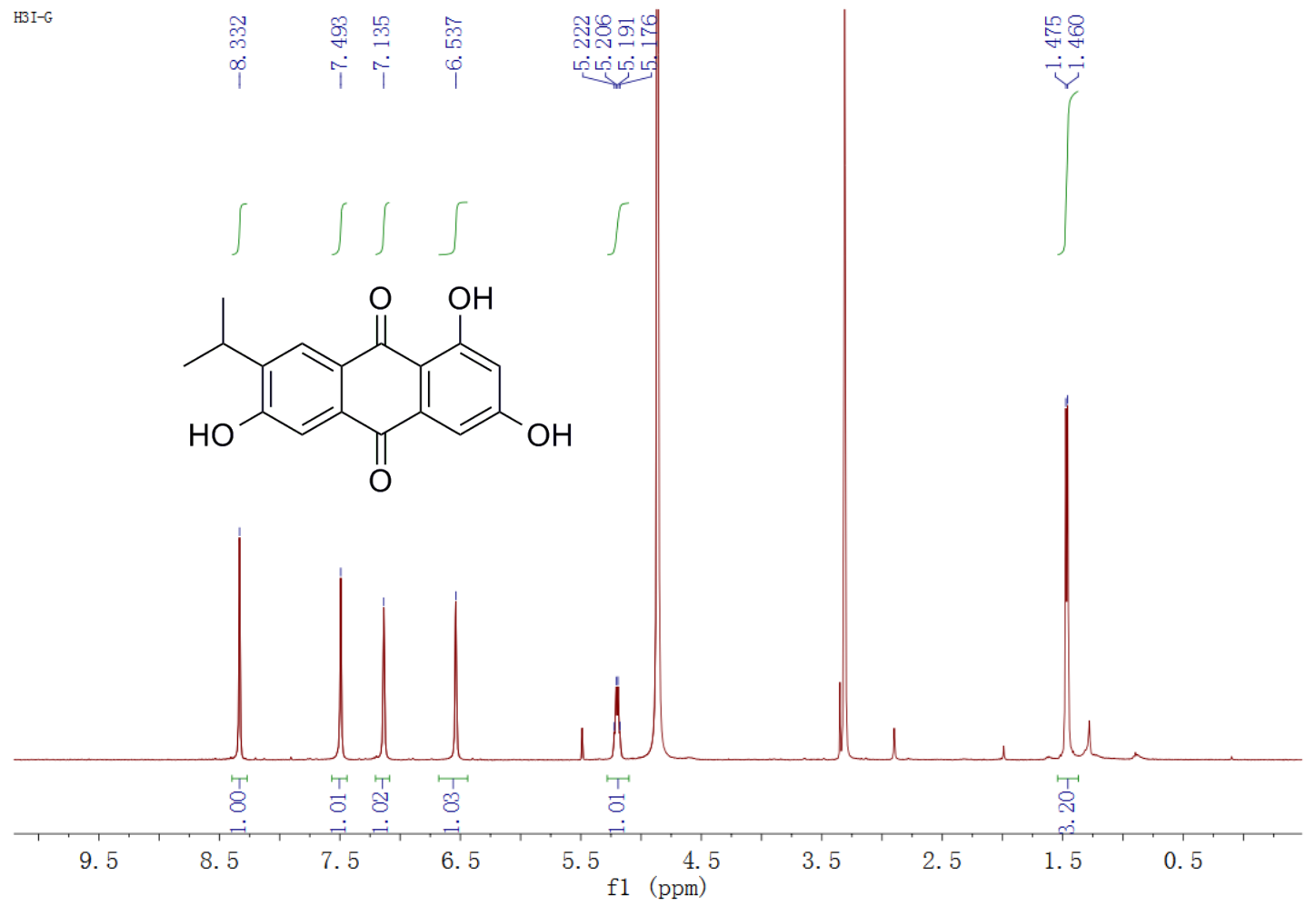

Figure S149. ${ }^{1} \mathrm{H}$ NMR spectrum of 24 in $\mathrm{CD}_{3} \mathrm{OD}$

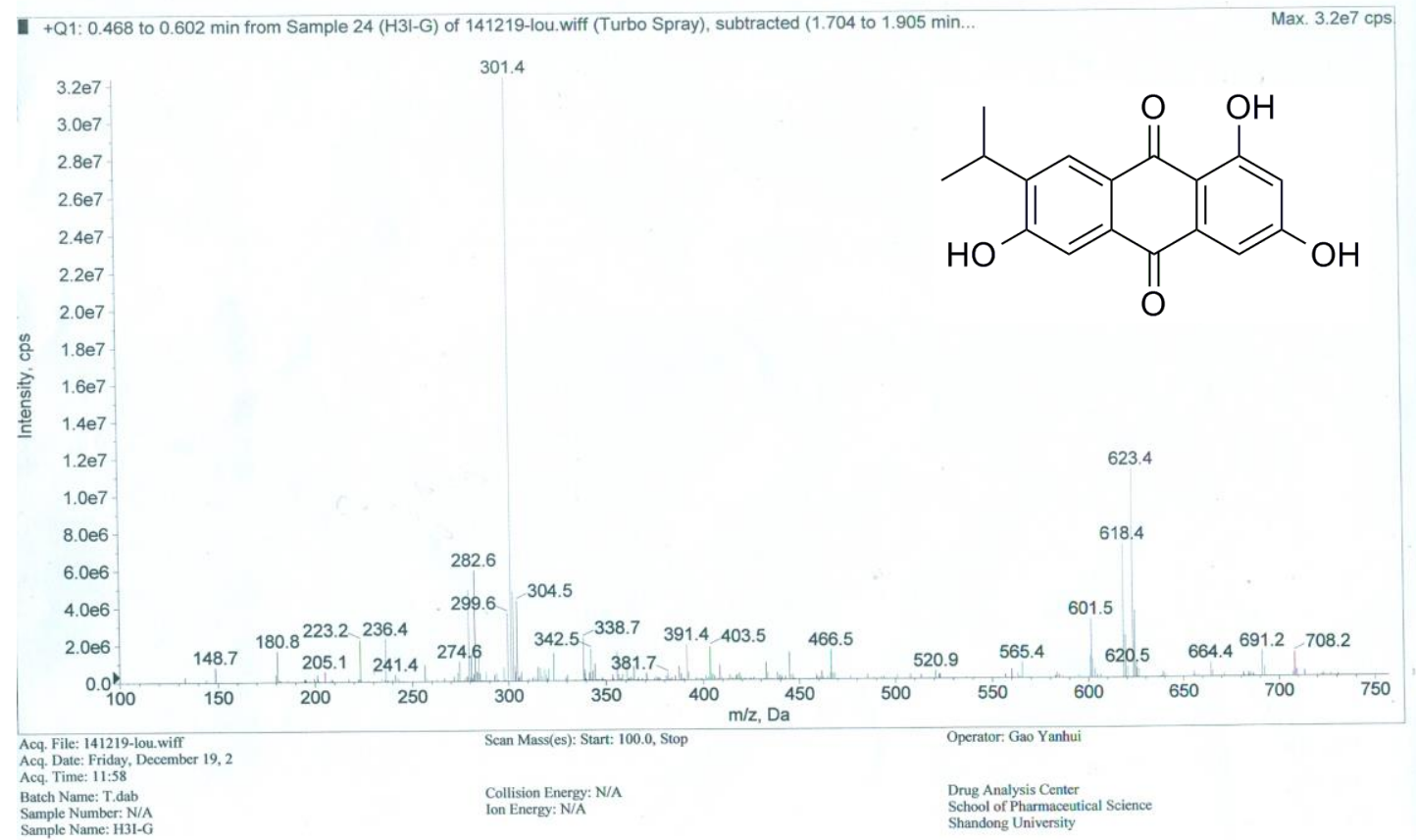

Figure S150. ESIMS spectrum of 24 


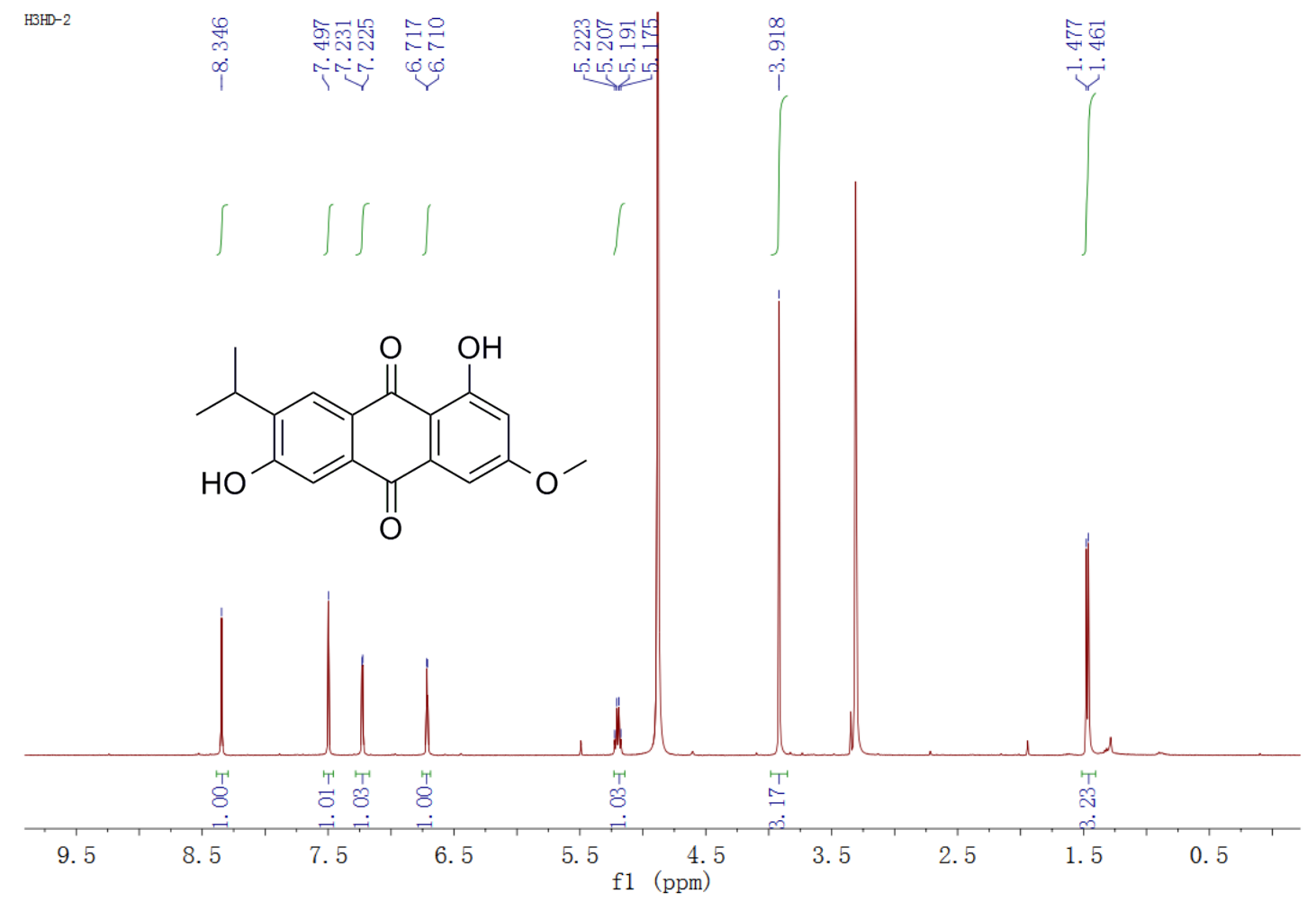

Figure S151. ${ }^{1} \mathrm{H}$ NMR spectrum of 25 in $\mathrm{CD}_{3} \mathrm{OD}$

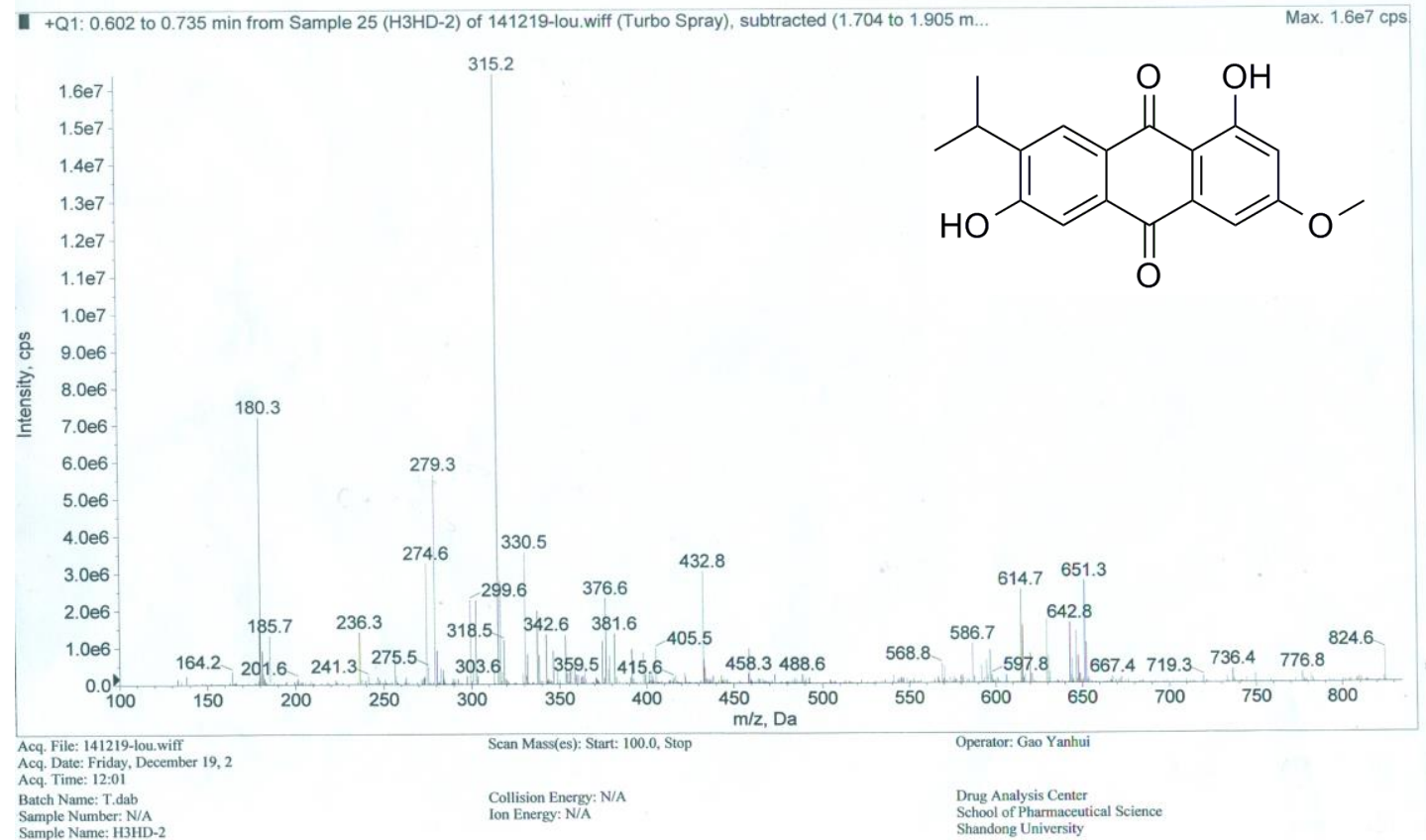

Figure S152. ESIMS spectrum of 25 


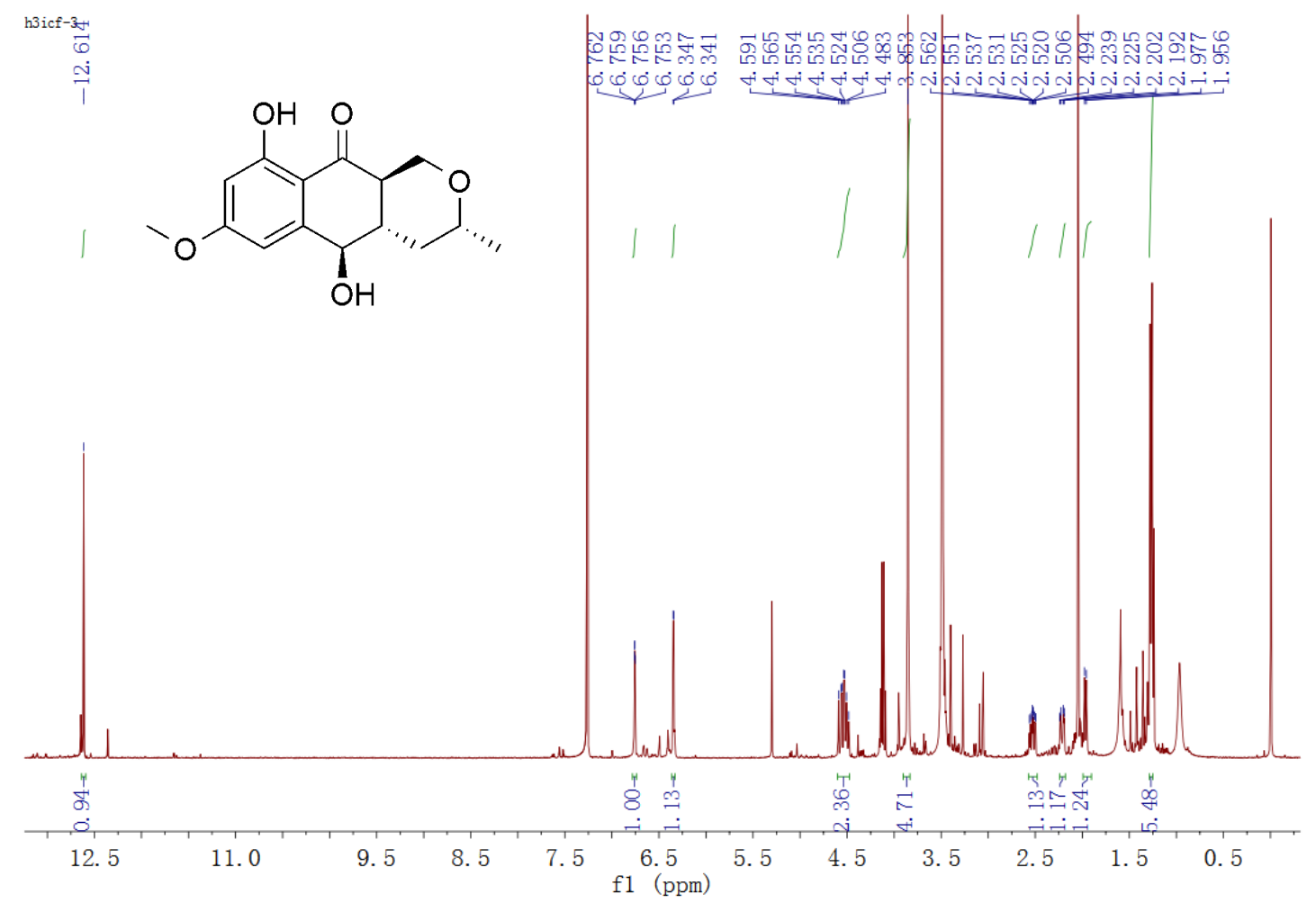

Figure S153. ${ }^{1} \mathrm{H}$ NMR spectrum of 26 in DMSO-d 6

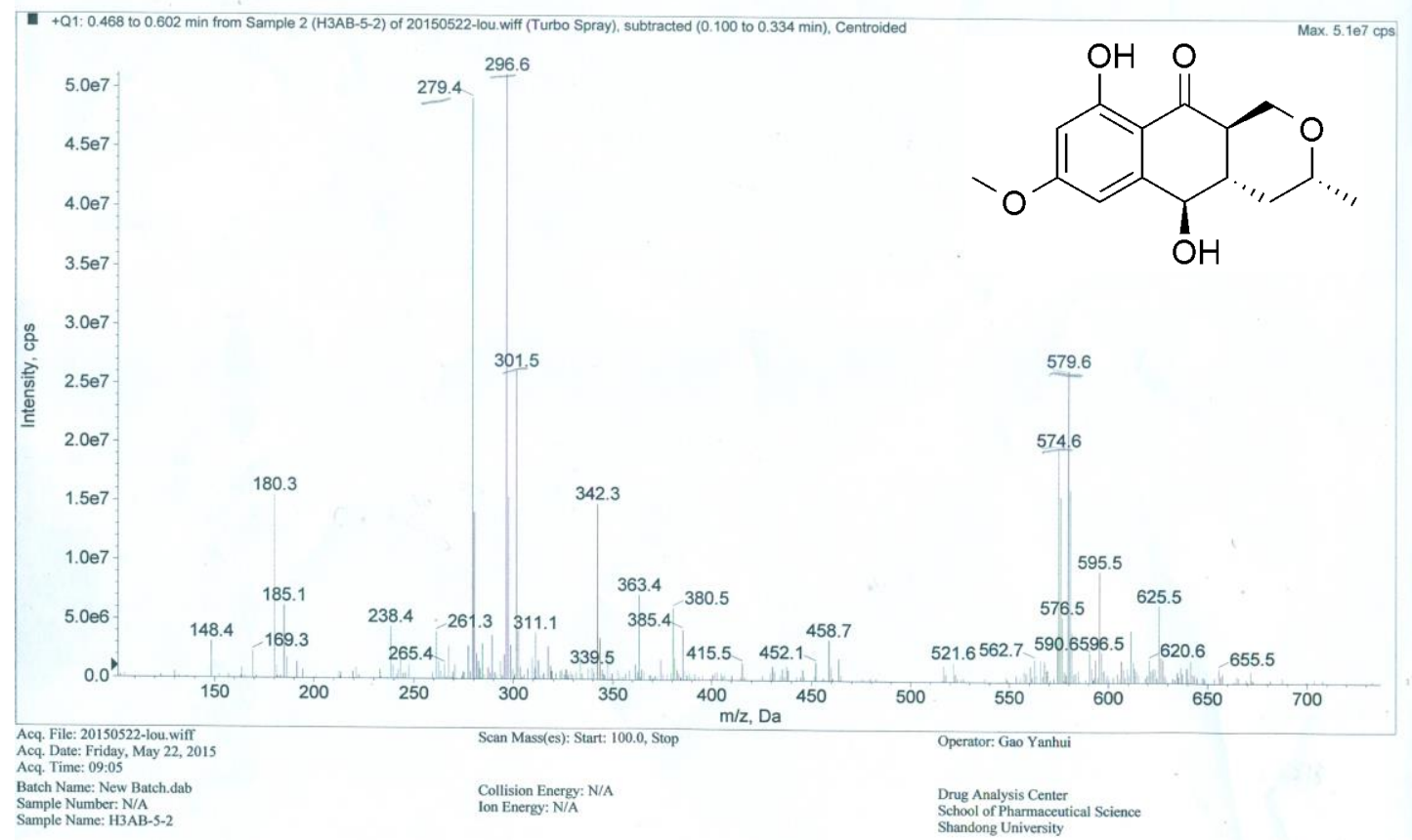

Figure S154. ESIMS spectrum of $\mathbf{2 6}$ 


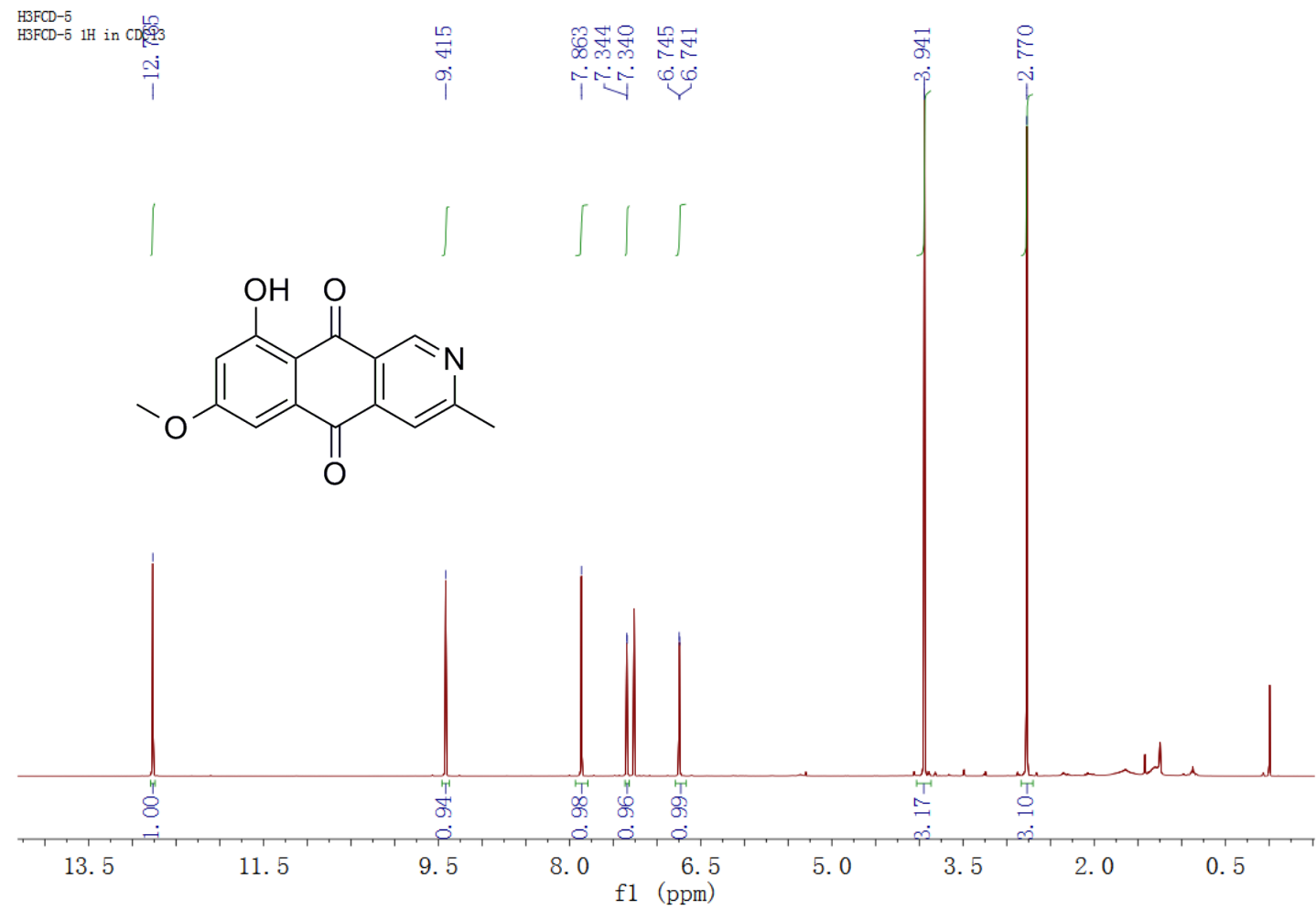

Figure S155. ${ }^{1} \mathrm{H}$ NMR spectrum of 27 in $\mathrm{CDCl}_{3}$

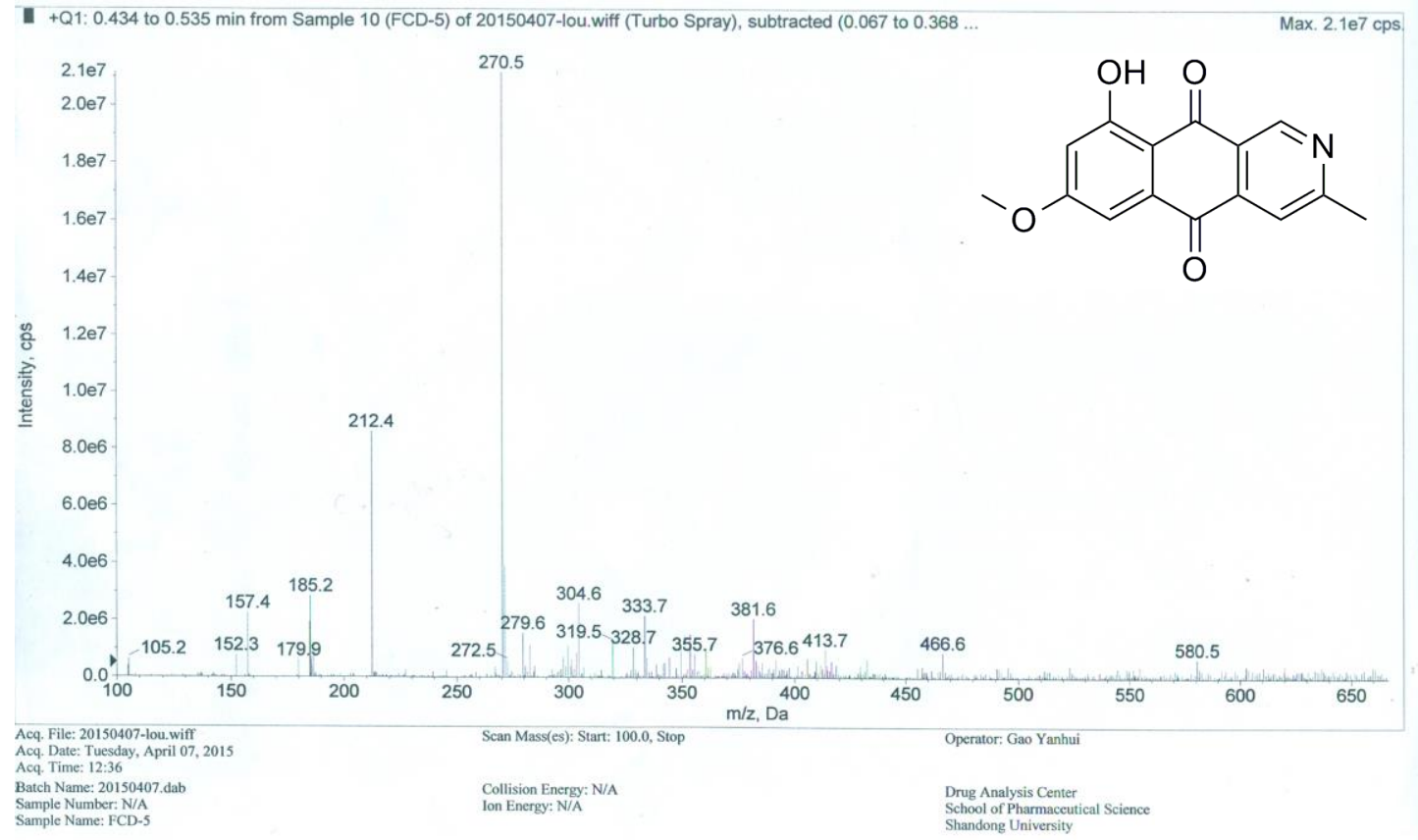

Figure S156. ESIMS spectrum of 27 


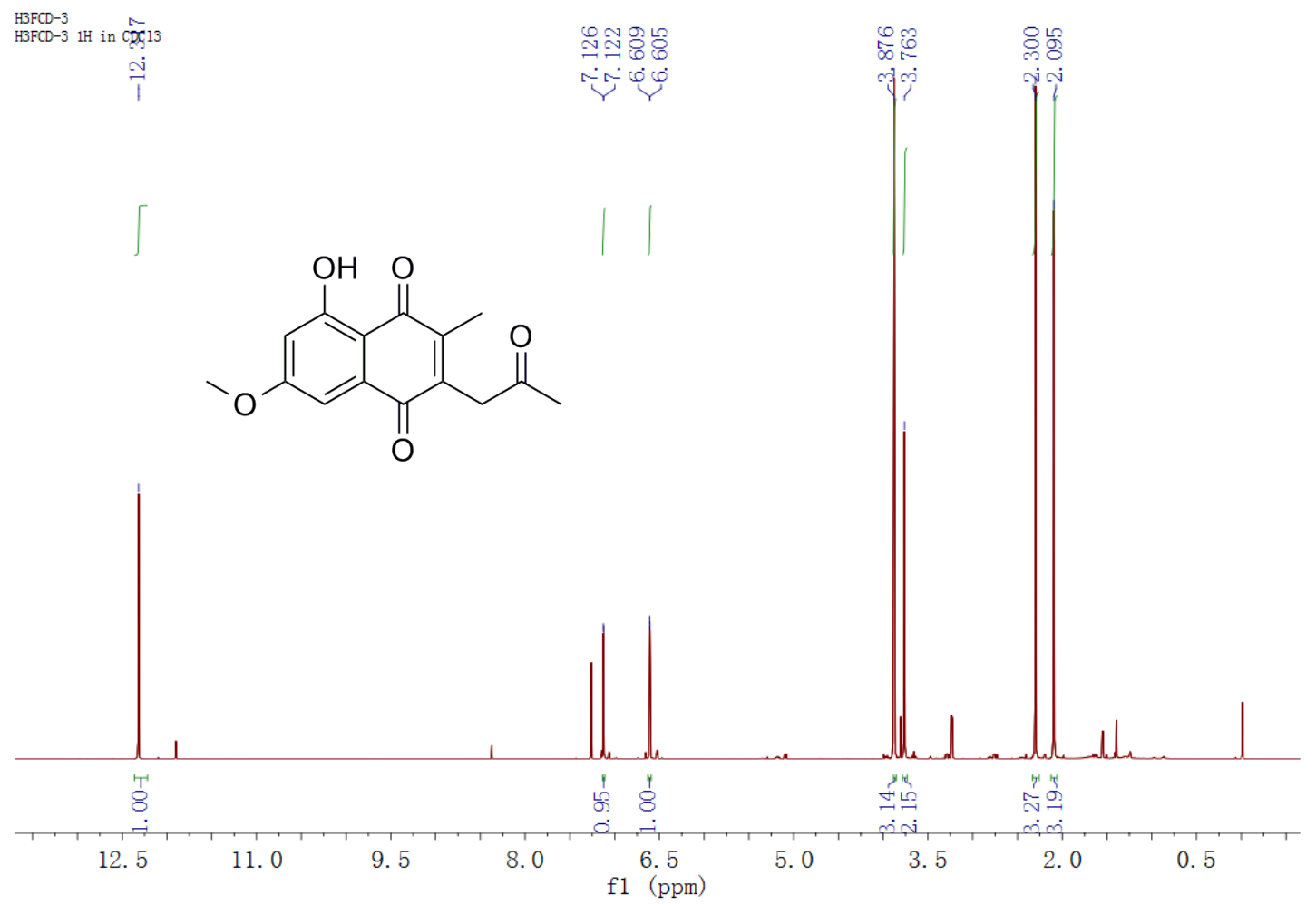

Figure S157. ${ }^{1} \mathrm{H}$ NMR spectrum of 28 in $\mathrm{CDCl}_{3}$

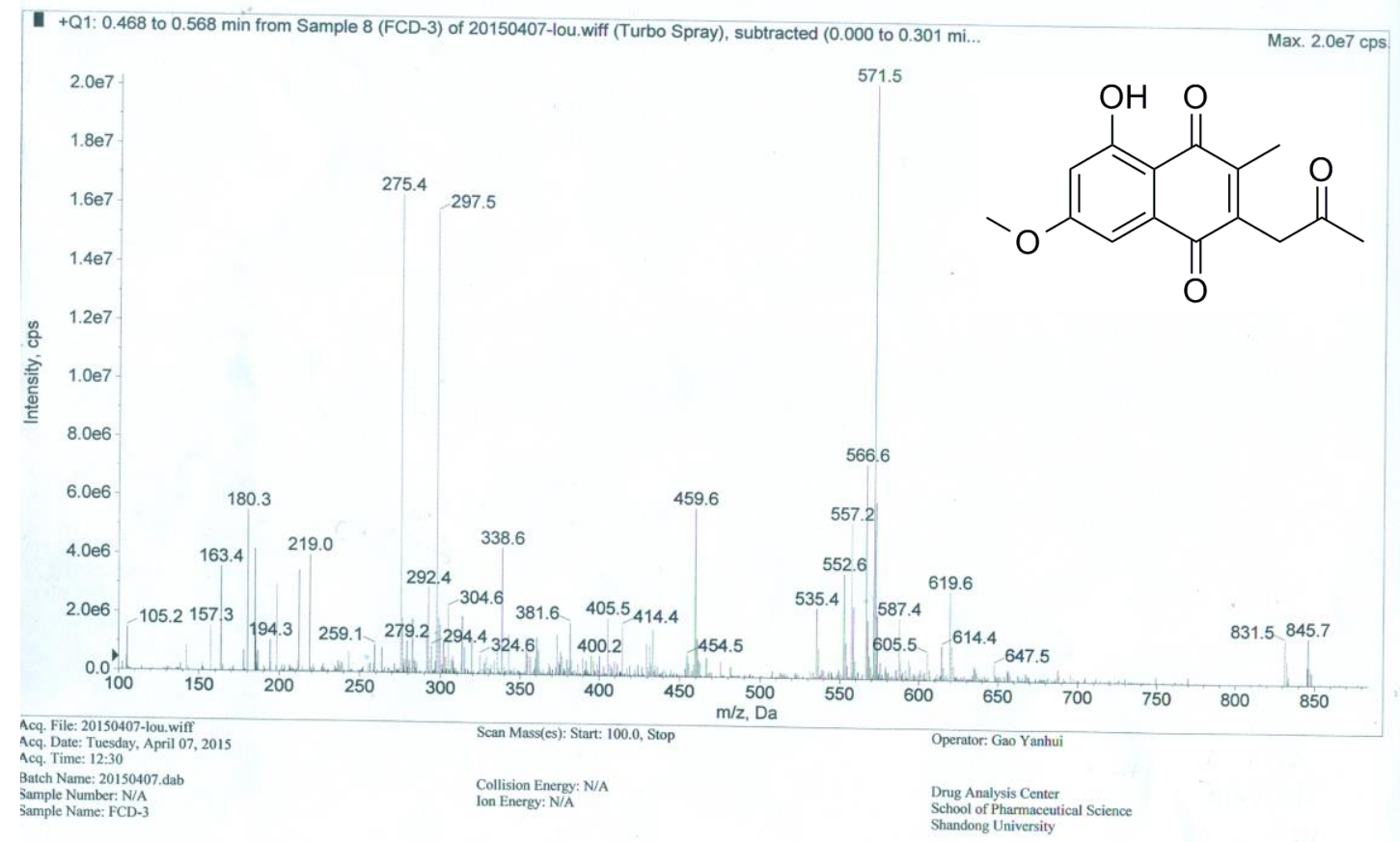

Figure S158. ESIMS spectrum of $\mathbf{2 8}$ 


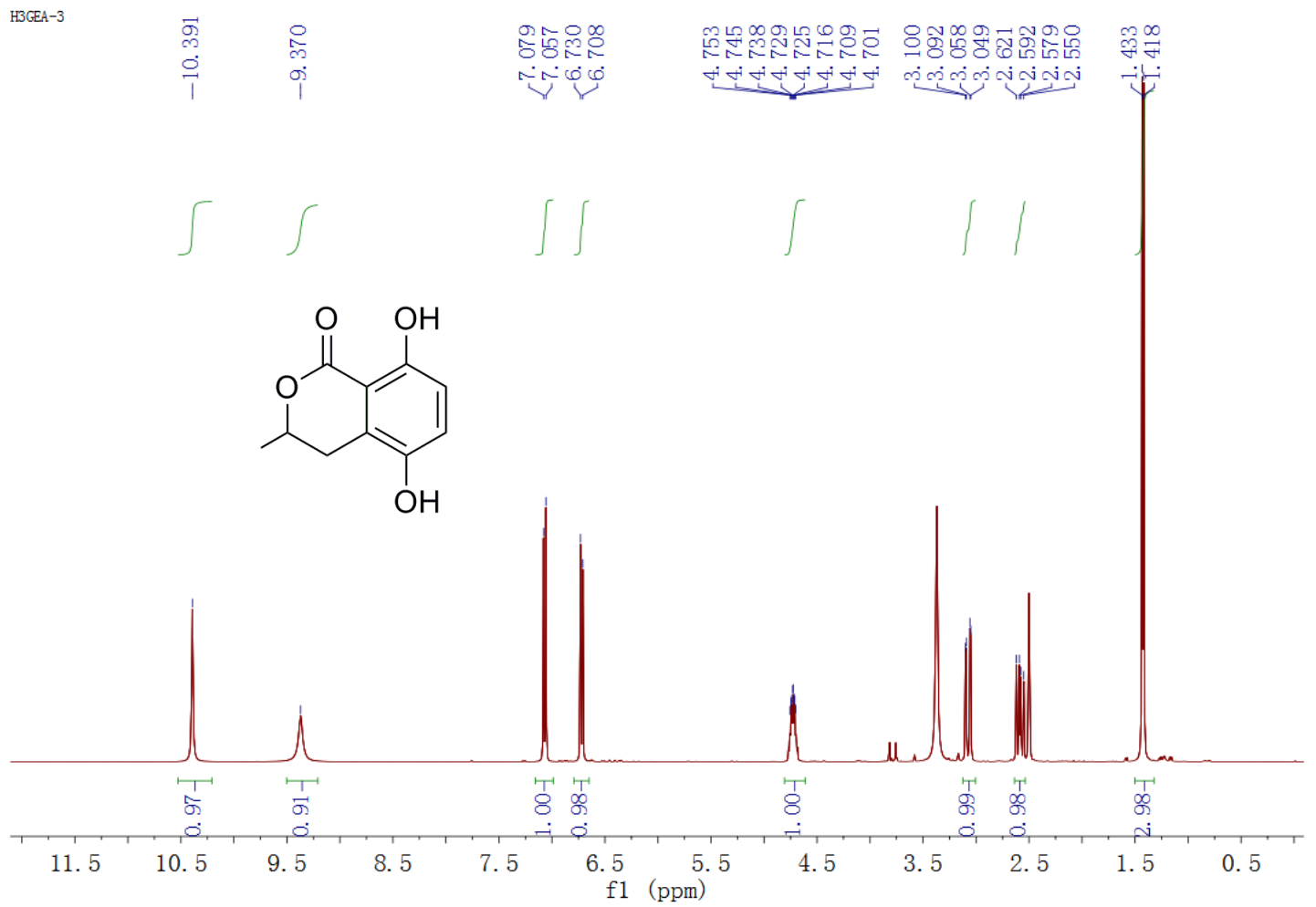

Figure S159. ${ }^{1} \mathrm{H}$ NMR spectrum of 29 in DMSO-d 6

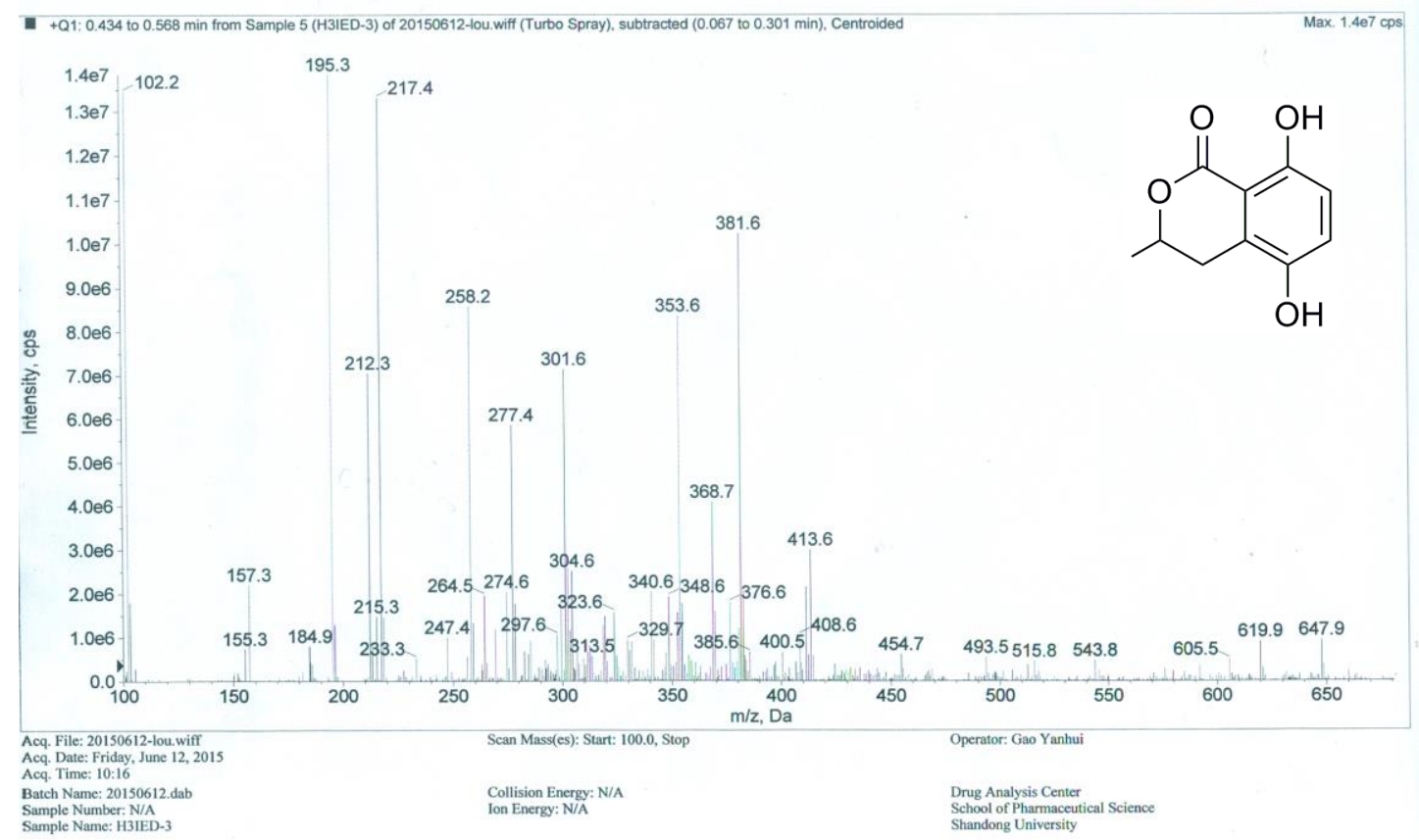

Figure S160. ESIMS spectrum of 29 


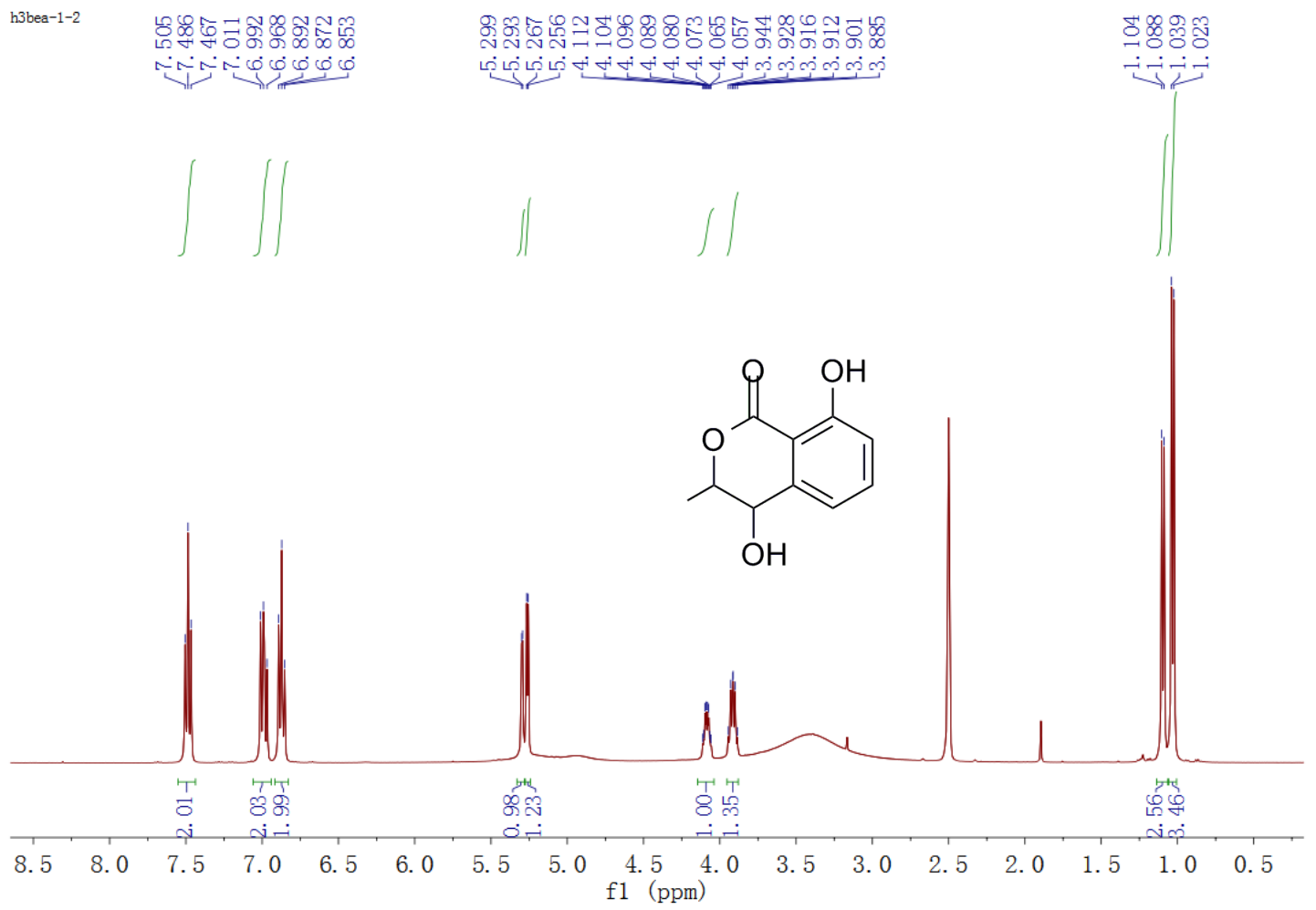

Figure S161. ${ }^{1} \mathrm{H}$ NMR spectrum of $\mathbf{3 0}$ in DMSO-d 6

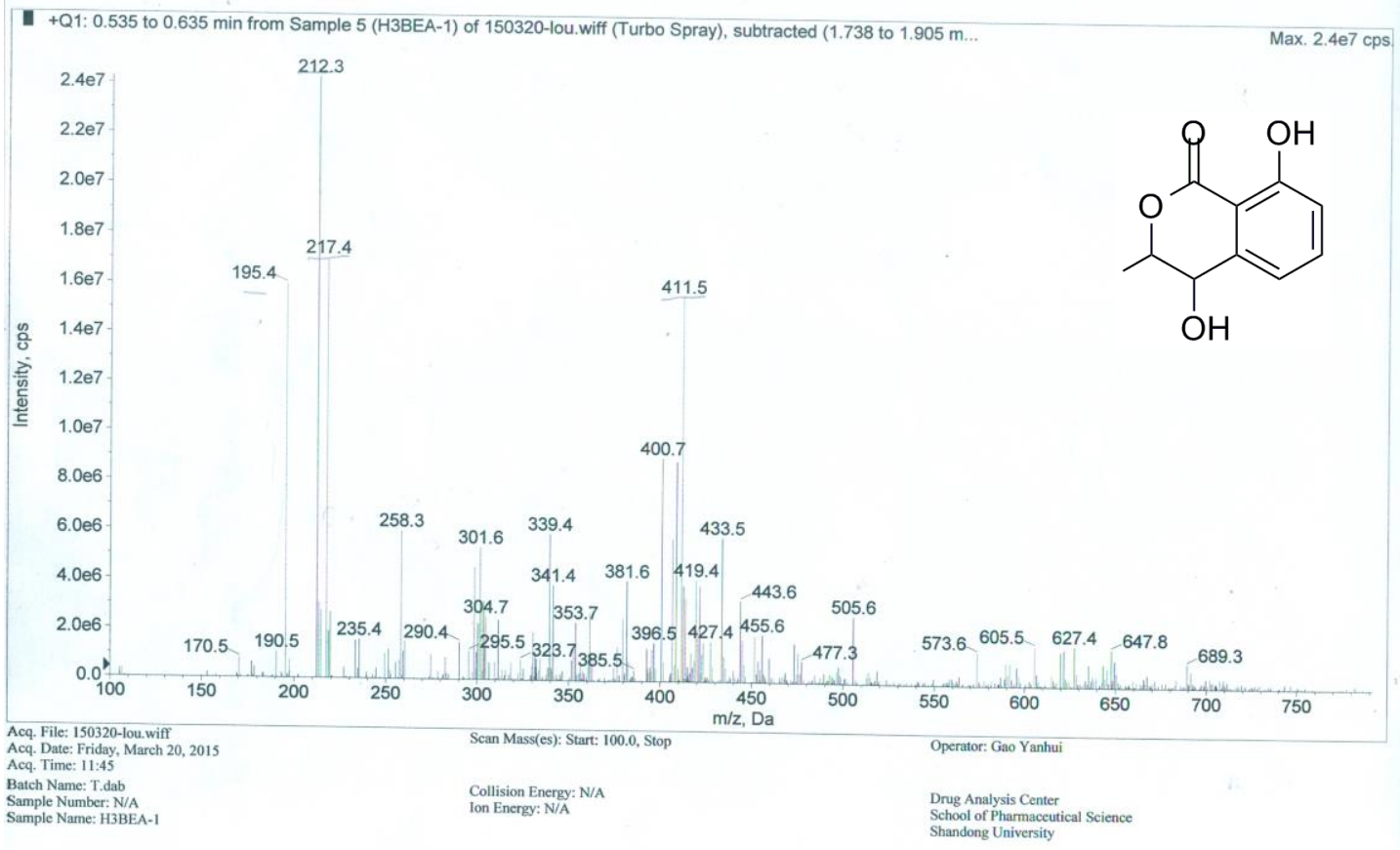

Figure S162. ESIMS spectrum of $\mathbf{3 0}$ 


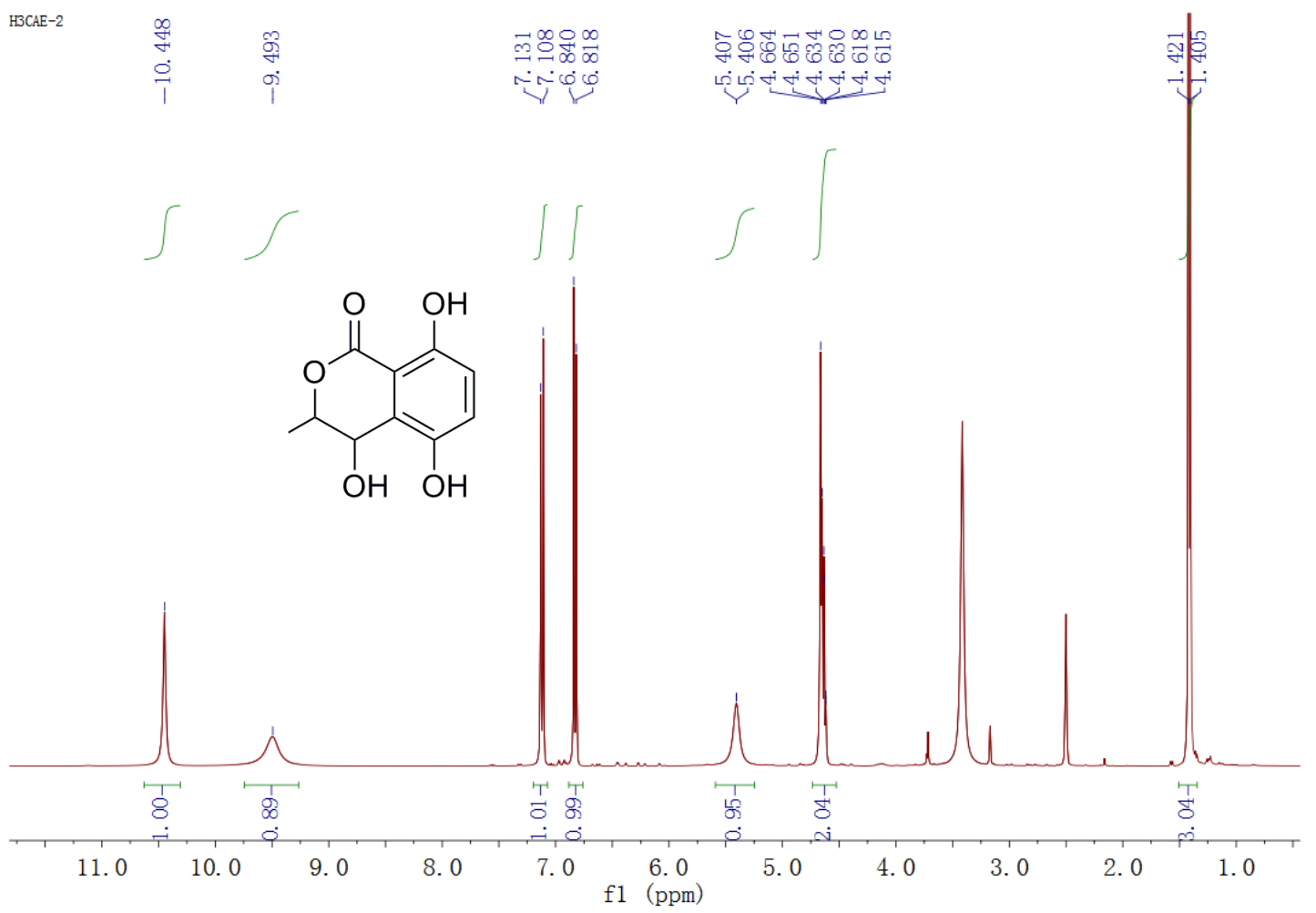

Figure S163. ${ }^{1} \mathrm{H}$ NMR spectrum of $\mathbf{3 1}$ in DMSO-d 6

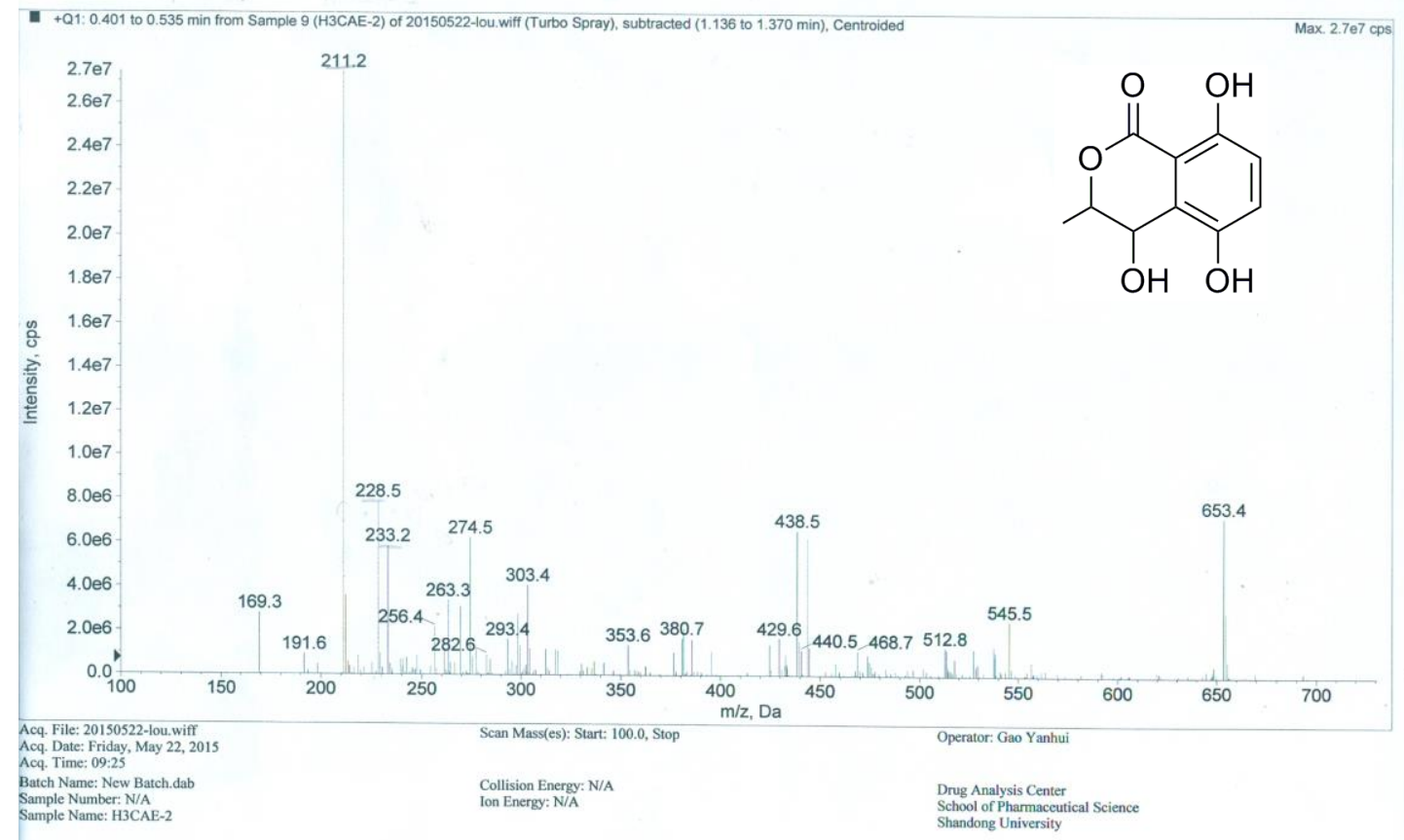

Figure S164. ESIMS spectrum of $\mathbf{3 1}$ 


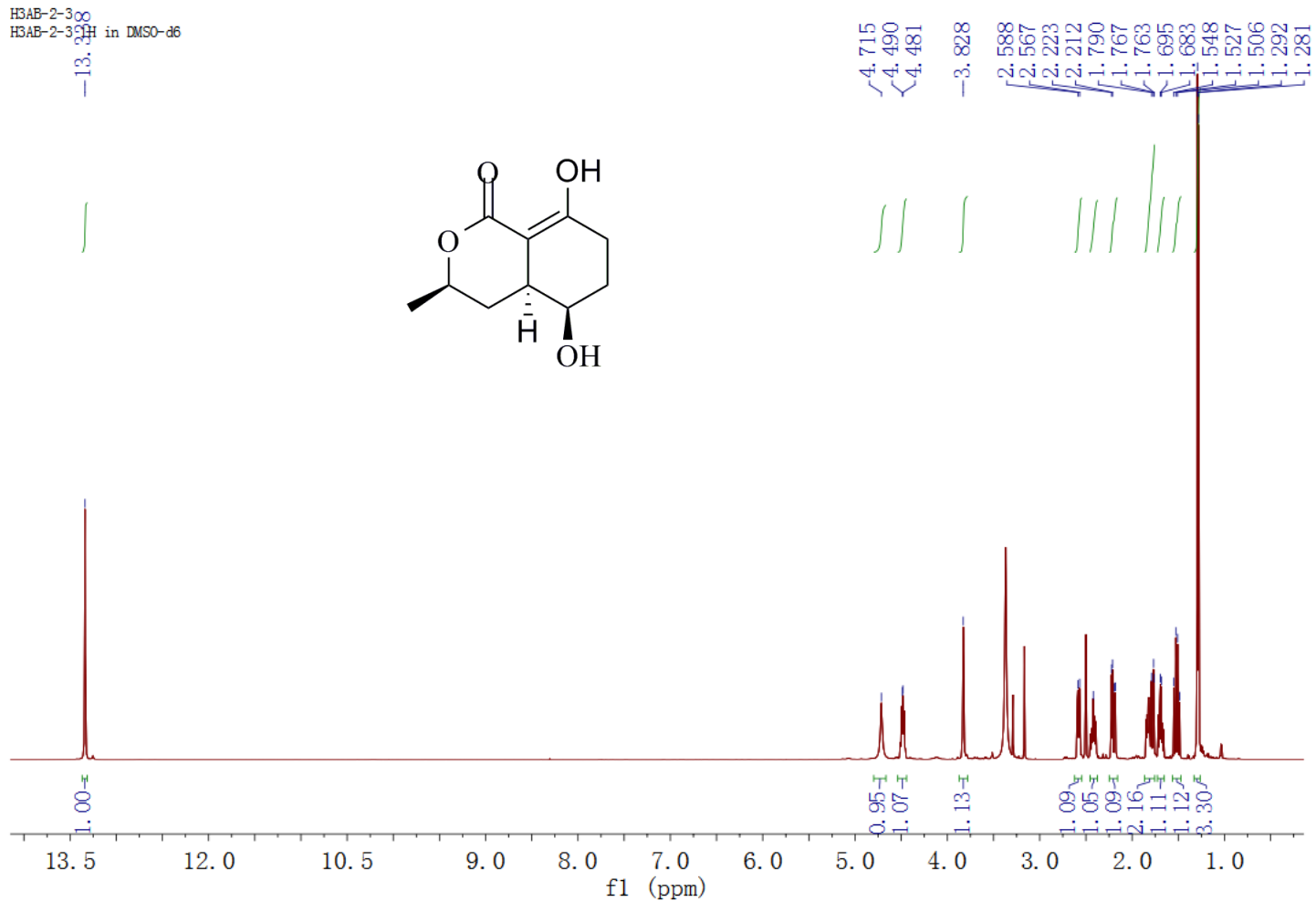

Figure S165. ${ }^{1} \mathrm{H}$ NMR spectrum of $\mathbf{3 2}$ in DMSO-d 6

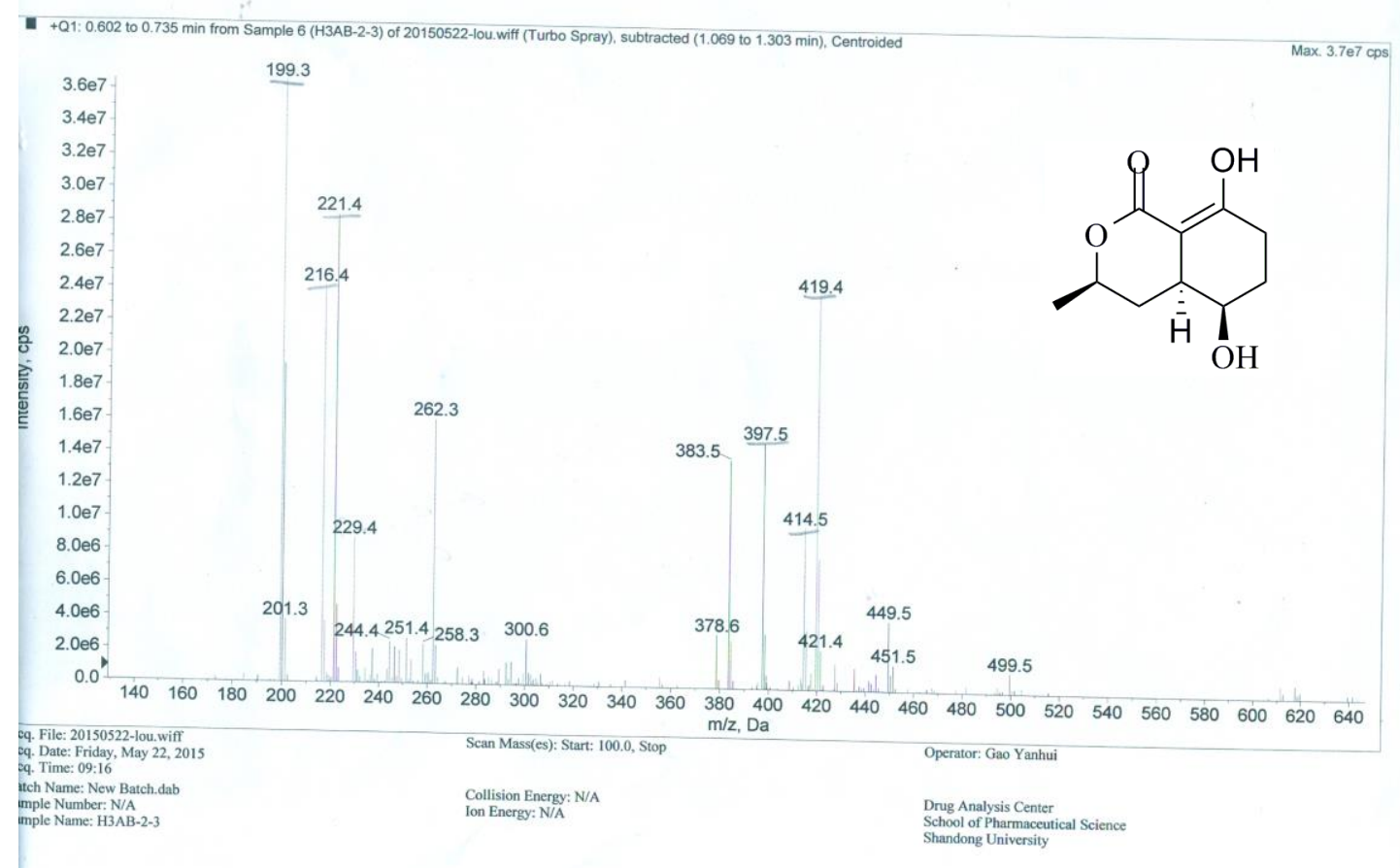

Figure S166. ESIMS spectrum of 32 